\title{
Kidney transplantation from donors after cardiac death : studies on the pathophysiology and prevention of ischemic acute kidney injury and on the long-term outcome after transplantation
}

Citation for published version (APA):

Snoeijs, M. G. (2010). Kidney transplantation from donors after cardiac death : studies on the pathophysiology and prevention of ischemic acute kidney injury and on the long-term outcome after transplantation. [Doctoral Thesis, Maastricht University]. Universitaire Pers Maastricht. https://doi.org/10.26481/dis.20100611ms

Document status and date:

Published: 01/01/2010

DOI:

$10.26481 /$ dis.20100611ms

Document Version:

Publisher's PDF, also known as Version of record

Please check the document version of this publication:

- A submitted manuscript is the version of the article upon submission and before peer-review. There can be important differences between the submitted version and the official published version of record. People interested in the research are advised to contact the author for the final version of the publication, or visit the DOI to the publisher's website.

- The final author version and the galley proof are versions of the publication after peer review.

- The final published version features the final layout of the paper including the volume, issue and page numbers.

Link to publication

\footnotetext{
General rights rights.

- You may freely distribute the URL identifying the publication in the public portal. please follow below link for the End User Agreement:

www.umlib.nl/taverne-license

Take down policy

If you believe that this document breaches copyright please contact us at:

repository@maastrichtuniversity.nl

providing details and we will investigate your claim.
}

Copyright and moral rights for the publications made accessible in the public portal are retained by the authors and/or other copyright owners and it is a condition of accessing publications that users recognise and abide by the legal requirements associated with these

- Users may download and print one copy of any publication from the public portal for the purpose of private study or research.

- You may not further distribute the material or use it for any profit-making activity or commercial gain

If the publication is distributed under the terms of Article 25fa of the Dutch Copyright Act, indicated by the "Taverne" license above

Download date: 26 Apr. 2023 
Kidney transplantation from donors after cardiac death

Studies on the pathophysiology and prevention of ischemic acute kidney injury and on the long-term outcome after transplantation 
ISBN:

Cover illustration:

Copyright:

Press:
978-90-5278-943-9

Paul de Win

M.G.J. Snoeijs, Maastricht 2010

Datawyse / Universitaire Pers Maastricht 


\section{Kidney transplantation from donors after cardiac death}

Studies on the pathophysiology and prevention of ischemic acute kidney injury and on the long-term outcome after transplantation

\section{PROEFSCHRIFT}

ter verkrijging van de graad van doctor aan de Universiteit Maastricht

op gezag van de Rector Magnificus,

Prof. mr. G.P.M.F. Mols,

volgens het besluit van het College van Decanen,

in het openbaar te verdedigen

op vrijdag 11 juni 2010 om 14:00 uur

$$
\text { door }
$$

Maarten Gerardus Jan Snoeijs 
Promotores:

Prof. dr. L.W.E. van Heurn

Prof. dr. W.A. Buurman

Beoordelingscommissie:

Prof. dr. M.J.A.P. Daemen (voorzitter)

Prof. dr. K.M.L. Leunissen

Prof. dr. M.L. Nicholson (Leicester University, Verenigd Koninkrijk)

Prof. dr. J. Pirenne (UZ Leuven, België)

Prof. dr. C.D.A. Stehouwer

De totstandkoming van dit proefschrift werd financieel ondersteund door Astellas Pharma B.V., Covidien Nederland B.V., Dr. Franz Köhler Chemie, Nederlandse Transplantatie Vereniging, Novartis Pharma B.V., Organ Recovery Systems, Roche Nederland B.V., Stichting Pélerin en ZonMW. 


\section{Contents}

Chapter $1 \quad$ General introduction

Chapter 2 Long-term outcome of kidney transplantation from

donors after cardiac death

Chapter 3 Survival benefit of kidney transplantation from donors

after cardiac death

Chapter 4 In situ preservation of kidneys from donors after

cardiac death: results and complications

Chapter 5 Histological assessment of pre-implantation biopsies

for selection of kidneys from old donors after

cardiac death

Chapter 6 Histological assessment of pre-transplant kidney

biopsies is reproducible and representative

Chapter $7 \quad$ Viability markers of kidneys from donors after cardiac

death in the perfusate proteome

Chapter 8 Recipient hemodynamics during kidney transplantation

from donors after cardiac death are major predictors of primary non-function 

in human kidney transplantation

Chapter 10 Tubular epithelial injury and inflammation after ischemia and reperfusion in human kidney transplantation

Chapter 11 Autologous transplantation of ischemically injured kidneys in pigs

Chapter 12 Therapeutic effect of propofol-enriched preservation solution in experimental kidney transplantation

Chapter 13 Biological effects of $\mathrm{F}_{2}$-isoprostanes in experimental acute kidney injury

Chapter 14 General discussion and summary

Samenvatting

Curriculum vitae

Dankwoord 
Aan mijn moeder 
$8 \mid$ 


\section{Chapter 1}

Kidney transplantation from donors after cardiac death - a general introduction to clinical practice and pathophysiology of ischemic acute allograft injury 


\begin{abstract}
Donation after cardiac death (DCD) refers to organ donation by patients who do not meet criteria for brain death but instead die from circulatory arrest after unsuccessful cardiopulmonary resuscitation or withdrawal of medically futile supportive treatment. DCD donation is expanding rapidly throughout the world in an effort to alleviate the shortage of organs for transplantation. In contrast to organs from brain-dead donors, DCD kidneys suffer warm ischemic injury during the period from circulatory arrest until organ preservation. This ischemic damage results in a relatively high incidence of delayed graft function and primary non-function after reperfusion of the kidney. In this chapter, we will review the clinical practice of DCD kidney transplantation and the pathophysiology of ischemic acute allograft injury. Based on this review, the following areas in need of further study were identified: the long-term outcome and survival benefit of DCD kidney transplantation, the prediction and prevention of primary non-function of DCD kidneys and the pathophysiology and treatment of ischemic acute allograft injury.
\end{abstract}

\title{
Published as
}

Snoeijs MG, van Heurn LW, van Mook WN, Christiaans MH, van Hooff JP. Controlled donation after cardiac death: a European experience. Transplant Rev 2007; 21:219-229.

Snoeijs MG, van Heurn LW, Buurman WA. Biological modulation of renal ischemiareperfusion injury. Curr Opin Organ Transplant 2010; 15:190-199. 


\section{Introduction}

Kidney transplantation results in longer life expectancy and superior quality of life compared to dialysis treatment and therefore is the treatment of choice for many patients with end-stage renal disease. ${ }^{1,2}$ However, the number of available donor kidneys is not sufficient to treat all candidates for transplantation in spite of recent increases in living donor kidney donation ${ }^{3-7}$ and expansion of criteria for kidney donation after brain death (DBD). ${ }^{8,9}$ Procurement of kidneys from donors after cardiac death (DCD, also referred to as non-heart-beating donation) holds the potential to expand the donor pool 2.5 to 4 times, ${ }^{10}$ which theoretically should suffice to stabilize or even reduce the waiting lists for kidney transplantation. ${ }^{11}$

In 1995, four types of DCD donors were recognized by the participants of the first international conference on non-heart-beating donation in Maastricht (Table 1.1). ${ }^{12}$ Maastricht category 1 constitutes of patients who are declared dead outside the hospital and are subsequently transferred to the hospital with the purpose of organ donation. Maastricht category 2 donors are patients who die in the hospital after unsuccessful resuscitation, mostly in accident and emergency departments. Both situations occur unexpectedly and therefore are referred to as uncontrolled DCD donations. Maastricht category 3 donors are patients in intensive care units (ICU) who do not meet brain death criteria and from whom supportive treatment is withdrawn because of medical futility. These patients in whom cardiac arrest is awaited are referred to as controlled DCD donors. Maastricht category 4 donors are brain dead donors with cardiac arrest before organ procurement.

The practice of DCD donation differs throughout the world. Since the early 1980s, several transplant centers in Europe have expanded their donor pools with DCD donors. ${ }^{13-40}$ Initially, most European centers predominantly relied on uncontrolled DCD donors. The contribution of controlled DCD donors

Table 1.1 Maastricht categories of donation after cardiac death

\begin{tabular}{lll}
\hline Category & Definition & Type \\
\hline 1 & Dead on arrival & Uncontrolled \\
2 & Unsuccessful resuscitation & Uncontrolled \\
3 & Awaiting cardiac arrest & Controlled \\
4 & Cardiac arrest while brain dead & Controlled / Uncontrolled \\
\hline
\end{tabular}


has increased more recently. In Japan, brain death legislation was not introduced until 1997 and so far the concept of brain death is not readily accepted by the general public. Therefore, organ donation in Japan has relied almost exclusively on living donors and DCD donors (mostly controlled category 4 donors). ${ }^{41-46}$ In the United States, surgical practice has been more conservative with respect to transplantation of DCD kidneys. However, since the late 1990s the contribution of controlled DCD donors to the donor pool has been steadily increasing and currently constitutes approximately $10 \%$ of all deceased donors. ${ }^{47-60}$ Uncontrolled DCD donors have only rarely been used in the United States. ${ }^{61,62}$

\section{History of organ donation after cardiac death}

After the initial success of kidney transplantation between identical twins in the $1950 \mathrm{~s},{ }^{63}$ the first successful deceased donor kidney transplantation was reported in $1963 .{ }^{64}$ The donor died after cardiac arrest during open heart surgery and the kidney was kept in a refrigerator at $4^{\circ} \mathrm{C}$ until transplantation 125 minutes later. After recovery from delayed graft function, the kidney continued to function during the first year after transplantation. However, this successful case was a rare exception since 67 contemporary attempts at DCD kidney transplantation failed within the first year after grafting. ${ }^{65}$ These poor results were generally attributed to "the damage which occurs to the kidney during the terminal phase of the donor's life, or in the period between his death and the time when the transplantation is carried out". ${ }^{66}$

As kidney preservation improved with the introduction of machine perfusion and special preservation solutions for cold storage, one-year graft survival from deceased donors increased from 12\% in the period of 1962-1965 to $46 \%$ in the period of 1969-1973.67-71 At the same time, in 1968, brain death was recognized as a clinical and legal entity by an ad hoc committee at Harvard Medical School. ${ }^{72}$ This allowed procurement of organs from deceased donors with intact circulation that had not suffered warm ischemic injury. ${ }^{73}$ As a result, donation after cardiac death was abandoned in favour of donation after brain death (DBD) in the 1970s. The parallel introduction of the immunosuppressive drug cyclosporine led to a dramatic decrease in acute rejections and improvement in graft survival, contributing greatly to successful kidney, liver and heart transplantation. $^{74,75}$

As clinical outcomes of kidney transplantation improved over the years, more and more patients with end-stage renal disease opted for transplantation to 
improve their quality of life and life expectancy. As a consequence, waiting lists for kidney transplantation started to increase in the United States and Europe in the 1980s. ${ }^{76,77}$ With the gradual increase in waiting time, the transplant community took a renewed interest in the procurement of organs from DCD donors in order to expand the pool of organs for transplantation. Several transplant centers, including our own, have since reported that the clinical outcome of DCD kidney transplantation is comparable to DBD grafts throughout the first 5 to 10 years after transplantation. ${ }^{13,17,26,30,49,58,78}$ For further reading on the history of donation after cardiac death we refer to the review by DeVita and colleagues. ${ }^{79}$

\section{Ethical and legal aspects of donation after cardiac death}

There are some general ethical principles concerning deceased organ donation. ${ }^{80}$

${ }^{83}$ First and foremost, the donor must be dead before organ procurement can take place (dead donor rule). Diagnosis of death - whether based on cardiopulmonary or neurological criteria - is based on both the presence and irreversibility of cessation of vital functions. In case of cardiac death, cessation of function is demonstrated by absence of responsiveness, pulse and respiratory effort. ${ }^{84} \mathrm{In}$ a US national meeting on DCD donation, it was concluded that absence of circulation by monitoring of arterial pulse pressure is sufficient for diagnosis of death and that electrocardiographic silence is not required. ${ }^{85}$ The requirement of irreversibility in DCD donation is open for ethical discussion due to different definitions of the term "irreversibility" and because of the time pressure to diagnose death while organs are suffering warm ischemic injury. ${ }^{80}$ Occasionally, ethical commentaries have stated that controlled DCD donation violates the dead donor rule because circulatory arrest may be reversed if cardiopulmonary resuscitation was to be initiated. ${ }^{86}$ However, in the context of withdrawal of supportive treatment in the ICU, cardiopulmonary resuscitation is not intended. Therefore, consensus within the transplant community defines irreversibility as cessation of function without the capability of spontaneous recovery. ${ }^{85}$ An observational period of five minutes after circulatory arrest is generally accepted to meet this requirement (no-touch period). ${ }^{87}$

Secondly, care of living patients must not be compromised in favour of potential organ recipients. In other words, patient treatment prevails donor management. Nevertheless, end-of-life care of potential controlled DCD donors seems to deviate substantially from published guidelines. ${ }^{86}$ Several strategies that aim to minimize warm ischemic injury to donor organs, including withdrawal of 
treatment in the operating room (OR) and cannulation before death, potentially compromise end-of-life care. ${ }^{88}$ To provide continuity of care, it is common practice in the Netherlands and United Kingdom to withdraw treatment in the ICU and transport the donor to the OR after cardiac death, which results in similar transplant outcomes. ${ }^{89}$ Furthermore, we argue that invasive instrumentation of a potential donor before death is not ethically sound. In the Netherlands and the United Kingdom, organs from DCD donors are therefore preserved either after rapid laparotomy and direct aortic cannulation or by in situ perfusion after a 5-minute no-touch period following circulatory arrest. To prevent a conflict of interests, the medical team providing care for dying patients and diagnosing death should be separate from the surgical team responsible for organ procurement. Furthermore, the decision to withdraw life-sustaining treatment or discontinue cardiopulmonary resuscitation should be made separately from the decision to donate organs. ${ }^{90}$ Protocols for donation after cardiac death should be discussed and approved by medical ethical committees of each institution. ${ }^{91}$

Legislation concerning DCD donation differs greatly throughout the world. In the Netherlands and the United Kingdom, DCD donation is encouraged by the government and laws have been passed that allow invasive instrumentation of uncontrolled DCD donors to preserve organs before consent has been obtained from the relatives. ${ }^{92,93}$ In contrast, organ preservation before consent for donation is not allowed in the US, which greatly limits the opportunities for recovery of organs from uncontrolled DCD donors. In Spain and France, controlled DCD donation is impossible since legislation prohibits procurement of organs after withdrawal of supportive treatment in the ICU. In Germany, procurement of organs from deceased donors can only proceed after formal declaration of brain death, which practically rules out any type of DCD donation.

\section{Donor selection}

\section{Transmittable diseases}

Selection of potential DCD donors starts with exclusion of transmittable diseases. Patients with malignancies, active systemic infections or serological evidence of HIV or hepatitis virus infection should not be organ donors. Exceptions can be made for recipients already infected by HIV or hepatitis virus, or when the 
benefit of transplantation outweighs the risk of transmission of a particular malignancy. ${ }^{94-96}$

\section{Renal functional capacity}

In the general population, age and cardiovascular risk factors such as hypertension, diabetes mellitus and smoking are associated with chronic kidney disease. ${ }^{98}$ However, even though creatinine clearance declines with age in most individuals, up to $35 \%$ of subjects have stable kidney function over time. ${ }^{99}$ Similarly, in a cross-sectional study of autopsy cases without renal disease, the percentage of sclerosed glomeruli was increased in subjects older than 50 years but ranged from $1-36 \% .{ }^{100}$ In addition, only $15 \%$ of healthy subjects with essential hypertension developed chronic kidney disease over a follow-up period of 13 years. ${ }^{101}$ With
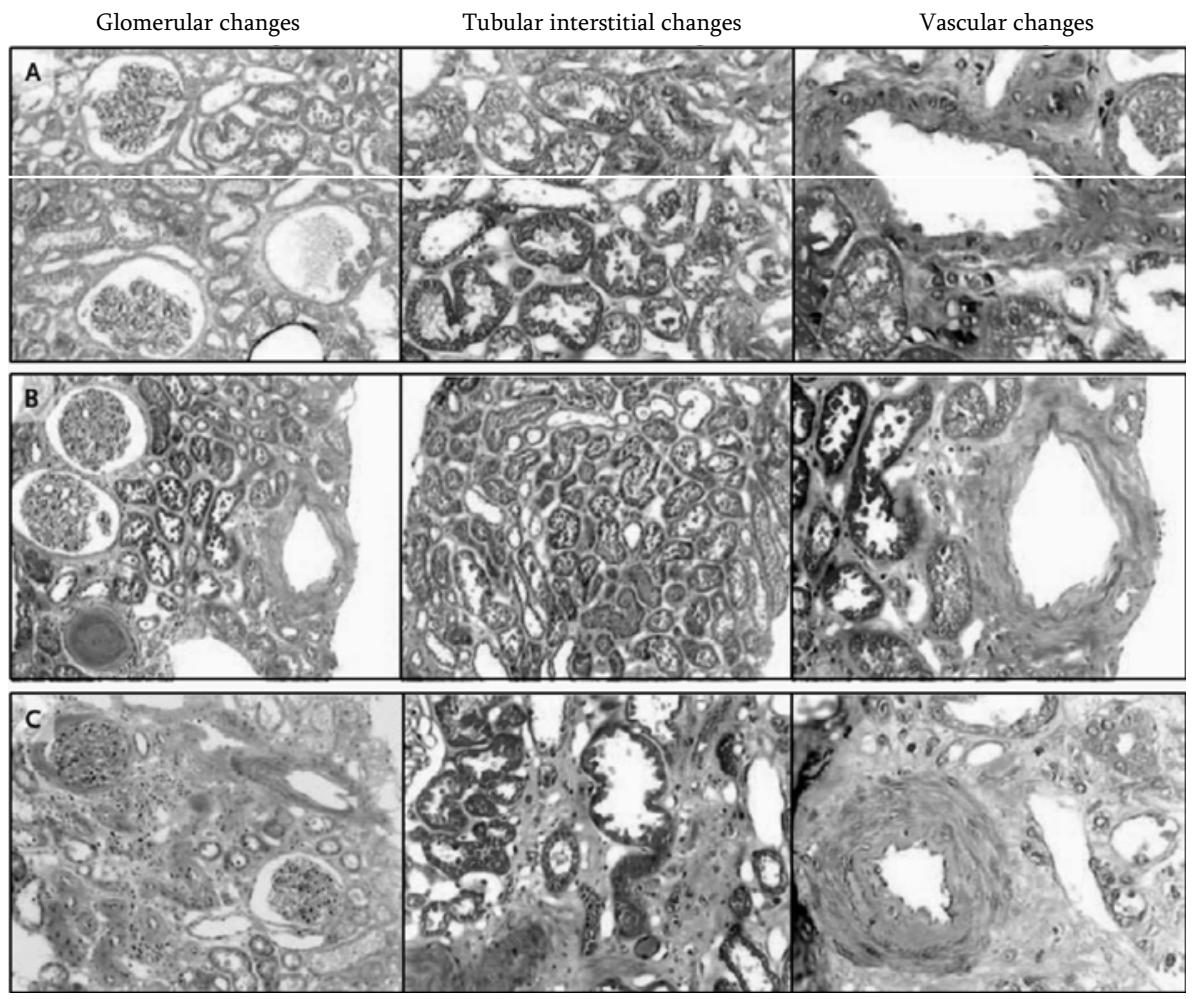

Figure 1.1 Light micrographs of pre-implantation kidney biopsies from donors over 60 years of age illustrating various degrees of structural abnormalities (glomerulosclerosis, tubular atrophy and interstitial fibrosis, and vascular narrowing). (A) Mild abnormalities; (B) Moderate abnormalities; (C) Severe abnormalities. The figure was adapted from Remuzzi et al. ${ }^{97}$ 
such individual variation, the acceptance of kidneys for transplantation should be based on the functional and structural condition of the organs rather than an arbitrary age limit or combination of risk factors for chronic kidney disease. The functional capacity of the kidney is determined by estimation of the glomerular filtration rate (GFR) and measurement of proteinurea. ${ }^{102-104}$ Structural abnormalities of the kidney may be diagnosed by histological assessment of preimplantation biopsies (Figure 1.1). ${ }^{105-107}$ The limits of functional and structural abnormalities that allow maximal expansion of the donor pool while maintaining acceptable clinical outcomes remain to be established. ${ }^{107-113}$ Furthermore, grafts with reduced functional capacity that are not suitable for standard kidney transplantation should not be routinely discarded but may be considered for dual transplantation in order to provide the recipient with adequate nephron mass. ${ }^{97,114-120}$

\section{Ischemic acute kidney injury}

Uncontrolled DCD kidneys suffer warm ischemic injury both during cardiopulmonary resuscitation and in the period between cessation of resuscitation and organ preservation. Cardiopulmonary resuscitation primarily aims to increase cardiac and cerebral perfusion whereas blood flow to visceral organs is relatively low. Indeed, renal blood flow in dogs was reduced by $85 \%$ during resuscitation as measured by radioactively labelled microspheres. ${ }^{121}$ When adrenalin was administered during resuscitation, renal blood flow was further reduced down to $2 \%$ of the blood flow before cardiac arrest. ${ }^{122}$ These data indicate that donor kidneys suffer warm ischemic injury during cardiopulmonary resuscitation. To prevent further ischemic injury, it is important to minimize the time to initiate organ preservation after resuscitation has been abandoned. Since uncontrolled DCD donors always present unexpectedly, this requires careful logistic preparation and repeated training of personnel in the emergency department.

Although warm ischemic injury is of most concern with uncontrolled DCD kidneys, prolonged periods of hypotension before death or failure to start timely organ preservation after circulatory arrest may lead to acute ischemic injury in controlled DCD kidneys as well. The period from withdrawal of supportive treatment until circulatory arrest may sometimes be protracted, especially with potential donors who do not receive ventilatory support. From a practical point of view, many US transplant centers consider a maximal waiting time of two hours for controlled DCD kidney donation. ${ }^{123}$ However, as long as blood pressure, oxygen saturation and urine output remain normal there is no reason why the kidneys would not be suitable for transplantation. ${ }^{52,124,125}$ After 
circulatory arrest, warm ischemia time should be kept to a minimum using logistic and surgical techniques within the context of optimal end-of-life care for potential donors and their families. Kidney transplantation from DBD and DCD donors with established acute kidney injury is associated with similar long-term outcomes as conventional kidney donors. ${ }^{126-129}$

\section{Management of the controlled DCD donor}

Until withdrawal of life-sustaining therapy, careful monitoring and supportive treatment of potential controlled DCD donors is in the best interest of both the potential donor and the recipients. Care of brain dead organ donors has been reviewed by Wood and colleagues. ${ }^{130}$ Management of the potential controlled DCD donor is less demanding since hormonal deficiencies, prolonged cardiac arrythmias and hypothermia associated with brain death do not occur frequently. Therefore, patient management focuses on cardiovascular status with the goals to achieve normovolemia, maintain blood pressure and optimize cardiac output using the lowest concentration of vasoactive drug support possible. Mean arterial pressure should be maintained at $\geq 60 \mathrm{mmHg}$ with central venous pressure of 6-8 $\mathrm{mmHg}$ and urine output of $\geq 1 \mathrm{~mL} / \mathrm{kg} / \mathrm{h}$. Vasoactive drug support is necessary when hemodynamic instability persists despite adequate volume resuscitation. More than $90 \%$ of donors can be successfully managed with volume resuscitation and low doses of vasopressors $(\leq 10 \mu \mathrm{g} / \mathrm{kg} / \mathrm{min}$ of dopamine or dobutamine $) .{ }^{131}$ Regardless of the hemodynamic status of the organ donor, infusion of low-dose dopamine in DBD donors improves early graft function after kidney transplantation. ${ }^{132}$ Graft function may be further optimized by avoidance of hydroxyethyl starch and correction of electrolyte disorders, in particular hypernatremia. ${ }^{133}$

When the relatives of the potential controlled DCD donor are present and the organ procurement team is ready, supportive treatment is withdrawn, preferably according to a standardized protocol. ${ }^{90,134}$ Clinical practice with respect to withdrawal of life-sustaining treatment differs greatly according to the preferences of individual physicians. ${ }^{135}$ However, a standardized protocol for withdrawal of supportive treatment in controlled DCD donors has been proposed. ${ }^{90}$ After administration of opioids and sedatives to prevent pain and recall, all non-ventilatory supportive measures are withdrawn. Subsequently, ventilator support is (gradually) stopped and the patient is extubated, providing additional sedation if the patient is stressed as demonstrated by increased respiratory rate or retention of secretions. If legally allowed, heparin may be administered to im- 
prove graft quality close to the time of death (e.g. when the systolic blood pressure falls below $60 \mathrm{mmHg}) .{ }^{90}$ A standardized check list for withdrawal of life support that may improve quality of end-of-life care in the ICU is available. ${ }^{136}$

\section{Organ preservation}

\section{In situ perfusion technique}

As discussed previously, DCD organs are inevitably subjected to a period of warm ischemia from circulatory arrest until organ preservation. During this period, cell death pathways are activated which set the stage for graft injury at reperfusion. ${ }^{137}$ Indeed, prolonged warm ischemia time is associated with reduced graft survival. ${ }^{138,139}$ Several techniques have been developed to reduce warm ischemic injury of DCD organs before procurement, either by applying topical or intravascular cooling or by re-establishing blood flow by mechanical resuscitation or extracorporeal circulation..$^{28,53-56,140-147}$ Over the past decades, our group has generally used in situ perfusion with double-balloon triple-lumen catheters for procurement of DCD kidneys (Figure 1.2A). ${ }^{148}$ This catheter is introduced via the femoral artery into the aorta, and subsequent inflation of the two balloons allows selective perfusion of the abdominal aorta, flushing and cooling the kidneys. This technique is minimally invasive, can be performed in the accidents and emergency department and in the ICU, and is intended for fast and effective use by surgeons with limited experience in transplant surgery. In situ perfusion provides additional time to make necessary arrangements for legal, logistical and medical requirements for organ procurement from uncontrolled DCD donors. For controlled DCD donors, however, logistical requirements for rapid laparotomy and direct aortic cannulation in the operating room can be arranged before withdrawal of supportive treatment (Figure 1.2B)..$^{54}$ Histidine tryptophan ketoglutarate (HTK) solution is used for perfusion since its low viscosity facilitates flushout at high flow rates. Addition of heparin and streptokinase to the perfusion solution results in thrombolysis and improves graft quality. ${ }^{149,150}$ Administration of a vasodilator such as phentolamine may prevent renal vasospasm and increase perfusion efficacy. ${ }^{140,151,152}$ 

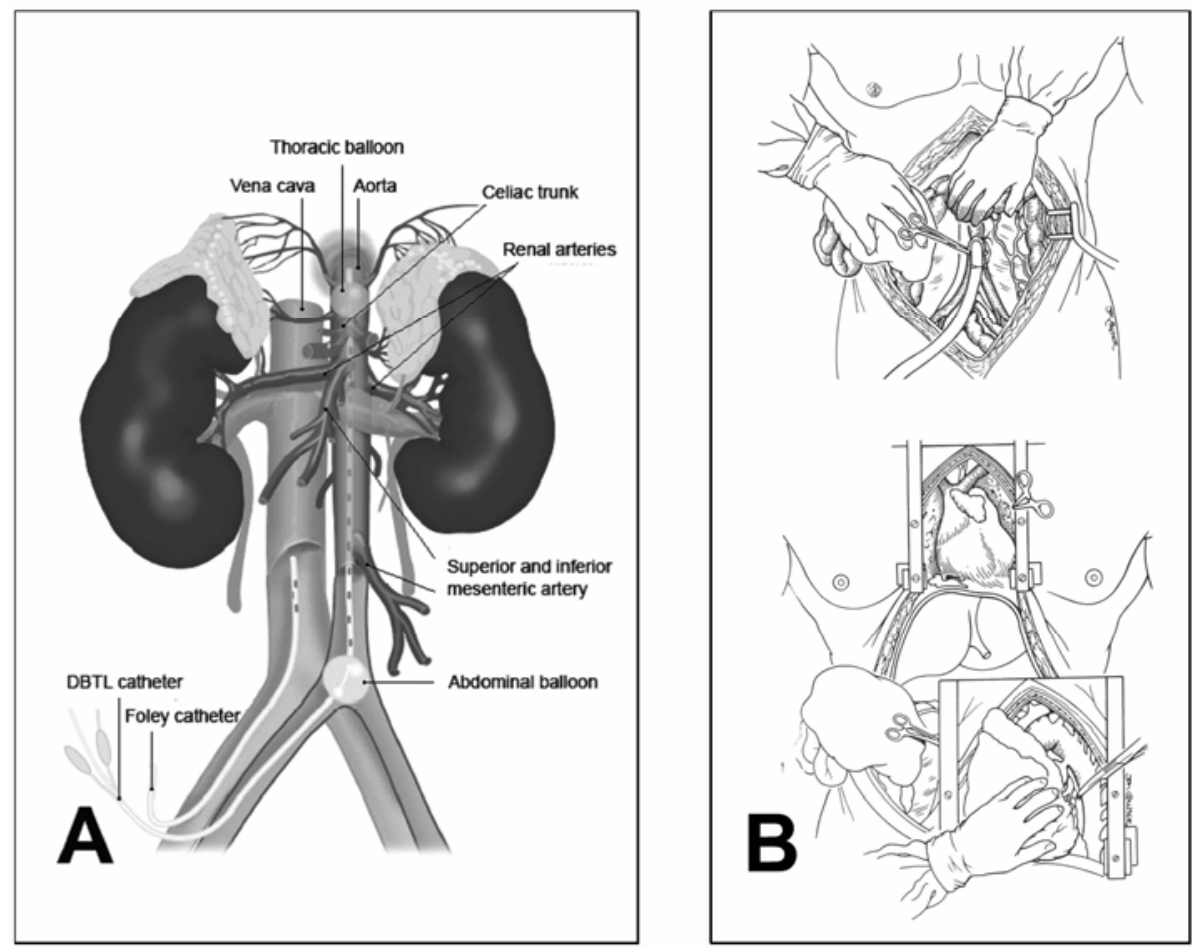

Figure 1.2 Surgical techniques for organ preservation in donors after cardiac death. (A) After insertion of a double-balloon triple-lumen catheter through the femoral artery, the abdominal aorta can be selectively perfused, flushing and cooling the kidneys. The figure was adapted from Kootstra et al. ${ }^{153}$ (B) After rapid laparotomy, the abdominal organs are perfused through an aortic canula. The thoracic aorta is subsequently clamped and the vena cava or left atrium is incised to allow outflow of the preservation solution. The figure was adapted from Casavilla et al. ${ }^{54}$

\section{Machine pulsatile perfusion}

After organ procurement, kidneys may be preserved by machine pulsatile perfusion or by static cold storage until the time of transplantation. ${ }^{154}$ There has been considerable debate about the relative merits of either technology. Randomized clinical trials comparing the two preservation modalities have often been underpowered to detect clinically important differences in graft outcome. A metaanalysis of these trials showed that a $20 \%$ reduction in the relative risk of delayed graft function (DGF) of both DBD and DCD donors can be achieved by using machine perfusion rather than cold storage. ${ }^{155}$ This conclusion was confirmed by a registry analysis of 907 paired kidneys transplanted in the United States, with DGF in $26 \%$ of cold stored kidneys versus $19 \%$ of machine perfused kidneys 
procured from the same donors. ${ }^{156}$ No difference in long-term graft survival was observed in this study. In contrast, a recent analysis from the Collaborative Transplant Study suggests that machine perfusion is associated with inferior long-term outcome. ${ }^{157}$ This may be explained by the tendency of transplant centers to pump only marginal kidneys which may be hard to account for in multivariate analyses of graft outcome. To provide definitive evidence of the superiority of either preservation method, a large multi-center randomized clinical trial was initiated in which kidneys from 336 deceased donors were preserved by machine perfusion or cold storage using pairwise randomization. ${ }^{158}$ Kidneys that were preserved by machine perfusion showed a reduced incidence of delayed graft function ( 21 vs. $27 \%, \mathrm{P}=0.01$ ) and greater survival at 1 year after transplantation ( 94 vs. $90 \%, \mathrm{P}=0.04$ ) than their cold-stored counterparts. The treatment effect of machine perfusion was similar for DCD and DBD donors.

In addition to improving graft function after transplantation, machine perfusion may be used to test the viability of DCD kidneys in order to prevent transplantation of grafts that will never regain function, which is referred to as primary non-function (PNF). ${ }^{159}$ Perfusion characteristics such as flow rate and pump pressure may be used to detect DCD kidneys at risk for primary nonfunction. ${ }^{160}$ In contrast, the increase in kidney weight due to edema during machine perfusion does not predict post-operative graft function. ${ }^{161}$ The presence of $\alpha$-glutathione S-transferase or fatty-acid binding proteins in the preservation solution indicates cell death of the proximal tubular epithelium and their measurement may be useful in selection of viable DCD kidneys for transplantation. ${ }^{20,162,163}$ Furthermore, we have recently found that DCD kidneys release redox-active iron into the preservation solution during machine perfusion which may catalyze the generation of reactive oxygen species. The level of perfusate iron was an independent predictor of primary non-function that added predictive value to other donor and graft characteristics. ${ }^{164}$ Finally, normothermic perfusion has shown great promise in preclinical animal studies but has yet to be applied to clinical kidney transplantation. ${ }^{165-167}$

\section{Reducing cold ischemia time}

The adverse effects of prolonged cold ischemia on graft outcome are well documented and include higher incidences of delayed graft function and acute rejection and a reduction of long-term graft survival. ${ }^{157,168-173}$ Although the strength of the association between cold ischemia time and delayed graft function varies across publications, a recent analysis of almost 100,000 kidney transplants in the Collaborative Transplant Study indicates that the relative risk of graft failure 
increases by $10-15 \%$ after 18 hours of cold ischemia time. ${ }^{157}$ Kidneys from DBD and DCD donors are affected by prolonged cold ischemia to similar degrees. These findings strongly suggest that efforts should be made to transplant all kidneys within 18 hours of procurement. Local allocation of DCD kidneys may reduce cold ischemia time considerably. ${ }^{89}$ In addition, it is essential that all transplant personnel involved are motivated to maximize efficiency and cooperation. Indeed, a French transplant center has recently reported an impressive reduction of mean cold ischemia time from 23 to 13 hours after the introduction of a simple quality assurance program. ${ }^{174}$

\section{Management of the recipient}

\section{Recipient selection}

DCD kidneys are generally allocated according to the same rules as DBD kidneys and all transplant candidates are therefore potential DCD kidney recipients. ${ }^{16,51}$ This policy is supported by the similar clinical outcome of viable DCD and DBD kidneys in observational studies and by the general principle of equal access to medical care. When placed on the waiting list, potential recipients are informed of the different donor types. As donor criteria have been extended in an effort to expand the pool of kidneys for transplantation, not all grafts confer the same prognosis for their recipients. For example, kidneys from DBD donors older than 60 years are associated with more than 1.7 times the risk of graft failure of ideal deceased donor kidneys. ${ }^{8}$ Despite this reduced graft survival, the majority of patients receiving kidneys from these expanded criteria DBD donors live longer than patients who refuse such kidneys and instead wait until kidneys from standard criteria donors are being offered..$^{9}$ It remains to be established whether wait-listed dialysis patients should similarly accept an offer for DCD kidney transplantation or instead continue dialysis treatment until a conventional DBD kidney becomes available.

Currently, transplant physicians make decisions for their patients, weighing survival and quality of life on dialysis against the shorter waiting times for kidneys with inferior prognosis. A change in practice towards shared decision making should be considered, encouraging patients to make an informed, autonomous decision about which types of donor kidneys they are willing to receive. ${ }^{175}$ It has been demonstrated that most patients are capable of making such complex decisions when adequately informed. ${ }^{176}$ 


\section{Hemodynamic management during transplant surgery}

Post-operative renal function is not only determined by pre-transplant donor and graft characteristics but also by the hemodynamic status of the recipient during kidney transplant surgery. Early graft function requires adequate perfusion of the kidney that can be achieved by expansion of the intravascular volume of the recipient. Fluid loading before or during surgery reduces the incidence of delayed graft function in DBD kidney transplantation, whereas pre-operative hemodialysis is associated with an increased incidence of delayed graft function. ${ }^{177-181}$ Since DCD kidneys are at increased risk of delayed graft function and primary non-function due to warm ischemic injury at procurement, optimization of the perioperative hemodynamic status may be particularly important for recipients of DCD kidneys. Therefore, transplant candidates with severe cardiovascular disease who are at risk of cardiac ischemia and pulmonary edema when subjected to intravascular volume expansion may not be the most suitable recipients for DCD kidneys. ${ }^{182}$

\section{Delayed graft function and acute rejection}

Most recipients of DCD kidneys will undergo a period of delayed graft function in which they continue to depend on dialysis treatment. During this period, clinical diagnosis of acute rejection is difficult because of continued renal failure. A solution to this problem may be provided by taking ultrasound-guided biopsies from the graft to exclude rejection every week until improvement of renal function, as is currently performed at our institution. ${ }^{183-185}$ If rejection is diagnosed, treatment should be initiated promptly. To further complicate recipient management, potent immunosuppression by calcineurin inhibitors to prevent acute rejection is nephrotoxic and reduces renal blood flow which may prolong recovery from delayed graft function (in particular with the use of cyclosporine). ${ }^{186-188}$ However, avoidance of calcineurin inhibitors and corticosteroids is associated with an unacceptably high incidence of acute rejection. ${ }^{189}$ Therefore, delayed or reduced-dose introduction of calcineurin inhibitors for recipients of DCD kidneys has been introduced by several transplant centers. ${ }^{26,30} \mathrm{~A}$ small randomized clinical trial failed to show benefit of induction therapy with daclizumab (monoclonal antibody against interleukin-2 receptor) and delayed introduction of the calcineurin inhibitor tacrolimus over early administration of tacrolimus without induction therapy in DCD kidney transplantation. ${ }^{190}$ Different immunosuppressive regimens for DCD kidneys that evolved over time were retrospectively compared by Sanchez-Fructuoso and colleagues. ${ }^{191}$ They conclude that induction therapy with daclizumab and triple therapy with low-dose tac- 
rolimus, mycophenolic acid and steroids was superior to three other regimens evaluated. Adequately powered clinical trials of immunosuppressive regimens that are specifically tailored to recipients of DCD kidneys are needed considering the expanding use of these kidneys for transplantation.

\section{Pathophysiology of ischemic acute allograft injury}

As outlined above, the early postoperative period after DCD kidney transplantation is characterized by delayed graft function due to acute ischemic kidney injury suffered at the time of organ recovery. Novel interventions are needed to reduce the incidence of early graft dysfunction and to allow expansion of the donor pool with organs that have suffered prolonged warm ischemic injury. In order to focus the development of new therapies, detailed knowledge on the pathophysiological mechanisms leading to ischemic acute allograft injury after ischemia and reperfusion is required. In the current paragraph, we will discuss the experimental models used to study ischemic acute kidney injury and review clinical studies that compare kidney transplant recipients with and without early graft dysfunction in order to elucidate the pathophysiology of ischemic acute allograft injury.

\section{Experimental models}

Several experimental models are available for the study of acute kidney injury after ischemia and reperfusion, each having their own strengths and weaknesses (Figure 1.3). ${ }^{192}$ In the following paragraph, the relative merits of in vitro studies with renal cells or tubules and in vivo models of acute kidney injury in rodents, large animals and kidney transplant recipients will be discussed.

\section{In vitro models}

Renal injury may be studied using cultured tubular cells or freshly isolated tubules that allow extensive manipulation in order to dissect the molecular pathways leading to acute kidney injury. Ischemia may be simulated by inhibitors of mitochondrial respiration (chemical anoxia) or by hypoxic culture conditions, whereas cold-induced injury is usually modelled with hypothermic incubation of cells or tubules in organ preservation solution. However, cell culture conditions may lead to selection of cells with high proliferative capacity and result in excessive formation of reactive oxygen species due to the elevated 


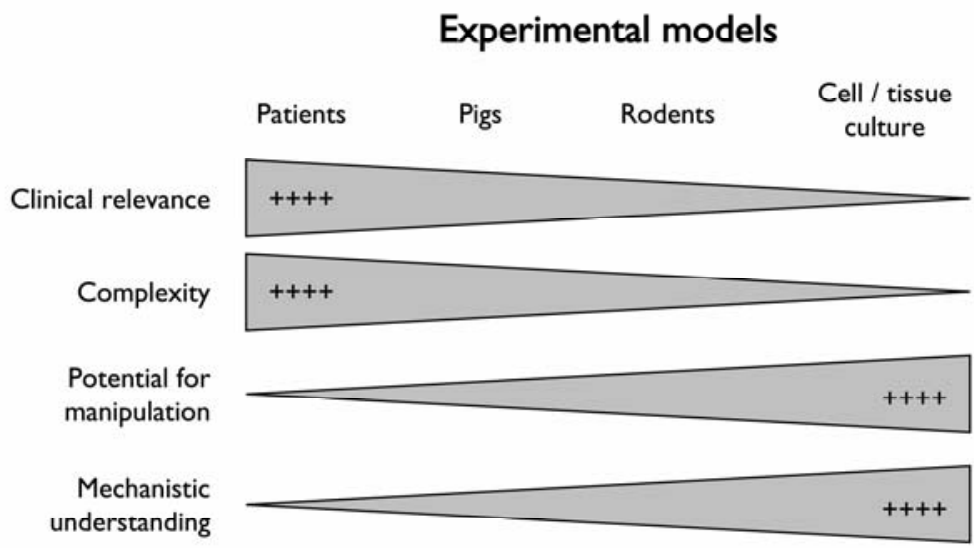

Figure 1.3 A comparison of the strengths and weaknesses of the various experimental models of acute kidney injury from ischemia and reperfusion.

oxygen concentrations from direct exposure to air during cell culture. In addition, freshly isolated tubules suffer extensive injury during preparation causing lethal damage to $10-15 \%$ of tubular cells. This isolation damage not only causes injury to the tubules, but may also induce cytoprotective responses that confound subsequent experiments. Although phenotypic changes can limit the generalization of findings from in vitro experiments, this approach has proven highly useful to dissect intracellular pathways associated with ischemic acute kidney injury.

\section{Rodent models}

Acute ischemic kidney injury is a complex disease in which the tubular epithelium, connective tissue, renal vasculature and immune system play critical and intertwined roles. Therefore, in vivo animal models may be more appropriate for the study of acute kidney injury than ex vivo cell culture. Temporary renal artery occlusion in mice or rats is the most frequently used experimental model and has recently been reviewed by Kennedy and Erlich. ${ }^{193}$ This model is technically straightforward and readily allows genetic modification and pharmacological intervention to study the pathophysiological mechanisms of acute ischemic kidney injury. However, the extensive necrosis of proximal tubules observed after complete renal artery occlusion in mice and rats does not correspond to the much milder histological changes in clinical biopsies of transplanted or native kidneys with acute renal failure. ${ }^{194,195}$ Other rodent models of acute kidney injury 
include administration of nephrotoxins such as cisplatin or radiocontrast, induction of rhabdomyolysis through intramuscular injection of glycerol, and generation of prolonged hypotension by partial ligation of the suprarenal aorta. ${ }^{196}$ Furthermore, kidney transplantation after variable periods of cold storage is possible in rodents - though technically demanding ${ }^{197}$ - and may generate fascinating mechanistic insights, in particular when kidneys from genetic knock-out mice are transplanted into their wild-type counterparts and vice versa. ${ }^{198}$

\section{Large animal models and clinical studies}

Rodent models have provided important insights into the pathophysiology of acute ischemic kidney injury that have encouraged translation of these findings to clinical kidney transplantation. In this regard, small animals have intrinsically higher metabolic rates and are therefore more susceptible to ischemic acute kidney injury and its systemic consequences. ${ }^{199}$ Therefore, large animal models of autologous kidney transplantation have been used for preclinical assessment of novel interventions targeted to attenuate renal injury due to ischemia and reperfusion. In this respect, pigs are particularly useful since their renal anatomy and physiology is highly comparable to humans and because inbred pigs have relatively little genetic variation. ${ }^{200}$ However, preclinical experiments with porcine models of kidney transplantation are limited by their complexity and considerable expense. ${ }^{201-204}$ Furthermore, these experiments are typically done in young and healthy animals that may not be representative of wait-listed dialysis patients. Observational studies in transplant recipients may therefore provide the most clinically relevant information on the pathophysiology of ischemic acute kidney injury. However, these studies are restricted by the limited potential for experimental manipulation in human subjects, which reduces the opportunities for tissue sampling and generally obviates a causal interpretation of findings. Taken together, we argue that the combined use of the available experimental models is the most fruitful approach to improve the understanding and treatment of acute kidney injury after ischemia and reperfusion.

\section{Pathophysiology of acute kidney injury in transplant recipients}

The reintroduction of blood flow to the ischemic kidney - although necessary to rescue the organ from necrosis and permanent loss of function - leads to acute cellular injury and severe renal dysfunction..$^{205-207}$ In contrast to the profound functional impairment, histological abnormalities in biopsies from kidneys with delayed graft function are relatively mild. ${ }^{195}$ Some studies have found higher 
semi-quantitative scores of brush border loss, tubular necrosis, cell shedding, tubular dilatation and interstitial inflammation in kidneys with delayed function compared to immediately functioning grafts, ${ }^{208-210}$ whereas others have observed very similar morphology in reperfusion biopsies of these kidneys. ${ }^{211-213}$ Overall, the low number of necrotic tubular cells in these biopsies does not adequately explain the profound functional impairment of grafts with early dysfunction. Total renal and regional cortical blood flow in the first hours and days after reperfusion - measured by electromagnetic, transit-time and laser-Doppler flow probes, magnetic resonance, radionuclide and infra-red imaging, thermodiffusion and videomicroscopy - are generally lower in kidneys with delayed graft function than in immediately functioning transplants. ${ }^{214-227}$ Similar to the mild histological abnormalities, however, the relatively small reductions in renal blood flow do not fully account for the severely depressed glomerular filtration rate in patients with early graft dysfunction. According to mathematical models, the reduction of glomerular filtration is instead primarily caused by a decline in the outward driving force for glomerular ultrafiltration. ${ }^{211}$ In patients with early graft dysfunction, the glomerular transcapillary hydraulic pressure difference (outward driving force) exceeds the glomerular oncotic pressure (inward driving force) by only $2 \mathrm{mmHg}$ as compared to $12 \mathrm{mmHg}$ in patients with adequately functioning grafts (Figure 1.4).

\section{Tubular obstruction}

The dissipation of the net ultrafiltration pressure may be caused by tubular obstruction from necrotic debris and sloughed tubular epithelial cells or by vasoconstriction of the afferent glomerular arterioles. Tubular dilatation - which may be interpreted as increased intraluminal pressure due to downstream obstruction - decreases within the first week of transplantation in renal biopsies from recovering grafts while it remains constant in grafts with sustained dysfunction. ${ }^{228}$ However, the number of tubular cells that have undergone necrotic cell death or have sloughed into the tubular lumen is low in renal biopsies (1$4 \%){ }^{211}$ Furthermore, the number of voided epithelial cells by recipients of grafts with delayed function is highly variable and not significantly different from patients with adequate graft function. ${ }^{229}$ Taken together, these findings do not support the hypothesis that tubular obstruction is an important cause of renal dysfunction after ischemia and reperfusion. 


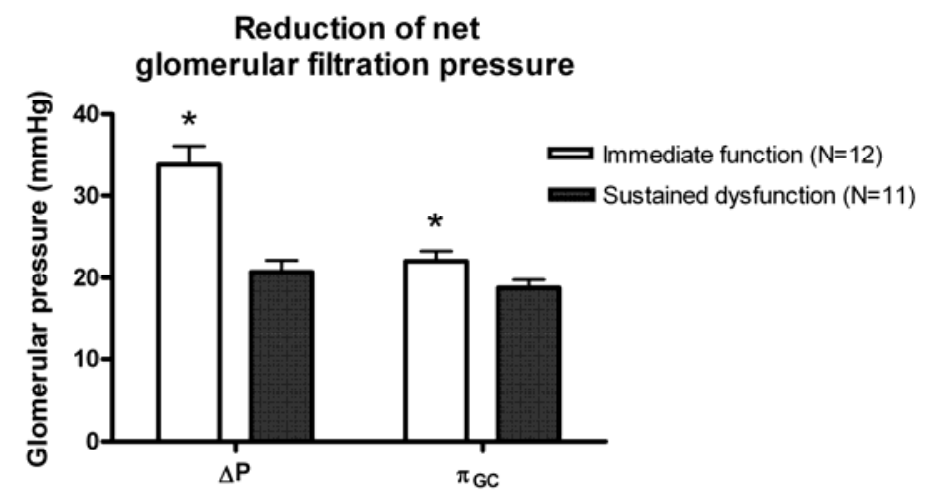

Figure 1.4 Calculated glomerular transcapillary hydraulic pressure difference $(\Delta \mathrm{P}$, the outward driving force for ultrafiltration) and glomerular oncotic pressure $(\pi \mathrm{GC}$, the inward driving force counteracting ultrafiltration) 1-3 hours after reperfusion. The calculations assume $1 \times 10^{6}$ glomeruli per kidney and the presence of $33 \%$ transtubular backleak in kidneys with sustained graft dysfunction but not in kidneys with immediate function. Data are presented as mean and standard error; the asterisk indicates a statistically significant difference between kidneys with sustained dysfunction and with immediate function $(\mathrm{P}<0.05)$. The figure was adapted from Alejandro et al. ${ }^{211}$

\section{Afferent arteriolar vasoconstriction}

As tubular obstruction does not explain the decline in glomerular filtration pressure, vasoconstriction of the afferent arterioles has to make an essential contribution to the reduction of ultrafiltration in patients with early graft dysfunction. This is supported by studies of spectral Doppler waveforms that have found higher resistive indices in the arteries of kidneys with delayed graft function than in immediately functioning grafts in the first hours and days after reperfusion. ${ }^{230-238}$ Afferent arteriolar vasoconstriction may be induced by the increased sodium load that is delivered to the macula densa as a result of its reduced reabsorption by the injured tubular epithelium (tubuloglomerular feedback). Indeed, the sodium load delivered to the macula densa decreases within the first week of transplantation in recovering grafts but remains constantly elevated in grafts with sustained dysfunction. ${ }^{239}$ The reduced capacity for sodium reabsorption may be explained by a redistribution of $\mathrm{Na}^{+} / \mathrm{K}^{+}$-ATPase and its cytoskeletal anchorage from their usual position at the basolateral membrane into the cytoplasm of injured proximal tubular epithelial cells as observed in reperfusion biopsies of grafts with sustained dysfunction (Figure 1.5). ${ }^{240}$ Additionally, in the first week but not in the first hours after reperfusion, patients 
with sustained graft dysfunction have higher plasma concentrations of the vasocontrictors endothelin- 1 and angiotensin- 2 and lower urinary metabolite concentrations of the vasodilator nitric oxide compared to recipients of recovering grafts. ${ }^{211,216,241}$ On the other hand, vasoconstriction in patients with early graft dysfunction was neither a result of a deficiency in atrial natriuretic peptide signaling - a selective vasodilator of the afferent glomerular arteriole - nor of increased production of the vasoconstrictors thromboxane $A_{2}$ or leukotriene $\mathrm{A}_{4 .}{ }^{242,243}$ Taken together, although a number of mechanisms have been suggested to reduce the glomerular ultrafiltration pressure in sustained graft dysfunction, the causes of afferent arteriolar vasoconstriction in the initiation phase of ischemic acute kidney injury remain to be elucidated.

\section{Transtubular backleak of ultrafiltrate}

Finally, backleak of glomerular ultrafiltrate through the injured tubular epithelial layer into the peritubular circulation may reduce the effective glomerular filtration rate. Intracellular redistribution of proteins necessary for tight junction formation and cell-cell adhesion within the damaged tubular epithelium may provide a paracellular pathway for backleak of ultrafiltrate in renal transplants with sustained dysfunction. ${ }^{244}$ By comparing the filtration rate of dextrans of different sizes to that of inulin in the first week after transplantation, it was estimated that half of the filtered inulin must have leaked back into the circulation in recipients of grafts with sustained dysfunction; in patients with recover-

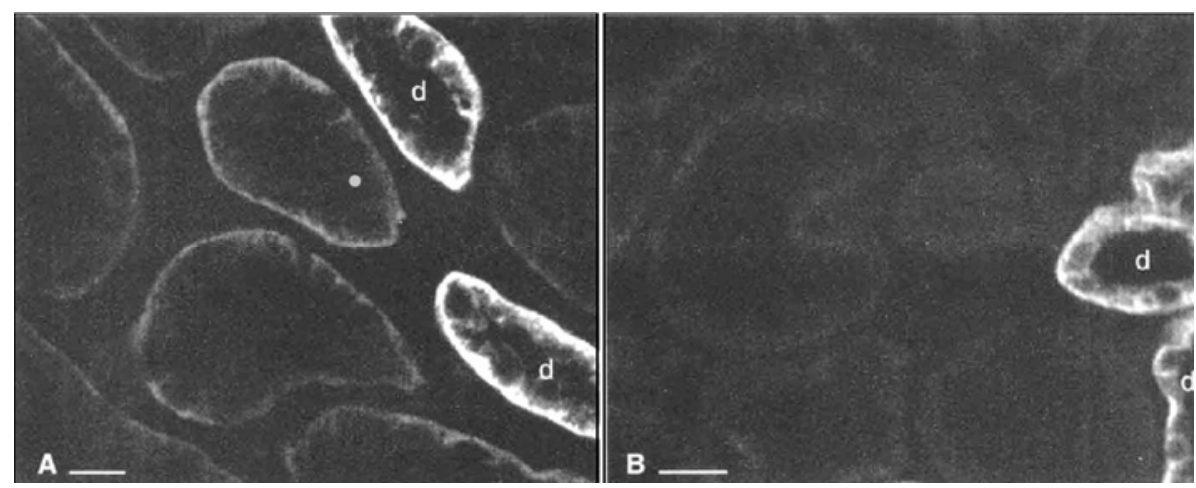

Figure 1.5 Confocal micrographs of the distribution of $\mathrm{Na}^{+} / \mathrm{K}^{+}-\mathrm{ATPase}$ in the tubular epithelium of kidneys with immediate function (A) and with sustained graft dysfunction (B). Distal tubules, labelled "d", have intense staining, whereas the proximal tubules with paler staining have a basolateral distribution of $\mathrm{Na}+\mathrm{K}+-\mathrm{ATPase}$ in kidneys with immediate function and a cytoplasmic distribution in kidneys with sustained dysfunction. The figure was adapted from Alejandro et al. ${ }^{240}$ 
ing allografts, no evidence for transtubular backleak was found. ${ }^{244}$ Therefore, transtubular backleak makes a relatively modest contribution to the profound reduction of effective glomerular filtration in ischemic acute kidney injury.

\section{Acute renal success?}

The reduction of effective glomerular filtration rate in ischemic acute kidney injury may be considered an adaptive response, since continuous glomerular filtration would rapidly lead to depletion of body fluids when the capacity for reabsorption is lost due to ischemic injury to the tubular epithelium. ${ }^{245}$ Reduced formation of ultrafiltrate will decrease the tubular workload and oxygen consumption which may facilitate recovery from ischemic cellular injury. In line with this concept, reperfusion biopsies of kidneys that do not produce adequate amounts of urine in the first hours after transplantation have significantly lower expression of the protein hypoxia-inducible factor- $1 \alpha$ and its target genes vascular endothelial growth factor and heme oxygenase-1 than immediately functioning kidneys. ${ }^{246,247}$ These findings suggest that a reduced glomerular filtration rate decreases the demand for tubular reabsorption and therefore increases renal oxygen availability. On the other hand, intense vasoconstriction of afferent glomerular arterioles in grafts with early dysfunction may substantially limit perfusion of the downstream peritubular capillary bed exacerbating ischemic injury. In support of this concept, the peritubular capillary network seems to suffer more extensive damage - indicated by a pronounced loss of endothelial von Willebrand factor staining - in kidneys with early graft dysfunction than in immediately functioning grafts, a finding that has also been observed in rat kidneys after ischemia and reperfusion. ${ }^{248,249}$

\section{Molecular basis of ischemic acute kidney injury in transplant recipients}

Understanding of the molecular pathways leading to human disease has been advanced through two complementary approaches: hypothesis-driven research that builds on previous experimental findings and unbiased data-driven studies that may generate novel hypotheses. The latter approach has received relatively little attention in the field of ischemic acute kidney injury. To date, neither genetic polymorphisms in donors and recipients nor protein and metabolite concentrations in plasma and urine have been compared between kidney transplantations with and without immediate graft function in an unbiased fashion, although some studies have recently reported on differences in gene expression profiles in kidneys biopsies taken at implantation. ${ }^{250-253}$ In these studies, grafts 
with delayed function were characterized by downregulation of genes involved in metabolism and by upregulation of genes involved in cellular injury and repair (particularly genes regulating oxidative stress and apoptosis) and inflammation (toll-like receptors, complement components, chemokines and adhesion molecules). More focused analyses of gene expression in reperfusion biopsies of transplant recipients have confirmed these findings. ${ }^{254}$ The molecular pathways associated with acute ischemic injury in clinical kidney transplantation are in general agreement with results from experiments in animal models. Studies on specific mechanisms of acute kidney injury in transplant recipients will be discussed below.

\section{Oxidative stress}

Oxidative stress is defined as an imbalance between the production of reactive oxygen species and the capacity of anti-oxidative defence. The sudden increase in renal oxygen concentration at reperfusion may lead to formation of reactive oxygen species through several mechanisms: by xanthine oxidase and phospholipase $A_{2}$ that are activated due to the increased cytosolic calcium concentrations during ischemia, by leakage of electrons from the mitochondrial respiratory chain that has suffered ischemic injury, and by activity of NADPH oxidase in infiltrating neutrophils and macrophages. Since it is difficult to directly measure reactive oxygen species due to their extremely short half-lives, a multitude of assays have been developed for indirect assessment of oxidative stress by measuring consumption of anti-oxidants or formation of oxidatively modified lipids, proteins and DNA. The accuracy of these biomarkers for the detection of oxidative stress has recently been studied in a highly standardized rodent model of carbon tetrachloride toxicity. ${ }^{255,256}$ Surprisingly, the vast majority of these biomarkers did not consistently detect oxidative stress in this experimental model. The only useful markers of oxidative stress in plasma were malondialdehyde and $\mathrm{F}_{2}$-isoprostanes measured by gas chromatography and mass spectrometry, whereas meaningful markers in urine were $\mathrm{F}_{2}$-isoprostanes measured by immunoassay and 8,12-iso-iPF ${ }_{2 \alpha}$-VI detected by liquid chromatography and mass spectrometry. Despite the large body of experimental work on oxidative stress in ischemic acute kidney injury, these markers have never been measured in clinical kidney transplantation. Studies measuring less appropriate markers of oxidative stress have obtained conflicting results, with some groups finding greater oxidative stress in recipients of kidneys with more extensive ischemic injury, whereas others could not confirm this finding. ${ }^{257-260}$ Randomized clinical trials using anti-oxidant supplements to improve early graft function have also pro- 
vided mixed results. Two clinical trials found that intravenous administration of a multivitamin preparation at reperfusion or oral administration of the polyphenolic anti-oxidants quercetin and curcumin for one month starting at the day of surgery improved kidney function in the first week after transplantation. ${ }^{261,262}$ However, these findings were not reproduced in other clinical trials testing the effects on early graft function of superoxide dismutase, allopurinol or vitamin C administration. ${ }^{263-267}$ It is important to note that markers of oxidative stress were not measured in most of these trials. Therefore, uncertainty remains regarding the effectiveness of the anti-oxidant interventions in reducing oxidative stress in the trial participants. Taken together, it remains to be established to what extent early graft dysfunction in clinical kidney transplantation is associated with oxidative stress at reperfusion; testing this hypothesis should be greatly facilitated by the recent establishment of meaningful biomarkers of oxidative stress. Interestingly, intravenous administration of one of these biomarkers, $\mathrm{F}_{2}-$ isoprostanes, results in profound reduction of glomerular filtration in rats due to thromboxane $\mathrm{A}_{2}$ receptor-mediated vasoconstriction of afferent glomerular arterioles. ${ }^{268,269}$ Therefore, the local production of $\mathrm{F}_{2}$-isoprostanes by reactive oxygen species might contribute to renal dysfunction after ischemia and reperfusion.

\section{Apoptotic and necrotic cell death and activation of innate immunity}

Apoptosis is a physiological and highly regulated form of cell death that is triggered either by signalling through death receptors at the plasma membrane or by disruption of mitochondrial integrity..$^{270,271}$ In clinical kidney transplantation and in rodent models of acute kidney injury, tubular epithelial and endothelial cells undergo apoptotic cell death in the early reperfusion phase (Figure 1.6)..$^{272,273}$ Kidneys with early graft dysfunction contain more apoptotic cells than immediately functioning grafts, which is associated with increased expression of proapoptotic proteins Bax and Bad, decreased expression of anti-apoptotic proteins Bcl-2 and Bcl-xL and release of cytochrome c from mitochondria into the cytoplasm of tubular epithelial cells. ${ }^{247,274-277}$ Whereas a limited amount of debris from apoptotic cells can be rapidly cleared by macrophages without triggering an inflammatory response, necrotic cell death or an overload of apoptotic debris may lead to spill of intracellular contents into the extracellular milieu. Several of the released molecules have been shown to function as danger signals that activate the innate immune system through pattern recognition receptors such as Toll-like receptors. ${ }^{278}$ In reperfusion biopsies taken during kidney transplanta- 

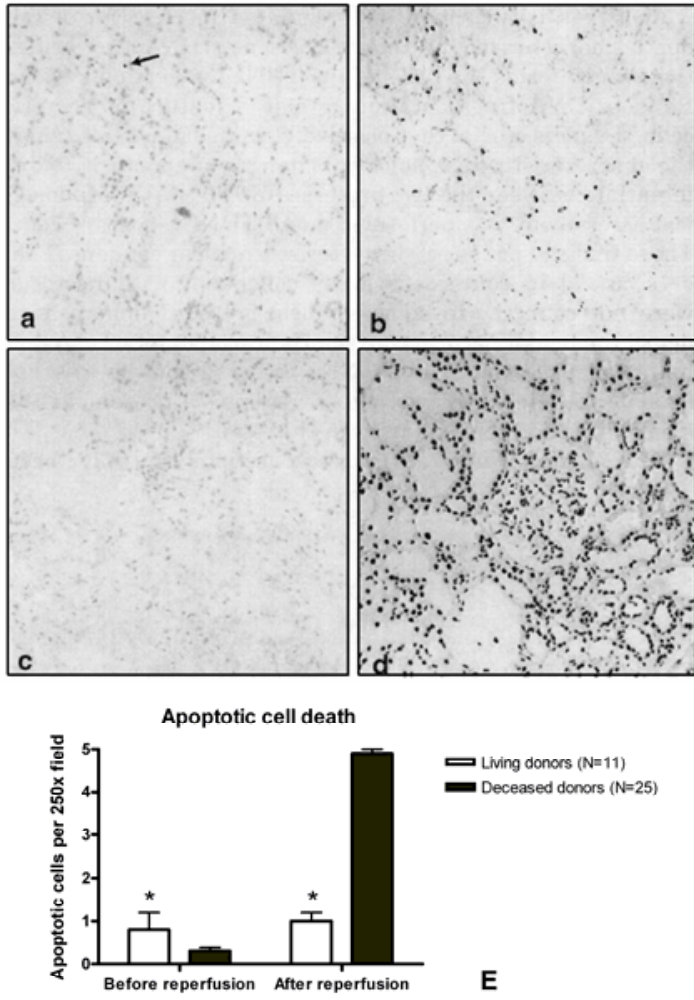

Figure 1.6

Detection of apoptosis in biopsy specimens from deceased donor kidneys by TUNEL staining before (A) and after (B) reperfusion. The biopsy before reperfusion shows an occasional apoptotic cell (labelled with an arrow), whereas the biopsy after reperfusion shows substantially more apoptotic cells. Panel C is a negative control with omission of TdT reagent and panel $\mathrm{D}$ is a positive control after DNase digestion. (E) The number of apoptotic cells per 250x field was significantly greater in deceased donor kidneys than in kidneys from living donors. Data are presented as mean and standard error; the asterisk indicates a statistically significant difference between deceased and living donor kidneys. The figure was adapted from Burns et al. ${ }^{272}$

tion, Toll-like receptor 4 and its ligand high-mobility group box 1 are more abundantly expressed in the tubular epithelium of deceased donor kidneys than in grafts from living donors. ${ }^{279}$ Furthermore, grafts from deceased donors with loss-of-function mutations in the gene encoding Toll-like receptor 4 had superior early graft function and reduced expression of inflammatory mediators than grafts from donors with functional Toll-like receptor 4. Similar findings have been reported from mouse models of ischemic acute kidney injury. ${ }^{280}$ In addition, the innate immune system may be activated by deposition of mannose-binding lectin on endogenous ligands present in ischemically injured kidneys in clinical transplantation and in rodent models. ${ }^{281}$ Although this may result in local activation of complement through the lectin pathway, deposition of downstream complement cleavage products is not readily observed in reperfusion biopsies from transplanted kidneys. ${ }^{282}$ These findings suggest that regulatory proteins such as decay-accelerating factor, factor $\mathrm{H}$ and membrane cofactor protein provide effective protection against further complement activation in ischemi- 
cally injured kidneys. After recovery from the early postoperative period, patients with low plasma concentrations of mannose-binding lectin have been reported to experience longer graft survival of deceased donor kidneys. ${ }^{283}$ Taken together, over the past decade evidence has accumulated that cellular injury due to ischemia and reperfusion locally activates innate immunity in clinical kidney transplantation.

\section{Inflammation}

Activation of the innate immune system by ischemically damaged tissue may increase the production of chemokines and adhesion molecules by the endothelium and tubular epithelial cells to facilitate the entry of leukocytes into the kidney. Since inhibition of inflammation attenuates kidney dysfunction in animal models of renal ischemia and reperfusion, the inflammatory response is considered maladaptive as it may exacerbate renal injury during the first hours and days after transplantation. ${ }^{285}$ Deceased donor kidneys are characterized by greater upregulation of the neutrophil chemoattractant interleukin-8 than living donor kidneys, whereas gene expression of chemoattractants for monocytes (MCP-1) and lymphocytes (IP-10 and RANTES) is comparable in these grafts during the first hour of reperfusion. ${ }^{286}$ Additionally, urine concentrations of neutrophil chemoattractants interleukin- 8 and Gro- $\alpha$ are higher in deceased donor kidneys with delayed graft function than in immediately functioning allografts. ${ }^{287,288}$ In parallel to the upregulation of chemokine expression in ische-

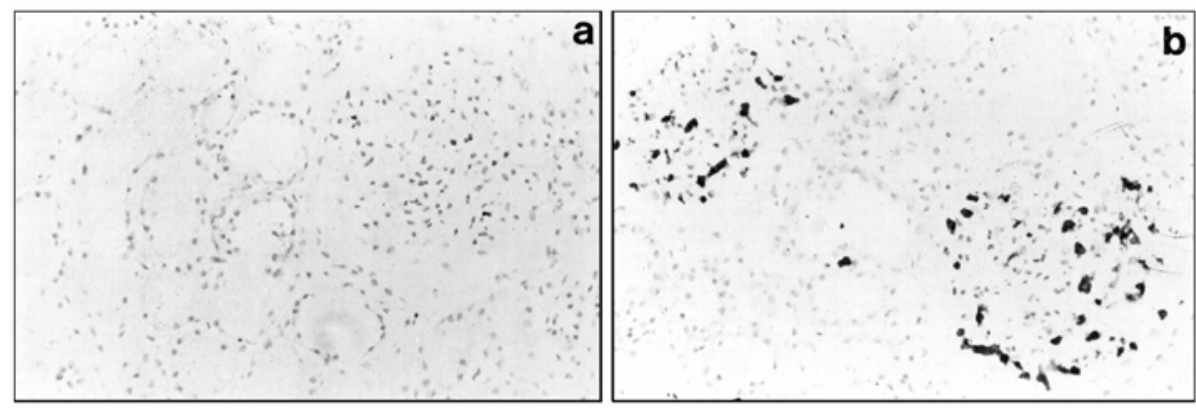

Figure 1.7 Detection of neutrophils in biopsy specimens from deceased donor kidneys by immunoperoxidase staining with a neutrophil elastase antibody before (A) and after (B) reperfusion. The biopsy before reperfusion shows the absence of neutrophils in the kidney, whereas the biopsy after reperfusion demonstrates glomerular infiltration of neutrophils. Neutrophil infiltration after reperfusion was detected in 29 out of 55 (53\%) deceased donor kidneys and in none of 29 (0\%) living donor kidneys. The figure was adapted from Koo et al..$^{284}$ 
mically injured kidneys, the adhesion molecules intracellular adhesion molecule1 and P-selectin - but not vascular cell adhesion molecule-1 and E-selectin - are more abundantly present in reperfusion biopsies from deceased donor kidneys with early graft dysfunction than in immediately functioning kidneys. ${ }^{284,289}$ The increased expression of chemokines and adhesion molecules in grafts with delayed function results in more renal sequestration of neutrophils compared to immediately functioning grafts (Figure 1.7). ${ }^{284,290}$ The inflammatory response may be stimulated by local and systemic production of various pro-inflammatory cytokines. Recipients of kidneys with delayed graft function are characterized by higher concentrations of plasma tumor necrosis factor and urine interleukin-6 and interleukin-18 than patients with immediately functioning grafts during the first day after transplantation. ${ }^{288,291,292}$ Genetic polymorphisms leading to reduced production of tumor necrosis factor in the donor and interleukin-18 in the recipient have been reported to protect against delayed graft function. ${ }^{293-296}$ Although these observational studies have established a strong association between graft dysfunction and innate immunity, the only randomized clinical trial to date that has attempted to prevent inflammation by administering antibodies blocking intracellular adhesion molecule-1 was not effective in reducing the incidence of delayed graft function in deceased donor kidney transplantation. ${ }^{297}$

\section{Opportunities to intervene in ischemic acute kidney injury}

From our review of the pathophysiology of ischemic acute renal injury after clinical kidney transplantation, several opportunities can be identified to support the kidney during the early post-transplant period (Figure 1.8). In the first minutes to hours after transplantation, priority should be given to adequate perfusion of the kidney in order to avoid ongoing ischemic tissue injury due to systemic hemodynamic compromise or local microcirculatory perfusion defects. When adequate renal perfusion is ensured, reduced urine production and renal clearance can be considered as a beneficial homeostatic mechanism that avoids fluid loss and reduces tubular workload. During the first hours to days after transplantation, the opportunity arises to protect the transplanted kidney from irreversible cellular injury and to dampen the activation of the innate immune system in response to tissue damage. ${ }^{298}$ In the context of sterile tissue injury, excessive inflammation does not restore homeostasis but rather exacerbates acute kidney injury and delays renal repair. Therefore, throughout the first days to weeks after transplantation, the regenerating tubular epithelium and peritubular capillary network should be supported in its recovery from injury to avoid interstitial fibrosis and permanent nephron loss. ${ }^{299,300}$ In this period, it is also 


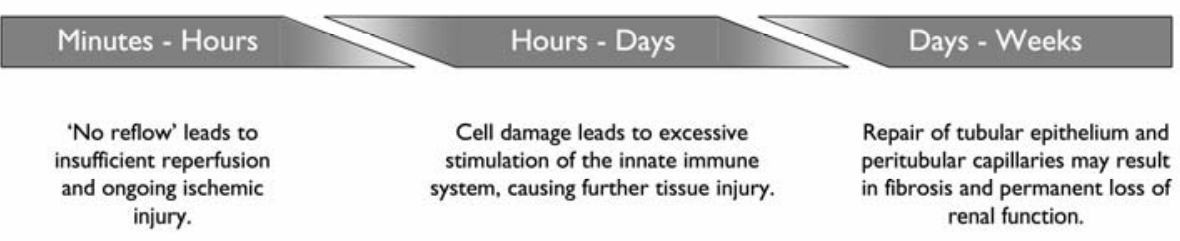

Figure 1.8 An overview of opportunities to modulate renal ischemia-reperfusion injury in clinical kidney transplantation.

important to ensure adequate immunosuppression to avoid additional damage as a result of subclinical acute rejection.

\section{Clinical outcome of DCD kidney transplantation}

The clinical outcome of DCD kidney transplantation has been compared to conventional DBD kidney transplantation in several studies. ${ }^{13,15-17,19,21,26,27,29-}$ 31,34,37,45,46,49,53,55,58,301-305 The main findings of these studies are summarized in Table 1.2. In general, DCD kidneys more often suffer from delayed graft function and primary non-function than DBD kidneys, although in most studies the higher incidence of primary non-function does not reach statistical significance due to limited sample size. Primary non-function after kidney transplantation is a serious complication, since patients receiving these kidneys are unnecessarily exposed to the risks of surgery and immunosuppression and may become sensitized to donor antigens, reducing the opportunities for retransplantation. ${ }^{306,307}$ Therefore, the development of novel strategies that prevent primary nonfunction of DCD kidneys is of major importance. Despite the inferior short-term function of DCD kidneys, most studies show that graft survival of DCD kidneys is comparable to DBD kidneys within the first 5 to 10 years after transplantation. The deleterious effects of delayed graft function on acute rejection, interstitial fibrosis, and long-term graft function in DBD kidneys have generally not been observed in DCD kidney transplantation. ${ }^{308-310}$ Although comparison of clinical outcomes between transplant centers is complicated by differences in selection and management of donors and recipients, a meta-analysis of studies comparing 
\begin{tabular}{l|ll}
36 & C H A P T E R 1
\end{tabular} 
\begin{tabular}{ll|l} 
IN TROD U C TION & 37
\end{tabular} 
DCD and DBD kidney transplantations has recently been published. ${ }^{311}$ The findings from this meta-analysis support the conclusions from our review of the literature on the outcome of DCD kidney transplantation presented above.

Despite the encouraging results from observational cohort studies comparing the outcome of DCD and DBD kidney transplantations, in many countries the large pool of DCD donors has not yet been fully utilized. In particular, the use of uncontrolled DCD kidneys that hold the greatest potential for expansion of the donor pool but suffer extensive ischemic injury remains controversial. The reluctance of many to recover and transplant DCD kidneys may be explained by two important medical reasons. First, although graft survival of viable DCD kidneys is comparable to DBD kidneys within the first 5 to 10 years after transplantation, their long-term outcome remains to be established. Second, it is unknown whether individual recipients benefit from accepting a DCD kidney instead of continuing dialysis treatment while waiting for a kidney from a conventional DBD donor. Studies that address these issues are needed to provide further information on the clinical outcome of DCD kidney transplantation. Evidence in favour of DCD kidney transplantation may lead to more widespread use of these grafts, resulting in reduced waiting times and overall improvement in survival of patients with end-stage renal disease.

\section{Aim of the thesis}

Given the current state of DCD kidney transplantation, the aims of this thesis were defined as follows: firstly, to report on the long-term outcome of DCD kidney transplantation and its effect on survival of wait-listed dialysis patients; secondly, to identify strategies that can be used to predict and prevent primary non-function of DCD kidneys; and thirdly, to increase the understanding of the pathophysiology and treatment of ischemic acute renal injury after DCD kidney transplantation. 


\section{References}

1. Wolfe RA, Ashby VB, Milford EL, et al. Comparison of mortality in all patients on dialysis, patients on dialysis awaiting transplantation, and recipients of a first cadaveric transplant. $\mathrm{N}$ Engl J Med 1999; 341:1725-1730.

2. Evans RW, Manninen DL, Garrison LP, Jr., et al. The quality of life of patients with end-stage renal disease. N Engl J Med 1985; 312:553-559.

3. Terasaki PI, Cecka JM, Gjertson DW, Takemoto S. High survival rates of kidney transplants from spousal and living unrelated donors. N Engl J Med 1995; 333:333-336.

4. Horvat LD, Shariff SZ, Garg AX. Global trends in the rates of living kidney donation. Kidney Int 2009; 75:1088-1098.

5. Montgomery RA, Gentry SE, Marks WH, et al. Domino paired kidney donation: a strategy to make best use of live non-directed donation. Lancet 2006; 368:419-421.

6. Rees MA, Kopke JE, Pelletier RP, et al. A nonsimultaneous, extended, altruistic-donor chain. N Engl J Med 2009; 360:1096-1101.

7. Roodnat JI, Kal-van Gestel JA, Zuidema W, et al. Successful expansion of the living donor pool by alternative living donation programs. Am J Transplant 2009; 9:2150-2156.

8. Port FK, Bragg-Gresham JL, Metzger RA, et al. Donor characteristics associated with reduced graft survival: an approach to expanding the pool of kidney donors. Transplantation 2002; 74:1281-1286.

9. Merion RM, Ashby VB, Wolfe RA, et al. Deceased-donor characteristics and the survival benefit of kidney transplantation. Jama 2005; 294:2726-2733.

10. Daemen JW, Oomen AP, Kelders WP, Kootstra G. The potential pool of non-heart-beating kidney donors. Clin Transplant 1997; 11:149-154.

11. Terasaki PI, Cho YW, Cecka JM. Strategy for eliminating the kidney shortage. Clin Transpl 1997:265-267.

12. Kootstra G, Daemen JH, Oomen AP. Categories of non-heart-beating donors. Transplant Proc 1995; 27:2893-2894.

13. Wijnen RM, Booster MH, Stubenitsky BM, de Boer J, Heineman E, Kootstra G. Outcome of transplantation of non-heart-beating donor kidneys. Lancet 1995; 345:1067-1070.

14. Snoeijs MG, Schaefer S, Christiaans MH, et al. Kidney transplantation using elderly non-heartbeating donors: a single-center experience. Am J Transplant 2006; 6:1066-1071.

15. Hordijk W, Hoitsma AJ, van der Vliet JA, Hilbrands LB. Results of transplantation with kidneys from non-heart-beating donors. Transplant Proc 2001; 33:1127-1128.

16. Keizer KM, de Fijter JW, Haase-Kromwijk BJ, Weimar W. Non-heart-beating donor kidneys in the Netherlands: allocation and outcome of transplantation. Transplantation 2005; 79:11951199.

17. Barlow AD, Metcalfe MS, Johari Y, Elwell R, Veitch PS, Nicholson ML. Case-matched comparison of long-term results of non-heart beating and heart-beating donor renal transplants. $\mathrm{Br}$ J Surg 2009; 96:685-691.

18. Gerstenkorn C, Deardon D, Koffman CG, Papalois VE, Andrews PA. Outcome of renal allografts from non-heart-beating donors with delayed graft function. Transpl Int 2002; 15:660663. 
19. Wells AC, Rushworth L, Thiru S, et al. Donor kidney disease and transplant outcome for kidneys donated after cardiac death. Br J Surg 2009; 96:299-304.

20. Balupuri S, Buckley P, Snowden C, et al. The trouble with kidneys derived from the non heartbeating donor: a single center 10-year experience. Transplantation 2000; 69:842-846.

21. Akoh JA, Denton MD, Bradshaw SB, Rana TA, Walker MB. Early results of a controlled nonheart-beating kidney donor programme. Nephrol Dial Transplant 2009; 24:1992-1996.

22. Navarro AP, Sohrabi S, Reddy M, Carter N, Ahmed A, Talbot D. Dual transplantation of marginal kidneys from nonheart beating donors selected using machine perfusion viability criteria. J Urol 2008; 179:2305-2309; discussion 2309.

23. Plata-Munoz JJ, Muthusamy A, Quiroga I, et al. Impact of pulsatile perfusion on postoperative outcome of kidneys from controlled donors after cardiac death. Transpl Int 2008; 21:899-907.

24. Laugharne MJ, Clarke E, Younie ME, et al. A Novel Scheme for Graft Allocation in Non-Heart Beating Donor Renal Transplantation. Transplantation 2008; 85:1663-1667.

25. Brook NR, Waller JR, Richardson AC, et al. A report on the activity and clinical outcomes of renal non-heart beating donor transplantation in the United Kingdom. Clin Transplant 2004; 18:627-633.

26. Sanchez-Fructuoso AI, Marques M, Prats D, et al. Victims of cardiac arrest occurring outside the hospital: a source of transplantable kidneys. Ann Intern Med 2006; 145:157-164.

27. Gonzalez-Segura C, Castelao AM, Torras J, et al. A good alternative to reduce the kidney shortage: kidneys from nonheartbeating donors. Transplantation 1998; 65:1465-1470.

28. Valero R, Cabrer C, Oppenheimer F, et al. Normothermic recirculation reduces primary graft dysfunction of kidneys obtained from non-heart-beating donors. Transpl Int 2000; 13:303-310.

29. Alonso A, Fernandez-Rivera C, Villaverde P, et al. Renal transplantation from non-heartbeating donors: a single-center 10-year experience. Transplant Proc 2005; 37:3658-3660.

30. Weber M, Dindo D, Demartines N, Ambuhl PM, Clavien PA. Kidney transplantation from donors without a heartbeat. N Engl J Med 2002; 347:248-255.

31. Pacholczyk MJ, Lagiewska B, Szostek M, et al. Transplantation of kidneys harvested from nonheart-beating donors: early and long-term results. Transpl Int 1996; 9 Suppl 1:S81-83.

32. Reznik ON, Bagnenko SF, Loginov IV, et al. Machine perfusion as a tool to select kidneys recovered from uncontrolled donors after cardiac death. Transplant Proc 2008; 40:1023-1026.

33. Rosental R, Strokan V, Bitsans J, Sheveliov V, Iljinsky I. Kidney harvesting from non-heartbeating donors (NHBD): a surgical approach. Transplant Proc 1991; 23:2588.

34. Guillard G, Rat P, Haas O, Letourneau B, Isnardon JP, Favre JP. Renal harvesting after in situ cooling by intra-aortic double-balloon catheter. Transplant Proc 1993; 25:1505-1506.

35. Droupy S, Blanchet P, Eschwege $\mathrm{P}$, et al. Long-term results of renal transplantation using kidneys harvested from non-heartbeating donors: a 15-year experience. J Urol 2003; 169:28-31.

36. Fieux F, Losser MR, Bourgeois E, et al. Kidney retrieval after sudden out of hospital refractory cardiac arrest: a cohort of uncontrolled non heart beating donors. Crit Care 2009; 13:R141.

37. Pokorny H, Rockenschaub S, Puhalla $\mathrm{H}$, et al. Transplantation of kidneys from non-heartbeating donors: retrospective analysis of the outcome. Transplant Proc 1997; 29:3545-3548.

38. Orlic P, Zelic M, Petrosic N, et al. Use of non-heart-beating donors: preliminary experience with perfusion in situ. Transplant Proc 1999; 31:2097-2098.

39. Aydin AE, Dibekoglu MS, Turkmen A, Carin MN, Eldegez U. Cadaveric kidney transplantation activities in Istanbul. Transplant Proc 1995; 27:2947; discussion 2935-2949.

40. Malaise J, Van Deynse D, Dumont V, et al. Non-heart-beating donor, 10-year experience in a Belgian transplant center. Transplant Proc 2007; 39:2578-2579. 
41. Teraoka S, Nomoto K, Kikuchi K, et al. Outcomes of kidney transplants from non-heartbeating deceased donors as reported to the Japan Organ Transplant Network from April 1995December 2003: a multi-center report. Clin Transpl 2004:91-102.

42. Tojimbara T, Fuchinoue S, Iwadoh K, et al. Improved outcomes of renal transplantation from cardiac death donors: a 30-year single center experience. Am J Transplant 2007; 7:609-617.

43. Hoshinaga K, Shiroki R, Fujita T, Kanno T, Naide Y. The fate of 359 renal allografts harvested from non-heart beating cadaver donors at a single center. Clin Transpl 1998:213-220.

44. Mizutani K, Ono Y, Kinukawa T, et al. Use of marginal organs from non-heart-beating cadaveric kidney donors. Transplantation 2001; 72:1376-1380.

45. Lee CY, Tsai MK, Ko WJ, et al. Expanding the donor pool: use of renal transplants from nonheart-beating donors supported with extracorporeal membrane oxygenation. Clin Transplant 2005; 19:383-390.

46. Lau KO, Vathsala A, Kong S, Li MK. Preliminary results of heart-beating and non-heartbeating donor kidney transplants--the Singapore experience. Ann Acad Med Singapore 1999; 28:222-226.

47. Tuttle-Newhall JE, Krishnan SM, Levy MF, McBride V, Orlowski JP, Sung RS. Organ donation and utilization in the United States: 1998-2007. Am J Transplant 2009; 9:879-893.

48. Reich DJ, Mulligan DC, Abt PL, et al. ASTS recommended practice guidelines for controlled donation after cardiac death organ procurement and transplantation. Am J Transplant 2009; 9:2004-2011.

49. Cho YW, Terasaki PI, Cecka JM, Gjertson DW. Transplantation of kidneys from donors whose hearts have stopped beating. N Engl J Med 1998; 338:221-225.

50. Rudich SM, Kaplan B, Magee JC, et al. Renal transplantations performed using non-heartbeating organ donors: going back to the future? Transplantation 2002; 74:1715-1720.

51. Locke JE, Segev DL, Warren DS, Dominici F, Simpkins CE, Montgomery RA. Outcomes of kidneys from donors after cardiac death: implications for allocation and preservation. Am J Transplant 2007; 7:1797-1807.

52. Ho KJ, Owens CD, Johnson SR, et al. Donor postextubation hypotension and age correlate with outcome after donation after cardiac death transplantation. Transplantation 2008; 85:15881594.

53. Orloff MS, Reed AI, Erturk E, et al. Nonheartbeating cadaveric organ donation. Ann Surg 1994; 220:578-583; discussion 583-575.

54. Casavilla A, Ramirez C, Shapiro R, et al. Experience with liver and kidney allografts from nonheart-beating donors. Transplantation 1995; 59:197-203.

55. Magliocca JF, Magee JC, Rowe SA, et al. Extracorporeal support for organ donation after cardiac death effectively expands the donor pool. J Trauma 2005; 58:1095-1101; discussion 1101-1092.

56. Farney AC, Singh RP, Hines MH, et al. Experience in renal and extrarenal transplantation with donation after cardiac death donors with selective use of extracorporeal support. J Am Coll Surg 2008; 206:1028-1037; discussion 1037.

57. Swanson M, Schweizer RT, Roper L, Bartus S, Hull D. Kidney transplantation from asystolic cadaveric donors. Transplant Proc 1997; 29:3488.

58. Cooper JT, Chin LT, Krieger NR, et al. Donation after cardiac death: the university of wisconsin experience with renal transplantation. Am J Transplant 2004; 4:1490-1494.

59. Olson L, Castro VL, Ciancio G, et al. Twelve years' experience with non-heart-beating cadaveric donors. J Transpl Coord 1996; 6:196-199. 
60. Naim MY, Hoehn KS, Hasz RD, White LS, Helfaer MA, Nelson RM. The Children's Hospital of Philadelphia's experience with donation after cardiac death. Crit Care Med 2008; 36:17291733.

61. Light JA, Sasaki TM, Aquino AO, Barhyte DY, Gage F. Excellent long-term graft survival with kidneys from the uncontrolled non-heart-beating donor. Transplant Proc 2000; 32:186-187.

62. Gagandeep S, Matsuoka L, Mateo R, et al. Expanding the donor kidney pool: utility of renal allografts procured in a setting of uncontrolled cardiac death. Am J Transplant 2006; 6:16821688 .

63. Merrill JP, Murray JE, Harrison JH, Guild WR. Successful homotransplantation of the human kidney between identical twins. J Am Med Assoc 1956; 160:277-282.

64. Merrill JP, Murray JE, Takacs FJ, Hager EB, Wilson RE, Dammin GJ. Successful transplantation of kidney from a human cadaver. Jama 1963; 185:347-353.

65. Human Kidney Transplant Conference. Transplantation 1964; 2:147-155.

66. Woodruff MF. Ethical Problems in Organ Transplantation. Br Med J 1964; 1:1457-1460.

67. Marchioro TL, Huntley RT, Waddell WR, Starzl TE. Extracorporeal Perfusion for Obtaining Postmortem Homografts. Surgery 1963; 54:900-911.

68. Belzer FO, Ashby BS, Gulyassy PF, Powell M. Successful seventeen-hour preservation and transplantation of human-cadaver kidney. N Engl J Med 1968; 278:608-610.

69. Hartley LC, Collins GM, Clunie GJ. Kidney preservation for transportation. Function of 29 human-cadaver kidneys preserved with an intracellular perfusate. N Engl J Med 1971; 285:1049-1052

70. Hume DM, Lee HM, Williams GM, et al. Comparative results of cadaver and related donor renal homografts in man, and immunologic implications of the outcome of second and paired transplants. Ann Surg 1966; 164:352-397.

71. Clark EA, Terasaki PI, Opelz G, Mickey MR. Cadaver-kidney transplant failures at one month. N Engl J Med 1974; 291:1099-1102.

72. A definition of irreversible coma. Report of the Ad Hoc Committee of the Harvard Medical School to Examine the Definition of Brain Death. Jama 1968; 205:337-340.

73. Rosenthal JT, Shaw BW, Jr., Hardesty RL, Griffith BP, Starzl TE, Hakala TR. Principles of multiple organ procurement from cadaver donors. Ann Surg 1983; 198:617-621.

74. Cyclosporin a as sole immunosuppressive agent in recipients of kidney allografts from cadaver donors. Preliminary results of a European multicentre trial. Lancet 1982; 2:57-60.

75. Rosenthal JT, Hakala TR, Iwatsuki S, Shaw BW, Jr., Starzl TE. Cadaveric renal transplantation under cyclosporine-steroid therapy. Surg Gynecol Obstet 1983; 157:309-315.

76. Randall T. Too few human organs for transplantation, too many in need . . . and the gap widens. Jama 1991; 265:1223, 1227.

77. Spital A. The shortage of organs for transplantation. Where do we go from here? N Engl J Med 1991; 325:1243-1246.

78. Gok MA, Buckley PE, Shenton BK, et al. Long-term renal function in kidneys from non-heartbeating donors: A single-center experience. Transplantation 2002; 74:664-669.

79. DeVita MA, Snyder JV, Grenvik A. History of organ donation by patients with cardiac death. Kennedy Inst Ethics J 1993; 3:113-129.

80. Youngner SJ, Arnold RM. Ethical, psychosocial, and public policy implications of procuring organs from non-heart-beating cadaver donors. Jama 1993; 269:2769-2774.

81. Aulisio MP, Devita M, Luebke D. Taking values seriously: Ethical challenges in organ donation and transplantation for critical care professionals. Crit Care Med 2007; 35:S95-S101. 
82. Recommendations for nonheartbeating organ donation. A position paper by the Ethics Committee, American College of Critical Care Medicine, Society of Critical Care Medicine. Crit Care Med 2001; 29:1826-1831.

83. Bernat JL. The boundaries of organ donation after circulatory death. N Engl J Med 2008; 359:669-671.

84. Guidelines for the determination of death. Report of the medical consultants on the diagnosis of death to the President's Commission for the Study of Ethical Problems in Medicine and Biomedical and Behavioral Research. Jama 1981; 246:2184-2186.

85. Bernat JL, D'Alessandro AM, Port FK, et al. Report of a National Conference on Donation after cardiac death. Am J Transplant 2006; 6:281-291.

86. Rady MY, Verheijde JL, McGregor J. Organ donation after circulatory death: the forgotten donor? Crit Care 2006; 10:166-168.

87. Institute of Medicine Division of Health Care Services. Non-heart-beating Organ Transplantation: Medical and Ethical Issues in Procurement. Washington D.C.: National Acadamy Press; 1997.

88. Antommaria AH, Trotochaud K, Kinlaw K, Hopkins PN, Frader J. Policies on donation after cardiac death at children's hospitals: a mixed-methods analysis of variation. Jama 2009; 301:1902-1908.

89. Johnson SR, Pavlakis M, Khwaja K, et al. Intensive care unit extubation does not preclude extrarenal organ recovery from donors after cardiac death. Transplantation 2005; 80:12441250 .

90. Ozark S, DeVita MA. Non-heartbeating organ donation: ethical controversies and medical considerations. Int Anesthesiol Clin 2001; 39:103-116.

91. Kootstra G. Statement on non-heart-beating donor programs. Transplant Proc 1995; 27:2965.

92. Rudge CJ. Organ donation in the United Kingdom. Kidney Int 2006; 70:2045-2046.

93. Bos MA. Ethical and legal issues in non-heart-beating organ donation. Transplantation 2005; 79:1143-1147.

94. Feng S, Buell JF, Cherikh WS, et al. Organ donors with positive viral serology or malignancy: risk of disease transmission by transplantation. Transplantation 2002; 74:1657-1663.

95. Nanni Costa A, Grossi P, Gianelli Castiglione A, Grigioni WF. Quality and safety in the Italian donor evaluation process. Transplantation 2008; 85:S52-56.

96. Reese PP, Feldman HI, Asch DA, et al. Transplantation of kidneys from donors at increased risk for blood-borne viral infection: recipient outcomes and patterns of organ use. Am J Transplant 2009; 9:2338-2345.

97. Remuzzi G, Cravedi P, Perna A, et al. Long-term outcome of renal transplantation from older donors. N Engl J Med 2006; 354:343-352.

98. Fox CS, Larson MG, Leip EP, Culleton B, Wilson PW, Levy D. Predictors of new-onset kidney disease in a community-based population. Jama 2004; 291:844-850.

99. Lindeman RD, Tobin J, Shock NW. Longitudinal studies on the rate of decline in renal function with age. J Am Geriatr Soc 1985; 33:278-285.

100. Kaplan C, Pasternack B, Shah H, Gallo G. Age-related incidence of sclerotic glomeruli in human kidneys. Am J Pathol 1975; 80:227-234.

101. Segura J, Campo C, Gil P, et al. Development of chronic kidney disease and cardiovascular prognosis in essential hypertensive patients. J Am Soc Nephrol 2004; 15:1616-1622.

102. Stevens LA, Coresh J, Greene T, Levey AS. Assessing kidney function--measured and estimated glomerular filtration rate. N Engl J Med 2006; 354:2473-2483. 
103. Levey AS, Bosch JP, Lewis JB, Greene T, Rogers N, Roth D. A more accurate method to estimate glomerular filtration rate from serum creatinine: a new prediction equation. Modification of Diet in Renal Disease Study Group. Ann Intern Med 1999; 130:461-470.

104. Levey AS, Coresh J, Balk E, et al. National Kidney Foundation practice guidelines for chronic kidney disease: evaluation, classification, and stratification. Ann Intern Med 2003; 139:137-147.

105. Leunissen KM, Bosman FT, Nieman FH, et al. Amplification of the nephrotoxic effect of cyclosporine by preexistent chronic histological lesions in the kidney. Transplantation 1989; 48:590-593.

106. Lopes JA, Moreso F, Riera L, et al. Evaluation of pre-implantation kidney biopsies: comparison of Banff criteria to a morphometric approach. Kidney Int 2005; 67:1595-1600.

107. Remuzzi G, Grinyo J, Ruggenenti P, et al. Early experience with dual kidney transplantation in adults using expanded donor criteria. Double Kidney Transplant Group (DKG). J Am Soc Nephrol 1999; 10:2591-2598.

108. Andres A, Morales JM, Herrero JC, et al. Double versus single renal allografts from aged donors. Transplantation 2000; 69:2060-2066.

109. Wolters HH, Palmes D, Heidenreich S, et al. Long-term follow-up of double kidney transplantation using a score for evaluation of marginal donors. Transpl Int 2005; 18:453-457.

110. Sola R, Guirado L, Lopez Navidad A, et al. Renal transplantation with limit donors: to what should the good results obtained be attributed? Transplantation 1998; 66:1159-1163.

111. Stratta RJ, Rohr MS, Sundberg AK, et al. Intermediate-Term Outcomes With Expanded Criteria Deceased Donors in Kidney Transplantation: A Spectrum or Specter of Quality? Ann Surg 2006; 243:594-603.

112. Foss A, Heldal K, Scott $\mathrm{H}$, et al. Kidneys from deceased donors more than 75 years perform acceptably after transplantation. Transplantation 2009; 87:1437-1441.

113. Collini A, Kalmar P, Dhamo A, Ruggieri G, Carmellini M. Renal transplant from very old donors: how far can we go? Transplantation 2009; 87:1830-1836.

114. Brenner BM, Cohen RA, Milford EL. In renal transplantation, one size may not fit all. J Am Soc Nephrol 1992; 3:162-169.

115. Knight AJ, Ali AA, White SA, Nicholson ML. Dual renal transplant from a non-heart beating donor. Transpl Int 1999; 12:466-467.

116. Johnson LB, Kuo PC, Dafoe DC, et al. The use of bilateral adult renal allografts - a method to optimize function from donor kidneys with suboptimal nephron mass. Transplantation 1996; 61:1261-1263.

117. Masson D, Hefty T. A technique for the transplantation of 2 adult cadaver kidney grafts into 1 recipient. J Urol 1998; 160:1779-1780.

118. Gill J, Cho YW, Danovitch GM, et al. Outcomes of dual adult kidney transplants in the United States: an analysis of the OPTN/UNOS database. Transplantation 2008; 85:62-68.

119. Rigotti P, Ekser B, Furian L, et al. Outcome of renal transplantation from very old donors. N Engl J Med 2009; 360:1464-1465.

120. Snanoudj R, Rabant M, Timsit MO, et al. Donor-Estimated GFR as an Appropriate Criterion for Allocation of ECD Kidneys into Single or Dual Kidney Transplantation. Am J Transplant 2009; 9:2542-2551.

121. Voorhees WD, Babbs CF, Tacker WA, Jr. Regional blood flow during cardiopulmonary resuscitation in dogs. Crit Care Med 1980; 8:134-136.

122. Ralston SH, Voorhees WD, Babbs CF. Intrapulmonary epinephrine during prolonged cardiopulmonary resuscitation: improved regional blood flow and resuscitation in dogs. Ann Emerg Med 1984; 13:79-86. 
123. Lewis J, Peltier J, Nelson H, et al. Development of the University of Wisconsin donation After Cardiac Death Evaluation Tool. Prog Transplant 2003; 13:265-273.

124. Sohrabi S, Navarro A, Wilson C, et al. Renal graft function after prolonged agonal time in nonheart-beating donors. Transplant Proc 2006; 38:3400-3401.

125. Suntharalingam C, Sharples L, Dudley C, Bradley JA, Watson CJ. Time to cardiac death after withdrawal of life-sustaining treatment in potential organ donors. Am J Transplant 2009; 9:2157-2165.

126. Kayler LK, Garzon P, Magliocca J, et al. Outcomes and utilization of kidneys from deceased donors with acute kidney injury. Am J Transplant 2009; 9:367-373.

127. Morgan C, Martin A, Shapiro R, Randhawa PS, Kayler LK. Outcomes after transplantation of deceased-donor kidneys with rising serum creatinine. Am J Transplant 2007; 7:1288-1292.

128. Sohrabi S, Navarro AP, Wilson C, et al. Donation after cardiac death kidneys with low severity pre-arrest acute renal failure. Am J Transplant 2007; 7:571-575.

129. Anil Kumar MS, Khan SM, Jaglan S, et al. Successful transplantation of kidneys from deceased donors with acute renal failure: Three-year results. Transplantation 2006; 82:1640-1645.

130. Wood KE, Becker BN, McCartney JG, D'Alessandro AM, Coursin DB. Care of the potential organ donor. N Engl J Med 2004; 351:2730-2739.

131. Lopez-Navidad A, Caballero F. For a rational approach to the critical points of the cadaveric donation process. Transplant Proc 2001; 33:795-805.

132. Schnuelle P, Gottmann U, Hoeger S, et al. Effects of donor pretreatment with dopamine on graft function after kidney transplantation: a randomized controlled trial. Jama 2009; 302:10671075.

133. Cittanova ML, Leblanc I, Legendre C, Mouquet C, Riou B, Coriat P. Effect of hydroxyethylstarch in brain-dead kidney donors on renal function in kidney-transplant recipients. Lancet 1996; 348:1620-1622.

134. Brody H, Campbell ML, Faber-Langendoen K, Ogle KS. Withdrawing intensive life-sustaining treatment -- recommendations for compassionate clinical management. N Engl J Med 1997; 336:652-657.

135. Vincent JL. Forgoing life support in western European intensive care units: the results of an ethical questionnaire. Crit Care Med 1999; 27:1626-1633.

136. Treece PD, Engelberg RA, Crowley L, et al. Evaluation of a standardized order form for the withdrawal of life support in the intensive care unit. Crit Care Med 2004; 32:1141-1148.

137. Wolfs TG, de Vries B, Walter SJ, et al. Apoptotic cell death is initiated during normothermic ischemia in human kidneys. Am J Transplant 2005; 5:68-75.

138. Shiroki R, Hoshinaga K, Higuchi T, et al. Prolonged warm ischemia affects long-term prognosis of kidney transplant allografts from non-heart-beating donors. Transplant Proc 1998; 30:111113.

139. Nishikido M, Noguchi M, Koga S, et al. Kidney transplantation from non-heart-beating donors: analysis of organ procurement and outcome. Transplant Proc 2004; 36:1888-1890.

140. Garcia-Rinaldi R, Lefrak EA, Defore WW, et al. In situ preservation of cadaver kidneys for transplantation: laboratory observations and clinical application. Ann Surg 1975; 182:576-584.

141. Lloveras J, Puig JM, Cerda M, et al. Optimization of in situ renal perfusion of non--heartbeating donors: four-lumen catheter developed for continuous perfusion pressure determination. Transplant Proc 1993; 25:3169-3170.

142. Kowalski AE, Light JA, Ritchie WO, Sasaki TM, Callender CO, Gage F. A new approach for increasing the organ supply. Clin Transplant 1996; 10:653-657. 
143. Anaise $\mathrm{D}$, Smith $\mathrm{R}$, Ishimaru $\mathrm{M}$, et al. An approach to organ salvage from non-heartbeating cadaver donors under existing legal and ethical requirements for transplantation. Transplantation 1990; 49:290-294.

144. Ko WJ, Chen YS, Tsai PR, Lee PH. Extracorporeal membrane oxygenation support of donor abdominal organs in non-heart-beating donors. Clin Transplant 2000; 14:152-156.

145. Koyama I, Hoshino T, Nagashima N, Adachi H, Ueda K, Omoto R. A new approach to kidney procurement from non-heart-beating donors: core cooling on cardiopulmonary bypass. Transplant Proc 1989; 21:1203-1205.

146. Alvarez-Rodriguez J, del Barrio-Yesa R, Torrente-Sierra J, Prats-Sanchez MD, Barrientos Guzman A. Posttransplant long-term outcome of kidneys obtained from asystolic donors maintained under extracorporeal cardiopulmonary bypass. Transplant Proc 1995; 27:2903-2904; discussion 2904-2905.

147. Morozumi J, Sakurai E, Matsuno N, et al. Successful kidney transplantation from donation after cardiac death using a load-distributing-band chest compression device during long warm ischemic time. Resuscitation 2009; 80:278-280.

148. Booster MH, Wijnen RM, Vroemen JP, van Hooff JP, Kootstra G. In situ preservation of kidneys from non-heart-beating donors--a proposal for a standardized protocol. Transplantation 1993; 56:613-617.

149. Gok MA, Shenton BK, Buckley PE, et al. How to improve the quality of kidneys from nonheart-beating donors: a randomised controlled trial of thrombolysis in non-heart-beating donors. Transplantation 2003; 76:1714-1719.

150. Yamauchi J, Schramm R, Richter S, Vollmar B, Menger MD, Minor T. Improvement of microvascular graft equilibration and preservation in non-heart-beating donors by warm preflush with streptokinase. Transplantation 2003; 75:449-453.

151. Belzer FO, Kountz SL. Preservation and transplantation of human cadaver kidneys: a two-year experience. Ann Surg 1970; 172:394-404.

152. Belzer FO, Reed TW, Pryor JP, Kountz SL, Dunphy JE. Cause of renal injury in kidneys obtained from cadaver donors. Surg Gynecol Obstet 1970; 130:467-477.

153. Kootstra G, van Hooff JP. [In-situ preservation of kidneys of 'non-heart-beating' donors: a possible way to offset the shortage of donor kidneys]. Ned Tijdschr Geneeskd 1998; 142:28382843.

154. St Peter SD, Imber CJ, Friend PJ. Liver and kidney preservation by perfusion. Lancet 2002; 359:604-613.

155. Wight JP, Chilcott JB, Holmes MW, Brewer N. Pulsatile machine perfusion vs. cold storage of kidneys for transplantation: a rapid and systematic review. Clin Transplant 2003; 17:293-307.

156. Schold JD, Kaplan B, Howard RJ, Reed AI, Foley DP, Meier-Kriesche HU. Are we frozen in time? Analysis of the utilization and efficacy of pulsatile perfusion in renal transplantation. Am J Transplant 2005; 5:1681-1688.

157. Opelz G, Dohler B. Multicenter analysis of kidney preservation. Transplantation 2007; 83:247253.

158. Moers C, Smits JM, Maathuis MH, et al. Machine perfusion or cold storage in deceased-donor kidney transplantation. N Engl J Med 2009; 360:7-19.

159. Kootstra G. The asystolic, or non-heartbeating, donor. Transplantation 1997; 63:917-921.

160. Matsuno N, Konno O, Mejit A, et al. Application of machine perfusion preservation as a viability test for marginal kidney graft. Transplantation 2006; 82:1425-1428.

161. Wilson CH, Gok MA, Shenton BK, et al. Weight increase during machine perfusion may be an indicator of organ and in particular, vascular damage. Ann Transplant 2004; 9:31-32. 
162. Daemen JW, Oomen AP, Janssen MA, et al. Glutathione S-transferase as predictor of functional outcome in transplantation of machine-preserved non-heart-beating donor kidneys. Transplantation 1997; 63:89-93.

163. Gok MA, Pelsers M, Glatz JF, et al. Use of two biomarkers of renal ischemia to assess machineperfused non-heart-beating donor kidneys. Clin Chem 2003; 49:172-175.

164. de Vries B, Snoeijs MG, von Bonsdorff L, Ernest van Heurn LW, Parkkinen J, Buurman WA. Redox-active iron released during machine perfusion predicts viability of ischemically injured deceased donor kidneys. Am J Transplant 2006; 6:2686-2693.

165. Brasile L, Stubenitsky BM, Booster MH, Arenada D, Haisch C, Kootstra G. Hypothermia--a limiting factor in using warm ischemically damaged kidneys. Am J Transplant 2001; 1:316-320.

166. Stubenitsky BM, Booster MH, Brasile L, Araneda D, Haisch CE, Kootstra G. Exsanguinous metabolic support perfusion--a new strategy to improve graft function after kidney transplantation. Transplantation 2000; 70:1254-1258.

167. Bagul A, Hosgood SA, Kaushik M, Kay MD, Waller HL, Nicholson ML. Experimental renal preservation by normothermic resuscitation perfusion with autologous blood. Br J Surg 2008; 95:111-118.

168. Ojo AO, Wolfe RA, Held PJ, Port FK, Schmouder RL. Delayed graft function: risk factors and implications for renal allograft survival. Transplantation 1997; 63:968-974.

169. Salahudeen AK, Haider N, May W. Cold ischemia and the reduced long-term survival of cadaveric renal allografts. Kidney Int 2004; 65:713-718.

170. Quiroga I, McShane P, Koo DD, et al. Major effects of delayed graft function and cold ischaemia time on renal allograft survival. Nephrol Dial Transplant 2006; 21:1689-1696.

171. Giblin L, O'Kelly P, Little D, et al. A comparison of long-term graft survival rates between the first and second donor kidney transplanted--the effect of a longer cold ischaemic time for the second kidney. Am J Transplant 2005; 5:1071-1075.

172. Peters TG, Shaver TR, Ames JEt, Santiago-Delpin EA, Jones KW, Blanton JW. Cold ischemia and outcome in 17,937 cadaveric kidney transplants. Transplantation 1995; 59:191-196.

173. Yarlagadda SG, Coca SG, Formica RN, Jr., Poggio ED, Parikh CR. Association between delayed graft function and allograft and patient survival: a systematic review and meta-analysis. Nephrol Dial Transplant 2009; 24:1039-1047.

174. Vacher-Coponat H, Purgus R, Indreies M, et al. Cold Ischemia Time in Renal Transplantation Is Reduced by a Timesheet in a French Transplant Center. Transplantation 2007; 83:561-565.

175. Ross LF, Zenios S, Thistlethwaite JR, Jr. Shared decision making in deceased-donor transplantation. Lancet 2006; 368:333-337.

176. Persson MO, Persson NH, Kallen R, Ekberg H, Hermeren G. Kidneys from marginal donors: views of patients on informed consent. Nephrol Dial Transplant 2002; 17:1497-1502.

177. Van Loo AA, Vanholder RC, Bernaert PR, Vermassen FE, Van der Vennet M, Lameire NH. Pretransplantation hemodialysis strategy influences early renal graft function. J Am Soc Nephrol 1998; 9:473-481.

178. Luciani J, Frantz $\mathrm{P}$, Thibault $\mathrm{P}$, et al. Early anuria prevention in human kidney transplantation. Advantage of fluid load under pulmonary arterial pressure monitoring during surgical period. Transplantation 1979; 28:308-312.

179. Carlier M, Squifflet JP, Pirson Y, Decocq L, Gribomont B, Alexandre GP. Confirmation of the crucial role of the recipient's maximal hydration on early diuresis of the human cadaver renal allograft. Transplantation 1983; 36:455-456.

180. Rajagopalan PR, Kay NA, Fitts CT, Majeski JA. Prevention of acute tubular necrosis after transplantation: effect of pretransplantation volume expansion. South Med J 1986; 79:972-974. 
181. Dawidson IJ, Sandor ZF, Coorpender L, et al. Intraoperative albumin administration affects the outcome of cadaver renal transplantation. Transplantation 1992; 53:774-782.

182. De Gasperi A, Narcisi S, Mazza E, et al. Perioperative fluid management in kidney transplantation: is volume overload still mandatory for graft function? Transplant Proc 2006; 38:807-809.

183. Jain S, Curwood V, White SA, Furness PN, Nicholson ML. Sub-clinical acute rejection detected using protocol biopsies in patients with delayed graft function. Transpl Int 2000; 13 Suppl 1:S52-55.

184. Gaber LW, Gaber AO, Hathaway DK, Vera SR, Shokouh-Amiri MH. Routine early biopsy of allografts with delayed function: correlation of histopathology and transplant outcome. Clin Transplant 1996; 10:629-634.

185. Qureshi F, Rabb H, Kasiske BL. Silent acute rejection during prolonged delayed graft function reduces kidney allograft survival. Transplantation 2002; 74:1400-1404.

186. Klein IH, Abrahams A, van Ede T, Hene RJ, Koomans HA, Ligtenberg G. Different effects of tacrolimus and cyclosporine on renal hemodynamics and blood pressure in healthy subjects. Transplantation 2002; 73:732-736.

187. Nankivell BJ, Chapman JR, Bonovas G, Gruenewald SM. Oral cyclosporine but not tacrolimus reduces renal transplant blood flow. Transplantation 2004; 77:1457-1459.

188. Fry WR, Dawidson I, Alway CC, Rooth P. Cyclosporine A induces decreased blood flow in cadaveric kidney transplants. Transplant Proc 1988; 20:222-225.

189. Gelens MA, Christiaans MH, van Heurn EL, van den Berg-Loonen EP, Peutz-Kootstra CJ, van Hooff JP. High rejection rate during calcineurin inhibitor-free and early steroid withdrawal immunosuppression in renal transplantation. Transplantation 2006; 82:1221-1223.

190. Wilson CH, Brook NR, Gok MA, Asher JF, Nicholson ML, Talbot D. Randomized clinical trial of daclizumab induction and delayed introduction of tacrolimus for recipients of non-heartbeating kidney transplants. Br J Surg 2005; 92:681-687.

191. Sanchez-Fructuoso AI, Marques M, Conesa J, et al. Use of different immunosuppressive strategies in recipients of kidneys from nonheart-beating donors. Transpl Int 2005; 18:596-603.

192. Lieberthal W, Nigam SK. Acute renal failure. II. Experimental models of acute renal failure: imperfect but indispensable. Am J Physiol Renal Physiol 2000; 278:F1-F12.

193. Kennedy SE, Erlich JH. Murine renal ischaemia-reperfusion injury. Nephrology (Carlton) 2008; 13:390-396.

194. Rosen S, Heyman SN. Difficulties in understanding human "acute tubular necrosis": limited data and flawed animal models. Kidney Int 2001; 60:1220-1224.

195. Rosen S, Stillman IE. Acute tubular necrosis is a syndrome of physiologic and pathologic dissociation. J Am Soc Nephrol 2008; 19:871-875.

196. Zager RA. Partial aortic ligation: a hypoperfusion model of ischemic acute renal failure and a comparison with renal artery occlusion. J Lab Clin Med 1987; 110:396-405.

197. Martins PN. Learning curve, surgical results and operative complications for kidney transplantation in mice. Microsurgery 2006; 26:590-593.

198. Pratt JR, Basheer SA, Sacks SH. Local synthesis of complement component C3 regulates acute renal transplant rejection. Nat Med 2002; 8:582-587.

199. Craddock GN. Species differences in response to renal ischemia. Arch Surg 1976; 111:582-584.

200. Sachs DH. The pig as a potential xenograft donor. Vet Immunol Immunopathol 1994; 43:185191.

201. Golby M, White HJ. The operation of orthotopic renal allografting in the pig and its complications. Br J Surg 1971; 58:287-288. 
202. Kirkman RL, Colvin RB, Flye MW, et al. Transplantation in miniature swine. VI. Factors influencing survival of renal allografts. Transplantation 1979; 28:18-23.

203. Yanaga K, Makowka L, Shimada M, et al. Improved method of porcine renal allografting for transplantation research. J Invest Surg 1991; 4:231-236.

204. Nicholson ML, Hosgood SA, Metcalfe MS, Waller JR, Brook NR. A comparison of renal preservation by cold storage and machine perfusion using a porcine autotransplant model. Transplantation 2004; 78:333-337.

205. Schrier RW, Wang W, Poole B, Mitra A. Acute renal failure: definitions, diagnosis, pathogenesis, and therapy. J Clin Invest 2004; 114:5-14.

206. Thadhani R, Pascual M, Bonventre JV. Acute renal failure. N Engl J Med 1996; 334:1448-1460.

207. Perico N, Cattaneo D, Sayegh MH, Remuzzi G. Delayed graft function in kidney transplantation. Lancet 2004; 364:1814-1827.

208. Solez K, Racusen LC, Marcussen N, et al. Morphology of ischemic acute renal failure, normal function, and cyclosporine toxicity in cyclosporine-treated renal allograft recipients. Kidney Int 1993; 43:1058-1067.

209. Rohr MS. Renal allograft acute tubular necrosis. II. A light and electron microscopic study of biopsies taken at procurement and after revascularization. Ann Surg 1983; 197:663-671.

210. Oda A, Morozumi K, Uchida K. Histological factors of 1-h biopsy influencing the delayed renal function and outcome in cadaveric renal allografts. Clin Transplant 1999; 13 Suppl 1:6-12.

211. Alejandro V, Scandling JD, Jr., Sibley RK, et al. Mechanisms of filtration failure during postischemic injury of the human kidney. A study of the reperfused renal allograft. J Clin Invest 1995; 95:820-831.

212. Gaber LW, Gaber AO, Tolley EA, Hathaway DK. Prediction by postrevascularization biopsies of cadaveric kidney allografts of rejection, graft loss, and preservation nephropathy. Transplantation 1992; 53:1219-1225.

213. Lehtonen SR, Taskinen EI, Isoniemi HM. Histopathological findings in renal allografts at time of transplantation and correlation with onset of graft function. Apmis 1999; 107:945-950.

214. Anderson CB, Etheredge EE. Human renal allograft blood flow and early renal function. Ann Surg 1977; 186:564-567.

215. Lundell A, Persson NH, Kallen R, Ekberg H. Impaired renal artery blood flow at transplantation is correlated to delayed onset of graft function. Transpl Int 1996; 9:57-61.

216. Bretan PN, Jr., Lobo E, Chang JA, Dumitrescu O, Miller B, Yen TS. Assessment of preservation induced reperfusion injury via intraoperative renal transplant blood flow and endothelin concentration studies. J Urol 1997; 158:714-718.

217. Corrigan G, Ramaswamy D, Kwon O, et al. PAH extraction and estimation of plasma flow in human postischemic acute renal failure. Am J Physiol 1999; 277:F312-318.

218. Yanagisawa T, Kuzuhara K, Nishimori S, et al. Evaluation of laser Doppler flowmetry in renal transplantation. J Clin Laser Med Surg 1994; 12:231-232.

219. Lisik W, Gontarczyk G, Kosieradzki M, et al. Intraoperative blood flow measurements in organ allografts can predict postoperative function. Transplant Proc 2007; 39:371-372.

220. Fechner G, von Pezold J, Luzar O, Hauser S, Tolba RH, Muller SC. Modified spectrometry (O2C device) of intraoperative microperfusion predicts organ function after kidney transplantation: a pilot study. Transplant Proc 2009; 41:3575-3579.

221. Hollenberg NK, Birtch A, Rashid A, et al. Relationships between intrarenal perfusion and function: serial hemodynamic studies in the transplanted human kidney. Medicine (Baltimore) 1972; 51:95-106. 
222. Hilson AJ, Maisey MN, Brown CB, Ogg CS, Bewick MS. Dynamic renal transplant imaging with Tc-99m DTPA (Sn) supplemented by a transplant perfusion index in the management of renal transplants. J Nucl Med 1978; 19:994-1000.

223. Kirchner PT, Goldman MH, Leapman SB, Kiepfer RF. Clinical application of the kidney to aortic blood flow index (K/A ratio). Contrib Nephrol 1978; 11:120-126.

224. Gorbach A, Simonton D, Hale DA, Swanson SJ, Kirk AD. Objective, real-time, intraoperative assessment of renal perfusion using infrared imaging. Am J Transplant 2003; 3:988-993.

225. Angelescu M, Kraus T, Wiesel M, Hergesell O, Haberkorn U, Klar E. Assessment of renal graft function by perioperative monitoring of cortical microcirculation in kidney transplantation. Transplantation 2003; 75:1190-1196.

226. Hattori R, Ono Y, Kato M, Komatsu T, Matsukawa Y, Yamamoto T. Direct visualization of cortical peritubular capillary of transplanted human kidney with reperfusion injury using a magnifying endoscopy. Transplantation 2005; 79:1190-1194.

227. Schmitz V, Schaser KD, Olschewski P, Neuhaus P, Puhl G. In vivo Visualization of Early Microcirculatory Changes following Ischemia/Reperfusion Injury in Human Kidney Transplantation. Eur Surg Res 2007; 40:19-25.

228. Ramaswamy D, Corrigan G, Polhemus C, et al. Maintenance and recovery stages of postischemic acute renal failure in humans. Am J Physiol Renal Physiol 2002; 282:F271-280.

229. Racusen LC, Fivush BA, Li YL, Slatnik I, Solez K. Dissociation of tubular cell detachment and tubular cell death in clinical and experimental "acute tubular necrosis". Lab Invest 1991; 64:546-556.

230. Allen KS, Jorkasky DK, Arger PH, et al. Renal allografts: prospective analysis of Doppler sonography. Radiology 1988; 169:371-376.

231. Meyer M, Paushter D, Steinmuller DR. The use of duplex Doppler ultrasonography to evaluate renal allograft dysfunction. Transplantation 1990; 50:974-978.

232. Rasmussen K, Pedersen E. Doppler ultrasound in the diagnosis of renal allograft rejection and in monitoring the effect of treatment. Scand J Clin Lab Invest 1990; 50:57-61.

233. Tranquart F, Lebranchu Y, Haillot O, Pourcelot D, Grezard O, Pourcelot L. The use of perioperative Doppler ultrasound as a screening test for acute tubular necrosis. Transpl Int 1993; 6:14-17.

234. Merkus JW, Hoitsma AJ, van Asten WN, Koene RA, Skotnicki SH. Doppler spectrum analysis to diagnose rejection during posttransplant acute renal failure. Transplantation 1994; 58:570576.

235. Sharma AK, Rustom R, Evans A, et al. Utility of serial Doppler ultrasound scans for the diagnosis of acute rejection in renal allografts. Transpl Int 2004; 17:138-144.

236. Chudek J, Kolonko A, Krol R, Ziaja J, Cierpka L, Wiecek A. The intrarenal vascular resistance parameters measured by duplex Doppler ultrasound shortly after kidney transplantation in patients with immediate, slow, and delayed graft function. Transplant Proc 2006; 38:42-45.

237. Fischer T, Filimonow S, Dieckhofer J, et al. Improved diagnosis of early kidney allograft dysfunction by ultrasound with echo enhancer--a new method for the diagnosis of renal perfusion. Nephrol Dial Transplant 2006; 21:2921-2929.

238. Kolonko A, Chudek J, Wicek A. Prediction of the severity and outcome of acute tubular necrosis based on continuity of Doppler spectrum in the early period after kidney transplantation. Nephrol Dial Transplant 2009; 24:1631-1635.

239. Kwon O, Corrigan G, Myers BD, et al. Sodium reabsorption and distribution of $\mathrm{Na}+/ \mathrm{K}+-\mathrm{ATPase}$ during postischemic injury to the renal allograft. Kidney Int 1999; 55:963-975. 
240. Alejandro VS, Nelson WJ, Huie $\mathrm{P}$, et al. Postischemic injury, delayed function and $\mathrm{Na}+\mathrm{K}(+)-$ ATPase distribution in the transplanted kidney. Kidney Int 1995; 48:1308-1315.

241. Kwon O, Hong SM, Ramesh G. Diminished NO generation by injured endothelium and loss of macula densa nNOS may contribute to sustained acute kidney injury after ischemiareperfusion. Am J Physiol Renal Physiol 2009; 296:F25-33.

242. Vinot O, Bialek J, Canaan-Kuhl S, et al. Endogenous ANP in postischemic acute renal allograft failure. Am J Physiol 1995; 269:F125-133.

243. Schilling M, Holzinger F, Friess H, Seiler C, Buchler MW. Pathogenesis of delayed kidney graft function: role of endothelin-1, thromboxane B2, and leukotriene B4. Transplant Proc 1996; 28:304-305.

244. Kwon O, Nelson WJ, Sibley R, et al. Backleak, tight junctions, and cell- cell adhesion in postischemic injury to the renal allograft. J Clin Invest 1998; 101:2054-2064.

245. Thurau K, Boylan JW. Acute renal success. The unexpected logic of oliguria in acute renal failure. Am J Med 1976; 61:308-315.

246. Rosenberger C, Pratschke J, Rudolph B, et al. Immunohistochemical detection of hypoxiainducible factor-1alpha in human renal allograft biopsies. J Am Soc Nephrol 2007; 18:343-351.

247. Lemos FB, Ijzermans JN, Zondervan PE, et al. Differential expression of heme oxygenase- 1 and vascular endothelial growth factor in cadaveric and living donor kidneys after ischemiareperfusion. J Am Soc Nephrol 2003; 14:3278-3287.

248. Kwon O, Hong SM, Sutton TA, Temm CJ. Preservation of peritubular capillary endothelial integrity and increasing pericytes may be critical to recovery from postischemic acute kidney injury. Am J Physiol Renal Physiol 2008; 295:F351-359.

249. Sutton TA, Mang HE, Campos SB, Sandoval RM, Yoder MC, Molitoris BA. Injury of the renal microvascular endothelium alters barrier function after ischemia. Am J Physiol Renal Physiol 2003; 285:F191-198.

250. Hauser P, Schwarz C, Mitterbauer C, et al. Genome-wide gene-expression patterns of donor kidney biopsies distinguish primary allograft function. Lab Invest 2004; 84:353-361.

251. Mueller TF, Reeve J, Jhangri GS, et al. The transcriptome of the implant biopsy identifies donor kidneys at increased risk of delayed graft function. Am J Transplant 2008; 8:78-85.

252. Mas VR, Archer KJ, Yanek K, et al. Gene Expression Patterns in Deceased Donor Kidneys Developing Delayed Graft Function After Kidney Transplantation. Transplantation 2008; 85:626-635.

253. Kusaka M, Kuroyanagi Y, Mori T, et al. Global expression profiles in 1-hour biopsy specimens of human kidney transplantation from donors after cardiac death. Cell Transplant 2009; 18:647-656.

254. Avihingsanon Y, Ma N, Pavlakis M, et al. On the intraoperative molecular status of renal allografts after vascular reperfusion and clinical outcomes. J Am Soc Nephrol 2005; 16:15421548.

255. Kadiiska MB, Gladen BC, Baird DD, et al. Biomarkers of oxidative stress study: are plasma antioxidants markers of $\mathrm{CCl}(4)$ poisoning? Free Radic Biol Med 2000; 28:838-845.

256. Kadiiska MB, Gladen BC, Baird DD, et al. Biomarkers of oxidative stress study II: are oxidation products of lipids, proteins, and DNA markers of CCl4 poisoning? Free Radic Biol Med 2005; 38:698-710.

257. Gok MA, Shenton BK, Pelsers M, et al. Ischemia-reperfusion injury in cadaveric nonheart beating, cadaveric heart beating and live donor renal transplants. J Urol 2006; 175:641-647.

258. Serino F, Citterio F, Lippa S, et al. Coenzyme Q alpha tocopherol and delayed function in human kidney transplantation. Transplant Proc 1990; 22:1375-1378. 
259. Davenport A, Hopton M, Bolton C. Measurement of malondialdehyde as a marker of oxygen free radical production during renal allograft transplantation and the effect on early graft function. Clin Transplant 1995; 9:171-175.

260. Domanski L, Dolegowska B, Safranow K, et al. Activity of CuZn-superoxide dismutase, catalase and glutathione peroxidase in erythrocytes in kidney allografts during reperfusion in patients with and without delayed graft function. Clin Transplant 2006; 20:67-71.

261. Rabl H, Khoschsorur G, Colombo T, et al. A multivitamin infusion prevents lipid peroxidation and improves transplantation performance. Kidney Int 1993; 43:912-917.

262. Shoskes D, Lapierre C, Cruz-Corerra M, et al. Beneficial effects of the bioflavonoids curcumin and quercetin on early function in cadaveric renal transplantation: a randomized placebo controlled trial. Transplantation 2005; 80:1556-1559.

263. Pollak R, Andrisevic JH, Maddux MS, Gruber SA, Paller MS. A randomized double-blind trial of the use of human recombinant superoxide dismutase in renal transplantation. Transplantation 1993; 55:57-60.

264. Land W, Schneeberger H, Schleibner S, et al. The beneficial effect of human recombinant superoxide dismutase on acute and chronic rejection events in recipients of cadaveric renal transplants. Transplantation 1994; 57:211-217.

265. Toledo-Pereyra LH, Simmons RL, Olson LC, Najarian JS. Clinical effect of allopurinol on preserved kidneys: a randomized double-blind study. Ann Surg 1977; 185:128-131.

266. Hower R, Minor $\mathrm{T}$, Schneeberger $\mathrm{H}$, et al. Assessment of oxygen radicals during kidney transplantation--effect of radical scavenger. Transpl Int 1996; 9 Suppl 1:S479-482.

267. Norio K, Wikstrom M, Salmela K, Kyllonen L, Lindgren L. Ascorbic acid against reperfusion injury in human renal transplantation. Transpl Int 2003; 16:480-485.

268. Takahashi K, Nammour TM, Fukunaga M, et al. Glomerular actions of a free radical-generated novel prostaglandin, 8-epi-prostaglandin F2 alpha, in the rat. Evidence for interaction with thromboxane A2 receptors. J Clin Invest 1992; 90:136-141.

269. Audoly LP, Rocca B, Fabre JE, et al. Cardiovascular responses to the isoprostanes iPF(2alpha)III and $\mathrm{PPE}(2)-\mathrm{III}$ are mediated via the thromboxane $\mathrm{A}(2)$ receptor in vivo. Circulation 2000; 101:2833-2840.

270. Sanz AB, Santamaria B, Ruiz-Ortega M, Egido J, Ortiz A. Mechanisms of renal apoptosis in health and disease. J Am Soc Nephrol 2008; 19:1634-1642.

271. Hotchkiss RS, Strasser A, McDunn JE, Swanson PE. Cell death. N Engl J Med 2009; 361:15701583.

272. Burns AT, Davies DR, McLaren AJ, Cerundolo L, Morris PJ, Fuggle SV. Apoptosis in ischemia/reperfusion injury of human renal allografts. Transplantation 1998; 66:872-876.

273. Daemen MA, van 't Veer C, Denecker G, et al. Inhibition of apoptosis induced by ischemiareperfusion prevents inflammation. J Clin Invest 1999; 104:541-549.

274. Matsuno T, Sasaki H, Ishido N, et al. Apoptosis in human kidney allografts. Transplant Proc 1996; 28:1226-1227.

275. Oberbauer R, Rohrmoser M, Regele H, Muhlbacher F, Mayer G. Apoptosis of tubular epithelial cells in donor kidney biopsies predicts early renal allograft function. J Am Soc Nephrol 1999; 10:2006-2013.

276. Schwarz C, Hauser P, Steininger R, et al. Failure of BCL-2 up-regulation in proximal tubular epithelial cells of donor kidney biopsy specimens is associated with apoptosis and delayed graft function. Lab Invest 2002; 82:941-948. 
277. Castaneda MP, Swiatecka-Urban A, Mitsnefes MM, et al. Activation of mitochondrial apoptotic pathways in human renal allografts after ischemiareperfusion injury. Transplantation 2003; 76:50-54

278. Mollen KP, Anand RJ, Tsung A, Prince JM, Levy RM, Billiar TR. Emerging paradigm: toll-like receptor 4-sentinel for the detection of tissue damage. Shock 2006; 26:430-437.

279. Kruger B, Krick S, Dhillon N, et al. Donor Toll-like receptor 4 contributes to ischemia and reperfusion injury following human kidney transplantation. Proc Natl Acad Sci U S A 2009; 106:3390-3395.

280. Wu H, Chen G, Wyburn KR, et al. TLR4 activation mediates kidney ischemia/reperfusion injury. J Clin Invest 2007; 117:2847-2859.

281. de Vries B, Walter SJ, Peutz-Kootstra CJ, Wolfs TG, van Heurn LW, Buurman WA. The mannose-binding lectin-pathway is involved in complement activation in the course of renal ischemia-reperfusion injury. Am J Pathol 2004; 165:1677-1688.

282. Haas M, Ratner LE, Montgomery RA. C4d staining of perioperative renal transplant biopsies. Transplantation 2002; 74:711-717.

283. Berger SP, Roos A, Mallat MJ, Fujita T, de Fijter JW, Daha MR. Association between mannosebinding lectin levels and graft survival in kidney transplantation. Am J Transplant 2005; 5:1361-1366.

284. Koo DD, Welsh KI, Roake JA, Morris PJ, Fuggle SV. Ischemia/reperfusion injury in human kidney transplantation: an immunohistochemical analysis of changes after reperfusion. Am J Pathol 1998; 153:557-566.

285. Bonventre JV, Zuk A. Ischemic acute renal failure: an inflammatory disease? Kidney Int 2004; 66:480-485.

286. Araki M, Fahmy N, Zhou L, et al. Expression of IL-8 during reperfusion of renal allografts is dependent on ischemic time. Transplantation 2006; 81:783-788.

287. Molls RR, Savransky V, Liu M, et al. Keratinocyte-derived chemokine is an early biomarker of ischemic acute kidney injury. Am J Physiol Renal Physiol 2006; 290:F1187-1193.

288. Kwon O, Molitoris BA, Pescovitz M, Kelly KJ. Urinary actin, interleukin-6, and interleukin-8 may predict sustained ARF after ischemic injury in renal allografts. Am J Kidney Dis 2003; 41:1074-1087.

289. Schwarz C, Regele H, Steininger R, Hansmann C, Mayer G, Oberbauer R. The contribution of adhesion molecule expression in donor kidney biopsies to early allograft dysfunction. Transplantation 2001; 71:1666-1670.

290. Turunen AJ, Lindgren L, Salmela KT, et al. Association of graft neutrophil sequestration with delayed graft function in clinical renal transplantation. Transplantation 2004; 77:1821-1826.

291. Wiggins MC, Bracher M, Mall A, Hickman R, Robson SC, Kahn D. Tumour necrosis factor levels during acute rejection and acute tubular necrosis in renal transplant recipients. Transpl Immunol 2000; 8:211-215.

292. Parikh CR, Jani A, Melnikov VY, Faubel S, Edelstein CL. Urinary interleukin-18 is a marker of human acute tubular necrosis. Am J Kidney Dis 2004; 43:405-414.

293. Israni AK, Li N, Cizman BB, et al. Association of donor inflammation- and apoptosis-related genotypes and delayed allograft function after kidney transplantation. Am J Kidney Dis 2008; 52:331-339.

294. Alakulppi NS, Kyllonen LE, Jantti VT, et al. Cytokine gene polymorphisms and risks of acute rejection and delayed graft function after kidney transplantation. Transplantation 2004; 78:1422-1428. 
295. Poli F, Boschiero L, Giannoni F, et al. Tumour necrosis factor-alpha gene polymorphism: implications in kidney transplantation. Cytokine 2000; 12:1778-1783.

296. Kolesar L, Novota P, Krasna E, et al. Polymorphism of interleukin-18 promoter influences the onset of kidney graft function after transplantation. Tissue Antigens 2007; 70:363-368.

297. Salmela K, Wramner L, Ekberg H, et al. A randomized multicenter trial of the anti-ICAM-1 monoclonal antibody (enlimomab) for the prevention of acute rejection and delayed onset of graft function in cadaveric renal transplantation: a report of the European Anti-ICAM-1 Renal Transplant Study Group. Transplantation 1999; 67:729-736.

298. Medzhitov R. Origin and physiological roles of inflammation. Nature 2008; 454:428-435.

299. Gupta S, Verfaillie C, Chmielewski D, Kim Y, Rosenberg ME. A role for extrarenal cells in the regeneration following acute renal failure. Kidney Int 2002; 62:1285-1290.

300. Loverre A, Capobianco C, Ditonno P, Battaglia M, Grandaliano G, Schena FP. Increase of proliferating renal progenitor cells in acute tubular necrosis underlying delayed graft function. Transplantation 2008; 85:1112-1119.

301. Doshi MD, Hunsicker LG. Short- and long-term outcomes with the use of kidneys and livers donated after cardiac death. Am J Transplant 2007; 7:122-129.

302. Daemen JH, de Vries B, Oomen AP, DeMeester J, Kootstra G. Effect of machine perfusion preservation on delayed graft function in non-heart-beating donor kidneys--early results. Transpl Int 1997; 10:317-322.

303. Chang RW. Transplantation of non-heart-beating donor kidneys. Lancet 1995; 346:322.

304. Sanni AO, Wilson CH, Wyrley-Birch H, et al. Non-heart-beating kidney transplantation: 6year outcomes. Transplant Proc 2006; 38:3396-3397.

305. Light JA, Kowalski AE, Sasaki TM, et al. A rapid organ recovery program for non-heart-beating donors. Transplant Proc 1997; 29:3553-3556.

306. Billen EV, Christiaans MH, Lee J, van den Berg-Loonen EM. Donor-directed HLA antibodies before and after transplantectomy detected by the luminex single antigen assay. Transplantation 2009; 87:563-569.

307. Meier-Kriesche HU, Scornik JC, Susskind B, Rehman S, Schold JD. A lifetime versus a graft life approach redefines the importance of HLA matching in kidney transplant patients. Transplantation 2009; 88:23-29.

308. Brook NR, White SA, Waller JR, Veitch PS, Nicholson ML. Non-heart beating donor kidneys with delayed graft function have superior graft survival compared with conventional heartbeating donor kidneys that develop delayed graft function. Am J Transplant 2003; 3:614-618.

309. Renkens JJ, Rouflart MM, Christiaans MH, van den Berg-Loonen EM, van Hooff JP, van Heurn LW. Outcome of nonheart-beating donor kidneys with prolonged delayed graft function after transplantation. Am J Transplant 2005; 5:2704-2709.

310. Bains JC, Sandford RM, Brook NR, Hosgood SA, Lewis GR, Nicholson ML. Comparison of renal allograft fibrosis after transplantation from heart-beating and non-heart-beating donors. $\mathrm{Br} \mathrm{J}$ Surg 2005; 92:113-118.

311. Kokkinos C, Antcliffe D, Nanidis T, Darzi AW, Tekkis P, Papalois V. Outcome of kidney transplantation from nonheart-beating versus heart-beating cadaveric donors. Transplantation 2007; 83:1193-1199. 
\begin{tabular}{l|l} 
I N T R O D U C T I O N & 55
\end{tabular} 
\begin{tabular}{l|l|l}
56 & C H A P T E R 1
\end{tabular} 


\section{Chapter 2}

Long-term outcome of kidney transplantation from donors after cardiac death 


\begin{abstract}
Background: The shortage of organ donors presents a major obstacle for adequate treatment of patients with end-stage renal disease. Donation after cardiac death (DCD) has been shown to increase the number of kidneys available for transplantation. The present paper reports on the long-term outcome of DCD kidney transplantation.

Methods: This observational cohort study included all DCD kidney transplantations recovered in our procurement area from 01/01/1981 until 31/12/2005 $(\mathrm{N}=297)$. Patients were followed until the earliest of death or 31/12/2006. Clinical outcomes were compared to matched kidney transplantations from brain dead donors (DBD, N=594), using multivariable regression models to adjust for potential confounders.

Findings: DCD activity resulted in a $44 \%$ increase in the number of deceased donor kidneys from our organ procurement area. After adjustment for potential confounders, the odds of primary non-function and delayed graft function were 7.5 (95\% CI: 4.0-14.1, $\mathrm{P}<0.001)$ and 10.3 (95\% CI: 6.7-15.9, $\mathrm{P}<0.001)$ times greater, respectively, for DCD kidneys compared to DBD kidneys. The high incidence of primary non-function of DCD kidneys resulted in an increased rate of graft loss (HR 1.82, 95\% CI: 1.37-2.42, $\mathrm{P}<0.001$ ). However, DCD kidneys that did not experience primary non-function functioned as long as DBD kidneys (HR=1.05, 95\% CI: 0.73-1.51, $\mathrm{P}=0.79$ ). Patient survival of DCD and DBD kidney recipients was equivalent ( $\mathrm{HR}=1.16,95 \% \mathrm{CI}: 0.87-1.54, \mathrm{P}=0.32$ ).

Interpretation: The long-term benefits of DCD kidney transplantation outweigh the increased risk of early graft loss. Expansion of the supply of DCD kidneys is likely to improve the treatment of wait-listed dialysis patients.
\end{abstract}

\title{
Published as
}

Snoeijs MG, Winkens B, Heemskerk MB, Hoitsma AJ, Christiaans MH, Buurman WA, van Heurn LW. Long-term outcome of kidney transplantation from donors after cardiac death. Manuscript submitted. 


\section{Introduction}

Patients with end-stage renal disease experience longer survival and improved quality of life after kidney transplantation compared to dialysis treatment. ${ }^{1,2}$ Hence, the current shortage of donor kidneys impedes the delivery of adequate health care and demands persistent efforts to expand the donor pool. Over the past decade, major increases in kidney transplantations from living donors and older donors after brain death (DBD) did not reduce the waiting times for transplantation. ${ }^{3}$ Therefore, additional sources of kidneys for transplantation are needed. Donation after cardiac death (DCD) has long been propagated as a promising approach to reduce the shortage of donor kidneys. ${ }^{4}$ Liberal use of DCD kidneys has been estimated to expand the donor pool 2-4.5 times, sufficient to reduce or even eliminate the waiting lists for transplantation., ${ }^{5,6}$

With donation after cardiac death, organs are recovered after scheduled withdrawal of supportive treatment in the intensive care unit (controlled DCD) or in an unplanned fashion after failed cardiopulmonary resuscitation (uncontrolled DCD). ${ }^{7}$ In either situation, organs suffer ischemic injury due to the inevitable delay between circulatory arrest and organ preservation. This may result in higher incidences of postoperative delayed graft function and primary nonfunction, which has led to a reluctance to accept DCD kidneys for transplantation. ${ }^{8}$ Interestingly, several transplant centers have reported similar graft and patient survival rates of DCD and DBD kidneys over the first 5 to 10 years after transplantation. ${ }^{8-14}$

Our transplant center has continuously directed a DCD programme in its organ procurement area since 1981. To maximize the number of kidneys available for transplantation, DCD donors were liberally selected and managed according to a standardized protocol. ${ }^{15}$ The recovered kidneys were transplanted throughout Eurotransplant in keeping with its regular allocation rules. In the present paper, we report on the impact of donation after cardiac death on the donor pool throughout the first 25 years of our experience and we present data on the long-term outcome of the resulting kidney transplantations as compared to matched DBD grafts. 


\section{Materials and methods}

\section{Study design}

All kidney transplantations in the Eurotransplant area from donors after cardiac death in our organ procurement area from 01/01/1981 until 31/12/2005 were included in the current observational cohort study. Patients were followed until the earliest of death or 31/12/2006. The clinical outcome of the DCD kidney transplantations recovered in our organ procurement area $(\mathrm{N}=297)$ was compared to a cohort of DBD kidney transplantations from the nationwide Dutch Organ Transplant Registry ( $\mathrm{N}=594$ ). To address potential bias due to differential distribution of outcome predictors among DCD and DBD kidney transplantations, for each DCD kidney transplantation two DBD kidney transplantations were selected that matched with regards to transplantation type (single / double; 100\% matched, first / re-transplant; 98\% matched) and calendar year (within 3 years; $97 \%$ matched). If several controls were available, further matching was done for donor and recipient age (within 10 years; 96 and 92\% matched, respectively) and cold ischemia time (within 6 hours; $68 \%$ matched). In case further selection of controls was possible, matching was done for calcineurin inhibitor use (cyclosporine / tacrolimus; 87\% matched) and transplant center (64\% matched). Sensitivity analyses including only kidneys that matched on all matching criteria $(\mathrm{N}=329)$ produced results similar to the entire study population.

\section{Data sources and definitions}

Data on DCD kidney transplantations were extracted from our annually updated database. Data on DBD kidney transplantations were obtained from the Dutch Organ Transplant Registry. Missing data were supplemented by chart review at the transplant center at the request of the study coordinator. Three patients were lost to follow-up in the DCD kidney transplantation group (1.0\%) after a minimum follow-up period of 0.4 years, two of whom had experienced graft loss. Ten patients were lost to follow-up in the DBD kidney transplantation cohort (1.7\%) after a minimum follow-up period of 5 years, none of whom had experienced graft loss. Patient data were collected, stored and used in agreement with the code of conduct 'Use of data in health research' put forward by the federation of Dutch medical scientific societies (http://www.federa.org/); ethics approval was not required.

Graft function in the early postoperative period was defined as immediate function (no dialysis treatment after transplantation), delayed graft function 
(temporary dialysis treatment initiated in the first week after transplantation), or primary non-function (continuous dialysis treatment after transplantation). Glomerular filtration rate (GFR) was estimated using the abbreviated Modification of Diet in Renal Disease equation, excluding recipients under 16 years $(\mathrm{N}=8) .{ }^{16-18}$ Estimated GFR at 1 year after transplantation and rate of decline in estimated GFR were studied as measures of kidney function. Death-censored graft loss was defined as permanent return to dialysis treatment or retransplantation; recipient death with a functioning transplant was not considered as graft loss.

\section{Statistical methods}

Continuous variables were expressed as means with standard deviations (SD) and categorical variables as percentages. Graft and patient survival were calculated with the Kaplan-Meier method. Baseline characteristics of donors, grafts and recipients in both cohorts were compared with paired samples t-tests for continuous variables (using the mean of the two DBD controls) and with MantelHaenszel chi-square tests for categorical variables.

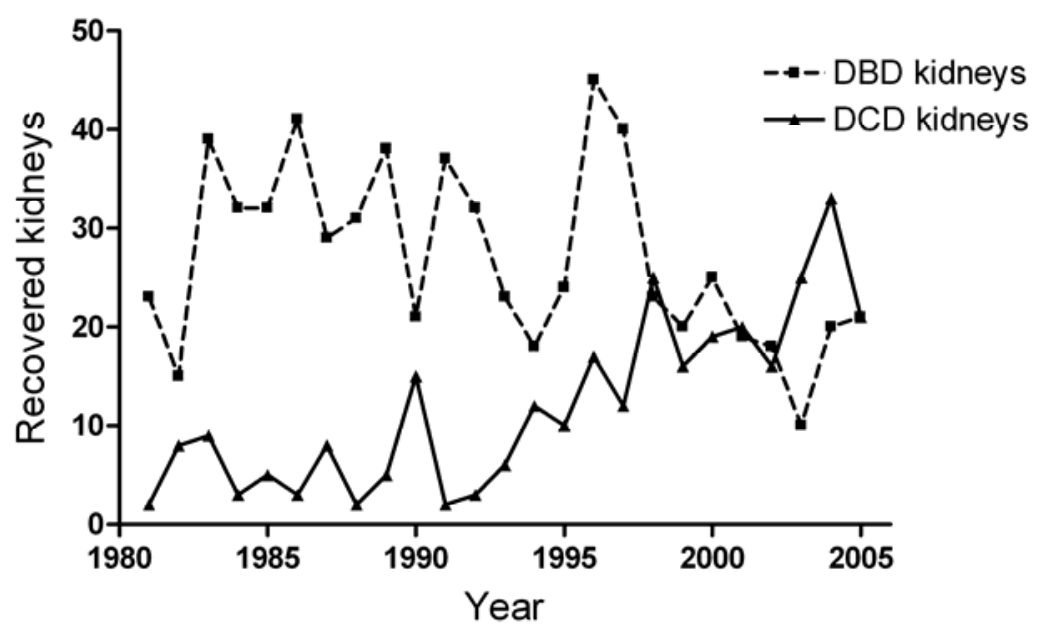

Figure 2.1 The number of DCD and DBD kidneys recovered in our organ procurement area and transplanted within Eurotransplant during the study period. DCD kidneys were used in the subsequent analyses of transplant outcome, whereas the matched DBD kidneys used for comparison in these analyses were derived from records of all kidneys transplanted throughout the country and were not restricted to the grafts recovered in our organ procurement area. 
Clinical outcomes of DCD and DBD kidney transplantations were compared with multivariable regression models. To account for matching, all matching variables were included as covariates in these models. Adjustment for other baseline characteristics and interaction terms was done in a two-step approach. Firstly, each baseline characteristic was added separately to multivariable regression models containing donor type and all matching variables and was tested for statistical significance. Donor creatinine and hypertension were not included in the models because of the large number of missing values ( $20 \%$ and $22 \%$, respectively). Sensitivity analyses including these covariates produced similar results. Cases with missing values for other variables were not included in the analyses. Secondly, interaction terms were added to models containing donor type, matching variables and baseline characteristics with $\mathrm{P} \leq 0.10$ in the previous step. Analysis of interaction terms was restricted to the clinically relevant interactions between donor age $\mathrm{x}$ donor type and cold ischemia time $\mathrm{x}$ donor type. Final models were obtained by removal of interaction terms that were not statistically significantly associated with the outcome of interest.

The incidence of delayed graft function and primary non-function in the transplant cohorts were compared with multivariable logistic regression analysis using the Wald test for statistical significance. Patients undergoing pre-emptive kidney transplantation were excluded from this analysis because dialysis dependency could not be used to define short-term graft function. For the analysis of delayed graft function, recipients of primarily non-functioning kidneys were excluded as well. The duration of delayed graft function, the estimated GFR at 1 year after transplantation and the rate of decline in estimated GFR of the cohorts were compared with multivariable linear regression using the t-test for statistical significance. The rate of decline in estimated GFR was calculated for each patient by simple linear regression from yearly GFR estimations starting at 1 year after transplantation. Graft and patient survival of the two study groups were compared with multivariable Cox regression analysis and were studied separately for all grafts and for viable grafts (kidneys that did not experience primary nonfunction). Sensitivity analyses were done conditional on graft survival at 3 months and 1 year after transplantation. Assumptions of the regression models were checked with normal probability-probability and residual plots and by addition of quadratic or time-dependent terms when appropriate; these terms were retained in the model if statistically significant. Multicollinearity and influential outliers were checked using variance inflation factors and Cook's distances. Results with $\mathrm{P}<0.05$ were considered statistically significant. All statistical computing was carried out by MGS using SPSS version 16.0. 
Table 2.1 Baseline characteristics of DCD and DBD kidney transplantations ${ }^{\mathrm{a}}$

\begin{tabular}{|c|c|c|c|}
\hline & $\begin{array}{c}\text { DCD Cases } \\
\qquad \mathrm{N}=297\end{array}$ & $\begin{array}{c}\text { DBD Controls } \\
\text { N=594 }\end{array}$ & $\mathrm{P}$ \\
\hline \multicolumn{4}{|l|}{ Donor characteristics } \\
\hline Age (years) & $45(16)$ & $44(16)$ & 0.04 \\
\hline Sex (male / female) & 62 / 38\% & $53 / 48 \%$ & 0.02 \\
\hline DCD category (controlled / uncontrolled) & $57 / 43 \%$ & - & - \\
\hline Cause of death (cardiovascular / other) & $41 / 59 \%$ & $54 / 46 \%$ & $<0.001$ \\
\hline Serum creatinine $(\mu \mathrm{mol} / \mathrm{L})^{\mathrm{b}}$ & $87(36)$ & $84(37)$ & 0.59 \\
\hline Hypertension (yes / no) & $14 / 86 \%$ & $24 / 76 \%$ & 0.01 \\
\hline Year of transplantation & $1997(7)$ & $1998(6)$ & $<0.001$ \\
\hline \multicolumn{4}{|l|}{ Preservation characteristics } \\
\hline CPR time $(\min )^{c}$ & $47(28)$ & - & - \\
\hline Ventilator switch-off time $(\mathrm{min})^{\mathrm{b}}$ & $68(116)$ & - & - \\
\hline Warm ischemia time $(\min )^{\mathrm{d}}$ & $27(13)$ & - & - \\
\hline Preservation (cold storage / machine perfusion) & $19 / 81 \%$ & - & - \\
\hline Cold ischemia time (hour) & $28(7)$ & $25(8)$ & $<0.001$ \\
\hline Anastomosis time (min) & $38(15)$ & $35(12)$ & $<0.001$ \\
\hline \multicolumn{4}{|l|}{ Recipient characteristics } \\
\hline Age (years) & $49(13)$ & $49(13)$ & 0.72 \\
\hline Sex (male / female) & $66 / 34 \%$ & $57 / 43 \%$ & 0.01 \\
\hline Transplant center (regional / export) & $50 / 50 \%$ & $20 / 80 \%$ & $<0.001$ \\
\hline Kidney (single / double) & $98 / 2 \%$ & $99 / 1 \%$ & 0.72 \\
\hline Kidney disease (renovascular / other) & $19 / 81 \%$ & $18 / 82 \%$ & 0.58 \\
\hline Dialysis time (years) & $3.5(3.0)$ & $3.5(2.6)$ & 0.92 \\
\hline Dialysis type (hemodialysis / peritoneal dialysis) & $66 / 35 \%$ & 67 / 33\% & 0.76 \\
\hline Retransplantation (yes / no) & $14 / 86 \%$ & $13 / 87 \%$ & 0.17 \\
\hline Total HLA mismatches & $2.4(1.0)$ & $2.4(1.4)$ & 0.23 \\
\hline Calcineurin inhibitor (cyclosporine / tacrolimus) & $43 / 58 \%$ & $45 / 55 \%$ & 0.70 \\
\hline Anti-metabolite (azathioprine / MMF) & $31 / 69 \%$ & $13 / 87 \%$ & 0.19 \\
\hline Sirolimus (yes / no) & 13 / 87\% & $3 / 97 \%$ & $<0.001$ \\
\hline Induction therapy (yes / no) & $13 / 87 \%$ & $13 / 87 \%$ & 0.94 \\
\hline Follow-up time (years) & $6.6(5.3)$ & $6.8(5.2)$ & 0.59 \\
\hline
\end{tabular}

a Data are presented as mean (standard deviation) or as percentages.

b Not for uncontrolled DCD kidney transplantations. Ventilator switch-off time was defined as the time from withdrawal of supportive treatment until circulatory arrest.

${ }^{\mathrm{c}}$ Not for controlled DCD kidney transplantations.

d Warm ischemia time was defined as the time from circulatory arrest until initiation of hypothermic organ perfusion and therefore does not include ventilator switch-off time and cardiopulmonary resuscitation time.

e $10 \%$ of DCD and DBD kidney transplantations did not receive any calcineurin inhibitor. 


\section{Results}

\section{Expansion of the donor pool}

In our organ procurement area, 973 kidneys that were subsequently transplanted within Eurotransplant were recovered from deceased donors during the 25-year study period. Of these kidneys, 676 (69\%) were recovered from DBD donors with the remaining 297 (31\%) kidneys having been recovered from DCD donors. Trends over time in recovery of DCD and DBD kidneys in our procurement area are presented in Figure 2.1. Overall, our DCD programme resulted in a $44 \%$ increase in the number of available donor kidneys. In the last 5 years of the study period, DCD kidneys outnumbered the grafts recovered from conventional DBD donors in our procurement area, resulting in a $131 \%$ increase in the number of available donor kidneys.

\section{Baseline characteristics of $D C D$ and $D B D$ kidney transplantations}

We compared the DCD kidney transplantations that had been recovered in our organ procurement area $(\mathrm{N}=297)$ with a matched cohort of nationwide $\mathrm{DBD}$ kidney transplantations $(\mathrm{N}=594)$. Baseline characteristics of donors, grafts and recipients in the DCD and DBD kidney transplantation cohorts are presented in Table 2.1. Mean warm ischemia time for DCD kidneys was $27 \pm 13$ minutes. DBD donors were significantly more likely to be female ( $48 \%$ vs. $38 \%, \mathrm{P}=0.02)$, present with a history of hypertension $(24 \%$ vs. $14 \%, \mathrm{P}=0.01)$ and have died from cardiovascular disease than DCD donors ( $54 \%$ vs. $41 \%, \mathrm{P}<0.001)$. Recipients of DBD kidneys were significantly more likely to be female ( $43 \%$ vs. $34 \%, \mathrm{P}=0.01$ ) and had shorter anastomosis times than recipients of DCD kidneys (mean difference $3.8 \mathrm{~min}, \mathrm{P}<0.001$ ). Furthermore, DBD kidney recipients were significantly less frequently transplanted at our unit $(20 \%$ vs. $50 \%, \mathrm{P}<0.001)$ and less often received sirolimus as immunosuppression compared to recipients of DCD kidneys ( $3 \%$ vs. $13 \%, \mathrm{P}<0.001)$. Despite the matching procedure, DBD donors were significantly younger (mean difference 0.61 years, $\mathrm{P}=0.04$ ) and their kidneys were transplanted with shorter cold ischemia times (mean difference 2.9 hours, $\mathrm{P}<0.001$ ) and at a later calendar year (mean difference 0.46 years, $\mathrm{P}<0.001$ ) than their DCD counterparts. The study groups were not significantly different with respect to other potentially confounding variables. Mean recipient follow-up time was 6.8 \pm 5.2 and 6.6 \pm 5.3 years for DBD and DCD kidney transplantations, respectively $(\mathrm{P}=0.59)$. Baseline characteristics of kidney transplantations that did 
Table 2.2 Clinical outcome of DCD and DBD kidney transplantations ${ }^{\mathrm{a}}$

\begin{tabular}{|c|c|c|c|c|}
\hline & \multicolumn{2}{|c|}{ UNADJUSTED ANALYSIS } & \multicolumn{2}{|c|}{ ADJUSTED ANALYSIS } \\
\hline & $\begin{array}{l}\text { DCD Cases } \\
\qquad \mathrm{N}=\mathbf{2 9 7}\end{array}$ & $\begin{array}{l}\text { DBD Controls } \\
\qquad \mathrm{N}=594\end{array}$ & Effect size $(95 \% \mathrm{CI})$ & $P$ \\
\hline \multicolumn{5}{|l|}{ ALL GRAFTS } \\
\hline Primary non-function (yes / no) ${ }^{\mathrm{b}}$ & 23 / 77\% & $4 / 96 \%$ & $7.51(4.01-14.1)^{\mathrm{d}}$ & $<0.001$ \\
\hline Graft survival at 15 years & $46 \%$ & $60 \%$ & $1.82(1.37-2.42)^{\mathrm{f}}$ & $<0.001$ \\
\hline Patient survival at 15 years & $45 \%$ & $48 \%$ & $1.16(0.87-1.54)^{\mathrm{f}}$ & 0.32 \\
\hline \multicolumn{5}{|l|}{ VIABLE GRAFTS } \\
\hline Delayed graft function (yes / no) ${ }^{b}$ & 72 / 28\% & $18 / 82 \%$ & $10.3(6.68-15.9)^{\mathrm{d}}$ & $<0.001$ \\
\hline Duration of DGF (days) & $18(12)$ & $13(16)$ & $3.20(-0.50,6.89)^{\mathrm{e}}$ & 0.09 \\
\hline GFR at 1 year $(\mathrm{mL} / \mathrm{min})^{\mathrm{c}}$ & $42(18)$ & $49(19)$ & $-6.2(-9.4,-3.0)^{\mathrm{e}}$ & $<0.001$ \\
\hline Decline in GFR (mL/min/year) ${ }^{c}$ & $0.9(6.4)$ & $1.6(7.7)$ & $0.1(-1.2,1.4)^{\mathrm{e}}$ & 0.87 \\
\hline Graft survival at 15 years & $60 \%$ & $61 \%$ & $1.05(0.73-1.51)^{\mathrm{f}}$ & 0.79 \\
\hline Patient survival at 15 years & $48 \%$ & $49 \%$ & $1.16(0.84-1.60)^{\mathrm{f}}$ & 0.36 \\
\hline $\begin{array}{l}\text { a Data are presented as mean (standard } \\
\text { a Pre-emptive kidney transplantations } \\
\text { b Glomerular filtration rate was estimat } \\
\text { ' The effect size is reported as odds rati } \\
\text { d The effect size is reported as mean dif } \\
\text { e The effect size is reported as hazard ra }\end{array}$ & $\begin{array}{l}\text { viation) or as } \mathrm{p} \\
\text { luded (1\% and } \\
\text { with the abbr } \\
\text { ence. }\end{array}$ & $\begin{array}{l}\text { entages. } \\
\text { o of DCD and DBI } \\
\text { ated MDRD formu }\end{array}$ & $\begin{array}{l}\text { kidney transplantations). } \\
{ }^{16}\end{array}$ & \\
\hline
\end{tabular}

not experience primary non-function were comparable to those of the entire study population (data not shown).

\section{Clinical outcome of DCD and DBD kidney transplantations}

The unadjusted clinical outcome of DCD and DBD kidney transplantations is presented in Table 2.2. After adjustment for potential confounders, the odds of primary non-function and delayed graft function were 7.5 and 10.3 times greater, respectively, for DCD kidneys compared to DBD kidneys $(\mathrm{P}<0.001$ for both comparisons). The estimated glomerular filtration rate of functioning $\mathrm{DCD}$ kidneys was $6.2 \mathrm{~mL} / \mathrm{min} / 1.73 \mathrm{~m}^{2}$ lower than that of DBD kidneys at 1 year after transplantation $(\mathrm{P}<0.001)$ and subsequently declined at a similar rate (mean difference $0.11 \mathrm{~mL} / \mathrm{min} / 1.73 \mathrm{~m}^{2} /$ year, $\mathrm{P}=0.87$ ). Information on the variables included in the final multivariable regression models is presented in the Supplementary tables.

Unadjusted Kaplan-Meier curves for death-censored graft and patient survival of the two cohorts are presented in Figure 2.2. Survival of transplant recipients 
from $\mathrm{DCD}$ and $\mathrm{DBD}$ donors was equivalent $(\mathrm{HR}=1.16, \mathrm{P}=0.32)$. The overall hazard of death-censored graft loss was $1.82(\mathrm{P}<0.001)$ times greater for $\mathrm{DCD}$ kidneys than for DBD kidneys. Because DCD kidneys had a high incidence of early graft failure, we subsequently compared the outcome of viable kidneys that had overcome the early postoperative period. Graft loss of DCD and DBD kidneys that did not experience primary non-function was comparable (HR=1.05, $\mathrm{P}=0.79$ ). Similar results were obtained when the analysis was restricted to kidneys that survived the first 3 months or 1 year after transplantation. Interactions between donor type and donor age or between donor type and cold ischemia time were not statistically significant for any of the analyses.
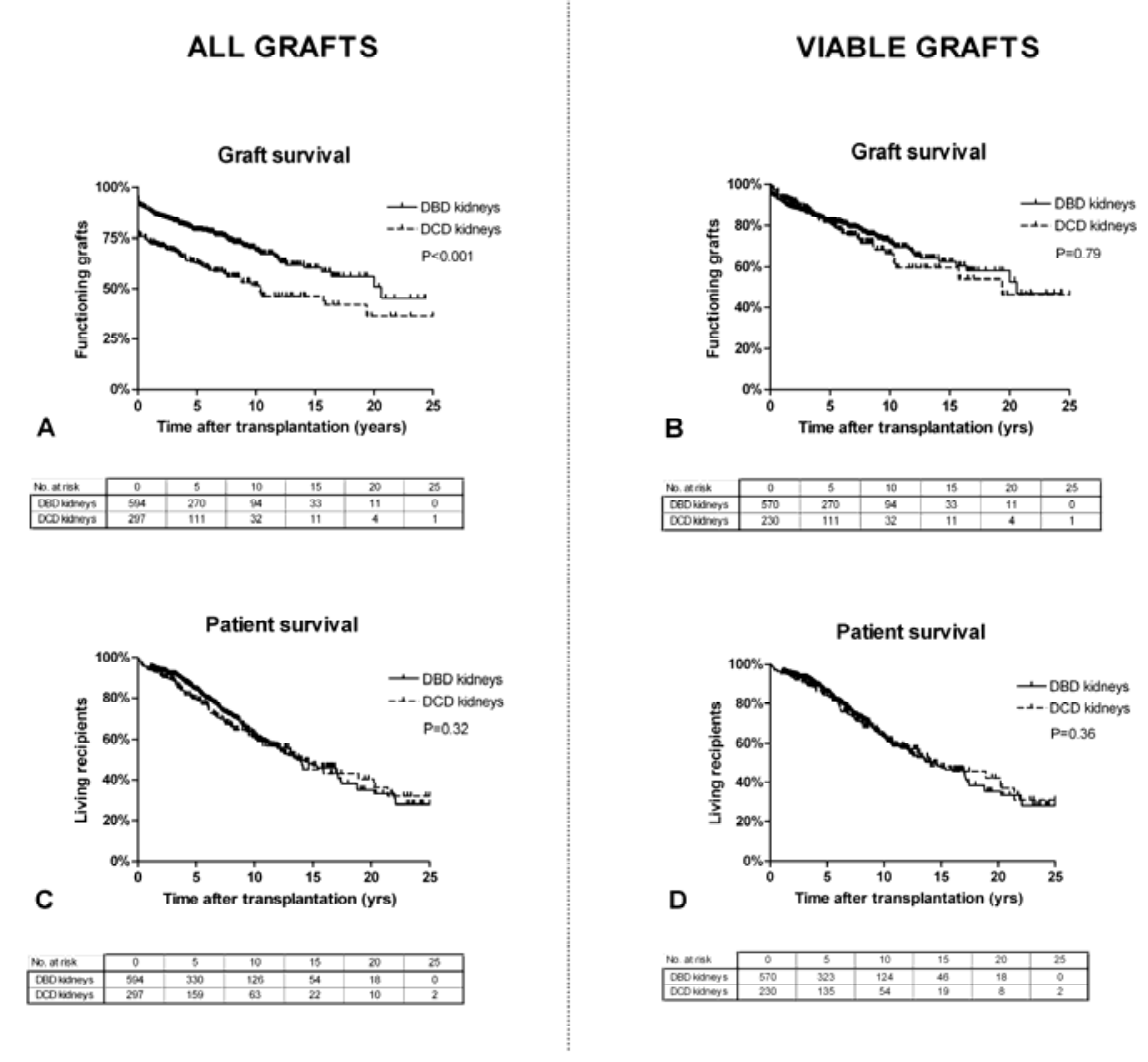

Figure 2.2 Unadjusted Kaplan-Meier curves of DCD and DBD kidney transplantations for (A) death-censored graft survival of all kidneys, (B) death-censored graft survival of viable kidneys (grafts that did not experience primary non-function), (C) recipient survival of all kidneys, and (D) recipient survival of viable kidneys (grafts that did not experience primary non-function). P values were calculated by Cox regression analysis adjusted for potential confounders. 


\section{SUBGROUP OF DCD KIDNEYS}
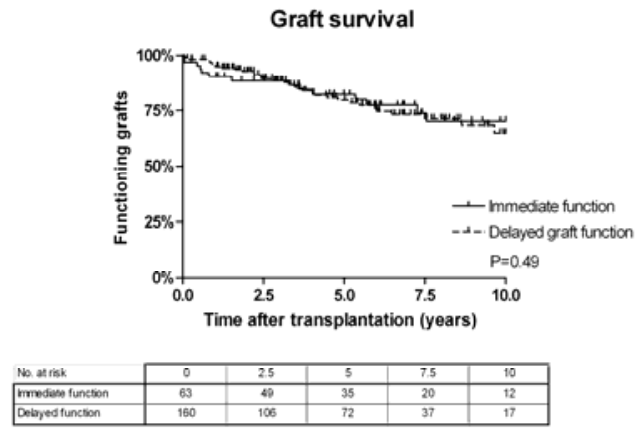

Figure 2.3 Unadjusted Kaplan-Meier curve for graft survival of DCD kidneys with immediate function and delayed graft function. Recipient death with a functioning graft was not considered as graft loss. $\mathrm{P}$ values were calculated by Cox regression analysis adjusted for potential confounders.

\section{Clinical outcome of DCD kidney transplantations with early graft dysfunction}

Considering the high incidence of early graft dysfunction in DCD kidneys, we studied the impact of these complications in more detail. DCD kidneys with delayed graft function had similar graft survival as immediately functioning DCD kidneys ( $\mathrm{HR}=1.27, \mathrm{P}=0.49$, Figure 2.3 ). After primary non-function, $24 \%$ of $\mathrm{DCD}$ kidney recipients were newly sensitized ( $>5 \%$ panel reactive antibodies). At the end of the study period, 24 (36\%) recipients of primarily non-functioning DCD kidneys had been retransplanted after a median of 2.4 (range: 0.1-7.5) years from graft failure. Median survival time without retransplantation was 6.5 years.

\section{Discussion}

The persistent shortage of organ donors presents a major obstacle for adequate treatment of patients with end-stage renal disease. By recovering organs from donors after cardiac death, our transplant center has more than doubled the pool of donor kidneys in its organ procurement area over the past decade (192 DBD kidneys supplemented with 221 DCD kidneys). DCD kidneys suffer acute ischemic injury from the inevitable delay between circulatory arrest and organ preservation, which results in an increased incidence of postoperative graft dysfunc- 
tion. ${ }^{8-14}$ Nevertheless, previous studies have demonstrated that viable DCD kidneys function as well as conventional DBD kidneys over the first 5 to 10 years after transplantation. ${ }^{8-14}$

The current study was designed to report on the long-term outcome of the kidney transplantations that resulted from 25 years of experience with DCD organ donation. It describes one of the largest series of DCD kidney transplantations from a single organ procurement area published to date and includes substantial numbers of both controlled and uncontrolled DCD kidneys. A liberal policy was applied with regards to donor selection with the intent to maximally expand the number of kidneys available for transplantation. Since recovered DCD kidneys were transplanted throughout Eurotransplant, our results are derived from common clinical practice and have broad generalisability. However, evolving medical practice may have introduced some variation in the management of transplant recipients. The virtually complete follow-up of patients, that continued after graft loss, contributes to the validity of our analysis.

In line with previous studies comparing DCD and DBD kidney transplantations, we found that the odds of primary non-function in DCD kidneys were more than 7 times higher than in conventional DBD kidneys, resulting in inferior graft survival throughout follow-up. ${ }^{9-11}$ Primary non-function is a major adverse event, since transplant candidates undergo unnecessary risks of surgery and immunosuppression and may become sensitized to donor antigens which decreases the opportunities for retransplantation. ${ }^{19,20}$ Recently, a number of interventions have been suggested to reduce the incidence of primary nonfunction after DCD kidney transplantation. ${ }^{21-23}$ These recommendations include organ preservation by rapid laparotomy and aortic cannulation for controlled DCD donors, selection of kidneys from old DCD donors by histological assessment of pre-implantation biopsies and careful management of recipient hemodynamics during transplant surgery to ensure adequate reperfusion of the graft. Implementation of these findings into clinical practice has reduced the incidence of primary non-function in DCD kidneys at our transplant unit to 5\% (4 out of 74) over the past three years. In spite of these preventive measures, primary nonfunction occasionally occurs and the need for strategies to reduce its consequences for patients must be recognized. Most importantly, patients should regain their waiting times when receiving a non-functioning graft, which is current practice in Eurotransplant. Furthermore, advances in tissue typing and immunosuppression may improve the clinical outcome of kidney transplantation in sensitized recipients. ${ }^{24,25}$ 
Patients receiving viable DCD kidneys were 10 times more likely to require temporary renal replacement therapy than recipients of DBD kidneys. In DBD kidney transplantation, delayed graft function is generally considered to be a major predictor of acute rejection and graft loss. ${ }^{26}$ In contrast, delayed graft function in DCD kidneys did not affect long-term graft survival in the current study, which is in line with previous publications. ${ }^{8-14,27,28} \mathrm{We}$ therefore suggest that delayed graft function is caused by different mechanisms in these two donor types (ischemic injury in DCD kidneys and neurogenic inflammation in DBD kidneys) and as a consequence may have a different impact on graft outcome. Indeed, in spite of the relatively high incidence of delayed graft function, viable DCD kidneys survived as long as DBD kidneys (15-year graft survival of $60 \%$ and $61 \%$, respectively). More importantly, survival of DCD kidney recipients was equal to that of patients receiving grafts from conventional DBD donors (15-year survival of $45 \%$ and $48 \%$, respectively), despite the increased risk of primary non-function with DCD kidneys. Since DBD kidney transplantation has repeatedly been shown to improve survival of wait-listed dialysis patients, ${ }^{1,29-31}$ it is reasonable to assume that transplantation of DCD kidneys is also associated with survival benefit.

Inherent limitations of observational studies are applicable to our study. Differential selection or management of donors and recipients may confound the comparison of clinical outcomes between DCD and DBD kidney transplantations. We have addressed this concern by matching for several baseline characteristics known to be associated with transplant outcome and we have corrected for potential confounders with multivariable regression analyses. Since randomized clinical trials comparing DCD and DBD kidney transplantation are ethically unacceptable, carefully conducted observational studies provide the highest level of evidence to be attained. Furthermore, formal measurement of glomerular filtration rate - the gold standard for assessment of kidney function - was not feasible in our study. The glomerular filtration rates reported in this study were instead derived from previously published equations and should be interpreted as estimates of true kidney function. ${ }^{32}$

In conclusion, we have doubled the number of kidneys recovered in our organ procurement area by liberal use of donors after cardiac death. Survival of recipients of DCD kidneys is similar to that of patients receiving conventional DBD kidneys, despite increased graft loss of DCD kidneys due to primary nonfunction. Therefore, expansion of the supply of kidneys from donors after cardiac death is likely to improve the treatment of wait-listed dialysis patients. 


\section{References}

1. Wolfe RA, Ashby VB, Milford EL, et al. Comparison of mortality in all patients on dialysis, patients on dialysis awaiting transplantation, and recipients of a first cadaveric transplant. $\mathrm{N}$ Engl J Med 1999; 341:1725-1730.

2. Evans RW, Manninen DL, Garrison LP, Jr., et al. The quality of life of patients with end-stage renal disease. N Engl J Med 1985; 312:553-559.

3. Wolfe RA, Merion RM, Roys EC, Port FK. Trends in organ donation and transplantation in the United States, 1998-2007. Am J Transplant 2009; 9:869-878.

4. Steinbrook R. Organ donation after cardiac death. N Engl J Med 2007; 357:209-213.

5. Daemen JW, Oomen AP, Kelders WP, Kootstra G. The potential pool of non-heart-beating kidney donors. Clin Transplant 1997; 11:149-154.

6. Terasaki PI, Cho YW, Cecka JM. Strategy for eliminating the kidney shortage. Clin Transpl 1997:265-267.

7. Kootstra G, Daemen JH, Oomen AP. Categories of non-heart-beating donors. Transplant Proc 1995; 27:2893-2894.

8. Wijnen RM, Booster MH, Stubenitsky BM, de Boer J, Heineman E, Kootstra G. Outcome of transplantation of non-heart-beating donor kidneys. Lancet 1995; 345:1067-1070.

9. Barlow AD, Metcalfe MS, Johari Y, Elwell R, Veitch PS, Nicholson ML. Case-matched comparison of long-term results of non-heart beating and heart-beating donor renal transplants. $\mathrm{Br}$ J Surg 2009; 96:685-691.

10. Sanchez-Fructuoso AI, Marques M, Prats D, et al. Victims of cardiac arrest occurring outside the hospital: a source of transplantable kidneys. Ann Intern Med 2006; 145:157-164.

11. Cho YW, Terasaki PI, Cecka JM, Gjertson DW. Transplantation of kidneys from donors whose hearts have stopped beating. N Engl J Med 1998; 338:221-225.

12. Weber M, Dindo D, Demartines N, Ambuhl PM, Clavien PA. Kidney transplantation from donors without a heartbeat. N Engl J Med 2002; 347:248-255.

13. Cooper JT, Chin LT, Krieger NR, et al. Donation after cardiac death: the university of wisconsin experience with renal transplantation. Am J Transplant 2004; 4:1490-1494.

14. Gok MA, Buckley PE, Shenton BK, et al. Long-term renal function in kidneys from non-heartbeating donors: A single-center experience. Transplantation 2002; 74:664-669.

15. Booster MH, Wijnen RM, Vroemen JP, van Hooff JP, Kootstra G. In situ preservation of kidneys from non-heart-beating donors--a proposal for a standardized protocol. Transplantation 1993; 56:613-617.

16. Levey AS, Bosch JP, Lewis JB, Greene T, Rogers N, Roth D. A more accurate method to estimate glomerular filtration rate from serum creatinine: a new prediction equation. Modification of Diet in Renal Disease Study Group. Ann Intern Med 1999; 130:461-470.

17. Poge U, Gerhardt T, Palmedo H, Klehr HU, Sauerbruch T, Woitas RP. MDRD equations for estimation of GFR in renal transplant recipients. Am J Transplant 2005; 5:1306-1311.

18. Gera M, Slezak JM, Rule AD, Larson TS, Stegall MD, Cosio FG. Assessment of changes in kidney allograft function using creatinine-based estimates of glomerular filtration rate. Am J Transplant 2007; 7:880-887. 
19. Billen EV, Christiaans MH, Lee J, van den Berg-Loonen EM. Donor-directed HLA antibodies before and after transplantectomy detected by the luminex single antigen assay. Transplantation 2009; 87:563-569.

20. Meier-Kriesche HU, Scornik JC, Susskind B, Rehman S, Schold JD. A lifetime versus a graft life approach redefines the importance of HLA matching in kidney transplant patients. Transplantation 2009; 88:23-29.

21. Snoeijs MG, Dekkers AJ, Buurman WA, et al. In Situ Preservation of Kidneys From Donors After Cardiac Death: Results and Complications. Ann Surg 2007; 246:844-852.

22. Snoeijs MG, Buurman WA, Christiaans MH, et al. Histological assessment of preimplantation biopsies may improve selection of kidneys from old donors after cardiac death. Am J Transplant 2008; 8:1844-1851.

23. Snoeijs MG, Wiermans B, Christiaans MH, et al. Recipient hemodynamics during non-heartbeating donor kidney transplantation are major predictors of primary nonfunction. Am J Transplant 2007; 7:1158-1166.

24. Claas FH, Witvliet MD, Duquesnoy RJ, Persijn GG, Doxiadis, II. The acceptable mismatch program as a fast tool for highly sensitized patients awaiting a cadaveric kidney transplantation: short waiting time and excellent graft outcome. Transplantation 2004; 78:190-193.

25. Vo AA, Lukovsky M, Toyoda $\mathrm{M}$, et al. Rituximab and intravenous immune globulin for desensitization during renal transplantation. N Engl J Med 2008; 359:242-251.

26. Ojo AO, Wolfe RA, Held PJ, Port FK, Schmouder RL. Delayed graft function: risk factors and implications for renal allograft survival. Transplantation 1997; 63:968-974.

27. Brook NR, White SA, Waller JR, Veitch PS, Nicholson ML. Non-heart beating donor kidneys with delayed graft function have superior graft survival compared with conventional heartbeating donor kidneys that develop delayed graft function. Am J Transplant 2003; 3:614-618.

28. Renkens JJ, Rouflart MM, Christiaans MH, van den Berg-Loonen EM, van Hooff JP, van Heurn LW. Outcome of nonheart-beating donor kidneys with prolonged delayed graft function after transplantation. Am J Transplant 2005; 5:2704-2709.

29. McDonald SP, Russ GR. Survival of recipients of cadaveric kidney transplants compared with those receiving dialysis treatment in Australia and New Zealand, 1991-2001. Nephrol Dial Transplant 2002; 17:2212-2219.

30. Rabbat CG, Thorpe KE, Russell JD, Churchill DN. Comparison of mortality risk for dialysis patients and cadaveric first renal transplant recipients in Ontario, Canada. J Am Soc Nephrol 2000; 11:917-922.

31. Oniscu GC, Brown H, Forsythe JL. Impact of cadaveric renal transplantation on survival in patients listed for transplantation. J Am Soc Nephrol 2005; 16:1859-1865.

32. Stevens LA, Coresh J, Greene T, Levey AS. Assessing kidney function--measured and estimated glomerular filtration rate. N Engl J Med 2006; 354:2473-2483. 


\section{Supplementary tables}

Final multivariable regression models for comparison of clinical outcomes between DCD and DBD kidney transplantations.

Table S2.1 Logistic regression model for comparison of primary non-function $(\mathrm{N}=811)^{\mathrm{a}}$

\begin{tabular}{lcc}
\hline & Odds ratio (95\% CI) & $\mathrm{P}$ \\
\hline Donor type (DCD vs. DBD) & $7.51(4.01-14.1)$ & $<0.001$ \\
\hline Kidney (double vs. single) & $130(14.6-1163)$ & $<0.001$ \\
\hline Retransplantation (yes vs. no) & $1.27(0.60-2.72)$ & 0.53 \\
\hline Year of transplantation (/year) & $1.04(0.98-1.11)$ & 0.22 \\
Donor age (/year) & $1.03(1.00-1.05)$ & 0.02 \\
Recipient age (/year) & $1.02(0.99-1.04)$ & 0.21 \\
Cold ischemia time (/hour) & $1.05(1.01-1.09)$ & 0.02 \\
Calcineurin inhibitor & & 0.05 \\
$\quad$ Any vs. none & $0.27(0.09-0.45)$ & 0.02 \\
\multicolumn{1}{c}{ Cyclosporine vs. other } & $1.04(0.49-2.22)$ & 0.91 \\
Transplant center (regional vs. export) & $1.56(0.78-3.14)$ & 0.21 \\
Cause of death (cardiovascular vs. other) & $1.82(1.05-3.17)$ & 0.03 \\
Anastomosis time (/min) & $1.02(1.01-1.04)$ & 0.01 \\
\hline Anti-metabolite & & 0.03 \\
\multicolumn{1}{c}{ Any vs. none } & $0.66(0.34-1.29)$ & 0.23 \\
\multicolumn{1}{c}{ Azathioprine vs. other } & $0.23(0.05-0.98)$ & 0.05 \\
Induction therapy (yes vs. no) & $2.29(1.04-5.06)$ & 0.04 \\
\hline
\end{tabular}

a Pre-emptive kidney transplantations were excluded. 50 cases with missing data were not used in this analysis. 
Table S2.2 Cox regression model for comparison of death-censored graft loss of all transplanted kidneys $(\mathrm{N}=851)^{\mathrm{a}}$

\begin{tabular}{lcc}
\hline & Hazard ratio (95\% CI) & P \\
\hline Donor type (DCD vs. DBD) & $1.82(1.37-2.42)$ & $<0.001$ \\
\hline Kidney (double vs. single) & $4.06(1.50-11.0)$ & 0.006 \\
Retransplantation (yes vs. no) & $1.17(0.82-1.69)$ & 0.39 \\
\hline Year of transplantation (/year) & $0.98(0.95-1.00)$ & 0.09 \\
Donor age (/year) & $1.01(1.01-1.02)$ & 0.003 \\
Recipient age (/year) & $1.00(0.99-1.01)$ & 0.34 \\
Cold ischemia time (/hour) & $1.03(1.01-1.05)$ & 0.01 \\
\hline \multicolumn{1}{c}{ Cold ischemia time x time } & $1.00(0.99-1.00)$ & 0.02 \\
Calcineurin inhibitor & & 1.00 \\
\multicolumn{1}{c}{ Any vs. none $\quad$} & $1.00(0.58-1.72)$ & 1.00 \\
\hline \multicolumn{1}{c}{ Cyclosporine vs. other } & $0.99(0.68-1.43)$ & 0.94 \\
Transplant center (regional vs. export) & $0.97(0.70-1.36)$ & 0.88 \\
Cause of death (cardiovascular vs. other) & $1.31(1.00-1.71)$ & 0.05 \\
Sirolimus (yes vs. no) & $2.48(1.51-4.06)$ & $<0.001$ \\
HLA mismatches (/count) & $1.23(1.09-1.40)$ & 0.001 \\
\hline \multicolumn{1}{c}{ HLA mismatches x time } & $0.97(0.94-1.00)$ & 0.02 \\
\hline
\end{tabular}

a 40 cases with missing data were not used in this analysis. 
Table S2.3 Cox regression model for comparison of recipient mortality using all transplanted kidneys (N=857)

\begin{tabular}{lcc}
\hline & Hazard ratio (95\% CI) & $\mathrm{P}$ \\
\hline Donor type (DCD vs. DBD) & $1.16(0.87-1.54)$ & 0.32 \\
Kidney (double vs. single) & $0.55(0.13-2.38)$ & 0.42 \\
Retransplantation (yes vs. no) & $1.21(0.82-1.77)$ & 0.33 \\
\hline Year of transplantation (/year) & $0.94(0.91-0.98)$ & 0.001 \\
\hline Donor age (/year) & $1.02(1.01-1.03)$ & 0.006 \\
$\quad$ Donor age x time & $1.00(1.00-1.00)$ & 0.01 \\
\hline Recipient age (/year) & $1.05(1.04-1.06)$ & $<0.001$ \\
Cold ischemia time (/hour) & $1.01(0.99-1.03)$ & 0.44 \\
Calcineurin inhibitor & & 0.09 \\
$\quad$ Any vs. none & $2.06(1.06-3.97)$ & 0.03 \\
\hline \multicolumn{1}{c}{ Cyclosporine vs. other } & $0.77(0.51-1.15)$ & 0.20 \\
Transplant center (regional vs. export) & $0.69(0.48-0.97)$ & 0.03 \\
Recipient sex (male vs. female) & $1.33(1.02-1.73)$ & 0.04 \\
Kidney disease & & 0.001 \\
\hline$\quad$ Known vs. unknown & $0.97(0.64-1.48)$ & 0.90 \\
\hline Renovascular vs. other & $1.86(1.34-2.60)$ & $<0.001$ \\
\hline
\end{tabular}

a 34 cases with missing data were not used in this analysis. 
Table S2.4 Logistic regression model for comparison of delayed graft function $(\mathrm{N}=726)^{\mathrm{a}}$

\begin{tabular}{lcc}
\hline & Odds ratio (95\% CI) & P \\
\hline Donor type (DCD vs. DBD) & $10.3(6.68-15.9)$ & $<0.001$ \\
\hline Kidney (double vs. single) ${ }^{\mathrm{b}}$ & - & - \\
\hline Retransplantation (yes vs. no) & $1.46(0.84-2.53)$ & 0.18 \\
\hline Year of transplantation (/year) & $1.05(1.00-1.11)$ & 0.05 \\
$\quad$ Quadratic term (/year $\left.{ }^{2}\right)$ & $1.01(1.00-1.01)$ & 0.02 \\
\hline Donor age (/year) & $1.01(1.00-1.02)$ & 0.22 \\
Recipient age (/year) & $0.99(0.98-1.01)$ & 0.30 \\
Cold ischemia time (/hour) & $1.01(0.99-1.04)$ & 0.39 \\
Calcineurin inhibitor & & 0.38 \\
\multicolumn{1}{c}{ Any vs. none } & $1.93(0.77-4.85)$ & 0.16 \\
$\quad$ Cyclosporine vs. other & $0.82(0.49-1.38)$ & 0.46 \\
Transplant center (regional vs. export) & $2.02(1.28-3.19)$ & 0.003 \\
Cause of death (cardiovascular vs. other) & $1.67(1.12-2.52)$ & 0.01 \\
\hline Anastomosis time (/min) & $1.02(1.01-1.04)$ & 0.005 \\
\hline Donor sex (male vs. female) & $1.70(1.16-2.49)$ & 0.007 \\
\hline
\end{tabular}

a Pre-emptive kidney transplantations and primary non-function were excluded. 45 cases with missing data were not used in this analysis.

b Odds ratio could not be estimated because no cases of double transplants with DGF were included in the model. 
Table S2.5 Linear regression model for comparison of duration of delayed graft function $(\mathrm{N}=246)^{\mathrm{a}}$

\begin{tabular}{lcc}
\hline & $\begin{array}{c}\text { Mean difference (95\% CI) } \\
\text { (days) }\end{array}$ & $\mathrm{P}$ \\
\hline Donor type (DCD vs. DBD) & $3.20(-0.50,6.89)$ & 0.09 \\
\hline Kidney (double vs. single) ${ }^{\mathrm{b}}$ & - & - \\
\hline Retransplantation (yes vs. no) & $0.69(-4.09,5.46)$ & 0.78 \\
Year of transplantation (/year) & $0.28(-0.10,0.65)$ & 0.14 \\
Donor age (/year) & $0.07(-0.05,0.19)$ & 0.23 \\
Recipient age (/year) & & \\
Cold ischemia time (/hour) & $-0.01(-0.26,0.25)$ & 0.97 \\
Calcineurin inhibitor & & 0.09 \\
$\quad$ Any vs. none & $0.64(-6.68,7.95)$ & 0.86 \\
$\quad$ Tacrolimus vs. other & $-4.29(-8.82,0.24)$ & 0.06 \\
Transplant center (regional vs. export) & $6.30(2.35,10.3)$ & 0.002 \\
Donor sex (male vs. female) & $3.07(-0.49,6.62)$ & 0.09 \\
Sirolimus (yes vs. no) & $9.80(3.25,16.3)$ & 0.004 \\
\hline
\end{tabular}

${ }^{a}$ Pre-emptive kidney transplantations and primary non-function were excluded. 11 cases with missing data were not used in this analysis.

b Mean difference could not be estimated because no cases of double transplants with DGF were included in the model. 
Table S2.6 Linear regression model for comparison of estimated glomerular filtration rate at 1 year after transplantation $(\mathrm{N}=646)^{\mathrm{a}}$

\begin{tabular}{lcc}
\hline & $\begin{array}{c}\text { Mean difference (95\% CI) } \\
\left(\mathrm{mL} / \mathrm{min} / 1.73 \mathrm{~m}^{2}\right)\end{array}$ & $\mathrm{P}$ \\
\hline Donor type (DCD vs. DBD) & $-6.22(-9.41,-3.02)$ & $<0.001$ \\
\hline Kidney (double vs. single) & $-10.4(-30.4,-9.65)$ & 0.31 \\
Retransplantation (yes vs. no) & $3.43(-0.61,7.48)$ & 0.10 \\
Year of transplantation (/year) & $0.22(-0.08,0.53)$ & 0.15 \\
Donor age (/year) & $-0.47(-0.56,-0.37)$ & $<0.001$ \\
Recipient age (/year) & $0.00(-0.11,0.12)$ & 0.94 \\
Cold ischemia time (/hour) & $-0.10(-0.29,0.10)$ & 0.32 \\
Calcineurin inhibitor & $-3.61(-8.90,1.68)$ & 0.001 \\
$\quad$ Any vs. none & $7.38(3.79,11.0)$ & $<0.001$ \\
$\quad$ Tacrolimus vs. other & $-4.40(-7.83,-0.98)$ & 0.01 \\
Transplant center (regional vs. export) & $-2.99(-5.84,-0.15)$ & 0.04 \\
Cause of death (cardiovascular vs. other) & $2.82(0.09,5.55)$ & 0.04 \\
Donor sex (male vs. female) & $-8.01(-14.4,-1.59)$ & 0.01 \\
\hline Sirolimus (yes vs. no) & & \\
\hline a Recipients under 16 years of age were excluded from analysis. 61 cases with missing data were not used in this \\
analysis.
\end{tabular}


Table S2.7 Linear regression model for comparison of decline in estimated glomerular filtration rate $(\mathrm{N}=576)^{\mathrm{a}}$

\begin{tabular}{|c|c|c|}
\hline & $\begin{array}{c}\text { Mean difference }(95 \% \mathrm{CI}) \\
\left(\mathrm{mL} / \mathrm{min} / 1.73 \mathrm{~m}^{2}\right)\end{array}$ & $P$ \\
\hline Donor type (DCD vs. DBD) & $0.11(-1.17,1.38)$ & 0.87 \\
\hline Kidney (double vs. single) & $-1.36(-8.79,6.07)$ & 0.72 \\
\hline Retransplantation (yes vs. no) & $1.46(-0.11,3.03)$ & 0.07 \\
\hline Year of transplantation (/year) & $-0.13(-0.56,-0.01)$ & 0.04 \\
\hline Donor age (/year) & $0.01(-0.02,0.05)$ & 0.51 \\
\hline Recipient age (/year) & $-0.01(-0.06,0.03)$ & 0.65 \\
\hline Cold ischemia time (/hour) & $0.03(-0.05,0.11)$ & 0.43 \\
\hline Calcineurin inhibitor & & 0.002 \\
\hline Any vs. none & $-0.90(-0.90,1.11)$ & 0.38 \\
\hline Tacrolimus vs. other & $2.63(1.18,4.08)$ & $<0.001$ \\
\hline Transplant center (regional vs. export) & $-2.04(-3.38,-0.69)$ & 0.003 \\
\hline Anastomosis time (/min) & $-0.05(-0.09,-0.01)$ & 0.01 \\
\hline Induction therapy (yes vs. no) & $-2.67(-4.32,-1.02)$ & 0.002 \\
\hline Kidney disease & & 0.02 \\
\hline Known vs. unknown & $2.19(0.65,3.74)$ & 0.006 \\
\hline Renovascular vs. other & $-0.02(-1.51,1.55)$ & 0.98 \\
\hline
\end{tabular}

${ }^{a}$ Recipients under 16 years of age were excluded from analysis. 43 cases with missing data were not used in this analysis. 
Table S2.8 Cox regression model for comparison of death-censored graft loss restricted to viable kidneys $(\mathrm{N}=774)^{\mathrm{a}}$

\begin{tabular}{lcc}
\hline & Hazard ratio (95\% CI) & $\mathrm{P}$ \\
\hline Donor type (DCD vs. DBD) & $1.05(0.73-1.51)$ & 0.79 \\
Kidney (double vs. single) & $1.50(0.34-6.61)$ & 0.59 \\
Retransplantation (yes vs. no) & $1.23(0.79-1.91)$ & 0.36 \\
Year of transplantation (/year) & $0.94(0.91-0.98)$ & 0.002 \\
Donor age (/year) & $1.01(1.00-1.02)$ & 0.02 \\
Recipient age (/year) & $0.99(0.97-1.00)$ & 0.02 \\
Cold ischemia time (/hour) & $1.02(1.00-1.05)$ & 0.11 \\
\multicolumn{1}{c}{ Cold ischemia time x time } & $1.00(0.99-1.00)$ & 0.04 \\
Calcineurin inhibitor & & 0.50 \\
\multicolumn{1}{c}{ Any vs. none } & $1.30(0.73-3.19)$ & 0.26 \\
$\quad$ Cyclosporine vs. other & $0.77(0.47-1.27)$ & 0.30 \\
Transplant center (regional vs. export) & $0.86(0.56-1.32)$ & 0.48 \\
Induction therapy (yes vs. no) & $0.59(0.29-1.18)$ & 0.14 \\
Sirolimus (yes vs. no) & $2.36(1.08-5.13)$ & 0.03 \\
HLA mismatches (/count) & $1.14(1.01-1.29)$ & 0.04 \\
\hline
\end{tabular}

a 26 cases with missing data were not used in this analysis. 
Table S2.9 Cox regression model for comparison of recipient mortality restricted to viable kidneys $(\mathrm{N}=775)^{\mathrm{a}}$

\begin{tabular}{lcc}
\hline & Hazard ratio (95\% CI) & P \\
\hline Donor type (DCD vs. DBD) & $1.16(0.84-1.60)$ & 0.36 \\
Kidney (double vs. single) & $0.80(0.18-3.58)$ & 0.77 \\
Retransplantation (yes vs. no) & $1.18(0.77-1.80)$ & 0.45 \\
\hline Year of transplantation (/year) & $0.93(0.90-0.97)$ & $<0.001$ \\
\hline Donor age (/year) & $1.02(1.01-1.04)$ & 0.007 \\
$\quad$ Donor age x time & $1.00(1.00-1.00)$ & 0.02 \\
Recipient age (/year) & $1.05(1.04-1.06)$ & $<0.001$ \\
Cold ischemia time (/hour) & $1.00(0.98-1.02)$ & 0.89 \\
Calcineurin inhibitor & & 0.02 \\
\hline \multicolumn{1}{c}{ Any vs. none } & $2.85(1.38-5.92)$ & 0.005 \\
\hline \multicolumn{1}{c}{ Cyclosporine vs. other } & $0.64(0.41-1.02)$ & 0.06 \\
Transplant center (regional vs. export) & $0.54(0.36-0.81)$ & 0.003 \\
Recipient sex (male vs. female) & $1.27(0.96-1.69)$ & 0.10 \\
Kidney disease & & $<0.001$ \\
$\quad$ Known vs. unknown & $0.87(0.56-1.37)$ & 0.55 \\
$\quad$ Renovascular vs. other & $2.19(1.54-3.12)$ & $<0.001$ \\
\hline
\end{tabular}

a 25 cases with missing data were not used in this analysis. 
Table S2.10 Cox regression model for comparison of death-censored graft loss of viable kidneys with immediate versus delayed graft function $(\mathrm{N}=203)^{\mathrm{a}}$

\begin{tabular}{lcc}
\hline & Hazard ratio (95\% CI) & $\mathrm{P}$ \\
\hline Delayed graft function (yes vs. no) & $1.27(0.65-2.47)$ & 0.49 \\
Kidney (double vs. single) & $16.2(1.27-208)$ & 0.03 \\
Retransplantation (yes vs. no) & $1.33(0.54-3.27)$ & 0.54 \\
Year of transplantation (/year) & $0.90(0.83-0.98)$ & 0.02 \\
Donor age (/year) & $1.02(1.00-1.05)$ & 0.06 \\
Recipient age (/year) & $0.98(0.95-1.00)$ & 0.07 \\
Cold ischemia time (/hour) & $1.02(0.97-1.07)$ & 0.46 \\
Calcineurin inhibitor & & 0.28 \\
\multicolumn{1}{c}{ Any vs. none } & $3.94(0.67-22.7)$ & 0.13 \\
\multicolumn{1}{c}{ Cyclosporine vs. other } & $0.68(0.25-1.80)$ & 0.43 \\
Transplant center (regional vs. export) & $0.66(0.32-1.37)$ & 0.26 \\
Cause of death (cardiovascular vs. other) & $1.54(0.79-3.02)$ & 0.21 \\
Anastomosis time (/min) & $0.97(0.94-1.00)$ & 0.07 \\
\hline
\end{tabular}

a Pre-emptive kidney transplantations and primary non-function were excluded. 23 cases with missing data were not used in this analysis. 
82 | 


\section{Chapter 3}

Survival benefit of

kidney transplantation from

donors after cardiac death 


\begin{abstract}
Background: The continuing shortage of kidneys for transplantation requires major efforts to expand the donor pool. Donation after cardiac death (DCD) increases the number of available kidneys, but it is unknown whether patients who receive a DCD kidney live longer than patients who remain on dialysis and wait for a conventional kidney from a brain dead donor (DBD).

Methods: This observational cohort study included all 2575 patients who were registered on the Dutch waiting list for a first kidney transplant between 01/01/1999 and 31/12/2004.

Findings: From listing until the earliest of death, living donor kidney transplantation or 31/12/2005, 459 patients received a DCD transplant and 680 patients received a DBD transplant. Graft failure in the first 3 months after transplantation was twice as likely for DCD kidneys than DBD kidneys (12\% vs. 6.3\%, $\mathrm{P}=0.001)$.Standard criteria DCD kidney transplantation was associated with a $56 \%$ reduced risk for mortality (hazard ratio $0.44 ; 95 \%$ CI $0.24-0.80$ ) compared with continuing on dialysis and awaiting a standard criteria DBD kidney. This reduction in mortality translates into 2.4 months additional expected lifetime during the first 4 years after transplantation for recipients of DCD kidneys compared with patients who await a DBD kidney.

Interpretation: Standard criteria DCD kidney transplantation is associated with increased survival of patients who have end-stage renal disease and are on the transplant waiting list.
\end{abstract}

\title{
Published as
}

Snoeijs MG, Schaubel DE, Hené R, Hoitsma AJ, Idu MM, Ijzermans JN, Ploeg RJ, Ringers J, Christiaans MH, Buurman WA, van Heurn LWE. Kidneys from donors after cardiac death provide survival benefit. J Am Soc Nephrol, in press. 


\section{Introduction}

Kidney transplantation results in substantial survival benefit for dialysis patients who are on the waiting list in North America, Europe and Australia. ${ }^{1-4}$ This survival benefit extends to subgroups of high-risk recipients at the extremes of age or after failure of a previous kidney transplant ${ }^{5-9}$ and also applies to high-risk donors with old age or medical co-morbidities. ${ }^{10}$

Considering the survival benefit of kidney transplantation, major efforts must be made to increase the supply of deceased donor kidneys and to reduce the waiting times for transplantation. In recent years, transplantation of organs from donors after cardiac death (DCD) has been advocated as a means to expand the donor pool. ${ }^{11}$ In contrast to organ donation after brain death (DBD), the delay between circulatory arrest and organ preservation may cause acute ischemic injury in DCD organs. As a consequence, the incidence of delayed graft function and primary non-function in DCD kidney transplantation is relatively high, although survival of functioning grafts seems to be satisfactory. ${ }^{12-18}$

During the past decade, donation after cardiac death has evolved into routine clinical practice that currently supplies more than $10 \%$ of all deceased donor kidneys in the United States and up to $50 \%$ in the Netherlands. However, it is unknown whether patients who receive a DCD kidney live longer than patients who receive conventional therapy, i.e. continue dialysis treatment with the option of later receiving a DBD kidney. The current study was performed to address this issue.

\section{Materials and methods}

\section{Study design}

The effect of kidney transplantation from different types of deceased donors on the survival of dialysis patients who were on the waiting list was evaluated in an observational cohort study including all patients who were registered on the Dutch waiting list for a first kidney transplantation between 01/01/1999 and 31/12/2004. Individuals who did not receive dialysis therapy while listed as candidates for kidney transplantation were excluded from this analysis. All patients were followed until the earliest of death, living donor kidney transplan- 
tation, transplantation outside the Eurotransplant area, listing for multi-organ transplantation or 31/12/2005. All kidneys were allocated through standard Eurotransplant policies that were identical for DCD and DBD grafts. Patients were informed of the possibility of DCD kidney transplantation at the time of placement on the waiting list.

\section{Data sources and definitions}

Dates of placement on the waiting list and transplantation were provided by Eurotransplant. The Dutch Organ Transplant Registry provided data on donor and recipient characteristics, including the dates of graft failure and death after transplantation. Characteristics of dialysis patients and dates of death during dialysis treatment were obtained from the Renine database which registers all dialysis patients in the Netherlands. Mortality data were checked with the Central Bureau of Genealogy which records all deaths reported to the Dutch authorities. The data sources were accessed from 01/03/2007 to 30/09/2007. Patient data were collected, stored and used in agreement with the code of conduct 'Use of data in health research' from the Dutch federation of biomedical scientific societies; ethics approval was not required. Dialysis time before waitlisting was missing at random in $2.3 \%$ of patients in which cases transplant center-specific means were imputed.

Expanded criteria donor (ECD) status was defined as donation at 60 years or older or between 50 and 60 years with two additional risk factors (last serum creatinine $>1.5 \mathrm{mg} / \mathrm{dl}$, history of hypertension, cardiovascular cause of death); all other donors were considered standard criteria donors (SCD). ${ }^{19}$ Panel reactive antibodies were categorized into three groups $(\leq 5 \%, 6-84 \%, \geq 85 \%)$ according to the Eurotransplant definition of non-immunized, immunized and highly immunized transplant candidates, respectively. Primary kidney disease was classified as renovascular (including hypertensive and diabetic nephropathy) or other reasons because of the difference in life expectancy between these subgroups..$^{20}$ Graft failure was defined as return to dialysis treatment or retransplantation; recipient death with a functioning transplant was not considered as graft failure.

\section{Statistical analysis}

Continuous variables were expressed as mean (standard deviation [SD]) and categorical variables as percentages. Baseline characteristics of DCD and DBD kidney transplantations were compared using independent samples $\mathrm{t}$-tests for continuous variables and Pearson chi-square tests for categorical variables. 


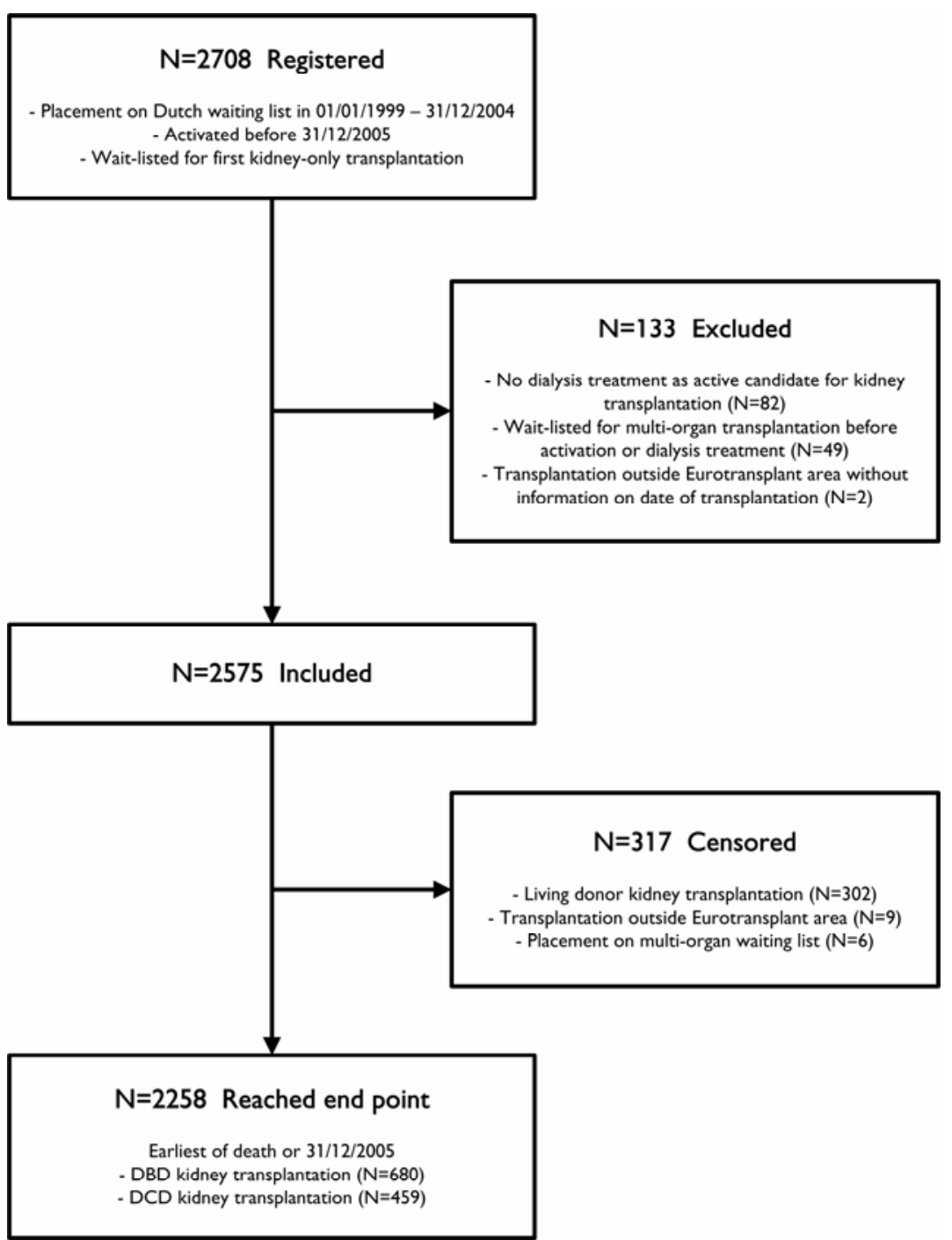

Figure 3.1 Flow chart of patient selection and follow-up in the current observational cohort study.

For each donor type, the covariate-adjusted effect of kidney transplantation on survival was evaluated by sequential stratification, an extension of Cox regression required for appropriately set-up of comparison groups for time-dependent treatments that has been used in several analyses of transplant registries. ${ }^{21-25}$ This method proceeds by first matching each transplant recipient to patients within the same age group $(\leq 19,20-39,40-59, \geq 60$ years $)$ and transplant center who 
were actual transplant candidates (i.e. not deceased, having received a transplant, de-listed or inactivated) at the follow-up time at which the index patient received his or her kidney transplant. The median number of matches per recipient was 46 (interquartile range: 20-91). These matched patients formed the conventional therapy group with which the index transplant recipient was being compared. To evaluate standard criteria DBD kidney transplantation, patients in the conventional therapy group continued to be followed up after de-listing but were censored when receiving any kidney transplant. To evaluate kidney transplantation from non-standard donors, however, follow-up of patients in the comparison group continued after receipt of a standard criteria DBD kidney because this is considered part of conventional therapy.

After sequentially creating matched sets (strata) of conventional therapy patients for each transplant recipient, we combined the matched sets and fitted a stratified Cox regression model. Matching adjusted for patient age, transplant center and time on the waiting list. The analysis was further adjusted for potential confounding by patient gender, kidney disease, dialysis time before placement on the waiting list, calendar year and panel reactive antibodies by including these covariates in the Cox model. Overall hazard ratios (HR) were computed as in standard Cox regression. To account for the repetition of patients across strata, we used a robust (sandwich) variance estimator to calculate standard errors. Interactions between therapy $\mathrm{x}$ patient age and therapy $\mathrm{x}$ kidney disease were evaluated.

It was previously reported that the mortality rate after kidney transplantation decreases progressively over time. ${ }^{1}$ Therefore, we fitted non-proportional hazard models which allowed the treatment effect to differ with time since transplantation. In addition, Nelson-Aalen survival curves were computed for the kidney transplantation and conventional therapy groups (10 randomly selected conventional therapy patients per stratum, excluding the approximately $5 \%$ of strata containing less than 10 matches). These analyses allowed estimation of the time at which mortality rates, survival probabilities and restricted residual mean lifetimes of the kidney transplantation and conventional therapy groups were equal. Furthermore, we estimated the lifetime gained through kidney transplantation within the first 4 years after transplantation.

Sensitivity analyses were done by exclusion of pediatric patients $(<16$ years), by exclusion of recipients of uncontrolled DCD kidneys, by exclusion of patients with missing data on dialysis time before placement on waiting list and by adjusting only for covariates used for stratification (patient age, transplant center and time since placement on the waiting list). $\mathrm{P}<0.05$ was considered 
Table 3.1 Patient characteristics and unadjusted mortality of the study cohort ${ }^{\mathrm{a}}$

\begin{tabular}{|c|c|c|c|}
\hline & $\begin{array}{c}\text { Wait-listed } \\
\text { patients } \\
\mathrm{N}=2575\end{array}$ & $\begin{array}{c}\text { DBD recipients } \\
\qquad \mathrm{N}=680\end{array}$ & $\begin{array}{c}\text { DCD recipients } \\
\qquad \mathrm{N}=459\end{array}$ \\
\hline Age (years) & $49(15)$ & $46(18)$ & $51(13)$ \\
\hline Sex (male / female) & $60 / 40 \%$ & $57 / 43 \%$ & $63 / 37 \%$ \\
\hline Kidney disease (renovascular / other) & $30 / 70 \%$ & $28 / 72 \%$ & $29 / 71 \%$ \\
\hline Panel reactive antibodies $(\leq 5 / 6-84 / \geq 85 \%)$ & $93 / 6 / 1 \%$ & $92 / 7 / 1 \%$ & $94 / 6 / 0 \%$ \\
\hline Dialysis before wait-listing (days) & $516(542)$ & $579(652)$ & $601(575)$ \\
\hline Dialysis type (hemodialysis / peritoneal) & $56 / 44 \%$ & $56 / 44 \%$ & $57 / 44 \%$ \\
\hline Time from listing until transplant (days) & - & $594(499)$ & $713(503)$ \\
\hline Donor age (years) & - & $47(16)$ & $45(16)$ \\
\hline Donor sex (male / female) & - & $46 / 54 \%$ & $55 / 45 \%$ \\
\hline Donor criteria (SCD / ECD) & - & $73 / 27 \%$ & 78 / 22\% \\
\hline DCD type (controlled / uncontrolled) & - & & $88 / 12 \%$ \\
\hline Average follow-up time (days) & $675(514)$ & $845(581)$ & $625(483)$ \\
\hline Total follow-up time (patient years) & 4774 & 1575 & 787 \\
\hline Deaths & 239 & 61 & 27 \\
\hline Unadjusted mortality rate (/patient year) & $5.0 \%$ & $3.9 \%$ & $3.4 \%$ \\
\hline Graft failure within 90 days & - & $6.3 \%$ & $12 \%$ \\
\hline
\end{tabular}

${ }^{a}$ Data are presented as mean (standard deviation) or as percentages.

statistically significant. All statistical computing was carried out by DES using SAS 9.1.3 (SAS Institute, Cary, NC).

\section{Results}

\section{Study population}

During the recruitment phase of the study, 2708 patients were actively listed for a first kidney transplantation (Figure 3.1). Of these patients, 133 were excluded because they did not receive dialysis therapy while actively listed for kidney transplantation or because they received a transplant outside Eurotransplant with an unknown transplantation date. Characteristics of the 2575 patients included in the study are described in Table 3.1. Of these patients, 680 underwent DBD kidney transplantation while 459 patients received a DCD transplant within the study period. Dialysis patients who were on the waiting list contributed a mean 
of $675 \pm 514$ days of follow-up, accumulating to a total follow-up time of 4774 patient years. Recipients of DBD and DCD kidneys were followed for $845 \pm 581$ and $625 \pm 483$ days, respectively, accumulating to total follow-up times of 1575 and 787 patient years. Unadjusted mortality rates were $5.0 \%$ per patient year in the dialysis patients who were on the waiting list and 3.9 and $3.4 \%$ per patient year for recipients of DBD and DCD kidneys, respectively.

Overall, $25 \%$ of the transplanted kidneys were recovered from expanded criteria donors. Among the DCD kidneys, $88 \%$ had been recovered after controlled withdrawal of treatment in the intensive care unit, whereas $12 \%$ were procured in an uncontrolled fashion after failed cardiopulmonary resuscitation. DCD donors were on average 1.9 years younger $(\mathrm{P}=0.05)$ and significantly more likely to be male ( 55 vs. $46 \%, \mathrm{P}=0.01$ ) than DBD donors. Recipients of DCD kidneys were on average 4.8 years older $(\mathrm{P}<0.001)$ and significantly more likely to be male (63 vs. $57 \%, \mathrm{P}=0.04$ ) than recipients of DBD kidneys. Mean waiting time for DCD kidneys was 141 days longer than for DBD kidneys $(\mathrm{P}<0.001)$. DCD and DBD kidney transplantations were not significantly different with respect to other baseline characteristics. DCD kidneys failed significantly more often than DBD kidneys in the first 3 months after transplantation ( $12 \%$ vs. $6.3 \%, \mathrm{P}=0.001$ ). Early graft failure occurred in 22\% of DCD-ECD and in 20\% of uncontrolled DCD kidney transplantations.

Effect of kidney transplantation on survival of dialysis patients on the waiting list Overall mortality rates of patients who received DBD and DCD kidneys were

Table 3.2 Reduced mortality rate after kidney transplantation compared to conventional therapy

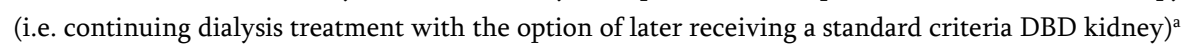

\begin{tabular}{lccc}
\hline & $\begin{array}{c}\text { Overall hazard } \\
\text { ratio }\end{array}$ & $\begin{array}{c}95 \% \text { confidence } \\
\text { interval }\end{array}$ & P \\
\hline $\begin{array}{l}\text { DBD-SCD kidney transplantation vs. } \\
\text { dialysis treatment }\end{array}$ & 0.51 & $0.32-0.81$ & 0.004 \\
\hline $\begin{array}{l}\text { DCD-SCD kidney transplantation vs. } \\
\text { conventional therapy }\end{array}$ & 0.44 & $0.24-0.80$ & 0.007 \\
$\begin{array}{l}\text { DBD-ECD kidney transplantation vs. } \\
\text { conventional therapy }\end{array}$ & 1.12 & $0.71-1.76$ & 0.62 \\
$\begin{array}{l}\text { DCD-ECD kidney transplantation vs. } \\
\text { conventional therapy }\end{array}$ & 0.61 & $0.31-1.19$ & 0.15 \\
\hline
\end{tabular}

${ }^{a}$ Results were adjusted for age, sex, calendar year, dialysis time before wait-listing, wait-listed dialysis time, kidney disease, transplant center and panel reactive antibodies. 
compared to the alternative therapeutic option of dialysis treatment or waiting on dialysis until standard criteria DBD kidney transplantation, respectively (Table 3.2). In line with previous studies, ${ }^{1-4}$ standard criteria DBD kidney transplantation was associated with a $49 \%$ mortality rate reduction compared to dialysis treatment (HR 0.51, 95\% CI: $0.32-0.81, \mathrm{P}=0.004$ ). We subsequently compared the survival benefit of receiving a standard criteria DCD kidney to dialysis treatment with the option of later receiving a standard criteria DBD kidney. The mortality rate after standard criteria DCD kidney transplantation was $56 \%$ lower than with this conventional therapy (HR 0.44, 95\% CI: $0.24-0.80$, $\mathrm{P}=0.007$ ). The effect of $\mathrm{DCD}$ kidney transplantation on mortality rate did not differ with patient age or kidney disease $(\mathrm{P}=0.44$ and $\mathrm{P}=0.83$ for interaction terms, respectively). Mortality rates after DBD-ECD or DCD-ECD kidney transplantation were not significantly different from conventional therapy $(\mathrm{P}=0.62$ and $\mathrm{P}=0.15$, respectively). Sensitivity analyses excluding pediatric patients, excluding recipients of uncontrolled DCD kidneys, excluding patients with missing data or by adjusting only for stratification covariates produced similar results.

Because mortality rates after kidney transplantation may change over time, ${ }^{1}$ statistical models with time-dependent hazard ratios were fitted. In the early post-transplant period, kidney transplant recipients experienced higher mortality rates and lower survival probabilities than patients treated with conventional therapy (Figure 3.2). The mortality rate of transplant recipients gradually decreased, however, which in time led to a survival benefit for patients who received a kidney transplant. The mortality rate and survival probability of standard criteria DCD kidney transplant recipients were equal to patients receiving conventional therapy at 7 and 13 months after transplantation, respectively, after which a survival benefit was observed for transplant recipients (Figure 3.2A, Table 3.3). Within the first 4 years after transplantation, recipients of standard criteria DCD kidneys were expected to live 2.4 months longer than patients who continued dialysis treatment with the option of later receiving a kidney from a standard criteria DBD donor. For comparison, after standard criteria DBD kidney transplantation mortality rates and survival probabilities were equal to those of dialysis treatment at 5 and 9 months after transplantation, respectively, whereupon transplant recipients had the advantage (Figure 3.2B). The estimates for DBD-ECD and DCD-ECD kidney transplantation, which were not associated with overall mortality rate reductions, are presented in Table 3.3. 


\section{DCD kidney transplantation}
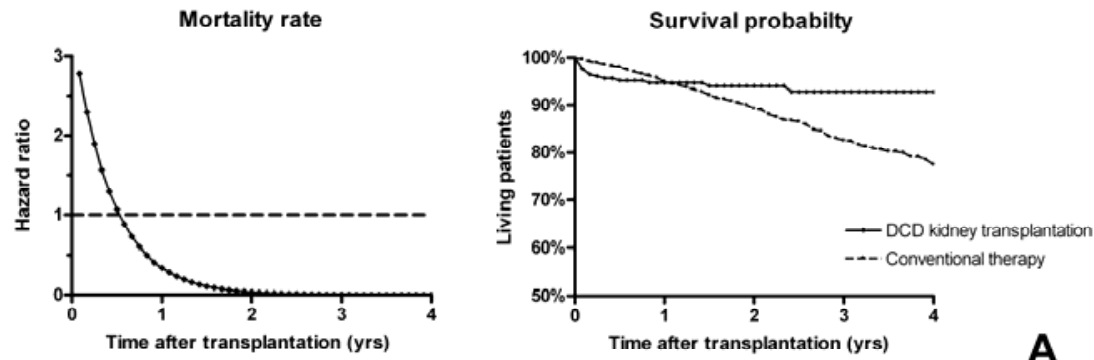

DBD kidney transplantation
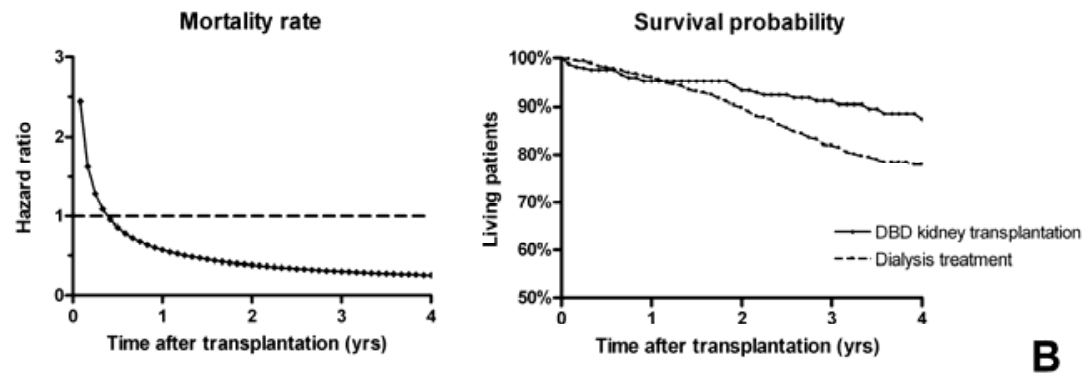

Figure 3.2 (A) Survival benefit of standard criteria DCD kidney transplantation compared to conventional therapy (i.e. continuing dialysis treatment with the option of later receiving a standard criteria DBD kidney), and (B) survival benefit of standard criteria DBD kidney transplantation compared to dialysis treatment. Comparison groups had spent equal times on the waiting list at time 0 .

\section{Discussion}

The continuing shortage of kidneys for transplantation requires major efforts to expand the donor pool. Despite substantial increases in kidney transplantation from living donors and expanded criteria DBD donors over the past decade, the supply of donor kidneys still does not meet demands. ${ }^{26}$ Liberal use of DCD kidneys may lead to considerable expansion of the donor pool, but is associated with a relatively high incidence of delayed graft function and primary nonfunction. ${ }^{12-18,27,28}$ In this study, graft failure in the first three months after trans- 
plantation was twice as likely for DCD kidneys than for DBD kidneys. However, DCD kidneys that overcome the early post-transplantation period function as long as DBD kidneys. ${ }^{12-18}$ Therefore, it is unclear whether dialysis patients who are on the waiting list should accept an offer for DCD kidney transplantation or continue dialysis treatment until a conventional DBD kidney is available.

In this study, we show for the first time that standard criteria DCD kidney transplantation was associated with a survival advantage compared with conventional therapy for patients waiting for a first kidney transplantation. The overall mortality rate was reduced by $56 \%$ after DCD kidney transplantation, which translated into a 2.4 month increase in expected lifetime during the first 4 years after transplantation. The follow-up period of 1 to 5 years from placement on the waiting list is relatively short to address long-term outcomes after transplantation. However, by extrapolating the survival curves, it seems likely that the additional lifetime gained from DCD kidney transplantation will increase with longer follow-up (Figure 3.2A). Our findings indicate that despite the relatively high incidence of delayed graft function and early graft loss, dialysis patients who are on the waitin list will enjoy longer life expectancy after DCD kidney transplantation compared with continuation of dialysis treatment with the option of later receiving a conventional DBD kidney.

The findings of this study should be interpreted within the limitations of observational studies that may be subject to selection bias. Patients who undergo kidney transplantation will inherently be healthier than the general dialysis

Table 3.3 Survival benefit of kidney transplantation compared to conventional therapy (i.e. continuing dialysis treatment with the option of later receiving a standard criteria DBD kidney) ${ }^{\mathrm{a}}$

\begin{tabular}{|c|c|c|c|c|}
\hline & $\begin{array}{l}\text { Time to equal } \\
\text { mortality rate }\end{array}$ & $\begin{array}{l}\text { Time to equal } \\
\text { survival }\end{array}$ & $\begin{array}{l}\text { Time to equal } \\
\text { lifetime }\end{array}$ & $\begin{array}{l}\text { Additional } \\
\text { lifetime }^{\mathrm{b}}\end{array}$ \\
\hline $\begin{array}{l}\text { DBD-SCD kidney transplantation vs. } \\
\text { dialysis treatment }\end{array}$ & $5 \mathrm{mts}$ & $9 \mathrm{mts}$ & $21 \mathrm{mts}$ & $+2.1 \mathrm{mts}$ \\
\hline $\begin{array}{l}\text { DCD-SCD kidney transplantation vs. } \\
\text { conventional therapy }\end{array}$ & $7 \mathrm{mts}$ & $13 \mathrm{mts}$ & $24 \mathrm{mts}$ & $+2.4 \mathrm{mts}$ \\
\hline $\begin{array}{l}\text { DBD-ECD kidney transplantation vs. } \\
\text { conventional therapy }\end{array}$ & $20 \mathrm{mts}$ & $43 \mathrm{mts}$ & Not observed & $-1.5 \mathrm{mts}$ \\
\hline $\begin{array}{l}\text { DCD-ECD kidney transplantation vs. } \\
\text { conventional therapy }\end{array}$ & $5 \mathrm{mts}$ & $14 \mathrm{mts}$ & $22 \mathrm{mts}$ & $+1.5 \mathrm{mts}$ \\
\hline
\end{tabular}

a Results were adjusted for age, transplant center and wait-listed dialysis time. Statistical analysis did not allow estimation of confidence intervals.

b Additional lifetime within the first 4 years after kidney transplantation. 
population because of selection at the time of waiting list registration and acceptance of an allocated organ. We used sequential stratification analysis, a refinement of Cox regression, to avoid comparison of transplant recipients with dialysis patients who had become medically unfit for transplantation. This statistical technique sequentially compares each transplant recipient with control subjects who were actual transplant candidates at that time while maintaining intentionto-treat analysis, which is not possible with standard Cox regression..$^{21,22}$ In addition, the survival benefit after DCD kidney transplantation was relatively large and remained stable when adjusted for several patient characteristics. Relative mortality rates were not affected by patient age or kidney disease and were insensitive to exclusion of potentially confounding cases. Taken together, we consider it unlikely that the effect of DCD kidney transplantation on survival has been overestimated as a result of patient selection bias.

The survival benefit of kidney transplantation over dialysis treatment was previously demonstrated in various geographical areas with different health care systems..$^{1-4}$ Our study confirms these results and adds contemporary information from a large European cohort of dialysis patients who were on the waiting list. The relative mortality rate reduction of $55 \%$ in our cohort at 18 months after standard criteria DBD kidney transplantation seems lower than previously reported $\left(68-82 \%\right.$ at 12 to 18 months after transplantation). ${ }^{1-4}$ This difference may be the result of the more rigorous sequential stratification analysis used in this study, because analysis of our data using time-dependent Cox regression produced a relative mortality rate reduction of $65 \%$ at 18 months after standard criteria DBD kidney transplantation. Furthermore, the survival benefit of kidney transplantation in the United States extends to kidneys recovered from ECD donors. ${ }^{10}$ We could not confirm these findings and instead report similar survival for dialysis patients and recipients of ECD kidneys from either DBD or DCD donors, which may be due to the relatively high mortality of patients receiving dialysis treatment in the United States. ${ }^{29}$ Despite the lack of survival benefit, ECD kidney transplantation can still be advantageous by improving quality of life and by reducing the mean waiting time to transplantation for dialysis patients.

Our study provides novel insight into the clinical outcome of DCD kidney transplantation. This is a timely subject because the contribution of donation after cardiac death to the pool of donor kidneys is growing exponentially. ${ }^{11}$ Currently, approximately $10 \%$ of deceased donor kidneys in the United States are being recovered from DCD donors and this proportion is expected to increase further. ${ }^{26}$ In the Netherlands, almost 50\% of deceased donor kidneys have been procured from DCD donors since the introduction of a nationwide protocol. ${ }^{30}$ 
This large proportion of DCD donors allowed accurate analysis of the survival benefit from liberal use of DCD kidneys for transplantation. The generalizability of our results may depend on the specific donor and recipient characteristics of other health care systems. DCD kidneys were mostly procured after controlled withdrawal of supportive treatment in the intensive care unit. Only a small proportion (12\%) of DCD kidneys were procured in an uncontrolled manner after failed cardiopulmonary resuscitation. Because organs from uncontrolled DCD donors generally sustain more extensive warm ischemic injury, it would be of interest to examine these kidney transplantations separately in future studies.

In conclusion, patients who receive a standard criteria DCD kidney live longer than patients who continue dialysis treatment with the option of later receiving a conventional DBD kidney transplantation. More widespread implementation of donation after cardiac death may further increase the life expectancy of patients with end-stage renal disease by reducing the waiting times for transplantation. 


\section{References}

1. Wolfe RA, Ashby VB, Milford EL, et al. Comparison of mortality in all patients on dialysis, patients on dialysis awaiting transplantation, and recipients of a first cadaveric transplant. $\mathrm{N}$ Engl J Med 1999; 341:1725-1730.

2. McDonald SP, Russ GR. Survival of recipients of cadaveric kidney transplants compared with those receiving dialysis treatment in Australia and New Zealand, 1991-2001. Nephrol Dial Transplant 2002; 17:2212-2219.

3. Rabbat CG, Thorpe KE, Russell JD, Churchill DN. Comparison of mortality risk for dialysis patients and cadaveric first renal transplant recipients in Ontario, Canada. J Am Soc Nephrol 2000; 11:917-922.

4. Oniscu GC, Brown H, Forsythe JL. Impact of cadaveric renal transplantation on survival in patients listed for transplantation. J Am Soc Nephrol 2005; 16:1859-1865.

5. Rao PS, Merion RM, Ashby VB, Port FK, Wolfe RA, Kayler LK. Renal Transplantation in Elderly Patients Older Than 70 Years of Age: Results From the Scientific Registry of Transplant Recipients. Transplantation 2007; 83:1069-1074.

6. Pereira BJ, Natov SN, Bouthot BA, et al. Effects of hepatitis C infection and renal transplantation on survival in end-stage renal disease. The New England Organ Bank Hepatitis C Study Group. Kidney Int 1998; 53:1374-1381.

7. Glanton CW, Kao TC, Cruess D, Agodoa LY, Abbott KC. Impact of renal transplantation on survival in end-stage renal disease patients with elevated body mass index. Kidney Int 2003; 63:647-653.

8. Ojo A, Wolfe RA, Agodoa LY, et al. Prognosis after primary renal transplant failure and the beneficial effects of repeat transplantation: multivariate analyses from the United States Renal Data System. Transplantation 1998; 66:1651-1659.

9. Gillen DL, Stehman-Breen CO, Smith JM, et al. Survival advantage of pediatric recipients of a first kidney transplant among children awaiting kidney transplantation. Am J Transplant 2008; 8:2600-2606.

10. Merion RM, Ashby VB, Wolfe RA, et al. Deceased-donor characteristics and the survival benefit of kidney transplantation. Jama 2005; 294:2726-2733.

11. Steinbrook R. Organ donation after cardiac death. N Engl J Med 2007; 357:209-213.

12. Wijnen RM, Booster MH, Stubenitsky BM, de Boer J, Heineman E, Kootstra G. Outcome of transplantation of non-heart-beating donor kidneys. Lancet 1995; 345:1067-1070.

13. Sanchez-Fructuoso AI, Marques M, Prats D, et al. Victims of cardiac arrest occurring outside the hospital: a source of transplantable kidneys. Ann Intern Med 2006; 145:157-164.

14. Weber M, Dindo D, Demartines N, Ambuhl PM, Clavien PA. Kidney transplantation from donors without a heartbeat. N Engl J Med 2002; 347:248-255.

15. Cho YW, Terasaki PI, Cecka JM, Gjertson DW. Transplantation of kidneys from donors whose hearts have stopped beating. N Engl J Med 1998; 338:221-225.

16. Cooper JT, Chin LT, Krieger NR, et al. Donation after cardiac death: the university of wisconsin experience with renal transplantation. Am J Transplant 2004; 4:1490-1494.

17. Gok MA, Buckley PE, Shenton BK, et al. Long-term renal function in kidneys from non-heartbeating donors: A single-center experience. Transplantation 2002; 74:664-669. 
18. Barlow AD, Metcalfe MS, Johari Y, Elwell R, Veitch PS, Nicholson ML. Case-matched comparison of long-term results of non-heart beating and heart-beating donor renal transplants. $\mathrm{Br}$ J Surg 2009; 96:685-691.

19. Port FK, Bragg-Gresham JL, Metzger RA, et al. Donor characteristics associated with reduced graft survival: an approach to expanding the pool of kidney donors. Transplantation 2002; 74:1281-1286.

20. Liem YS, Wong JB, Hunink MG, de Charro FT, Winkelmayer WC. Comparison of hemodialysis and peritoneal dialysis survival in The Netherlands. Kidney Int 2007; 71:153-158.

21. Schaubel DE, Wolfe RA, Port FK. A sequential stratification method for estimating the effect of a time-dependent experimental treatment in observational studies. Biometrics 2006; 62:910917.

22. Schaubel DE, Wolfe RA, Sima CS, Merion RM. Estimating the effect of a time-dependent treatment by levels of an internal time-dependent covariate. J Am Stat Assoc 2009; 104:49-59.

23. Miles CD, Schaubel DE, Jia X, Ojo AO, Port FK, Rao PS. Mortality experience in recipients undergoing repeat transplantation with expanded criteria donor and non-ECD deceased-donor kidneys. Am J Transplant 2007; 7:1140-1147.

24. Schaubel DE, Sima CS, Goodrich NP, Feng S, Merion RM. The survival benefit of deceased donor liver transplantation as a function of candidate disease severity and donor quality. Am J Transplant 2008; 8:419-425.

25. Berg CL, Gillespie BW, Merion RM, et al. Improvement in survival associated with adult-toadult living donor liver transplantation. Gastroenterology 2007; 133:1806-1813.

26. Port FK, Merion RM, Roys EC, Wolfe RA. Trends in organ donation and transplantation in the United States, 1997-2006. Am J Transplant 2008; 8:911-921.

27. Daemen JW, Oomen AP, Kelders WP, Kootstra G. The potential pool of non-heart-beating kidney donors. Clin Transplant 1997; 11:149-154.

28. Terasaki PI, Cho YW, Cecka JM. Strategy for eliminating the kidney shortage. Clin Transpl 1997:265-267.

29. Foley RN, Hakim RM. Why is the mortality of dialysis patients in the United States much higher than the rest of the world? J Am Soc Nephrol 2009; 20:1432-1435.

30. Keizer KM, de Fijter JW, Haase-Kromwijk BJ, Weimar W. Non-heart-beating donor kidneys in the Netherlands: allocation and outcome of transplantation. Transplantation 2005; 79:11951199 . 
98 


\section{Chapter 4}

In situ preservation of kidneys from donors after cardiac death: results and complications 


\begin{abstract}
Background: Donors after cardiac death (DCD) are increasingly being utilized to expand the pool of donor kidneys. In situ preservation (ISP) reduces warm ischemic injury which is associated with DCD donation. This study describes the results and complications of ISP of DCD kidneys.

Methods: Insertion of a double-balloon triple-lumen (DBTL) catheter allows selective perfusion of the abdominal aorta to preserve the kidneys in situ. From January 2001 until August 2005, 133 ISP procedures were initiated in our procurement area.

Findings: Fifty-six (42\%) ISP procedures led to transplantation; in the remaining 77 cases (58\%), the donation procedure was abandoned or both kidneys were discarded due to ISP complications ( $n=31)$, poor graft quality $(n=23)$, no consent for donation $(n=13)$, medical contra-indications $(n=8)$, or unknown cause $(n=2)$. Increasing donor age (odds ratio $(\mathrm{OR}) 1.06$ per year, $\mathrm{P}<0.001)$ and uncontrolled DCD donation (OR 5.4, $\mathrm{P}<0.001)$ were independently correlated with ISP complications. After transplantation, prolonged DBTL catheter insertion time was an independent predictor of graft failure (OR 2.0, $\mathrm{P}=0.05)$. Selected controlled DCD donors were managed by rapid laparotomy and direct aortic cannulation; graft survival of these kidneys was superior to kidneys from controlled DCD donors managed by ISP.

Interpretation: A minority of initiated ISP procedures led to transplantation, resulting in a high workload compared to donation after brain death. The association between increasing catheter insertion time and inferior graft outcome emphasizes the need for fast and effective surgery. Therefore, rapid laparotomy with direct aortic cannulation is preferred over ISP in controlled DCD donation. Despite these limitations, we have expanded our donor pool three- to fourfold by procuring DCD kidneys that were preserved in situ.
\end{abstract}

\title{
Published as
}

Snoeijs MG, Dekkers AJ, Buurman WA, van den Akker L, Welten RJ, Schurink GW, van Heurn LW. In Situ Preservation of Kidneys From Donors After Cardiac Death: Results and Complications. Ann Surg 2007; 246:844-852. 


\section{Introduction}

Kidney transplantation is the treatment of choice for patients with end-stage renal disease, resulting in long-term survival benefit and sustained improvement in quality of life compared to dialysis. ${ }^{1,2}$ However, many patients with end-stage renal disease do not receive optimal care due to the shortage of organ donors. Therefore, donor criteria have gradually been expanded to include patients older than 60 years and patients older than 50 years with additional risk factors. ${ }^{3}$ Although clinical outcomes of such expanded criteria donor kidneys are less favorable than those of ideal brain-dead or living donor kidneys, transplantation of these kidneys increases survival of wait-listed patients. ${ }^{4}$ Furthermore, transplantation of expanded criteria donor kidneys is cost-effective when compared to hemodialysis. $^{5}$

Next to expanding the criteria for donation after brain death (DBD), the donor pool can be increased by including patients who die after cardiac arrest, either after failed resuscitation in the emergency room or after controlled withdrawal of ventilatory support in the intensive care unit. ${ }^{6}$ Donation after cardiac death (DCD; also referred to as non-heart-beating donation) holds the potential to increase the donor pool 2.5 to $4-\mathrm{fold}^{7}{ }^{7}$ which stabilizes or even reduces the waiting list for kidney transplantation. ${ }^{8}$ Despite a higher incidence of delayed graft function in DCD kidneys compared to DBD kidneys, long-term graft and recipient survival are similar. ${ }^{9-15}$ Therefore, DCD donors are increasingly being utilized in many countries. ${ }^{16}$

DCD organs are inevitably subjected to a period of warm ischemia. Prolonged warm ischemia time is associated with reduced graft survival. ${ }^{17,18}$ Therefore, DCD organs have to be flushed and cooled as fast as possible to minimize warm ischemia time. In uncontrolled donors, a rush to the operating room generally is not feasible since legal, logistical and medical requirements must be met before procurement. In controlled donors, these issues are preferably arranged before cardiac arrest, which enables withdrawal of treatment in a controlled environment with more rapid cannulation and preservation, reducing warm ischemia time. Therefore, different techniques have been developed to preserve the organs inside the body of the donor in order to "buy time" for organ procurement. ${ }^{19-25}$

Kidneys can be preserved in situ using a double-balloon triple-lumen (DBTL) catheter introduced via the femoral artery into the aorta. ${ }^{19}$ After inflation 
of both balloons, the abdominal aorta including the renal arteries can be selectively perfused, flushing and cooling the kidneys. This technique is minimally invasive, can be performed in the emergency room and in the intensive care unit, and should allow fast and effective use by surgeons with limited experience in donation procedures. Using DBTL catheters for in situ preservation (ISP) of DCD kidneys, our institution as well as various other transplant centers have reported acceptable clinical outcomes of grafts that would otherwise not have been suitable for transplantation. ${ }^{26-29}$

Although insertion of the DBTL catheter seems a relatively simple surgical procedure that can be performed by every trained surgeon, the results and complications of this technique have never been described. In this report, we present data on the clinical results and efficacy of ISP of DCD kidneys. We show that ISP complications occur frequently, especially with increasing donor age and in uncontrolled donation procedures, and that prolonged catheter insertion time is associated with poor transplant outcome.

\section{Materials and methods}

\section{Donors}

DCD donors can be categorized into four types, as discussed at the first international meeting on non-heart-beating donation in Maastricht in 1995. ${ }^{30}$ These categories are defined as: (1) patients who are found dead and are brought to the hospital for organ donation; (2) patients who die after failed resuscitation, mostly in the emergency room; (3) patients who do not meet brain death criteria and die after controlled withdrawal of supportive treatment, mostly in the intensive care unit; and (4) patients who experience cardiac arrest after brain death has been diagnosed. Except for category 3 donors, DCD donations are uncontrolled procedures.

Our DCD program includes category 2, 3 and 4 donors in the university hospital as well as in the district hospitals of the Maastricht organ procurement area (population: 0.9 million). All donation procedures within our organ procurement area from January 2001 until August 2005 were included in the current study. Excluded from analysis of ISP complications were selected category 3 donors that were rushed to the operating room for procurement of the liver as well as the kidneys. In these cases $(\mathrm{N}=7)$, rapid laparotomy followed by direct aortic cannulation was performed instead of ISP by a DBTL catheter. 

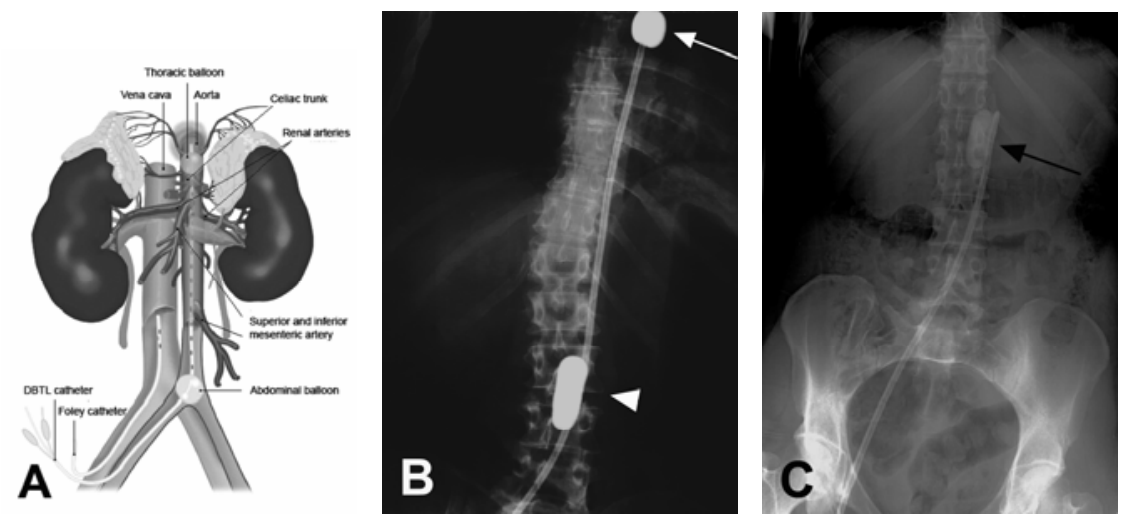

Figure 4.1 In situ preservation technique. (A) After introduction of the double-balloon triplelumen catheter via the femoral artery, the abdominal aorta including the renal arteries can be selectively perfused, flushing and cooling the kidneys (adapted from Kootstra and Van Hooff, Ned Tijdschr Geneeskd, 1998). ${ }^{31}$ (B) Correct position of DBTL catheter visualized by an X-ray from the heart to the umbilicus. The abdominal balloon (arrowhead) is located at the level of the aortic bifurcation and the thoracic balloon (arrow) above the level of the diaphragm. (C) Malposition of DBTL catheter. The abdominal balloon was not sufficiently inflated and pulled back into the iliac artery. The thoracic balloon (arrow) lies at the level of the renal arteries, obstructing flush-out of the kidneys.

\section{In situ preservation technique}

After declaration of patient death by an independent physician who is not taking part in the donation procedure, donor kidneys can be preserved in situ by a double-balloon triple-lumen catheter (AJ6516, Porgès, Le Plessis Robinson Cedex, France) designed to block the aorta at the diaphragm level and at the bifurcation in order to selectively perfuse the renal arteries (Figure 4.1A). This 16Ch catheter has an intra-balloon distance of $25 \mathrm{~cm}$ and its fully inflated balloons have a diameter of $40 \mathrm{~mm}$; a $12 \mathrm{Ch}$ pediatric DBTL catheter with an intraballoon distance of $15 \mathrm{~cm}$ and a balloon diameter of $30 \mathrm{~mm}$ is also available (61.630.12.080, Meddev, Holm, Germany). HTK solution (Custodiol, Dr. Franz Köhler Chemie, Alsbach, Germany) is used for perfusion since its low viscosity facilitates flush-out at high flow rates.

According to Dutch legislation, in situ preservation is allowed before consent for donation is obtained from the relatives. In case the relatives are not immediately available, this minimally invasive procedure preserves organ viability and empowers families with the opportunity to decide about donation. ${ }^{23} \mathrm{After}$ cardiac arrest, a five minute 'no-touch' period without invasive actions makes 
sure that irreversible brain damage has occurred before in situ preservation is initiated and provides a clear distinction between patient treatment and donor management. In situ preservation is performed in the emergency room for category 2 DCD donors and in the intensive care unit for category 3 DCD donors.

After the no-touch period, a longitudinal incision of $10-15 \mathrm{~cm}$ is made in one of the groins. The femoral vein and artery are identified and both vessels are looped. Venous branches are not ligated in order to save time. After femoral arteriotomy, the DBTL catheter is introduced until the STOP sign is inside the artery. The abdominal balloon is inflated with $7 \mathrm{~mL}$ of diluted contrast medium and the catheter is retracted until the balloon hooks onto the aortic bifurcation. Subsequently, $150 \mathrm{~mL}$ blood is drawn for chemistry, virological screening and blood group typing and both the abdominal and the thoracic balloon are fully inflated $(12 \mathrm{~mL})$. If logistics allow, a bolus of streptokinase is administered through the DBTL catheter. ${ }^{32}$ A gravity-driven infusion system is then connected to the DBTL catheter and in situ preservation is initiated. Maximal perfusate flow with the infusion system placed $150 \mathrm{~cm}$ above the donor is maintained until donor nephrectomy. When in situ perfusion has been initiated, a 22Ch Foley catheter is introduced into the femoral vein to allow outflow of the perfusate. The Foley catheter balloon should not be inflated as this may obstruct outflow. The correct position of the DBTL catheter can then be confirmed by an X-ray from the heart to the umbilicus (Figure 4.1B); the surgeon maintains sterility to adjust the position of the catheter if necessary. Finally, the catheters are fixed, the skin incision is closed and the relatives can be offered the opportunity to visit the deceased patient.

\section{Kidney transplantations}

After in situ preservation has been successfully initiated, donor nephrectomy is performed as soon as possible. The kidneys are carefully inspected by the transplant surgeon and biopsies are taken for histological assessment of graft quality. DCD kidneys were preserved by hypothermic machine pulsatile perfusion on a Gambro PF-3B machine using UW-MPS (Belzer MPS, Trans-Med Corporation, Elk River, MN). ${ }^{33}$ The kidneys were allocated through the Eurotransplant Kidney Allocation System. ${ }^{34}$

Recipients of kidneys that were transplanted in The Netherlands were followed up for graft function. Primary non-function (PNF) was defined as a kidney transplant that never resulted in discontinuation of dialysis treatment. Glomerular filtration rate at 1 year post-transplant was estimated by the abbreviated MDRD formula. ${ }^{35}$ In addition, date and cause of graft failure and recipient 
death were recorded. No recipients were lost to follow-up; median follow-up was 2.2 years (range $0.03-5.2$ years). Data on recipients of DBD kidneys were kindly provided by the Dutch Organ Transplant Registry.

\section{Statistics}

For continuous variables, differences between groups were compared using the unpaired Student's t-test or the Mann-Whitney U-test, depending on the distribution of the data set. For categorical variables, differences between groups were compared using the $\chi^{2}$ test. Recipient and graft survival curves were constructed by the Kaplan-Meier method and compared using the log-rank test. Graft survival was censored for recipient death with a functioning graft. Risk factors for in situ preservation complications and graft failure were identified by univariate and multivariate (backward stepwise with exclusion at $\mathrm{P}>0.10$ ) logistic regression and Cox regression, respectively. All statistical analyses were performed using SPSS 12.0.1 for Windows software (SPSS Inc., Chicago, IL). P $<0.05$ was considered evidence of statistical significance.

\section{Results}

\section{In situ preservation procedures}

From January 2001 until August 2005, 133 in situ preservation procedures were initiated in the Maastricht donor region. These procedures involved 73 category 2 DCD donors (55\%), 57 category 3 DCD donors (43\%), 1 category 4 DCD donor (1\%), and 2 DCD donors of unknown category (2\%). 79 ISP procedures were performed in the university hospital (59\%), whereas 54 procedures took place in one of the district hospitals (41\%).

Out of 133 potential donations in which ISP was initiated, 56 (42\%) led to transplantation of at least one organ. In the remaining 77 cases $(58 \%)$, the donation procedure was abandoned or both kidneys were discarded. The proportion of these failed procedures was higher for category 2 DCD donors than for category 3 DCD donors ( $67 \%$ vs. $33 \%, \mathrm{P}<0.001)$. Causes of unsuccessful procedures are presented in Figure 4.2. In 13 uncontrolled procedures (17\%), ISP was initiated but either the relatives or the legal authorities (in case of non-natural death) did not consent to organ donation. In 8 cases (10\%), further donor evaluation demonstrated a medical contra-indication for organ donation (positive viral 


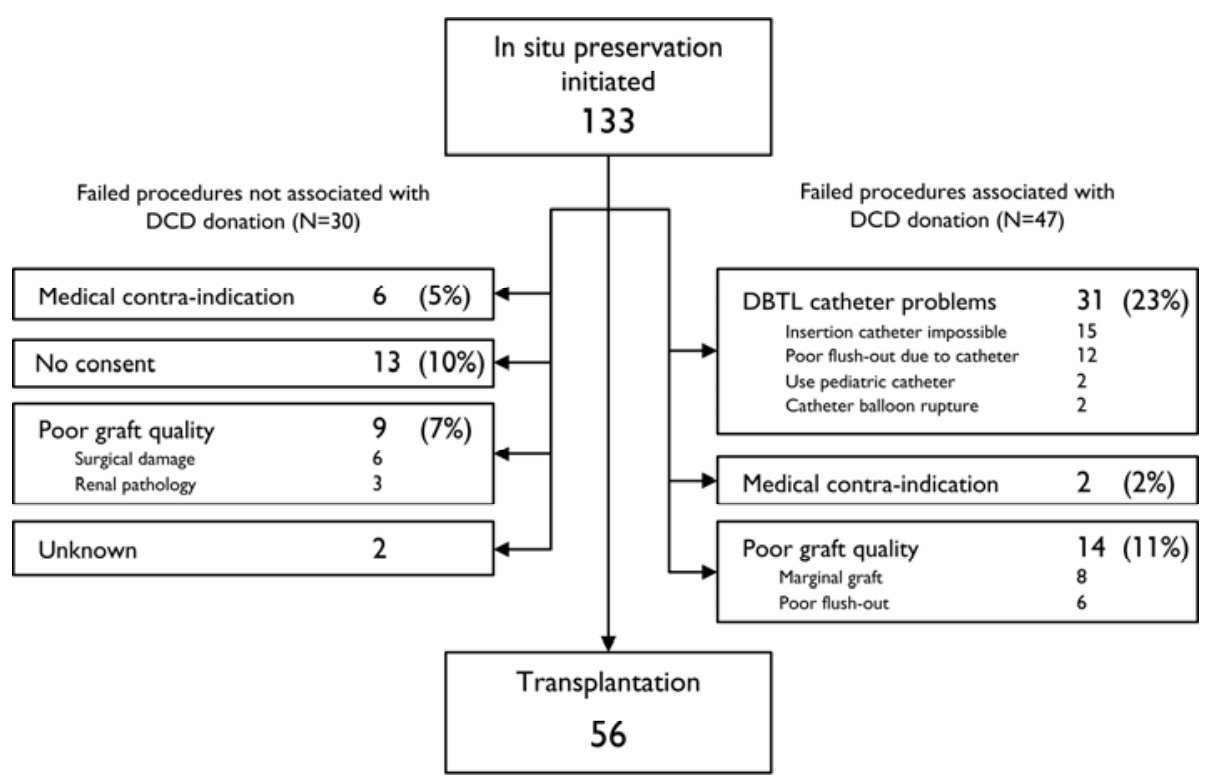

Figure 4.2 Results of in situ preservation procedures. The figure summarizes the results of 133 ISP procedures from January 2001 until August 2005.

serology, malignancy, and prolonged warm ischemia time all in two cases, and drug abuse and active infection both in one case).

The main cause of unsuccessful donation procedures were technical complications, occurring in 31 cases (23\% of potential donors). In 15 of these cases, insertion of the DBTL catheter through the femoral artery was not possible. Twice, a pediatric DBTL catheter was accidentally inserted into an adult donor, which led us to remove these catheters from our DCD kits. In 12 cases, wrong position of the DBTL catheter resulted in poor flush-out of the kidneys. Malposition of the DBTL catheter was mostly due to retraction of the abdominal balloon onto the iliac bifurcation, leading to obstruction of the renal arteries by the thoracic balloon (Figure 4.1C). In the remaining 2 cases, the abdominal balloon ruptured resulting in poor flush-out of the kidneys.

In 23 cases (17\% of potential donors), both kidneys were discarded because of poor graft quality. In 6 of these cases, kidneys were discarded at procurement because of poor flush-out, even though correct positioning of the DBTL catheter was verified during nephrectomy. Another 5 pairs of kidneys were procured in one of the district hospitals and transported to the university hospital for machine pulsatile perfusion; careful inspection at that time demonstrated surgical injury sustained at procurement, mostly stripping of the ureteral 
vasculature, leading us to discard these kidneys. In one case, technical failure during machine preservation resulted in graft injury. Three pairs of kidneys were discarded due to renal pathology (renal tumor, severe atherosclerosis, and degenerative renal changes). Finally, 8 pairs of marginal grafts with poor perfusion characteristics and/or prolonged warm ischemia times were not accepted for transplantation in the Eurotransplant region. Taken together, a minority of initiated ISP procedures led to transplantation resulting in a relatively high workload. Since the main cause of unsuccessful DCD procedures were technical complications we decided to further study these complications.

\section{Risk factors for technical complications}

As technical complications of the in situ preservation procedure were frequently encountered, we analyzed which donor characteristics were risk factors for unsuccessful ISP (Table 4.1). As previously shown, technical complications directly led to discard of donor kidneys in 31 cases. Another 4 donation procedures in which complications were experienced were prematurely abandoned due to family refusal and donor history of malignancy. Only once, DBTL catheter

Table 4.1 Logistic regression analysis of risk factors for in situ preservation complications

\begin{tabular}{|c|c|c|c|c|c|}
\hline & \multirow[b]{2}{*}{ Demographics $^{\mathrm{a}}$} & \multicolumn{2}{|c|}{ Univariable analysis } & \multicolumn{2}{|c|}{ Multivariable analysis } \\
\hline & & $\begin{array}{c}\text { Odds ratio } \\
(95 \% \mathrm{CI})\end{array}$ & $\mathrm{P}$ & $\begin{array}{c}\text { Odds ratio } \\
(95 \% \mathrm{CI})\end{array}$ & $\mathrm{P}$ \\
\hline Donor age (years) & $51 \pm 15$ & $1.06(1.02-1.09)$ & 0.001 & $1.07(1.03-1.11)$ & 0.001 \\
\hline Donor sex (female) & $39 \%$ & & 0.98 & & \\
\hline Donor type (uncontrolled) & $56 \%$ & $4.1(1.6-10.3)$ & 0.003 & $5.8(2.1-16.3)$ & 0.001 \\
\hline \multicolumn{6}{|l|}{ Cause of death ${ }^{\mathrm{b}}$} \\
\hline Cardiovascular & $48 \%$ & $4.1(1.1-15.2)$ & 0.04 & & 0.71 \\
\hline Cerebral & $35 \%$ & $1.3(0.31-5.5)$ & 0.72 & & 0.93 \\
\hline Other & $17 \%$ & 1 & - & & - \\
\hline Donor creatinine $(\mu \mathrm{mol} / \mathrm{l})$ & $103 \pm 44$ & & 0.15 & & \\
\hline Resuscitation time (min) & $23 \pm 28$ & $1.02(1.00-1.03)$ & 0.06 & & 0.91 \\
\hline Hospital (district) & $40 \%$ & & 0.76 & & \\
\hline \multicolumn{6}{|l|}{ Surgical experience ${ }^{b}$} \\
\hline No staff surgeon present & $23 \%$ & & 0.29 & & \\
\hline Staff surgeon operating & $65 \%$ & & 0.64 & & \\
\hline Staff surgeon assisting & $13 \%$ & & - & & \\
\hline
\end{tabular}

a Demographic data are presented as means \pm standard deviations or as percentage of cases.

${ }^{b}$ Other cause of death and staff surgeon assisting were chosen as reference categories. 
malposition discovered by X-ray was successfully corrected resulting in transplantation of both kidneys. In total, 36 donors with technical complications during ISP were identified.

Donor characteristics associated with ISP complications were entered in a multivariable logistic regression model. Increasing donor age and uncontrolled donation were independent predictors of ISP complications: increasing donor age by one year increased the odds of ISP complications 1.07 times (95\% CI: 1.03$1.11, \mathrm{P}=0.001$ ), and in uncontrolled donation procedures the odds of ISP complications were 5.8 times as high as in controlled donations (95\% CI: $2.1-16.3$, $\mathrm{P}=0.001)$. These results indicate that technical complications with in situ preservation can be expected in older donors, probably due to the increased incidence of atherosclerosis, and in uncontrolled donation procedures, possibly due to logistic difficulties.

\section{Risk factors for graft failure}

From January 2001 until August 2005, 56 in situ preservation procedures in our donor region resulted in transplantation of at least one kidney. 13 single kidneys were discarded because of poor perfusion characteristics in 5 cases, surgical injury to renal capsule or arteries in 4 cases, and multiple cysts, adhesions, lack of a suitable recipient, and unknown reason in one case. In two cases, only one donor kidney was present at procurement due to renal agenesis and prior living

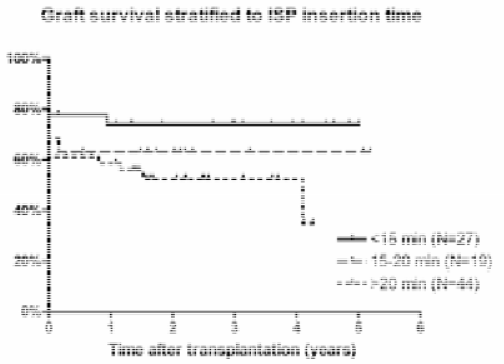

A

Figure 4.3 Graft survival of DCD kidneys. Graft survival was censored for recipient death with a functioning graft. (A) Graft survival stratified to ISP insertion time. Increased DBTL catheter insertion time is associated with inferior graft survival. (B) Graft survival stratified to donor management. Selected category 3 DCD donors were managed by rapid laparotomy and direct aortic cannulation to procure the liver as well as the kidneys (DCD-3 Direct). Graft survival of kidneys from these donors was superior to controlled DCD kidneys managed by in situ preservation (DCD3 ISP; $\mathrm{P}=0.02$ ). Kidney transplants from DBD donors within our organ procurement area during the study period are included for comparison.

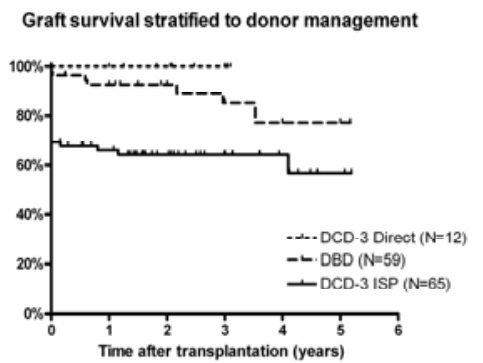

B (1) 
kidney donation. This results in a total of 97 DCD kidney transplants, 91 of which were grafted in The Netherlands and available for follow-up of transplant outcome.

In order to assess the impact of time required for insertion of the DBTL catheter on transplant outcome, kidney transplants were divided into tertiles based on the period from inguinal incision to start of perfusate flow. As might be expected, longer duration of DBTL catheter insertion was associated with inferior graft survival (Figure 4.3A). In multivariable Cox regression analysis of donor characteristics, donor sex and ISP insertion time were identified as independent risk factors for graft failure: the hazard of graft failure of female donor kidneys was 2.2 times higher than for male donor kidneys (95\% CI: 1.1-4.3, $\mathrm{P}=0.03$ ), and the hazard of graft failure of donor kidneys with ISP insertion time above the median (17 minutes) was 2.0 times higher than donor kidneys with faster ISP insertion (95\% CI: 1.0-4.1, $\mathrm{P}=0.05$ ) (Table 4.2). Taken together, increased DBTL catheter insertion time was associated with inferior graft survival and function, emphasizing that efforts should be made to perform this surgical procedure as fast as possible.

Comparison of in situ perfusion with direct aortic cannulation in controlled DCD donors and $D B D$ donors

In Maastricht category 3 DCD procedures, supportive treatment is withdrawn in a controlled environment and rapid laparotomy with direct aortic cannulation can therefore be arranged. A selected group of controlled DCD donors $(\mathrm{N}=7)$ were managed with this technique in order to procure the liver as well as the kidneys. Furthermore, all DBD donors in our organ procurement area $(\mathrm{N}=39)$ were managed by direct aortic cannulation during the study period. To further study the impact of preservation technique on graft outcome, we compared in situ perfused category 3 DCD kidney transplants with DBD kidneys and DCD kidneys from donors managed by direct aortic cannulation. Rapid laparotomy resulted in significantly shorter warm ischemia times compared to ISP ( $15 \pm 8$ vs. $30 \pm 7$ minutes, respectively; $\mathrm{P}<0.001)$. All kidneys from donors with rapid laparotomy were successfully procured and transplanted, whereas $20 \%$ of kidneys from category 3 DCD donors managed by ISP were discarded due to failed in situ perfusion. Graft survival of DBD kidneys and DCD kidneys managed by rapid laparotomy was significantly superior to DCD kidneys that were preserved in situ $(92 \%, 100 \%$ and $66 \%$ at 1 year after transplantation, respectively; $\mathrm{P}=0.008$; Figure 4.3B). This difference was attributable to the increased incidence of primary non-function of in situ perfused category 3 DCD kidneys (3\%, $0 \%$ and 
$34 \%$, respectively; $\mathrm{P}<0.001$ ), since graft loss beyond the first month was similar $(\mathrm{P}=0.68)$. Donor and recipient age and sex were similar between the three groups of donors, whereas cold ischemia time was significantly longer for category 3 DCD kidneys with ISP $(21 \pm 8,22 \pm 5$ and $27 \pm 6$ h, respectively; $\mathrm{P}<0.001)$. After correction for these transplant characteristics in multivariable analysis, the hazard of graft loss of in situ perfused DCD kidneys was 3.4 times higher than for DBD kidneys (95\% CI: 1.4-8.4, $\mathrm{P}=0.007)$. In contrast, the risk of graft loss of DCD kidneys managed by rapid laparotomy was similar to DBD kidneys $(\mathrm{P}=0.98)$. These findings indicate that from a surgical point of view, rapid laparotomy with direct aortic cannulation is to be preferred to in situ preservation by DBTL catheters in the management of controlled DCD donors.

Table 4.2 Cox regression analysis of risk factors for graft failure

\begin{tabular}{|c|c|c|c|c|c|}
\hline & \multicolumn{3}{|c|}{ Univariable analysis } & \multicolumn{2}{|c|}{ Multivariable analysis } \\
\hline & $\begin{array}{l}\text { Demo- } \\
\text { graphics }^{\mathrm{a}}\end{array}$ & $\begin{array}{l}\text { Odds ratio } \\
(95 \% \mathrm{CI})\end{array}$ & $\mathrm{P}$ & $\begin{array}{c}\text { Odds ratio } \\
(95 \% \mathrm{CI})\end{array}$ & $P$ \\
\hline \multicolumn{6}{|l|}{ Donor } \\
\hline Age (years) & $45 \pm 15$ & $1.02(1.00-1.04)$ & 0.10 & & 0.27 \\
\hline Sex (female) & $46 \%$ & $2.01(1.02-3.97)$ & 0.04 & $2.17(1.09-4.29)$ & 0.03 \\
\hline Type (uncontrolled) & $29 \%$ & & 0.84 & & \\
\hline Creatinine $(\mu \mathrm{mol} / \mathrm{L})$ & $94 \pm 38$ & & 0.82 & & \\
\hline Resuscitation time (min) & $40 \pm 25$ & & 0.60 & & \\
\hline Warm ischemic time ( $>30 \mathrm{~min})$ & $61 \%$ & $1.84(0.86-3.95)$ & 0.12 & & 0.65 \\
\hline ISP insertion time (>17 min) & $50 \%$ & $1.85(0.92-3.69)$ & 0.08 & $2.02(1.00-4.06)$ & 0.05 \\
\hline \multicolumn{6}{|l|}{ Graft } \\
\hline Cold ischemic time (h) & $26 \pm 6$ & & 0.64 & & \\
\hline Anastomosis time (min) & $38 \pm 14$ & & 0.21 & & \\
\hline \multicolumn{6}{|l|}{ Recipient } \\
\hline Age (years) & $34 \%$ & & 0.32 & & \\
\hline Sex (female) & $50 \pm 13$ & & 0.26 & & \\
\hline Dialysis time (years) & $3.9 \pm 2.3$ & & 0.85 & & \\
\hline Re-transplantation & $14 \%$ & & 0.61 & & \\
\hline HLA-mismatches ${ }^{\mathrm{b}}$ & & & NS & & \\
\hline Immunosuppressive regimen $^{\mathrm{b}}$ & & & NS & & \\
\hline
\end{tabular}

a Demographic data are presented as means \pm standard deviations or as percentage of cases.

b The number of HLA-A, HLA-B, and HLA-DR mismatches and the presence of cyclosporine, tacrolimus, mycophenolic acid, daclizumab or sirolimus in the initial immunosuppressive regimen were not significantly associated with graft survival in univariable analysis. 


\section{Discussion}

Procurement of DCD kidneys makes an attractive solution to the growing shortage of donor organs. Implementation of a DCD program holds the potential to increase the donor pool 2.5 to 4 -fold, ${ }^{7}$ and several studies have reported that graft and patient survival using DCD kidneys are similar to conventional DBD transplants. ${ }^{9-13}$ In contrast, increasing the donor pool with expanded criteria donors is by definition associated with a higher rate of graft loss than ideal DBD transplants. $^{3}$ Despite this inferior graft outcome, transplantation of kidneys from expanded criteria donors results in increased survival of wait-listed dialysis patients. ${ }^{4}$ Therefore, it is plausible to assume a survival benefit for recipients of DCD kidneys. Indeed, in this study, the 5-year survival rate of recipients of DCD kidneys was $78 \%$ (71\% for recipients of uncontrolled DCD kidneys), which compares favorably to the annual death rate of $8-10 \%$ of wait-listed dialysis patients in The Netherlands. Therefore, focus on donation after cardiac death is both legitimate and necessary.

In this paper, we analyse the outcome of clinical in situ preservation of DCD kidneys by intravascular flush-out through the DBTL catheter. Since only $42 \%$ of initiated DCD procedures resulted in kidney transplantation, the workload was high compared with DBD procedures. Thirty-one donation procedures (23\%) were unsuccessful due to complicated in situ perfusion. Balloon rupture or catheter malposition was found in 16 of these cases. Another common problem is the inability to insert the DBTL catheter, probably due to atherosclerosis of the femoral or iliac artery. Obviously, it is possible to insert the catheter through the contralateral femoral artery; in case both sides fail, perfusion through a partially inserted DBTL catheter should probably not be attempted. ${ }^{36}$ Next to these technical complications, in 6 donation procedures both kidneys were found blue and warm at laparotomy, indicating poor flush-out even though correct positioning of the catheter was verified. Renal vasospasm may account for the poor flush-out in these cases, and increased flush pressure or administration of a vasodilator such as phentolamine might have increased ISP efficacy. ${ }^{19,37,38}$

The incidence of ISP complications correlates with donor age, probably because atherosclerosis in older donors makes insertion of the DBTL catheter more difficult. Moreover, the odds of ISP failure in uncontrolled donation procedures were 5.4 times as high as in controlled donation procedures; this could not be explained by increased donor age or different causes of donor death. However, ISP is especially important in uncontrolled donation procedures since the time 
required for obtaining consent and arranging the nephrectomy would leave most kidneys unsuitable for transplantation. Uncontrolled procedures always occur unexpectedly and require fast action and therefore logistical factors may account for the higher rate of unsuccessful ISP. Since transplant surgeons and coordinators often are not immediately present, medical staff with relatively little experience in organ donation have to start ISP in uncontrolled DCD donors. Therefore, we introduced a training program for surgical residents and nurses working in the emergency room, not only teaching surgical and communicative skills but also addressing emotional aspects concerning organ donation. Moreover, we have distributed specially designed DCD kits to the intensive care units and emergency rooms of our organ procurement area. These kits contain all surgical equipment necessary for ISP, including DBTL catheters, preservation fluids, and an outline of the surgical procedure.

The time required for inserting the DBTL catheter was associated with graft outcome. Prolonged catheter insertion time not only indicates increased warm ischemia time, but may also reflect severe atherosclerotic lesions. For clinical practice, the poor outcome associated with prolonged catheter insertion time emphasizes that this surgical procedure should be performed as fast as possible. With the unavailability of reliable viability testing, ${ }^{6}$ a point may be reached when the donation procedure had better be discontinued to prevent transplantation of non-viable grafts. The small sample size of this study, however, does not allow us to accurately define such a general cut-off value and we believe that all DCD donors should be evaluated individually.

Several techniques have been developed to reduce warm ischemic injury of DCD organs before procurement, either by applying topical or intravascular cooling or by re-establishing blood flow by mechanical resuscitation or extracorporeal circulation. The double-balloon triple-lumen catheter discussed in this paper was designed to selectively perfuse the abdominal aorta in order to flush and cool the kidneys in situ to $10-15^{\circ} \mathrm{C} .1^{19}$ Other catheters with larger diameter have been designed to increase intra-aortic flush pressure and prevent baroreceptor-mediated renal vasoconstriction. ${ }^{20,37}$ However, the larger diameter of these catheters makes introduction via the femoral artery difficult. Other techniques for in situ preservation of DCD kidneys include intraperitoneal cooling and extracorporeal circulation. Intraperitoneal cooling is established by circulating sterile iced saline through two laparoscopy ports. ${ }^{23}$ Alternatively, cold Ringer's lactate can be infused through a chest tube located deep in the pelvis with drainage provided by a Foley catheter. ${ }^{22}$ Although these techniques result in more efficient cooling in an experimental model, ${ }^{39}$ combined topical and intravascular 
cooling was not associated with superior clinical transplant outcome when compared with intravascular cooling alone. ${ }^{40}$

Other groups have applied extracorporeal bypass in order to recirculate cooled, oxygenated blood. ${ }^{21,24,41-43}$ In a small retrospective analysis, this technique was superior to intra-aortic flushing; moreover, a period of normothermic recirculation prior to cooling was associated with further improvement of transplant outcome. ${ }^{21}$ Although transplant outcome may be better with extracorporeal bypass techniques, these interventions are technically and logistically demanding and are not readily available for uncontrolled DCD donors in most hospitals. Moreover, from an ethical point of view, in situ preservation procedures should be kept simple and minimally invasive, especially when consent for organ donation has not yet been obtained. This is also the reason why we did not continue resuscitating the donor after declaration of death. In our opinion, insertion of a DBTL catheter is the procedure of choice for in situ preservation of uncontrolled DCD kidneys.

In controlled DCD donation, the logistic and legal requirements for organ donation can be fulfilled before cardiac arrest. In this setting, rapid laparotomy with direct aortic cannulation is feasible and organs other than kidneys can be procured. This procedure was followed in selected category 3 DCD donors that were medically suitable for liver donation and for which consent for liver donation was obtained. Warm ischemia time was shorter and kidney graft survival was superior to category 3 DCD kidneys that were managed by ISP. This difference in graft survival was attributable to the high incidence of primary non-function in the ISP group; graft loss beyond the first month of transplantation was similar. Furthermore, the number of kidneys discarded due to technical complications of organ perfusion was lower with rapid laparotomy. Therefore, rapid laparotomy with direct aortic cannulation should be preferred to ISP in the management of category 3 DCD donors.

There is a growing opinion that the donation process should not interfere with end-of-life care for patients and their families. ${ }^{44}$ In order to provide continuity of care for potential donors and their relatives, we prefer to have treatment withdrawn in the ICU rather than in the OR as is practiced by many other transplant centers. In clinical practice, this does not lead to inferior graft outcome. ${ }^{45}$ Therefore, the controlled DCD donor may be transferred to the OR for rapid laparotomy with direct aortic cannulation immediately after death in the ICU. In case the relatives explicitly request to be present at the moment of cardiac arrest and shortly afterwards, in situ perfusion in the ICU may be more 
acceptable in the context of end-of-life care, even though rapid laparotomy may be preferred by the transplant surgeon.

In conclusion, continuous investments in logistics and training of surgical and nursing staff have resulted in a program for controlled and uncontrolled donation after cardiac death in all hospitals in our organ procurement area. In situ preservation by intra-aortic flush through the DBTL catheter was performed in 32 potential DCD donors per million inhabitants per year. The yield of transplantable organs was low compared to donation after brain death, in particular with uncontrolled DCD and older donors. Nevertheless, ISP of uncontrolled DCD kidneys led to acceptable function of grafts that otherwise would not have been transplanted. For controlled DCD donors, rapid laparotomy and direct aortic cannulation can be arranged and should be preferred to ISP since it was associated with reduced warm ischemia time, lower discard rate and superior graft survival in this series. Moreover, organs other than kidneys may be procured by this technique. However, this surgical point of view may need to be balanced against the preferences of the relatives in order to deliver optimal endof-life care. Since successful transplantation of DCD kidneys is very likely to increase the life expectancy of wait-listed dialysis patients, we consider in situ preservation of DCD kidneys a vitally important surgical procedure. 


\section{References}

1. Wolfe RA, Ashby VB, Milford EL, et al. Comparison of mortality in all patients on dialysis, patients on dialysis awaiting transplantation, and recipients of a first cadaveric transplant. $\mathrm{N}$ Engl J Med 1999; 341:1725-1730.

2. Evans RW, Manninen DL, Garrison LP, Jr., et al. The quality of life of patients with end-stage renal disease. N Engl J Med 1985; 312:553-559.

3. Port FK, Bragg-Gresham JL, Metzger RA, et al. Donor characteristics associated with reduced graft survival: an approach to expanding the pool of kidney donors. Transplantation 2002; 74:1281-1286.

4. Merion RM, Ashby VB, Wolfe RA, et al. Deceased-donor characteristics and the survival benefit of kidney transplantation. Jama 2005; 294:2726-2733.

5. Whiting JF, Zavala EY, Alexander JW, First MR. The cost-effectiveness of transplantation with expanded donor kidneys. Transplant Proc 1999; 31:1320-1321.

6. Brook NR, Waller JR, Nicholson ML. Nonheart-beating kidney donation: current practice and future developments. Kidney Int 2003; 63:1516-1529.

7. Daemen JW, Oomen AP, Kelders WP, Kootstra G. The potential pool of non-heart-beating kidney donors. Clin Transplant 1997; 11:149-154.

8. Terasaki PI, Cho YW, Cecka JM. Strategy for eliminating the kidney shortage. Clin Transpl 1997:265-267.

9. Wijnen RM, Booster MH, Stubenitsky BM, de Boer J, Heineman E, Kootstra G. Outcome of transplantation of non-heart-beating donor kidneys. Lancet 1995; 345:1067-1070.

10. Weber M, Dindo D, Demartines N, Ambuhl PM, Clavien PA. Kidney transplantation from donors without a heartbeat. N Engl J Med 2002; 347:248-255.

11. Cho YW, Terasaki PI, Cecka JM, Gjertson DW. Transplantation of kidneys from donors whose hearts have stopped beating. N Engl J Med 1998; 338:221-225.

12. Rudich SM, Kaplan B, Magee JC, et al. Renal transplantations performed using non-heartbeating organ donors: going back to the future? Transplantation 2002; 74:1715-1720.

13. Nicholson ML, Metcalfe MS, White SA, et al. A comparison of the results of renal transplantation from non-heart-beating, conventional cadaveric, and living donors. Kidney Int 2000; 58:2585-2591.

14. Cooper JT, Chin LT, Krieger NR, et al. Donation after cardiac death: the university of wisconsin experience with renal transplantation. Am J Transplant 2004; 4:1490-1494.

15. Gok MA, Buckley PE, Shenton BK, et al. Long-term renal function in kidneys from non-heartbeating donors: A single-center experience. Transplantation 2002; 74:664-669.

16. Cohen DJ, St Martin L, Christensen LL, Bloom RD, Sung RS. Kidney and pancreas transplantation in the United States, 1995-2004. Am J Transplant 2006; 6:1153-1169.

17. Shiroki R, Hoshinaga K, Higuchi T, et al. Prolonged warm ischemia affects long-term prognosis of kidney transplant allografts from non-heart-beating donors. Transplant Proc 1998; 30:111113.

18. Nishikido M, Noguchi M, Koga S, et al. Kidney transplantation from non-heart-beating donors: analysis of organ procurement and outcome. Transplant Proc 2004; 36:1888-1890.

19. Garcia-Rinaldi R, Lefrak EA, Defore WW, et al. In situ preservation of cadaver kidneys for transplantation: laboratory observations and clinical application. Ann Surg 1975; 182:576-584. 
20. Lloveras J, Puig JM, Cerda M, et al. Optimization of in situ renal perfusion of non--heartbeating donors: four-lumen catheter developed for continuous perfusion pressure determination. Transplant Proc 1993; 25:3169-3170.

21. Valero R, Cabrer C, Oppenheimer F, et al. Normothermic recirculation reduces primary graft dysfunction of kidneys obtained from non-heart-beating donors. Transpl Int 2000; 13:303-310.

22. Orloff MS, Reed AI, Erturk E, et al. Nonheartbeating cadaveric organ donation. Ann Surg 1994; 220:578-583; discussion 583-575.

23. Kowalski AE, Light JA, Ritchie WO, Sasaki TM, Callender CO, Gage F. A new approach for increasing the organ supply. Clin Transplant 1996; 10:653-657.

24. Marchioro TL, Huntley RT, Waddell WR, Starzl TE. Extracorporeal Perfusion for Obtaining Postmortem Homografts. Surgery 1963; 54:900-911.

25. Anaise D, Smith R, Ishimaru M, et al. An approach to organ salvage from non-heartbeating cadaver donors under existing legal and ethical requirements for transplantation. Transplantation 1990; 49:290-294.

26. Digard N, Geoghegan T, Harris KR, Slapak M. A seven-year experience in the use of the intraaorta balloon catheter perfusion technique during kidney retrieval. Transplant Proc 1984; 16:107-108.

27. Fujita T, Matsui M, Yanaoka M, Shinoda M, Naide Y. Clinical application of in situ renal cooling: experience with 61 cardiac-arrest donors. Transplant Proc 1989; 21:1215-1217.

28. Johnson HK, Skelley L, Warner H, et al. Results following use of the Garcia-Lefrak double balloon catheter. Transplant Proc 1984; 16:122-125.

29. Booster MH, Wijnen RM, Vroemen JP, van Hooff JP, Kootstra G. In situ preservation of kidneys from non-heart-beating donors--a proposal for a standardized protocol. Transplantation 1993; 56:613-617.

30. Kootstra G, Daemen JH, Oomen AP. Categories of non-heart-beating donors. Transplant Proc 1995; 27:2893-2894.

31. Kootstra G, van Hooff JP. [In-situ preservation of kidneys of 'non-heart-beating' donors: a possible way to offset the shortage of donor kidneys]. Ned Tijdschr Geneeskd 1998; 142:28382843.

32. Gok MA, Shenton BK, Buckley PE, et al. How to improve the quality of kidneys from nonheart-beating donors: a randomised controlled trial of thrombolysis in non-heart-beating donors. Transplantation 2003; 76:1714-1719.

33. Hoffmann RM, Stratta RJ, D'Alessandro AM, et al. Combined cold storage-perfusion preservation with a new synthetic perfusate. Transplantation 1989; 47:32-37.

34. Keizer KM, de Fijter JW, Haase-Kromwijk BJ, Weimar W. Non-heart-beating donor kidneys in the Netherlands: allocation and outcome of transplantation. Transplantation 2005; 79:11951199 .

35. Poge U, Gerhardt T, Palmedo H, Klehr HU, Sauerbruch T, Woitas RP. MDRD equations for estimation of GFR in renal transplant recipients. Am J Transplant 2005; 5:1306-1311.

36. Gok MA, Bhatti AA, Asher J, et al. The effect of inadequate in situ perfusion in the non heartbeating donor. Transpl Int 2005; 18:1142-1146.

37. Anaise D, Yland MJ, Waltzer WC, Frischer Z, Rapaport FT. A new perfusion tube for multiple organ procurement. Transplant Proc 1987; 19:4129-4136.

38. Belzer FO, Kountz SL. Preservation and transplantation of human cadaver kidneys: a two-year experience. Ann Surg 1970; 172:394-404.

39. Asher J, Wilson C, Stamp S, et al. Peritoneal cooling for in situ preservation of non-heart beating donor kidneys (Abstract). Transpl Int 2005; 18:25. 
40. Matsuno N, Kozaki M, Sakurai E, et al. Effect of combination in situ cooling and machine perfusion preservation on non-heart-beating donor kidney procurement. Transplant Proc 1993; 25:1516-1517.

41. Koyama I, Hoshino T, Nagashima N, Adachi H, Ueda K, Omoto R. A new approach to kidney procurement from non-heart-beating donors: core cooling on cardiopulmonary bypass. Transplant Proc 1989; 21:1203-1205.

42. Ko WJ, Chen YS, Chen RJ, Lai MK, Lee PH. Non-heart-beating donors under extracorporeal membrane oxygenation support. Transplant Proc 2002; 34:2600-2601.

43. Alvarez-Rodriguez J, del Barrio-Yesa R, Torrente-Sierra J, Prats-Sanchez MD, Barrientos Guzman A. Posttransplant long-term outcome of kidneys obtained from asystolic donors maintained under extracorporeal cardiopulmonary bypass. Transplant Proc 1995; 27:2903-2904; discussion 2904-2905.

44. Rady MY, Verheijde JL, McGregor J. Organ donation after circulatory death: the forgotten donor? Crit Care 2006; 10:166-168.

45. Johnson SR, Pavlakis M, Khwaja K, et al. Intensive care unit extubation does not preclude extrarenal organ recovery from donors after cardiac death. Transplantation 2005; 80:12441250. 
118 


\section{Chapter 5}

Histological assessment of pre-implantation biopsies for selection of kidneys from old donors after cardiac death 


\begin{abstract}
Background: Kidneys from old donors after cardiac death (DCD) may increase the donor pool but the prognosis of these kidneys is unsatisfactory. To improve these results, we retrospectively evaluated the diagnostic utility of published selection algorithms for old donor kidneys.

Methods: We studied all DCD kidney transplantations between January $1^{\text {st }}, 1994$ and July $1^{\text {st }}, 2005$ at our institution $(\mathrm{N}=199)$. Selection algorithms were evaluated in the subset of kidney transplantations from donors aged 60 years or older (N=52). For histological assessment of kidney biopsies, glomerulosclerosis, tubular atrophy, interstitial fibrosis and vascular narrowing were blindly scored. Functional kidney weight was calculated as renal mass multiplied by the fraction of non-sclerosed glomeruli.

Findings: Graft function and survival of kidneys from DCD donors aged 60 years or older were inferior to those from younger DCD donors. Histological scores were associated with kidney function and graft survival of old DCD kidney transplantations. Functional kidney weight was associated with kidney function but not graft survival, while donor GFR, donor age and machine perfusion characteristics were associated with neither of the clinical outcomes of interest. Interpretation: Histological assessment of pre-implantation biopsies may improve the selection of kidneys from old DCD donors and may therefore contribute to expansion of the donor pool.
\end{abstract}

\title{
Published as
}

Snoeijs MG, Buurman WA, Christiaans MH, van Hooff JP, Goldschmeding R, van Suylen RJ, Peutz-Kootstra CJ, van Heurn LW. Histological assessment of preimplantation biopsies may improve selection of kidneys from old donors after cardiac death. Am J Transplant 2008; 8:1844-1851. 


\section{Introduction}

Kidney transplantation is the treatment of choice for most patients with endstage renal disease and is associated with longer life expectancy and better quality of life than dialysis treatment. ${ }^{1,2}$ However, the supply of kidneys from ideal deceased donors does not meet its demands and kidneys from old donors and from donors after cardiac death (DCD, also referred to as non-heart-beating donors) have therefore increasingly been used over the past decade. Although these developments have led to more favorable outcomes for wait-listed dialysis patients, ${ }^{3}$ waiting lists for transplantation continue to increase and the pressure to expand the number of available donor kidneys remains. Within this context, it is likely that the trend towards utilization of ever more marginal donors will continue. This necessitates selection of donor kidneys that provide satisfactory clinical outcomes after single or dual transplantation, especially for kidneys from the potentially large pool of old DCD donors that are associated with a poor prognosis when used indiscriminately. ${ }^{4}$

Several algorithms for selection of kidneys from older brain-dead donors have been published. Although most of these algorithms have been assessed for use in dual transplantation, they may also be useful for selection of kidneys from old donors for single transplantation. It has been suggested to select kidneys from donors older than 60 years by histological assessment of chronic renal injury in pre-implantation biopsies..$^{5-7}$ The transplant team in Münster relied on 'functional kidney weight', i.e. kidney weight multiplied by the fraction of nonsclerosed glomeruli in pre-implantation biopsies. ${ }^{8}$ Andres and colleagues selected kidneys from older donors primarily by donor age, ${ }^{9}$ whereas other transplant teams relied on estimated glomerular filtration rate (GFR) when selecting kidneys for transplantation. ${ }^{10,11}$ Finally, machine perfusion characteristics such as flow rate and renal resistance may be used to select kidneys for transplantation. ${ }^{12,13}$ Although the selection algorithms resulted in satisfactory graft function after transplantation, these studies do not provide evidence that the donor pool has been fully expanded and that as many patients as possible have received renal allografts. Furthermore, these selection criteria have only been applied to braindead donors, whereas selection of kidneys from old DCD donors may be more important considering their poor clinical outcome when used indiscriminately. ${ }^{4}$

Given the clinical relevance of appropriate selection of older donor kidneys and the lack of consensus on selection criteria, we have retrospectively 
evaluated the diagnostic utility of published selection algorithms (i.e. donor age, estimated GFR, functional kidney weight, histological score and machine perfusion characteristics) in an unselected, consecutive series of single kidney transplantations from old DCD donors at our institution.

\section{Materials and methods}

\section{Donors and organ preservation}

DCD kidneys are recovered after cardiac arrest and are categorized according to the Maastricht classification. ${ }^{14}$ Management of DCD donors at our institution has recently been reported in detail. ${ }^{15}$ Briefly, after declaration of death by an independent physician and a no-touch period, in situ perfusion of donor kidneys with HTK preservation solution is initiated by introduction of a double-balloon triplelumen catheter via the femoral artery. When consent for organ donation is obtained from the relatives, the donor is transferred to the operating room for organ recovery. Each kidney is weighed and biopsies are taken. The kidneys are subsequently preserved with $500 \mathrm{~mL}$ UW-MPS on Gambro-PF3B perfusion units until transplantation. After 4 hours of machine perfusion, flow rate (perfusate flow / 100 g kidney weight) and renal resistance (perfusion pressure / perfusate flow) are calculated. Sixty-three percent of the grafts in this study were locally recovered according to this protocol; the other grafts were imported from other procurement areas that used similar DCD protocols.

\section{Transplantation and recipient characteristics}

Kidneys were allocated according to Eurotransplant policies. ${ }^{16}$ As of 1999, kidneys from donors aged 65 years or older were allocated to older recipients without HLA matching through the Eurotransplant Senior Program. Donor, graft and recipient characteristics and transplant outcomes were extracted from our prospectively recorded DCD database. Initial graft function was categorized as immediate function (IF: post-operative dialysis was not necessary), delayed graft function (DGF: dialysis was required in the first week post-transplant but lifesupporting graft function was eventually achieved), or primary non-function (PNF: dialysis could never be discontinued). The immunosuppressive regimen evolved over the study period as different trials were conducted. Immunosuppression was mainly based on a combination of prednisolone and a calcineurin inhibitor (cyclosporine or tacrolimus). Depending on the protocol at the time, 
Table 5.1 Characteristics of kidney transplantations from donors after cardiac death at our institution from January 1st, 1994 until July 1st, 2005a

\begin{tabular}{|c|c|c|c|}
\hline & Donors $<60$ years & Donors $\geq 60$ years & \\
\hline & $\mathrm{N}=147$ & $\mathrm{~N}=52$ & $\mathbf{P}$ \\
\hline Donor age (yrs) & $40 \pm 14$ & $65 \pm 4$ & $<0.001$ \\
\hline Donor sex (male / female) & $61 / 39 \%$ & 62 / 39\% & 0.98 \\
\hline Donor GFR (mL/min/1.73m2) & $89 \pm 26$ & $79 \pm 30$ & 0.07 \\
\hline Donor type (DCD 1 / 2 / 3 / 4) & $2 / 35 / 61 / 2 \%$ & $0 / 27 / 73$ / 0\% & 0.28 \\
\hline Cause of death & & & 0.35 \\
\hline Cardiovascular & $35 \%$ & $35 \%$ & \\
\hline Neurological & $37 \%$ & $37 \%$ & \\
\hline Trauma & $24 \%$ & $19 \%$ & \\
\hline Other & $3 \%$ & $10 \%$ & \\
\hline Procurement area (local / imported) & $59 / 41 \%$ & $75 / 25 \%$ & 0.04 \\
\hline Resuscitation time (min) & $53 \pm 62$ & $49 \pm 60$ & 0.80 \\
\hline Warm ischemia time (min) & $25 \pm 9$ & $28 \pm 12$ & 0.10 \\
\hline Cold ischemia time (h) & $27 \pm 6$ & $25 \pm 6$ & 0.33 \\
\hline Anastomosis time (min) & $37 \pm 16$ & $39 \pm 12$ & 0.42 \\
\hline Kidney weight (g) & $238 \pm 62$ & $238 \pm 58$ & 0.96 \\
\hline Recipient age (yrs) & $53 \pm 13$ & $56 \pm 12$ & 0.11 \\
\hline Recipient sex (male / female) & $66 / 34 \%$ & $58 / 42 \%$ & 0.29 \\
\hline Dialysis time (yrs) & $3.5 \pm 2.6$ & $3.3 \pm 3.2$ & 0.67 \\
\hline Diabetes mellitus (yes / no) & $12 / 88 \%$ & $10 / 90 \%$ & 0.61 \\
\hline Retransplantation (yes / no) & $12 / 88 \%$ & $6 / 94 \%$ & 0.23 \\
\hline HLA mismatches & $2.5 \pm 0.9$ & $2.8 \pm 1.2$ & 0.07 \\
\hline Short-term graft function & & & 0.11 \\
\hline Immediate function & $17 \%$ & $19 \%$ & \\
\hline Delayed graft function & $65 \%$ & $50 \%$ & \\
\hline Primary non-function & $18 \%$ & $31 \%$ & \\
\hline Acute rejection (yes / no) & $22 / 78 \%$ & $19 / 81 \%$ & 0.70 \\
\hline GFR after 1 year (mL/min/1.73m2) & $44 \pm 16$ & $34 \pm 13$ & 0.001 \\
\hline GFR after 5 years $(\mathrm{mL} / \mathrm{min} / 1.73 \mathrm{~m} 2)$ & $44 \pm 19$ & $34 \pm 10$ & 0.07 \\
\hline Death-censored graft survival after 1 year & $79 \%$ & $67 \%$ & 0.006 \\
\hline Death-censored graft survival after 5 years & $70 \%$ & $52 \%$ & \\
\hline Patient survival after 1 year & $96 \%$ & $94 \%$ & 0.21 \\
\hline Patient survival after 5 years & $87 \%$ & $83 \%$ & \\
\hline
\end{tabular}

a Data are presented as mean (standard deviation) or as percentages. 
these were combined with azathioprine, mycophenolate mofetil (MMF), sirolimus or daclizumab in recipients at increased immunological risk (e.g. HLA immunization and retransplants). Biopsy-proven acute rejection (observed in $21 \%$ of recipients) was treated with methylprednisolone; patients with vascular and steroid-resistant rejections were given anti-thymocyte globulins. GFR was estimated by the abbreviated MDRD formula. ${ }^{17}$

\section{Biopsies and morphometry}

Wedge biopsies were taken from 23 kidneys (47\%), whereas needle biopsies were taken from the other kidneys (Table 5.2). Biopsies were formalin-fixed, cut at 3 $\mu \mathrm{m}$ and stained with hematoxylin and eosin, periodic acid-Schiff, silver methenamine and Masson's trichrome. Biopsies containing only renal medulla were discarded. The mean number of glomeruli in all biopsies was $23 \pm 17$ (range 5-89). If the cortical area was small and therefore poorly representative of the entire kidney, data on glomerulosclerosis and vascular narrowing were supplemented by additional biopsies taken within 30 days of transplantation $(\mathrm{N}=5)$. This approach is valid since de novo chronic injury to glomeruli and blood vessels does not occur during the first year of transplantation. ${ }^{18}$ In another 5 cases, no baseline biopsies were available and kidney biopsies taken within 30 days of transplantation were studied. These biopsies were taken because of rising serum creatinine concentration $(\mathrm{N}=4$, acute tubulo-interstitial rejection confirmed in 3 cases) or transplantectomy $(\mathrm{N}=1)$. Biopsies taken after transplantation may have slightly overestimated pre-existent interstitial fibrosis and tubular atrophy. Kidney biopsies from old donors were blindly assessed according to the scoring system put forward by Remuzzi and colleagues ${ }^{6}$ and according to the Banff classification. ${ }^{19}$ For statistical analysis, a total chronic Banff score was calculated by adding the allograft glomerulopathy (cg), mesangial matrix increase $(\mathrm{mm})$, tubular atrophy (ct), interstitial fibrosis (ci), vascular fibrous intimal thickening (cv) and arteriolar hyaline thickening (ah) scores to the fraction of sclerosed glomeruli multiplied by three.

\section{Statistics}

Continuous variables are presented as means \pm standard deviations (SD); categorical variables are presented as percentages. Differences between groups of patients were compared with the Pearson $\chi^{2}$ test for categorical variables and with the Student's t-test for continuous variables. Death-censored graft survival was calculated using Kaplan-Meier curves and compared with the log-rank test. Due to PNF, Kaplan-Meier curves do not start at 100\% graft survival. Correlation 
of selection algorithms with GFR was tested with the Pearson correlation coefficient, whereas correlation with graft survival was evaluated with Cox regression analysis. Area under the receiver operator characteristic curve (ROC AUC) was used to assess diagnostic accuracy for graft failure within 5 years of transplantation irrespective of cut-off points. P-values below 0.05 were considered statistically significant. Statistical analysis was performed with SPSS for Windows version 12.0.1.

\section{Ethics}

Collection, storage and use of tissue and patient data were performed in agreement with the codes of conduct 'Use of data in health research' and 'Proper secondary use of human tissue' put forward by the federation of Dutch medical scientific societies (http://www.federa.org/).

\section{Results}

\section{Comparison of clinical outcomes of old and young donors}

All kidney transplantations from DCD donors between January $1^{\text {st }}, 1994$ and July $1^{\text {st }}, 2005$ at our institution ( $\left.\mathrm{N}=199\right)$ were included in this study. Recipients were followed until death or January $1^{\text {st }}, 2007$ to ensure at least 18 months of followup. Donor, graft and recipient characteristics of the kidney transplantations included in this study are presented in Table 5.1. Although baseline characteristics of kidney transplantations from DCD donors aged over and under 60 years

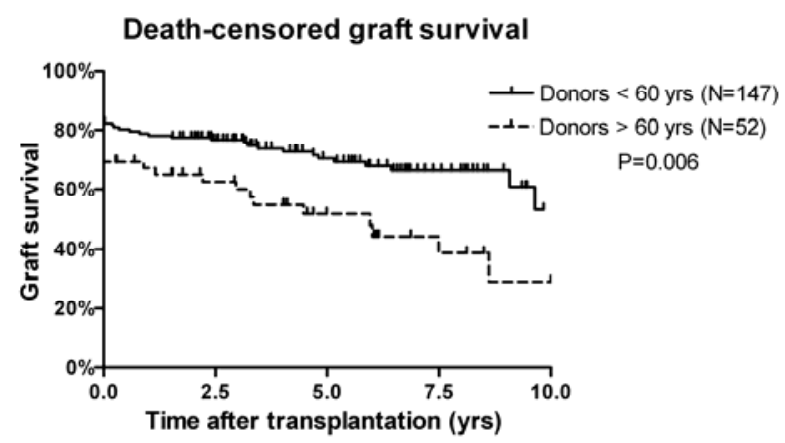

Figure 5.1 Death-censored graft survival of kidney transplantations from donors after cardiac death at our institution from January 1st, 1994 until July 1st, 2005. 
Table 5.2 Biopsy characteristics

\begin{tabular}{|c|c|c|}
\hline & \multicolumn{2}{|c|}{$\begin{array}{c}\text { Donors } \geq 60 \text { years } \\
\mathrm{N}=52\end{array}$} \\
\hline \multicolumn{3}{|l|}{ Timing of biopsies } \\
\hline Pre-implantation & \multicolumn{2}{|c|}{$30(58 \%)$} \\
\hline Reperfusion & \multicolumn{2}{|c|}{$14(27 \%)$} \\
\hline Within 30 days of transplantation & \multicolumn{2}{|c|}{$5(10 \%)$} \\
\hline No biopsy & \multicolumn{2}{|c|}{$3(6 \%)$} \\
\hline \multicolumn{3}{|l|}{ Type of biopsy } \\
\hline Wedge & \multicolumn{2}{|c|}{$23(47 \%)$} \\
\hline \multirow[t]{2}{*}{ Needle } & \multicolumn{2}{|c|}{$26(53 \%)$} \\
\hline & Mean \pm SD & Median (range) \\
\hline Number of glomeruli & $23 \pm 17$ & $19(5-89)$ \\
\hline Number of arteries & $3.6 \pm 2.1$ & $3(1-8)$ \\
\hline Remuzzi score & $4.0 \pm 1.8$ & $4(1-8)$ \\
\hline Glomerulosclerosis & $0.9 \pm 0.6$ & $1(0-2)$ \\
\hline Tubular atrophy & $1.1 \pm 0.7$ & $1(0-3)$ \\
\hline Interstitial fibrosis & $0.6 \pm 0.6$ & $1(0-2)$ \\
\hline Vascular narrowing & $1.3 \pm 0.5$ & $1(0-2)$ \\
\hline \multicolumn{3}{|l|}{ Banff score } \\
\hline Glomerulosclerosis (\%) & $14 \pm 16$ & $8(0-57)$ \\
\hline Allograft glomerulopathy (cg) & 0 & 0 \\
\hline Mesangial matrix increase (mm) & 0 & 0 \\
\hline Tubular atrophy (ct) & $1.0 \pm 0.7$ & $1(0-3)$ \\
\hline Interstitial fibrosis (ci) & $0.8 \pm 0.7$ & $1(0-3)$ \\
\hline Vascular fibrous intimal thickening (cv) & $0.5 \pm 0.7$ & $0(0-2)$ \\
\hline Arteriolar hyaline thickening (ah) & $0.5 \pm 0.8$ & $0(0-3)$ \\
\hline Total chronic Banff score ${ }^{\mathrm{a}}$ & $3.2 \pm 2.2$ & $2.5(0-10)$ \\
\hline
\end{tabular}

a Total chronic Banff score was calculated as $\mathrm{cg}+\mathrm{mm}+\mathrm{ct}+\mathrm{ci}+\mathrm{cv}+\mathrm{ah}+($ fraction sclerosed glomeruli $\mathrm{x} 3$ ).

generally were similar, kidneys from old donors were associated with inferior graft function and survival (Figure 5.1). Graft survival of kidneys from donors between 60 and 64 years and from donors aged 65 years and older were similar $(\mathrm{P}=0.80)$. With a median death-censored graft survival of approximately 5 years, kidneys from DCD donors over 60 years of age constitute a group of marginal grafts that lead to unsatisfactory clinical outcomes without further selection. 
Distribution of selection criteria in kidneys from old donors

Selection algorithms were evaluated in the subset of kidney transplantations from donors aged 60 years or older $(\mathrm{N}=52)$. From these kidneys, 30 preimplantation biopsies (58\%) and 14 reperfusion biopsies (27\%) were available. Biopsies taken within 30 days of transplantation were studied for 5 additional transplants (10\%) and the remaining 3 kidneys (6\%) were excluded from analysis because biopsy material was unavailable (Table 5.2). Therefore, 49 kidneys (94\%) were available for histological analysis of biopsies and 40 of these kidneys (82\%) were weighed before machine perfusion. Chronic renal injury was assessed in kidney biopsies according to both the Banff classification ${ }^{19}$ and the histological scoring system put forward by Remuzzi and colleagues. ${ }^{6}$ For some DCD kidneys $(\mathrm{N}=13)$, donor blood was not sampled until after resuscitation efforts had ceased, resulting in elevated serum creatinine concentrations. These kidney transplantations, as well as two transplants from a donor with acute renal failure in the ICU, were excluded from analysis of donor GFR. For the remaining 37 kidneys (71\%), estimated donor GFR ranged between 48 and $134 \mathrm{~mL} / \mathrm{min} / 1.73 \mathrm{~m}^{2}$. Donor age was available for all kidney transplantations and ranged between 60 and 74 years. Within the group of kidneys from old donors, estimated GFR was correlated with functional kidney weight $(\mathrm{R}=0.54, \mathrm{P}=0.004)$, but not with donor age or histological score. Furthermore, functional kidney weight was inversely correlated with histological scores $(\mathrm{R}=-0.39, \mathrm{P}=0.01)$. Functional kidney weight and histological scores did not correlate significantly with donor age $(\mathrm{R}=-0.18, \mathrm{P}=0.28$ and $\mathrm{R}=0.12, \mathrm{P}=0.42$, respectively). Machine perfusion characteristics were not correlated to other selection criteria. The general lack of close associations between selection criteria indicates that these variables may have different clinical utility in predicting the outcome of kidneys from old donors.

\section{Association of algorithms with clinical outcome}

Kidneys from donors aged 60 years or older $(\mathrm{N}=52)$ were selected by the same criteria as kidneys from younger DCD, i.e. warm ischemia time less than 45 minutes and serum creatinine concentrations within the normal range. Preimplantation biopsies and kidney weight were not routinely used for decisions regarding acceptance of donor kidneys. Therefore, these transplants are appropriate for unbiased assessment of selection criteria that allow maximal expansion of the donor pool. Since the primary interest of the analysis was to evaluate selection algorithms for kidneys with pre-existent chronic injury, primary graft failure due to post-operative complications was excluded ( $\mathrm{N}=7: 2$ thrombosis, 2 


\section{Correlation between selection criteria and recipient GFR after 1 year}
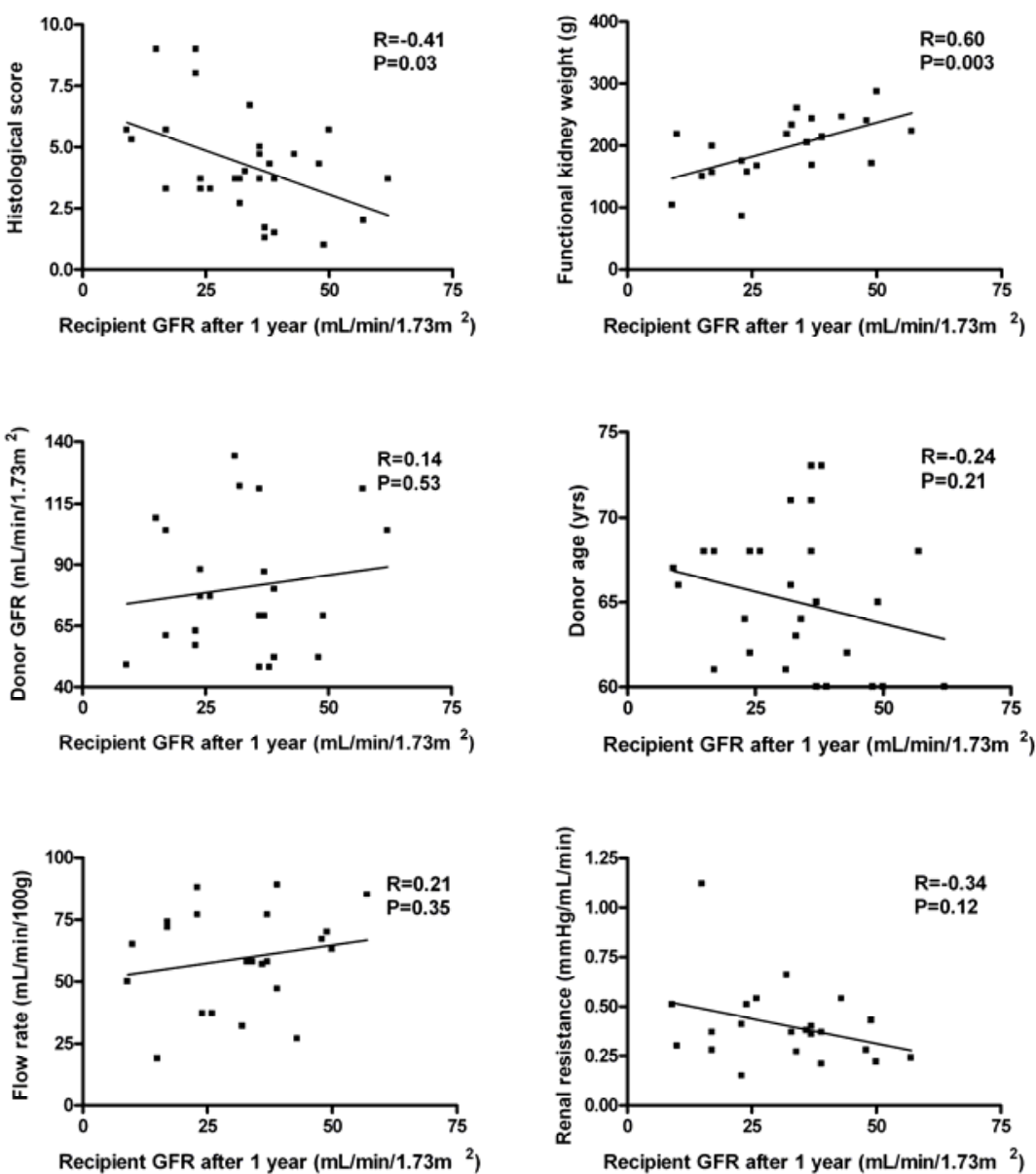

Figure 5.2 Correlation of selection algorithms for kidneys from old donors after cardiac death with estimated GFR at 1 year after transplantation.

no perfusion, 1 rejection, 1 hemorrhage and 1 renal artery stenosis). None of the selection variables were associated with short-term graft function.

Histological score and functional kidney weight were both correlated with recipient GFR at 1 year after transplantation $(\mathrm{R}=-0.41, \mathrm{P}=0.03$ and $\mathrm{R}=0.60$, $\mathrm{P}=0.003$, respectively), whereas donor GFR, donor age and machine perfusion characteristics were not significantly correlated with recipient GFR (Figure 5.2). 
Histological scores, but not donor GFR, donor age, functional kidney weight, or machine perfusion parameters, were associated with graft survival after transplantation (Table 5.3). Among the individual items from the histological scores, glomerulosclerosis and vascular narrowing in kidney biopsies were both associated with graft survival of old DCD kidneys ( $\mathrm{P}=0.01$ and $\mathrm{P}=0.06$, respectively), whereas interstitial fibrosis and tubular atrophy were not. The histological scores of chronic renal injury according to Remuzzi and colleagues and according to the Banff classification were similarly associated with graft outcome after transplantation (Table 5.3).

The selection algorithms were not associated with recipient kidney disease or acute rejection. Donor age and histological scores were correlated with recipient age $(\mathrm{R}=0.42, \mathrm{P}=0.003$ and $\mathrm{R}=0.30, \mathrm{P}=0.04$, respectively). However, recipient age was not significantly associated with recipient GFR at 1 year after transplantation $(\mathrm{R}=-0.32, \mathrm{P}=0.09)$ or with death-censored graft survival (HR 1.03, $\mathrm{P}=0.30$ ). Moreover, control for recipient age in multivariable analyses did not change the results of our analyses. Furthermore, re-analysis excluding biopsies taken after transplantation produced similar results (data not shown). Taken

Table 5.3 Diagnostic utility of selection algorithms for graft survival of kidneys from old donors after cardiac death

\begin{tabular}{|c|c|c|c|c|}
\hline & \multicolumn{2}{|c|}{$\begin{array}{c}\text { Correlation } \\
\text { with graft survival }^{\mathrm{a}}\end{array}$} & \multicolumn{2}{|c|}{$\begin{array}{c}\text { Diagnostic accuracy } \\
\text { for graft loss within } 5 \mathrm{yrs}^{\mathrm{a}}\end{array}$} \\
\hline & Hazard ratio & $P$ & ROC AUC & $\mathrm{P}^{\mathrm{b}}$ \\
\hline Donor age (yrs) & 1.07 & 0.28 & 0.55 & 0.62 \\
\hline Donor GFR (mL/min/1.73m²) & 1.01 & 0.49 & 0.59 & 0.44 \\
\hline Functional kidney weight (g) & 1.00 & 0.60 & 0.55 & 0.62 \\
\hline Kidney weight (g) & 1.01 & 0.30 & 0.61 & 0.29 \\
\hline Histological score & 1.27 & 0.04 & 0.73 & 0.02 \\
\hline Glomerulosclerosis & 2.68 & 0.01 & 0.74 & 0.01 \\
\hline Tubular atrophy & 1.37 & 0.28 & 0.58 & 0.42 \\
\hline Interstitial fibrosis & 1.23 & 0.59 & 0.54 & 0.70 \\
\hline Vascular narrowing & 2.34 & 0.06 & 0.63 & 0.18 \\
\hline Banff score ${ }^{c}$ & 1.20 & 0.04 & 0.74 & 0.01 \\
\hline Machine flow rate $(\mathrm{mL} / \mathrm{min} / 100 \mathrm{~g})$ & 0.99 & 0.38 & 0.49 & 0.93 \\
\hline Machine resistance $(\mathrm{mmHg} / \mathrm{mL} / \mathrm{min})$ & 1.26 & 0.86 & 0.45 & 0.60 \\
\hline \multicolumn{3}{|c|}{$\begin{array}{l}{ }^{a} \text { Graft loss was censored for PNF due to post-operative complications (N=7). } \\
\text { b Tested against the null hypothesis of a true ROC AUC of } 0.5 \text {. }\end{array}$} & c Total chronic Banff score was calculated as cg $+\mathrm{mm}+\mathrm{ct}+\mathrm{ci}+\mathrm{cv}+\mathrm{ah}+$ (fraction sclerosed glomeruli * 3$)$. & \\
\hline
\end{tabular}


together, we show that histological scores are associated with graft function and survival of kidney transplantations from old DCD donors. Functional kidney weight is associated with graft function but not survival, while donor GFR and age are associated with neither of the clinical outcomes of interest.

\section{Clinical utility of histological score}

Diagnostic accuracy of continuous variables may be assessed irrespectively of cut-off points by ROC curve analysis. ${ }^{20}$ ROC curve analysis confirmed the diagnostic value of both histological scores for prediction of graft loss within 5 years of transplantation and showed that none of the other selection criteria predicts this adverse outcome (Table 5.3). Sensitivity, specificity, positive and negative predictive value for graft loss within 5 years of transplantation were calculated for different cut-off points of histological score according to Remuzzi and colleagues (Figure 5.3). Since the aim of our study was to select kidneys from old donors with satisfactory graft survival, specificity of the diagnostic test was more important than sensitivity. Therefore, the optimal cut-off point was set between

\section{Predictive value of histological score for graft loss within 5 years}

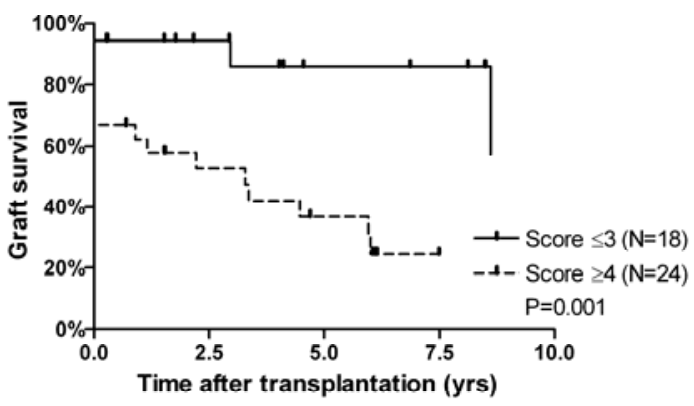

\begin{tabular}{|l|c|c|c|c|}
\cline { 2 - 5 } \multicolumn{1}{c|}{} & Sensitivity & Specificity & $\begin{array}{c}\text { Positive } \\
\text { predictive value }\end{array}$ & $\begin{array}{c}\text { Negative } \\
\text { predictive value }\end{array}$ \\
\hline Cut-off between score 3-4 & $88 \%$ & $62 \%$ & $58 \%$ & $89 \%$ \\
\hline Cut-off between score 4-5 & $50 \%$ & $73 \%$ & $53 \%$ & $70 \%$ \\
\hline Cut-off between score 5-6 & $25 \%$ & $85 \%$ & $50 \%$ & $65 \%$ \\
\hline
\end{tabular}

Figure 5.3 Sensitivity, specificity, positive and negative predictive value for graft loss within 5 years of transplantation for different cut-off points of histological score (proposed by Remuzzi and colleagues) of kidney biopsies from old donors after cardiac death (excluding graft loss due to postoperative complications). Death-censored graft survival of old DCD kidney transplantations stratified to the optimal cut-off point between histological score 3 and 4 is shown. 
histological scores of 3 and 4 (specificity $88 \%$, sensitivity 62\%). Death-censored graft survival of old DCD kidneys with histological scores $\leq 3$ was significantly better than for kidneys with scores $\geq 4$ ( $\mathrm{P}=0.001$, Figure 5.3). These findings suggest that kidneys from old DCD donors with histological scores $\leq 3$ are suitable for transplantation, whereas kidneys with scores $\geq 4$ lead to unacceptable graft survival and should therefore be either discarded or used for dual transplantation.

\section{Discussion}

In this study, several published algorithms for selection of kidneys from old donors - histological scores of chronic renal injury in pre-implantation biopsies, functional kidney weight, estimated GFR of the donor, donor age and machine perfusion characteristics - were analyzed in a consecutive series of kidney transplantations from DCD donors aged 60 years or older at our institution. Kidney transplantations from old DCD donors were associated with inferior graft function and survival than younger DCD kidneys. Death-censored and overall graft survival of old DCD kidneys was $52 \%$ and $42 \%$ at 5 years after transplantation, respectively. These data extend our previous finding of poor clinical outcomes with kidneys from DCD donors aged 65 years or older. ${ }^{4}$ Although selected elderly transplant candidates may benefit from short-term freedom from dialysis, the relatively poor overall graft survival of old DCD kidneys calls for efforts to identify a subset of grafts with more satisfactory long-term outcomes. In general, we did not find statistically significant correlations between the selection criteria examined in this study, indicating that these variables may have different clinical utility in predicting the outcome of kidneys from old donors. Out of five selection criteria, only histological score was associated with both kidney function and long-term graft survival of kidney transplantations from old donors. Stratification of kidneys based on histological score accurately defined a subset of kidneys with good long-term prognosis. These findings indicate that preimplantation biopsies may hold distinct diagnostic value for selection of old DCD kidneys that are suitable for transplantation. However, sensitivity and specificity may be overestimated when calculated with the same data set that has been used to determine the optimal cut-off point for a diagnostic test. Therefore, the diagnostic accuracy of our suggested cut-off point of histological score should be validated in future studies before it can routinely be applied to accept or discard donor kidneys for clinical use. 
Many transplant centers have previously studied the association of chronic renal injury in pre-implantation biopsies with clinical outcome of kidneys from deceased brain-dead donors. Most series of unselected grafts found that interstitial fibrosis, ${ }^{21}$ arteriosclerosis, ${ }^{22}$ glomerulosclerosis, ${ }^{23}$ or a combination of these lesions is associated with inferior long-term graft function. However, these studies did not take into account the association of chronic renal injury with donor age, which by itself is associated with graft failure. Studies that included only old donor kidneys or that corrected for donor age in multivariable analyses have shown mixed results. ${ }^{524-28}$ To the best of our knowledge, no studies have previously evaluated the clinical utility of histological assessment of pre-implantation biopsies from old DCD kidneys, even though selection of these kidneys is particularly important considering their poor clinical outcome. In our study, we have applied the scoring systems put forward by Remuzzi and colleagues and by the Banff classification to assess chronic degenerative changes in donor kidneys. ${ }^{6,19}$ These scoring systems are very similar and had comparable diagnostic value for predicting graft survival after transplantation, suggesting that these histological scoring systems can be used as preferred by the pathologist. Since the system proposed by Remuzzi provides a combined score of chronic renal injury, we have focused on this system for assessment of clinical utility of histological evaluation of pre-implantation biopsies.

In our study, pre-existent chronic renal injury was of more diagnostic value than other selection criteria such as donor age, estimated donor GFR and functional kidney weight. Donor age has been shown to strongly predict graft function and survival, ${ }^{29}$ but may not be as useful for further selection of grafts within the subset of older donors, considering the wide variation in renal function and structure between old individuals. ${ }^{30,31}$ Functional kidney weight and donor GFR are both estimates of transplanted nephron mass which may accurately predict graft function. ${ }^{32}$ However, the rate of decline of renal function that eventually results in graft failure may be determined by additional structural changes in the kidney such as vascular narrowing that are not represented by donor GFR and functional kidney weight. ${ }^{33}$ Our study suggests that comprehensive assessment of chronic injury in all compartments of the kidney (glomerular, vascular and tubulo-interstitial) is more predictive of graft outcome than other selection criteria. Selection algorithms based on renal function are further limited by the unavailability of recent serum creatinine concentrations for GFR estimation in case of donation after uncontrolled cardiac death.

The major strength of our study is its 'unselected' population of kidneys from DCD over 60 years of age that need further stratification to identify grafts 
with acceptable outcomes. These kidneys had not routinely been selected by preimplantation biopsies or kidney weight and were procured from donors with a wide range of glomerular filtration rates. Therefore, this study population is well suited for unbiased assessment of selection criteria that allow maximal expansion of the donor pool for single kidney transplantation while ensuring satisfactory outcome. Kidneys from younger DCD do not need such selection because longterm graft survival is satisfactory and similar to kidneys from deceased braindead donors. ${ }^{34}$ A potential limitation of our study is the variable quality of the kidney biopsies, since both wedge and needle biopsies were assessed. Superficial wedge biopsies may overestimate the percentage of sclerosed glomeruli as these are more frequently found in the subcapsular region of the kidney. ${ }^{35}$ Furthermore, we chose to study formalin-fixed sections instead of frozen sections that are typically used for rapid histological evaluation. Interstitial fibrosis, tubular atrophy and arterial narrowing are difficult to evaluate in frozen sections and the percentage of glomerulosclerosis tends to be underestimated. ${ }^{36}$ Novel ultra-rapid processing protocols may be useful to reduce the time required to obtain formalin-fixed sections of pre-implantation kidney biopsies. ${ }^{37}$ Furthermore, the sample size of renal biopsies is an important determinant of accurate assessment of the percentage glomerulosclerosis in the kidney. ${ }^{38}$ With a mean of 23 glomeruli per biopsy, glomerulosclerosis in the donor kidney was estimated with a standard deviation of approximately $10 \%$ in our study. ${ }^{38}$ Finally, even though we present one of the larger single-center series of old DCD kidney transplants in the literature, the number of cases is still rather small $(\mathrm{N}=52)$. Although the correlation between histological scores and graft outcome was statistically significant, the relatively small sample size may have resulted in insufficient statistical power to detect more subtle associations between variables.

DCD kidneys suffer warm ischemic injury during the period from circulatory arrest and organ preservation, which leads to a high incidence of early postoperative graft dysfunction. Short-term graft function was not explained by any of the selection algorithms based on chronic functional or structural renal changes and is more likely related to acute warm ischemic injury of DCD kidneys. Previous studies have shown that histological assessment of acute tubular injury in pre-implantation kidney biopsies is also of limited value. ${ }^{39}$ In our series of old DCD kidneys, 7 grafts (13\%) failed due to post-operative complications and severe ischemic injury may have played a major role in causing these graft losses. Since the primary interest of the study was to predict long-term graft function by chronic degenerative renal changes, these kidneys were excluded 
from analysis. In recent years we have become more cautious in accepting old DCD kidneys with extended warm ischemia times.

The results of this study should be extrapolated to kidneys from braindead donors with caution, since it has been shown that clinical outcomes of kidneys from brain-dead donors aged 60 years or older are satisfactory. ${ }^{3}$ Therefore, graft selection by pre-implantation biopsies may only be useful when age limits for deceased brain-dead donors are further relaxed. In addition, DCD kidneys suffer warm ischemic injury before organ procurement that adds to preexistent chronic renal injury. This combination of warm ischemic damage and chronic renal injury may synergistically reduce graft survival, similar to the increased sensitivity of old donor kidneys to DGF and acute rejection. ${ }^{40,41}$

In summary, our study suggests that kidneys from DCD donors aged 60 years or older should be histologically assessed before implantation to avoid the use of kidneys with unacceptably poor prognosis due to pre-existent chronic injury. The histological scores put forward by Remuzzi and colleagues and by the Banff classification are both associated with graft function and survival and are superior to other published selection algorithms such as donor age, donor GFR and functional kidney weight. We propose that careful expansion of the donor pool with old DCD kidneys is possible and may be guided by assessment of preimplantation biopsies instead of donor age and kidney function only. 


\section{References}

1. Wolfe RA, Ashby VB, Milford EL, et al. Comparison of mortality in all patients on dialysis, patients on dialysis awaiting transplantation, and recipients of a first cadaveric transplant. $\mathrm{N}$ Engl J Med 1999; 341:1725-1730.

2. Evans RW, Manninen DL, Garrison LP, Jr., et al. The quality of life of patients with end-stage renal disease. N Engl J Med 1985; 312:553-559.

3. Merion RM, Ashby VB, Wolfe RA, et al. Deceased-donor characteristics and the survival benefit of kidney transplantation. Jama 2005; 294:2726-2733.

4. Snoeijs MG, Schaefer S, Christiaans MH, et al. Kidney transplantation using elderly non-heartbeating donors: a single-center experience. Am J Transplant 2006; 6:1066-1071.

5. Leunissen KM, Bosman FT, Nieman FH, et al. Amplification of the nephrotoxic effect of cyclosporine by preexistent chronic histological lesions in the kidney. Transplantation 1989; 48:590-593.

6. Remuzzi G, Grinyo J, Ruggenenti P, et al. Early experience with dual kidney transplantation in adults using expanded donor criteria. Double Kidney Transplant Group (DKG). J Am Soc Nephrol 1999; 10:2591-2598.

7. Lopes JA, Moreso F, Riera L, et al. Evaluation of pre-implantation kidney biopsies: comparison of Banff criteria to a morphometric approach. Kidney Int 2005; 67:1595-1600.

8. Wolters HH, Palmes D, Heidenreich S, et al. Long-term follow-up of double kidney transplantation using a score for evaluation of marginal donors. Transpl Int 2005; 18:453-457.

9. Andres A, Morales JM, Herrero JC, et al. Double versus single renal allografts from aged donors. Transplantation 2000; 69:2060-2066.

10. Sola R, Guirado L, Lopez Navidad A, et al. Renal transplantation with limit donors: to what should the good results obtained be attributed? Transplantation 1998; 66:1159-1163.

11. Stratta RJ, Rohr MS, Sundberg AK, et al. Intermediate-Term Outcomes With Expanded Criteria Deceased Donors in Kidney Transplantation: A Spectrum or Specter of Quality? Ann Surg 2006; 243:594-603.

12. Tesi RJ, Elkhammas EA, Davies EA, Henry ML, Ferguson RM. Pulsatile kidney perfusion for evaluation of high-risk kidney donors safely expands the donor pool. Clin Transplant 1994; 8:134-138.

13. Matsuno N, Konno O, Mejit A, et al. Application of machine perfusion preservation as a viability test for marginal kidney graft. Transplantation 2006; 82:1425-1428.

14. Kootstra G, Daemen JH, Oomen AP. Categories of non-heart-beating donors. Transplant Proc 1995; 27:2893-2894.

15. Snoeijs MG, Dekkers AJ, Buurman WA, et al. In Situ Preservation of Kidneys From Donors After Cardiac Death: Results and Complications. Ann Surg 2007; 246:844-852.

16. Persijn GG. Allocation of organs, particularly kidneys, within Eurotransplant. Hum Immunol 2006; 67:419-423.

17. Levey AS, Bosch JP, Lewis JB, Greene T, Rogers N, Roth D. A more accurate method to estimate glomerular filtration rate from serum creatinine: a new prediction equation. Modification of Diet in Renal Disease Study Group. Ann Intern Med 1999; 130:461-470.

18. Nankivell BJ, Borrows RJ, Fung CL, O'Connell PJ, Allen RD, Chapman JR. The natural history of chronic allograft nephropathy. N Engl J Med 2003; 349:2326-2333. 
19. Solez K, Colvin RB, Racusen LC, et al. Banff 07 classification of renal allograft pathology: updates and future directions. Am J Transplant 2008; 8:753-760.

20. Zou KH, O'Malley AJ, Mauri L. Receiver-operating characteristic analysis for evaluating diagnostic tests and predictive models. Circulation 2007; 115:654-657.

21. Seron D, Carrera M, Grino JM, et al. Relationship between donor renal interstitial surface and post-transplant function. Nephrol Dial Transplant 1993; 8:539-543.

22. Bosmans JL, Woestenburg A, Ysebaert DK, et al. Fibrous intimal thickening at implantation as a risk factor for the outcome of cadaveric renal allografts. Transplantation 2000; 69:2388-2394.

23. Gaber LW, Moore LW, Alloway RR, Amiri MH, Vera SR, Gaber AO. Glomerulosclerosis as a determinant of posttransplant function of older donor renal allografts. Transplantation 1995; 60:334-339.

24. Escofet X, Osman H, Griffiths DF, Woydag S, Adam Jurewicz W. The presence of glomerular sclerosis at time zero has a significant impact on function after cadaveric renal transplantation. Transplantation 2003; 75:344-346.

25. Edwards EB, Posner MP, Maluf DG, Kauffman HM. Reasons for non-use of recovered kidneys: the effect of donor glomerulosclerosis and creatinine clearance on graft survival. Transplantation 2004; 77:1411-1415.

26. Randhawa PS, Minervini MI, Lombardero M, et al. Biopsy of marginal donor kidneys: correlation of histologic findings with graft dysfunction. Transplantation 2000; 69:1352-1357.

27. Pokorna E, Vitko S, Chadimova M, Schuck O, Ekberg H. Proportion of glomerulosclerosis in procurement wedge renal biopsy cannot alone discriminate for acceptance of marginal donors. Transplantation 2000; 69:36-43.

28. Bajwa M, Cho YW, Pham PT, et al. Donor biopsy and kidney transplant outcomes: an analysis using the Organ Procurement and Transplantation Network/United Network for Organ Sharing (OPTN/UNOS) database. Transplantation 2007; 84:1399-1405.

29. Port FK, Bragg-Gresham JL, Metzger RA, et al. Donor characteristics associated with reduced graft survival: an approach to expanding the pool of kidney donors. Transplantation 2002; 74:1281-1286.

30. Lindeman RD, Tobin J, Shock NW. Longitudinal studies on the rate of decline in renal function with age. J Am Geriatr Soc 1985; 33:278-285.

31. Kaplan C, Pasternack B, Shah H, Gallo G. Age-related incidence of sclerotic glomeruli in human kidneys. Am J Pathol 1975; 80:227-234.

32. Kim YS, Moon JI, Kim DK, Kim SI, Park K. Ratio of donor kidney weight to recipient bodyweight as an index of graft function. Lancet 2001; 357:1180-1181.

33. Nankivell BJ, Fenton-Lee CA, Kuypers DR, et al. Effect of histological damage on long-term kidney transplant outcome. Transplantation 2001; 71:515-523.

34. Wijnen RM, Booster MH, Stubenitsky BM, de Boer J, Heineman E, Kootstra G. Outcome of transplantation of non-heart-beating donor kidneys. Lancet 1995; 345:1067-1070.

35. Muruve NA, Steinbecker KM, Luger AM. Are wedge biopsies of cadaveric kidneys obtained at procurement reliable? Transplantation 2000; 69:2384-2388.

36. Leichtman AB, Rennke HG, Killen PD, et al. Pre-placement fresh frozen kidney biopsies are poor predictors of percent glomerular obsolescence. Transplantation 2006; 82:632.

37. Hafajee ZA, Leong AS. Ultra-rapid microwave-stimulated tissue processing with a modified protocol incorporating microwave fixation. Pathology 2004; 36:325-329.

38. Corwin HL, Schwartz MM, Lewis EJ. The importance of sample size in the interpretation of the renal biopsy. Am J Nephrol 1988; 8:85-89. 
39. Oberbauer R, Rohrmoser M, Regele H, Muhlbacher F, Mayer G. Apoptosis of tubular epithelial cells in donor kidney biopsies predicts early renal allograft function. J Am Soc Nephrol 1999; 10:2006-2013.

40. Moreso F, Seron D, Gil-Vernet S, et al. Donor age and delayed graft function as predictors of renal allograft survival in rejection-free patients. Nephrol Dial Transplant 1999; 14:930-935.

41. de Fijter JW, Mallat MJ, Doxiadis, II, et al. Increased immunogenicity and cause of graft loss of old donor kidneys. J Am Soc Nephrol 2001; 12:1538-1546. 
138 | 


\section{Chapter 6}

Histological assessment of pre-transplant kidney biopsies is reproducible and representative 


\begin{abstract}
Background: Histological examination of pre-transplant renal biopsy specimens can be used to select grafts from older donors after cardiac death (DCD) with a satisfactory transplant outcome. The aim was to determine whether such biopsy specimens can be reproducibly scored between pathologists and are representative of the whole kidney.

Methods and findings: In renal biopsy specimens from DCD donors aged 60 years or older $(\mathrm{N}=44)$, globally sclerosed glomeruli, vascular narrowing, tubular atrophy and interstitial fibrosis were scored by 3 independent pathologists according to the Pirani scoring system. Interobserver agreement on the sum of scores improved considerably with the introduction of a combined tubulo-interstitial scoring item (intraclass correlation coefficient increased from 0.38 to 0.64 ). In small needle biopsy specimens ( $\mathrm{N}=144)$ obtained at autopsy, estimates of the proportion of globally sclerosed glomeruli were more precise with increasing sample size. Reasonably precise estimates may be obtained from specimens with at least 7 glomeruli.

Interpretation: It is feasible to implement pre-transplant renal biopsy specimen analysis as a selection criterion in clinical practice in order to accept kidneys from marginal donors for transplantation.
\end{abstract}

\title{
Published as
}

Snoeijs MG, Boonstra LA, Buurman WA, Goldschmeding R, van Suylen RJ, van Heurn LW, Peutz-Kootstra CJ. Histological assessment of pre-transplant kidney biopsies is reproducible and representative. Histopathology 2010; 56: 198-202. 


\section{Introduction}

Patients with end-stage renal disease attain longer life expectancy and better quality of life through kidney transplantation. ${ }^{1}$ Given the shortage of donor organs, efforts have been made to expand the deceased donor pool with older donors and donors after cardiac death (DCD). Indiscriminate use of kidneys from DCD donors aged 60 years or older leads to unsatisfactory graft function and survival, but careful selection may identify a subset of old DCD kidneys suitable for transplantation. ${ }^{2}$ We have previously shown that histological assessment of chronic degenerative changes in pre-implantation biopsy specimens retrospectively differentiated between old DCD kidneys with satisfactory and unacceptable outcomes after transplantation, whereas other potential selection criteria such as donor age and kidney function did not. ${ }^{3}$

When histological assessment is to be used for prospective clinical decision-making, biopsy specimens should be reproducibly assessed between pathologists and be representative of the entire kidney. Currently, no data are available on agreement between pathologists on assessment of pre-implantation kidney biopsies with the Pirani scoring system used by Remuzzi and Anglicheau. ${ }^{4,5}$ Furthermore, the precision of estimates of globally sclerosed glomeruli from small biopsy samples has been theoretically calculated but has not been evaluated in clinical practice. ${ }^{6}$ The current study was designed to address these unresolved issues.

\section{Materials and methods}

All baseline kidney biopsy specimens from DCD donors aged 60 years or older transplanted at our institution between 01/01/1994 and 01/07/2005 containing cortical tissue were studied ( $\mathrm{N}=44)$. Management of DCD donors at our institution has recently been described in detail. ${ }^{7}$ DCD kidneys were allocated according to standard Eurotransplant policies, with kidneys from donors aged 65 years or older having been allocated through the Eurotransplant Senior Program since $1999^{8}$. Specimens from kidneys with primary non-function due to postoperative complications $(\mathrm{N}=6)$ were excluded from analysis of diagnostic accuracy for prediction of long-term graft survival. Recipients were followed up until death or 01/01/2008. 
One renal biopsy specimen from a macroscopically normal part of each kidney was taken at organ recovery or reperfusion. Specimens (50\% needle biopsies, $50 \%$ small wedge biopsies) were formalin-fixed, cut at $3 \mu \mathrm{m}$ and stained with periodic acid-Schiff, hematoxylin and eosin, silver methenamine and Masson's trichrome. The median (range) number of glomeruli and arteries in the biopsies were 18 (5-70) and 3 (1-8), respectively. Globally sclerosed glomeruli, tubular atrophy, interstitial fibrosis and vascular narrowing were scored semiquantitatively on a scale of 0 to 3 by three independent pathologists (R.G., R.J.v.S. and C.J.P-K.) who were unaware of graft outcome. ${ }^{4,5}$ One pathologist (C.J.P-K.) scored all biopsies twice after an interval of more than 6 months. Agreement between or within observers was evaluated using intraclass correlation coefficients (ICC), a measure that is corrected for agreement by chance, with values between zero (chance agreement) and one (perfect agreement). ${ }^{9,10}$

To study the precision of estimates of globally sclerosed glomeruli, two $16 \mathrm{G}$ needle biopsies and one large cortical wedge (10 $\mathrm{mm}$ deep) were taken from different regions of both kidneys of 20 unselected deceased patients who underwent autopsy at our institution (aged $66 \pm 14$ years). Total glomeruli and globally sclerosed glomeruli were counted in formalin-fixed sections. Agreement on the proportion of glomerulosclerosis in large cortical wedges and needle biopsies was calculated according to Bland and Altman. ${ }^{11}$ Collection, storage and use of patient data and tissue were in agreement with the code of conduct 'Proper secondary use of human tissue' from the Dutch federation of biomedical scientific societies (http://www.federa.org/).

\section{Results}

Using the Pirani scoring system, we have previously shown that the optimal cutoff point for selection of kidneys with satisfactory long-term outcome lies between histological scores of 3 or less and 4 or more. ${ }^{3}$ ICC for classification of specimens according to this clinically relevant cut-off point was 0.38 , indicating poor agreement between pathologists (Table 1 ). The ICCs differed considerably between the separate scoring items and was highest for glomerulosclerosis $(0.87)$ and lowest for interstitial fibrosis (0.35). ICCs were similar for wedge and needle biopsies $(\mathrm{P}>0.14){ }^{12}$ In order to improve interobserver agreement, we evaluated a combined score of interstitial fibrosis and tubular atrophy, obtained by selecting the highest score of the two items. The ICC for this combined score was 0.61 and substitution of the two separate items with this combined tubulo-interstitial 
Table 6.1 Inter- and intraobserver agreement of three independent pathologists for scoring of pre-implantation biopsies with the Pirani scoring system ${ }^{4}$

\begin{tabular}{|c|c|c|c|c|}
\hline & \multicolumn{4}{|c|}{ INTRACLASS CORRELATION COEFFICIENT } \\
\hline & \multicolumn{3}{|c|}{ Between 3 independent observers } & \multirow{2}{*}{$\begin{array}{l}\text { Within } 1 \text { observer } \\
\text { All biopsies }(\mathrm{N}=44)\end{array}$} \\
\hline & $\begin{array}{l}\text { All biopsies } \\
\quad(\mathrm{N}=44)\end{array}$ & $\begin{array}{l}\text { Wedges } \\
(\mathrm{N}=22)\end{array}$ & $\begin{array}{c}\text { Needles } \\
(\mathrm{N}=22)\end{array}$ & \\
\hline $\begin{array}{l}\text { Sum of scores }(\mathrm{G}+\mathrm{V}+\mathrm{T}+\mathrm{I}) \text { : } \\
\text { Cut-off point: } \leq 3 \text { vs. } \geq 4\end{array}$ & 0.38 & 0.42 & 0.36 & 0.49 \\
\hline Globally sclerosed glomeruli (G) & 0.87 & 0.86 & 0.86 & 0.81 \\
\hline Vascular narrowing $(\mathrm{V})$ & 0.51 & 0.50 & 0.50 & 0.54 \\
\hline Tubular atrophy $(\mathrm{T})$ & 0.71 & 0.73 & 0.64 & 0.62 \\
\hline Interstitial fibrosis (I) & 0.35 & 0.45 & 0.16 & 0.51 \\
\hline Tubular atrophy / interstitial fibrosis ${ }^{b}$ & 0.61 & 0.67 & 0.47 & 0.62 \\
\hline $\begin{array}{l}\text { Sum of scores }(\mathrm{G}+\mathrm{V}+\mathrm{T} / \mathrm{I}) \text { : } \\
\text { Cut-off point: } \leq 3 \text { vs. } \geq 4\end{array}$ & 0.64 & 0.71 & 0.59 & 0.64 \\
\hline
\end{tabular}

a Two-way random effects models with absolute agreement definitions were applied.

${ }^{\mathrm{b}}$ Combined scores were obtained by selecting the highest score on either of these items.

score improved the ICC for the sum of scores from 0.38 to 0.64 . This indicates substantial interobserver agreement of similar magnitude as intraobserver agreement (ICC 0.64, Table 1). Of note, diagnostic accuracy for predicting graft loss within 5 years of transplantation remained constant after this substitution and was similar for all observers, as determined by receiver operator characteristic curves (data not shown)..$^{13}$

Subsequently, the precision of estimates of globally sclerosed glomeruli from small renal biopsy specimens was studied by comparing $16 \mathrm{G}$ needle biopsies with large cortical wedges obtained at autopsy (Figure 1). The mean difference in the proportion of globally sclerosed glomeruli between wedges and needle biopsy specimens $(\mathrm{N}=144)$ was $0.6 \pm 18 \%$, which shows that the estimation of glomerulosclerosis from needle biopsy specimens makes no systematic difference. ${ }^{11}$ The limits of agreement ( 2 standard deviations above and below the mean difference) between wedges and needle biopsy specimens were calculated according to the minimal number of glomeruli present in the needle biopsy specimens. ${ }^{11}$ The limits of agreement were $20 \%$ when at least 7 glomeruli were found in the needle biopsy sample, and were $10 \%$ when at least 17 glomeruli were available. Moreover, the precision of the estimate of globally sclerosed glomeruli increased with larger minimal sample size. 


\section{Precision of glomerulosclerosis estimates by sample size}

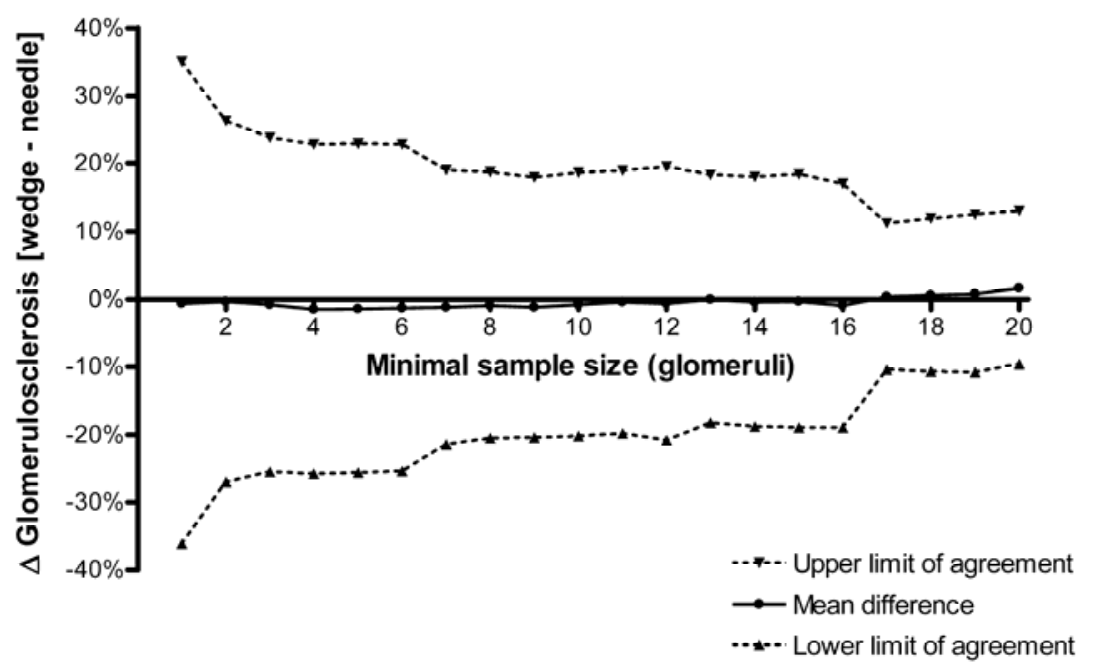

Figure 6.1 Precision of estimates of the fraction of sclerosed glomeruli from 16G needle biopsy specimens $(\mathrm{N}=144)$ and large cortical wedges obtained at autopsy according to the minimal number of glomeruli found in the needle biopsies. Limits of agreement are two standard deviations above and below the mean difference. ${ }^{11}$ Mean age of the deceased patients $(\mathrm{N}=20)$ was $66 \pm 14$ years.

\section{Discussion}

The critical shortage of kidneys for transplantation calls for efforts to expand the donor pool maximally while avoiding kidneys which result in an unsatisfactory outcome. This is of particular importance in kidneys from old DCD donors that are associated with a suboptimal outcome when transplanted indiscriminately. ${ }^{2}$ We have previously shown that histological examination of pre-implantation biopsy specimens may improve the selection of kidneys from DCD donors aged 60 years or older. ${ }^{3}$ Other groups have recently reported similar findings and have shown that degenerative changes in different renal compartments (globally sclerosed glomeruli, tubular atrophy, interstitial fibrosis and vascular narrowing) independently predict transplant outcome.5,14 The current study extends these findings by presenting data on the agreement on histological scores between different observers and on the sampling error resulting from the small size of the renal biopsy specimens. 
Several studies have previously shown that interstitial fibrosis, tubular atrophy and arteriolar hyalinosis as defined in the Banff classification typically have ICC or $\kappa$ statistics of $0.20-0.60$ indicating poor to moderate agreement between pathologists. ${ }^{15,16}$ Interobserver agreement on the area affected by a process with diffuse gradual expansion such as interstitial fibrosis seems to be particularly troublesome. ${ }^{15}$ In the light of these previous findings, it is not surprising that we found interobserver variability in the assessment of pre-existing degenerative changes in renal biopsy specimens according to the Pirani scoring system. ${ }^{4}$ Agreement between pathologists improved by combining interstitial fibrosis the item with least interobserver agreement that probably determines the variability of the scoring system - with tubular atrophy into a single parameter. This approach is in line with the probable pathophysiology of these phenomena and is also suggested in a recent update of the Banff classification of renal transplant biopsy specimens. ${ }^{17}$ It has been suggested that studies of pathologists working closely together in one institution may inflate estimates of interobserver agreement. ${ }^{15}$ To increase the generalizability of our results, a pathologist practising at a separate institution (R.G.) participated in the current study. Assessment of renal pathology on frozen sections is difficult and would probably have resulted in greater variation between observers than with the formalin-fixed sections used in the current study. However, it should be feasible to assess pre-implantation biopsy specimens on formalin-fixed sections if novel ultra-rapid processing protocols are used. ${ }^{18}$

In addition to imperfect agreement between observers, sampling error may also compromise the interpretation of the relatively small specimens taken from donor kidneys. For example, superficial wedge biopsy specimens may overestimate the percentage of sclerosed glomeruli as these are more frequently found in the subcapsular region of the kidney. ${ }^{19}$ Specimens containing $3 \mathrm{~mm}^{2}$ of cortex (corresponding to approximately 6-10 glomeruli) are sufficient for accurate analysis of the area affected by tubular atrophy and interstitial fibrosis. ${ }^{20}$ Therefore, assessment of globally sclerosed glomeruli sets the highest demands for sample size and several arbitrary cut-offs have been proposed for the minimal number of glomeruli present in the specimen: the Banff classification asks for 7 glomeruli, ${ }^{21}$ whereas the Pirani score suggests at least 25 glomeruli ${ }^{4}$. Our findings show that the precision of estimates of globally sclerosed glomeruli from small needle biopsy specimens rises with increasing sample size, and we suggest that reasonably precise estimates may be obtained from specimens with at least 7 glomeruli. These findings from clinical practice are in line with previous theoretical arguments based on probability calculations. ${ }^{6,22}$ The proportion of globally 
sclerosed glomeruli observed in renal biopsy specimens should therefore be interpreted as an estimate of actual glomerulosclerosis with precision depending on sample size.

In summary, histological assessment of pre-implantation biopsy specimens from older DCD kidneys is reproducible among pathologists and representative of the entire kidney. We therefore conclude that it is feasible to implement this selection criterion into clinical practice in order to safely accept kidneys from DCD donors aged 60 years or older for transplantation.

\section{References}

1. Wolfe RA, Ashby VB, Milford EL, et al. Comparison of mortality in all patients on dialysis, patients on dialysis awaiting transplantation, and recipients of a first cadaveric transplant. $\mathrm{N}$ Engl J Med 1999; 341:1725-1730.

2. Snoeijs MG, Schaefer S, Christiaans MH, et al. Kidney transplantation using elderly non-heartbeating donors: a single-center experience. Am J Transplant 2006; 6:1066-1071.

3. Snoeijs MG, Buurman WA, Christiaans MH, et al. Histological assessment of preimplantation biopsies may improve selection of kidneys from old donors after cardiac death. Am J Transplant 2008; 8:1844-1851.

4. Remuzzi G, Grinyo J, Ruggenenti P, et al. Early experience with dual kidney transplantation in adults using expanded donor criteria. Double Kidney Transplant Group (DKG). J Am Soc Nephrol 1999; 10:2591-2598.

5. Anglicheau D, Loupy A, Lefaucheur C, et al. A simple clinico-histopathological composite scoring system is highly predictive of graft outcomes in marginal donors. Am J Transplant 2008; 8:2325-2334.

6. Corwin HL, Schwartz MM, Lewis EJ. The importance of sample size in the interpretation of the renal biopsy. Am J Nephrol 1988; 8:85-89.

7. Snoeijs MG, Dekkers AJ, Buurman WA, et al. In Situ Preservation of Kidneys From Donors After Cardiac Death: Results and Complications. Ann Surg 2007; 246:844-852.

8. Frei U, Noeldeke J, Machold-Fabrizii V, et al. Prospective age-matching in elderly kidney transplant recipients--a 5-year analysis of the Eurotransplant Senior Program. Am J Transplant 2008; 8:50-57.

9. Landis JR, Koch GG. The measurement of observer agreement for categorical data. Biometrics 1977; 33:159-174. 
10. Shrout PE, Fleiss JL. Intraclass correlations: uses in assessing rater reliability. Psychol Bull 1979; 86:420-428.

11. Bland JM, Altman DG. Statistical methods for assessing agreement between two methods of clinical measurement. Lancet 1986; 1:307-310.

12. Donner A, Bull S. Inferences concerning a common intraclass correlation coefficient. Biometrics 1983; 39:771-775.

13. Obuchowski NA. ROC analysis. AJR Am J Roentgenol 2005; 184:364-372.

14. Munivenkatappa RB, Schweitzer EJ, Papadimitriou JC, et al. The Maryland aggregate pathology index: a deceased donor kidney biopsy scoring system for predicting graft failure. Am J Transplant 2008; 8:2316-2324.

15. Furness PN, Taub N, Assmann KJ, et al. International variation in histologic grading is large, and persistent feedback does not improve reproducibility. Am J Surg Pathol 2003; 27:805-810.

16. Gough J, Rush D, Jeffery J, et al. Reproducibility of the Banff schema in reporting protocol biopsies of stable renal allografts. Nephrol Dial Transplant 2002; 17:1081-1084.

17. Solez K, Colvin RB, Racusen LC, et al. Banff '05 Meeting Report: Differential Diagnosis of Chronic Allograft Injury and Elimination of Chronic Allograft Nephropathy ('CAN'). Am J Transplant 2007; 7:518-526.

18. Hafajee ZA, Leong AS. Ultra-rapid microwave-stimulated tissue processing with a modified protocol incorporating microwave fixation. Pathology 2004; 36:325-329.

19. Muruve NA, Steinbecker KM, Luger AM. Are wedge biopsies of cadaveric kidneys obtained at procurement reliable? Transplantation 2000; 69:2384-2388.

20. Oberholzer M, Torhorst J, Perret E, Mihatsch MJ. Minimum sample size of kidney biopsies for semiquantitative and quantitative evaluation. Nephron 1983; 34:192-195.

21. Racusen LC, Solez K, Colvin RB, et al. The Banff 97 working classification of renal allograft pathology. Kidney Int 1999; 55:713-723.

22. Madaio MP. Renal biopsy. Kidney Int 1990; 38:529-543. 
148 | 


\section{Chapter 7}

Viability markers of kidneys

from donors after cardiac death in the perfusate proteome 


\begin{abstract}
Background: Donation after cardiac death (DCD) may greatly expand the donor pool, but concerns about warm ischemic injury before organ recovery have resulted in a reluctance to use DCD kidneys for transplantation. Accurate assessment of the extent of ischemic acute kidney injury before implantation would therefore increase the confidence to transplant DCD kidneys after prolonged warm ischemia.

Methods: We explored the proteome of perfusate samples from machineperfused human donor kidneys $(\mathrm{N}=18)$ in an unbiased fashion using difference gel electrophoresis to discover novel biomarkers of ischemic acute kidney injury. Findings: 221 unique protein spots were identified in renal perfusate, of which 16 spots were present in $>70 \%$ of the samples. Standardized volumes of two highly correlated spots - most likely representing a single protein - were significantly higher, whereas the concentration of a third spot was significantly lower in the preservation solution of ischemically injured kidneys from DCD donors compared to that of kidneys from brain-dead donors that had not suffered warm ischemic injury. The ratio of these markers provided clear distinction between kidney types with different levels of warm ischemic injury $(\mathrm{P}=0.001)$.

Interpretation: We discovered two biomarkers of ischemic acute renal injury in human donor kidneys. The identity of these biomarkers and their diagnostic value for the selection of ischemically injured DCD kidneys in clinical transplantation should be determined in future studies.
\end{abstract}

\title{
Published as
}

Snoeijs MG, Pulinx B, van Dieijen-Visser MP, Buurman WA, van Heurn LW, Wodzig W. Viability markers of kidneys from donors after cardiac death in the perfusate proteome. Manuscript in preparation. 


\section{Introduction}

Kidney transplantation is the optimal therapy for patients with end-stage renal disease but its use is limited by the shortage of organ donors. ${ }^{1-3}$ Widespread implementation of donation after cardiac death (DCD) may substantially increase the number of kidneys available for transplantation. ${ }^{4,5}$ However, concerns about early graft dysfunction due to warm ischemic injury before organ recovery have resulted in a general reluctance to expand the use of DCD kidneys to its full potential. The extent of ischemic injury suffered by these kidneys varies widely and does not necessarily correspond to the period of absolute warm ischemia, because inconsistent renal perfusion during cardiopulmonary resuscitation and withdrawal of supportive treatment and the variable efficacy of renal cooling during in situ preservation also contribute to the ischemic injury. Therefore, accurate assessment of the extent of ischemic acute kidney injury before implantation is needed and may increase the confidence to transplant DCD kidneys after prolonged warm ischemia.

Organ preservation by hypothermic machine perfusion results in superior transplant outcomes compared to static cold storage. ${ }^{6}$ Moreover, hypothermic machine preservation provides the opportunity to study the renovascular resistance to perfusate flow and to measure biomarkers of cellular injury in samples of the perfusion solution. High vascular resistance and increased levels of 'viability markers' such as lactate dehydrogenase (LDH), glutathione Stransferase (GST), fatty acid-binding proteins (FABP) and redox-active iron are associated with early graft dysfunction and are used by transplant centers to decide whether or not to accept donor kidneys for transplantation..$^{7-12}$ However, it has recently been demonstrated that the predictive value of these parameters for adverse transplant outcomes is insufficient to be useful in clinical decision making. ${ }^{13-15}$

To discover novel biomarkers of ischemic acute kidney injury, we explored the protein content of perfusate samples from human donor kidneys in an unbiased fashion using difference gel electrophoresis. We found two proteins with significantly different concentrations in perfusate of ischemically injured kidneys from uncontrolled DCD donors compared to samples from brain-dead donor kidneys without warm ischemic injury. These biomarkers may provide novel diagnostic tools to identify DCD kidneys with prolonged ischemia times that are still suitable for transplantation. 


\section{Materials and methods}

\section{Study design}

This observational cohort study included 18 donor kidneys that were preserved by hypothermic machine perfusion at our transplant center between 01/05/2007 and 31/03/2009. All kidneys were recovered from separate donors between 18 and 65 years of age and were transplanted within the Eurotransplant area. Among the 21 donor kidneys fulfilling these criteria, 6 kidneys from donors after brain death (DBD), 6 kidneys from DCD donors after controlled withdrawal of supportive treatment in the intensive care unit and 6 kidneys from uncontrolled DCD donors after failed cardiopulmonary resuscitation were selected. The perfusate proteome of these kidneys types was compared to discover novel biomarkers of ischemic acute kidney injury.

\section{Hypothermic machine perfusion}

DBD kidneys were recovered according to standard multi-organ procurement techniques. ${ }^{16}$ DCD kidneys were recovered after rapid laparotomy and direct aortic cannulation for controlled donors and after in situ perfusion with doubleballoon triple-lumen catheters (Coloplast A/S, Humlebaeck, Denmark) for uncontrolled donors. ${ }^{17}$ After recovery, donor kidneys were transported to our institution for hypothermic perfusion on a LifePort machine with 1 L UW-MPS preservation solution (Organ Recovery Systems, Des Plaines, IL). Maximum perfusion pressure was $30 \mathrm{mmHg}$ for DBD and controlled DCD kidneys and 40 $\mathrm{mmHg}$ for uncontrolled DCD kidneys.

After 1 hour of perfusion, a sample of the preservation solution was taken from the machine and centrifuged at $900 \mathrm{~g}$ at $4^{\circ} \mathrm{C}$ for 10 minutes. Within 30 minutes from sampling, $100 \mu \mathrm{L}$ and $1 \mathrm{~mL}$ aliquots of the perfusate were stored at $-80^{\circ} \mathrm{C}$ until further analysis. At 4 hours of perfusion, renovascular resistance was recorded and the perfusate concentrations of LDH and GST were measured. LDH was determined by standard colorimetric assay (Boehringer Mannheim, Almere, the Netherlands) and total GST activity was measured as described previously. ${ }^{18}$ All perfusion characteristics were adjusted for kidney weight.

\section{$2 D$ fluorescence difference gel electrophoresis}

From each perfusate sample, $5 \mu \mathrm{g}$ protein mass was labeled at random with 400 pmol Cy3 or Cy5, whereas $2.5 \mu \mathrm{g}$ protein mass was added to a pooled internal standard which was labeled with 200 pmol Cy2. Labeling was done on ice and in 
the dark at $\mathrm{pH} 8.5$ (adjusted by $50 \mathrm{mM} \mathrm{NaOH}$ ) for 30 minutes. The labeling reactions were quenched by incubation with $10 \mathrm{mM}$ lysine for 10 minutes. Subsequently, an equal volume of $2 \mathrm{x}$ lysis buffer (7 M urea, $2 \mathrm{M}$ thiourea, $4 \%$ CHAPS, $0.04 \%$ bromophenol blue, 2\% DTT, 2\% IPG buffer $\mathrm{pH} 3-10$ ) was added to the samples.

Perfusate samples were applied on Immobiline DryStrip gels $(18 \mathrm{~cm}, 3-$ $10 \mathrm{~nL}$; GE Healthcare, Chalfont St. Giles, United Kingdom) that had been passively rehydrated with DeStreak Rehydration Solution (GE Healthcare) supplemented with $0.5 \%$ IPG buffer $\mathrm{pH}$ 3-10 for 6 hours. Iso-electric focussing was done at a constant temperature of $20^{\circ} \mathrm{C}$ using the following voltages: $150 \mathrm{~V}$ for 3 hours, $300 \mathrm{~V}$ for 3 hours, gradient from 300 to $1000 \mathrm{~V}$ for 6 hours, gradient from 1000 to $8000 \mathrm{~V}$ for 1 hour and $8000 \mathrm{~V}$ for 2 hours. Thereafter, proteins were equilibrated by incubation in equilibration solution (6 M urea, 2\% CHAPS, 50 $\mathrm{mM}$ Tris pH 8.8, 0.02\% bromophenol blue, 30\% glycerol) supplemented with $1 \%$ DTT for 15 minutes at room temperature, followed by incubation with 2.5\% iodoacetamide in equilibration solution for 15 minutes at room temperature. The strips were then transferred onto $12.5 \%$ homogeneous polyacrylamide gels that had been precasted in low fluorescence glass plates. Finally, SDS-PAGE was carried out using the Ettan DALTsix (GE Healthcare) at $5 \mathrm{~W}$ for 1 hour and $90 \mathrm{~W}$ until the bromophenol blue front reached the bottom of the gels.

\section{Gel analysis}

The gels were scanned on an EDI imager (GE Healthcare) using excitation / emission wavelengths specific for $\mathrm{Cy} 2, \mathrm{Cy} 3$ and $\mathrm{Cy} 5$. Images were analyzed using DeCyder 7.0 software (GE Healthcare) according to manufacturer's instructions. Spot volumes (representing protein abundance) were standardized to the pooled internal standard. Log standard abundance was calculated using the differential in-gel analysis (DIA) and biological variation analysis (BVA) modules.

\section{Ethics}

Patient data were collected, stored and used in agreement with the code of conduct 'Use of data in health research' put forward by the federation of Dutch medical scientific societies (http://www.federa.org/). 
Table 7.1 Transplantation characteristics of machine perfused donor kidneys ${ }^{a}$

\begin{tabular}{|c|c|c|c|c|}
\hline & $\begin{array}{c}\text { Uncontrolled } \\
\text { DCD kidneys } \\
(\mathrm{N}=6)\end{array}$ & $\begin{array}{c}\text { Controlled } \\
\text { DCD kidneys } \\
(\mathrm{N}=6)\end{array}$ & $\begin{array}{c}\text { DBD kidneys } \\
\qquad(\mathrm{N}=6)\end{array}$ & $\mathbf{P}$ \\
\hline \multicolumn{5}{|l|}{ Donor characteristics } \\
\hline Age (years) & $51(3)$ & $56(3)$ & $49(1)$ & 0.24 \\
\hline Sex (male / female) & $83 / 17 \%$ & 33 / 67\% & $16 / 83 \%$ & 0.05 \\
\hline Cause of death (neurological / vascular) & $0 / 100 \%$ & $100 / 0 \%$ & $83 / 17 \%$ & 0.001 \\
\hline Serum creatinine $(\mu \mathrm{mol} / \mathrm{L})$ & $93(16)$ & $84(14)$ & $65(8)$ & 0.30 \\
\hline Hypertension (yes / no) & $20 / 80 \%$ & $0 / 100 \%$ & $20 / 80 \%$ & 0.50 \\
\hline \multicolumn{5}{|l|}{ Graft characteristics } \\
\hline CPR time (min) & $45(10)$ & - & - & - \\
\hline Ventilator switch-off time (min) ${ }^{b}$ & - & $28(8)$ & - & - \\
\hline Warm ischemia time $(\min )^{c}$ & $37(10)$ & $18(2)$ & $0(0)$ & 0.002 \\
\hline Cold ischemia time (hour) & $22(1)$ & $17(2)$ & $31(3)$ & 0.001 \\
\hline Anastomosis time (min) & $41(5)$ & $43(6)$ & $68(15)$ & 0.12 \\
\hline Vascular resistance $(\mathrm{mmHg} / \mathrm{mL} / \mathrm{min} / 100 \mathrm{~g})$ & $0.20(0.01)$ & $0.24(0.03)$ & $0.37(0.09)$ & 0.15 \\
\hline LDH concentration (U/L/100g) & $339(20)$ & $193(45)$ & $188(31)$ & 0.005 \\
\hline GST activity (U/L/100g) & $48(9)$ & $19(4)$ & $17(7)$ & 0.02 \\
\hline \multicolumn{5}{|l|}{ Recipient characteristics } \\
\hline Age (years) & $65(2)$ & $49(6)$ & $43(6)$ & 0.02 \\
\hline Sex (male / female) & 83 / 17\% & $83 / 17 \%$ & 33 / 67\% & 0.11 \\
\hline Graft function (immediate / delayed / never) & 0 / 67 / 33\% & $50 / 50 / 0 \%$ & $50 / 50 / 0 \%$ & 0.13 \\
\hline Duration of delayed graft function (days) & $13(2)$ & $16(6)$ & $8(5)$ & 0.52 \\
\hline GFR at 3 months $(\mathrm{mL} / \mathrm{min})^{\mathrm{d}}$ & $48(6)$ & $31(6)$ & $52(7)$ & 0.06 \\
\hline
\end{tabular}

a Data are presented as mean (standard error) or as percentages.

b Ventilator switch-off time was defined as the time from withdrawal of supportive treatment until circulatory arrest.

${ }^{\mathrm{c}}$ Warm ischemia time was defined as the time from circulatory arrest until initiation of hypothermic organ perfusion and therefore does not include ventilator switch-off time and cardiopulmonary resuscitation time.

${ }^{\mathrm{d}}$ Glomerular filtration rate was estimated using the abbreviated Modification of Diet in Renal Disease formula. ${ }^{19}$

\section{Statistics}

Continuous variables were expressed as means with standard errors and categorical variables as percentages. For continuous variables, differences between groups were compared with one-way ANOVA and independent samples t-tests. For categorical variables, differences between groups were compared with Fisher exact tests. Correlations between continuous variables were assessed with Pearson correlation coefficients. Results with $\mathrm{P}<0.05$ were considered statistically significant. 


\section{Results}

\section{Transplant characteristics}

Donor, preservation and recipient characteristics of the machine perfused kidneys are presented in Table 7.1. As expected, uncontrolled DCD donors died significantly more often from cardiovascular causes than controlled DCD and DBD donors and warm ischemia times of DCD kidneys were significantly longer than those of DBD kidneys. Furthermore, DBD kidneys were associated with significantly longer cold ischemia times, since our policy was to preserve DBD kidneys by hypothermic machine perfusion only for recipients residing in the Dutch Antilles with expected prolonged cold ischemia. Patients who received uncontrolled DCD kidneys were significantly older than recipients of controlled DCD and DBD kidneys, which may be explained by the tendency to transplant grafts of perceived lower quality into older recipients with a worse prognosis on dialysis therapy. Other baseline characteristics were similar between the study groups.

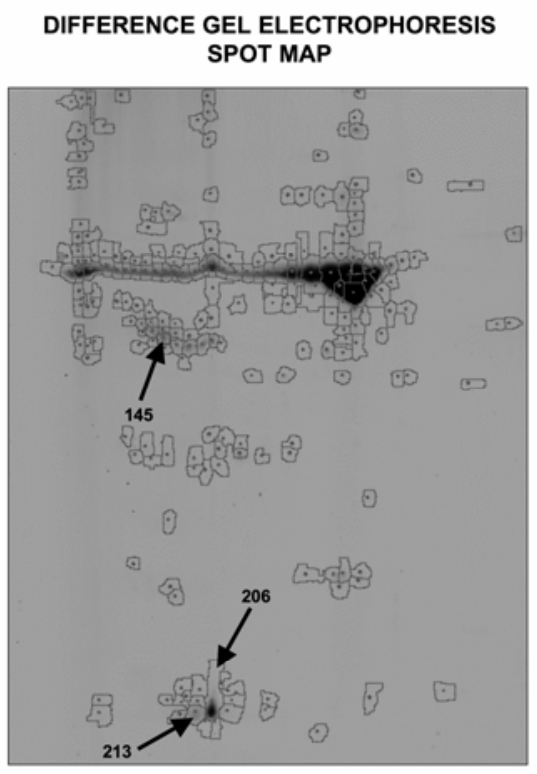

Figure 7.1 Difference gel electropheresis of perfusate samples from machine perfused donor kidneys. 221 unique protein spots were identified and 16 of these spots were present in $>70 \%$ of the perfusate samples. Among the latter, the intensity of spots 145, 206 and 213 were significantly different between the three groups of kidneys. 
During machine perfusion, renovascular resistance of the three kidney types was comparable, whereas LDH and GST concentrations in the perfusate were significantly higher for uncontrolled DCD kidneys than for controlled DCD and DBD kidneys. Immediate graft function was observed in 50\% of controlled DCD and DBD kidneys and in $0 \%$ of uncontrolled DCD kidneys, whereas $50 \%$ of controlled DCD and DBD kidneys and 67\% of uncontrolled DCD kidneys suffered from delayed graft function. Only among uncontrolled DCD kidneys, 2 grafts (33\%) never functioned, which is referred to as primary non-function. At three months after transplantation, estimated glomerular filtration rate of functioning grafts was not significantly different between the study groups.

\section{Difference gel electrophoresis of renal perfusate}

Using difference gel electrophoresis of perfusate samples from machine perfused donor kidneys, 221 unique protein spots were identified (Figure 7.1). In contrast, no protein spots were found in gels from preservation solution that was sampled before the start of renal perfusion (data not shown). Statistical analysis was restricted to 16 protein spots present in $>70 \%$ of perfusate samples. The intensity of three of these spots was significantly different between the three kidney types with at least 1.5-fold difference in intensity (Table 7.2). The abundance of spots 206 and 213 was significantly greater in DCD kidneys as compared to DBD kidneys, whereas the abundance of spot 145 was significantly lower in uncontrolled DCD kidneys than in kidneys from DBD donors.

Spots 206 and 213 were located in close proximity on the gels and their standardized spot volumes were strongly correlated $(\mathrm{R}=0.94, \mathrm{P}<0.001)$. Therefore, these spots most likely represent different post-translational modifications of the same protein. In contrast, no correlation was observed between spot 145 and spots 206 and $213(\mathrm{R}=-0.07, \mathrm{P}=0.81$ and $\mathrm{R}=0.05, \mathrm{P}=0.85$, respectively), indicating that these markers may hold distinct diagnostic value. The ratio of standardized volumes of spot 213 to spot 145 provided clear distinction between kidney types

Table 7.2 Differently expressed proteins in perfusion solution of donor kidneys ${ }^{\mathrm{a}}$

\begin{tabular}{lcccc}
\hline & $\begin{array}{c}\text { Uncontrolled DCD } \\
\text { kidneys }\end{array}$ & $\begin{array}{c}\text { Controlled DCD } \\
\text { kidneys }\end{array}$ & DBD kidneys & P \\
\hline Spot 145 (standardized spot volume) & $1.0 \pm 0.2$ & $1.9 \pm 0.6$ & $3.1 \pm 0.8$ & 0.02 \\
Spot 206 (standardized spot volume) & $5.0 \pm 0.6$ & $6.8 \pm 2.0$ & $2.5 \pm 0.3$ & 0.01 \\
Spot 213 (standardized spot volume) & $3.6 \pm 0.3$ & $4.4 \pm 1.0$ & $2.1 \pm 0.4$ & 0.007 \\
\hline
\end{tabular}

a Data are presented as mean (standard error). P-values are derived from comparison of log standard abundances. 


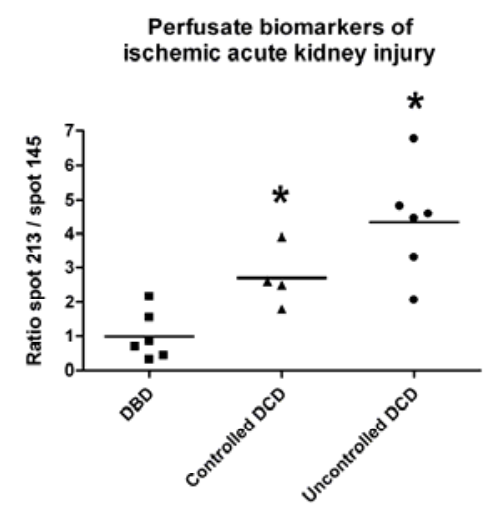

Figure 7.2 The ratio of standardized volumes of spot 213 to spot 145 in difference gel electrophoresis of perfusate samples increases with the extent of ischemic acute kidney injury. Data are presented as individual values and means. Asterisk indicates statistical significance compared to DBD kidneys ( $\mathrm{P}=0.001$ for uncontrolled DCD kidneys and $\mathrm{P}=0.02$ for controlled DCD kidneys).

that suffered different levels of ischemic injury ( $\mathrm{P}=0.001$, Figure 7.2).

\section{Discussion}

Donation after cardiac death may greatly expand the number of kidneys available for transplantation, but its use is limited by the reluctance of many to transplant donor kidneys with acute ischemic injury that are at increased risk of early graft dysfunction. In the current study, we analyzed the proteome of the preservation solution of machine perfused donor kidneys and identified novel biomarkers of ischemic acute kidney injury. The concentrations of two highly correlated markers (most likely representing a single protein) were significantly higher whereas the concentration of a distinct marker was significantly lower in the preservation solution of ischemically injured kidneys from DCD donors compared to that of DBD kidneys that had not suffered warm ischemic injury. These biomarkers may present the opportunity to assess the extent of ischemic injury of human donor kidneys before transplantation.

Until now, hypothesis-driven selection of parameters for evaluation of ischemic injury to donor kidneys has failed to produce clinically useful predictors of graft viability. Characteristics of hypothermic machine perfusion such as renovascular resistance and perfusate concentrations of enzymes released from damaged tubular epithelial cells (LDH, GST and FABP) did not predict early graft 
failure with sufficient accuracy to justify the discard of scarce donor kidneys. ${ }^{13-15}$ Since the hypothesis-driven identification of biomarkers for acute ischemic injury so far has met with limited success, we decided to take an alternative approach by performing unbiased data-driven analysis of the perfusate proteome. Rather than building on previous experimental findings, this approach may generate novel hypotheses about the pathophysiology and diagnosis of ischemic acute kidney injury. ${ }^{20}$ In renal transplant recipients, analyses of the urinary proteome has previously been successful in the identification of biomarkers for acute rejection, chronic allograft nephropathy and BK virus nephropathy. ${ }^{21-27}$ Furthermore, acute kidney injury after cardiopulmonary bypass or administration of iodinated contrast agents was also reflected by changes in the urinary proteome. ${ }^{28-30}$ These findings illustrate the potential of proteomics for the diagnosis of renal disease.

A major strength of the current proteome analysis is the use of preservation solution from isolated perfused human donor kidneys. Since the preservation solution did not contain proteins before perfusion, all protein spots in the gels must have been derived from the donor kidneys. In contrast, plasma or urine samples are contaminated by proteins derived from organs other than the kidneys, reducing the chances of discovering biomarkers for renal injury. Proteome analysis has been criticized because of its low reproducibility between laboratories. Indeed, some techniques are sensitive to seemingly minor differences in the analytical protocol. ${ }^{31} \mathrm{We}$ therefore took care to collect, process and store the perfusate samples in a highly standardized fashion. Moreover, the reproducibility of gel electrophoresis was improved by normalizing the spot intensities to a pooled control sample that was run on each gel.

The current study on injury biomarkers in the preservation solution of human donor kidneys did not account for recipient factors, which is an inherent limitation of all research on the assessment of donor organ quality before implantation. We have previously shown that the hemodynamic status of the recipient during transplant surgery is a major predictor of primary non-function after DCD kidney transplantation. ${ }^{32}$ Therefore, primary non-function is not exclusively determined by donor and graft characteristics but recipient factors also contribute to this complication. This indicates that it would be unrealistic to expect viability testing before transplantation to entirely eliminate primary nonfunction. Nevertheless, new biomarkers of ischemic acute kidney injury will be useful to identify DCD kidneys with prolonged ischemia times that have a low risk of early graft failure and are therefore suitable for clinical transplantation. 
In conclusion, after unbiased exploration of the protein content of perfusate samples from machine perfused kidneys, we discovered two novel biomarkers of ischemic acute renal injury in human donor kidneys. The identity of these biomarkers and their diagnostic value for the selection of ischemically injured DCD kidneys in clinical transplantation should be determined in future studies. 


\section{References}

1. Wolfe RA, Ashby VB, Milford EL, et al. Comparison of mortality in all patients on dialysis, patients on dialysis awaiting transplantation, and recipients of a first cadaveric transplant. $\mathrm{N}$ Engl J Med 1999; 341:1725-1730.

2. Gridelli B, Remuzzi G. Strategies for making more organs available for transplantation. N Engl J Med 2000; 343:404-410.

3. Lechler RI, Sykes M, Thomson AW, Turka LA. Organ transplantation--how much of the promise has been realized? Nat Med 2005; 11:605-613.

4. Daemen JW, Oomen AP, Kelders WP, Kootstra G. The potential pool of non-heart-beating kidney donors. Clin Transplant 1997; 11:149-154.

5. Terasaki PI, Cho YW, Cecka JM. Strategy for eliminating the kidney shortage. Clin Transpl 1997:265-267.

6. Moers C, Smits JM, Maathuis MH, et al. Machine perfusion or cold storage in deceased-donor kidney transplantation. N Engl J Med 2009; 360:7-19.

7. Baxby K, Taylor RM, Anderson M, Johnson RW, Swinney J. Assessment of cadaveric kidneys for transplantation. Lancet 1974; 2:977-979.

8. Daemen JW, Oomen AP, Janssen MA, et al. Glutathione S-transferase as predictor of functional outcome in transplantation of machine-preserved non-heart-beating donor kidneys. Transplantation 1997; 63:89-93.

9. Gok MA, Pelsers M, Glatz JF, et al. Comparison of perfusate activities of glutathione Stransferase, alanine aminopeptidase and fatty acid binding protein in the assessment of nonheart-beating donor kidneys. Ann Clin Biochem 2003; 40:252-258.

10. de Vries B, Snoeijs MG, von Bonsdorff L, Ernest van Heurn LW, Parkkinen J, Buurman WA. Redox-active iron released during machine perfusion predicts viability of ischemically injured deceased donor kidneys. Am J Transplant 2006; 6:2686-2693.

11. Matsuno N, Konno O, Mejit A, et al. Application of machine perfusion preservation as a viability test for marginal kidney graft. Transplantation 2006; 82:1425-1428.

12. Tesi RJ, Elkhammas EA, Davies EA, Henry ML, Ferguson RM. Pulsatile kidney perfusion for evaluation of high-risk kidney donors safely expands the donor pool. Clin Transplant 1994; 8:134-138.

13. Sonnenday CJ, Cooper M, Kraus E, Gage F, Handley C, Montgomery RA. The hazards of basing acceptance of cadaveric renal allografts on pulsatile perfusion parameters alone. Transplantation 2003; 75:2029-2033.

14. Moers C, Varnav OC, Treckmann J, et al. GST and HFABP during machine perfusion of deceased donor kidneys are independent predictors of delayed graft function but not of primary non-function and graft survival. Transpl Int 2009; 22:42.

15. Pirenne J, Smits J, Monbaliu D, et al. Renal resistance during machine perfusion is a risk factor for delayed graft function and poorer graft survival. Transpl Int 2009; 22:56.

16. Rosenthal JT, Shaw BW, Jr., Hardesty RL, Griffith BP, Starzl TE, Hakala TR. Principles of multiple organ procurement from cadaver donors. Ann Surg 1983; 198:617-621.

17. Snoeijs MG, Dekkers AJ, Buurman WA, et al. In Situ Preservation of Kidneys From Donors After Cardiac Death: Results and Complications. Ann Surg 2007; 246:844-852. 
18. Van Kreel BK, Janssen MA, Kootstra G. Functional relationship of alpha-glutathione Stransferase and glutathione S-transferase activity in machine-preserved non-heart-beating donor kidneys. Transpl Int 2002; 15:546-549.

19. Levey AS, Bosch JP, Lewis JB, Greene T, Rogers N, Roth D. A more accurate method to estimate glomerular filtration rate from serum creatinine: a new prediction equation. Modification of Diet in Renal Disease Study Group. Ann Intern Med 1999; 130:461-470.

20. Fliser D, Novak J, Thongboonkerd V, et al. Advances in urinary proteome analysis and biomarker discovery. J Am Soc Nephrol 2007; 18:1057-1071.

21. Clarke W, Silverman BC, Zhang Z, Chan DW, Klein AS, Molmenti EP. Characterization of renal allograft rejection by urinary proteomic analysis. Ann Surg 2003; 237:660-664; discussion 664-665.

22. Schaub S, Rush D, Wilkins J, et al. Proteomic-based detection of urine proteins associated with acute renal allograft rejection. J Am Soc Nephrol 2004; 15:219-227.

23. O'Riordan E, Orlova TN, Mei JJ, et al. Bioinformatic analysis of the urine proteome of acute allograft rejection. J Am Soc Nephrol 2004; 15:3240-3248.

24. Wittke S, Haubitz M, Walden M, et al. Detection of acute tubulointerstitial rejection by proteomic analysis of urinary samples in renal transplant recipients. Am J Transplant 2005; 5:2479-2488.

25. Oetting WS, Rogers TB, Krick TP, Matas AJ, Ibrahim HN. Urinary beta2-microglobulin is associated with acute renal allograft rejection. Am J Kidney Dis 2006; 47:898-904.

26. Quintana LF, Sole-Gonzalez A, Kalko SG, et al. Urine proteomics to detect biomarkers for chronic allograft dysfunction. J Am Soc Nephrol 2009; 20:428-435.

27. Jahnukainen T, Malehorn D, Sun M, et al. Proteomic analysis of urine in kidney transplant patients with BK virus nephropathy. J Am Soc Nephrol 2006; 17:3248-3256.

28. Nguyen MT, Ross GF, Dent CL, Devarajan P. Early prediction of acute renal injury using urinary proteomics. Am J Nephrol 2005; 25:318-326.

29. Vanhoutte KJ, Laarakkers C, Marchiori E, et al. Biomarker discovery with SELDI-TOF MS in human urine associated with early renal injury: evaluation with computational analytical tools. Nephrol Dial Transplant 2007; 22:2932-2943.

30. Hampel DJ, Sansome C, Sha M, Brodsky S, Lawson WE, Goligorsky MS. Toward proteomics in uroscopy: urinary protein profiles after radiocontrast medium administration. J Am Soc Nephrol 2001; 12:1026-1035.

31. Bons JA, Wodzig WK, van Dieijen-Visser MP. Protein profiling as a diagnostic tool in clinical chemistry: a review. Clin Chem Lab Med 2005; 43:1281-1290.

32. Snoeijs MG, Wiermans B, Christiaans MH, et al. Recipient hemodynamics during non-heartbeating donor kidney transplantation are major predictors of primary nonfunction. Am J Transplant 2007; 7:1158-1166. 
162 


\section{Chapter 8}

Recipient hemodynamics during kidney transplantation from donors after cardiac death are major predictors of primary non-function 


\begin{abstract}
Background: Kidneys from donors after cardiac death (DCD) may substantially expand the donor pool, but many transplant centers are reluctant to use these kidneys because of the relatively high incidence of primary non-function (PNF). In kidneys from donors after brain death, intravascular fluid depletion during transplant surgery is associated with delayed graft function (DGF).

Methods: We studied the effect of the recipients' hemodynamic status on the outcome of 177 DCD kidney transplantations.

Findings: Independent statistically significant predictors of PNF were average central venous pressure (CVP) below $6 \mathrm{cmH}_{2} \mathrm{O}$ (adjusted odds ratio (AOR) 3.1 (95\% CI: 1.4-7.1), $\mathrm{P}=0.007$ ), average systolic blood pressure below $110 \mathrm{mmHg}$ (AOR 2.6 (95\% CI: 1.1-5.9), $\mathrm{P}=0.03$ ) and pre-operative diastolic blood pressure below $80 \mathrm{mmHg}$ (AOR 2.4 (95\% CI: 1.0-5.9), $\mathrm{P}=0.05$ ). Donor characteristics were not independently associated with PNF $(\mathrm{P}>0.10)$. In a subgroup analysis of 56 paired kidneys, $29 \%$ of the recipients with the lower CVP of the pair experienced PNF compared to $11 \%$ of their counterparts with higher CVP $(\mathrm{P}=0.09)$.

Interpretation: Recipient hemodynamics during transplant surgery are major predictors of PNF. Therefore, improving recipient hemodynamics by expansion of the intravascular volume is expected to enhance the results of DCD kidney transplantations and may enlarge the donor pool by increasing the acceptance of DCD kidneys.
\end{abstract}

\title{
Published as
}

Snoeijs MG, Wiermans B, Christiaans MH, van Hooff JP, Timmerman BE, Schurink GW, Buurman WA, van Heurn LW. Recipient hemodynamics during non-heart-beating donor kidney transplantation are major predictors of primary nonfunction. Am J Transplant 2007; 7:1158-1166. 


\section{Introduction}

Kidney transplantation results in superior life expectancy and quality of life compared to dialysis treatment for patients with end-stage renal disease. ${ }^{1,2} \mathrm{De}$ spite continuing efforts to increase the donor pool with living ${ }^{3}$ and expanded criteria donors, ${ }^{4}$ the shortage of donor kidneys has increased over the past decades. Inclusion of donors after cardiac death (DCD) may alleviate this shortage by expanding the donor pool 2-4.5 times.,6 Transplantation of DCD kidneys is associated with an increased incidence of initial graft dysfunction that is attributed to the extended period of warm ischemia before procurement. Nevertheless, long-term graft and patient survival are comparable to kidney transplants from donors after brain death (DBD). ${ }^{7-13}$ Despite these encouraging results, many transplant centers are reluctant to accept DCD kidneys, in part because of the higher primary non-function (PNF) rate of these grafts. ${ }^{14}$ Although high concentrations of cellular injury markers and redox-active iron in the kidney preservation solution are associated with $\mathrm{PNF},{ }^{15,16}$ it is not yet possible to accurately predict the viability of individual kidneys to prevent transplantation of nonfunctioning grafts.

Post-operative graft function is not exclusively determined by pretransplant donor and graft characteristics. Several lines of evidence indicate that the hemodynamic status of the recipient during kidney transplant surgery is associated with initial graft function. First, pre-operative hemodialysis that may result in intravascular fluid depletion is associated with an increased incidence of delayed graft function (DGF). ${ }^{17-20}$ Furthermore, introduction of protocols for fluid loading before or during surgery reduced the DGF rate in DBD kidney transplantation. ${ }^{21-27}$ Additionally, pulmonary arterial pressure below $20 \mathrm{mmHg}$, mean arterial pressure below $100 \mathrm{mmHg}$, and plasma volume below $45 \mathrm{~mL} / \mathrm{kg}$ at reperfusion of the graft are risk factors for DGF. ${ }^{28-31}$ Finally, blood flow to the transplanted kidney after reperfusion may predict immediate graft function. . $2,33^{2}$ Taken together, these observations imply that early graft function requires adequate perfusion of the transplanted kidney that can be achieved by expansion of the intravascular volume of the recipient.

All studies on recipient hemodynamics during transplant surgery have focused on traditional donor sources that have a low incidence of PNF. Therefore, it is not known whether these hemodynamic variables are associated with PNF of kidneys from donors after cardiac death. Since recipient hemodynamics 
during surgery are open to intervention, identification of an increased risk of graft failure may lead to improved transplant outcomes and more effective use of DCD kidneys. Therefore, we studied the effect of central venous and arterial blood pressure on the outcome of 177 DCD kidney transplants at our institution with a multivariable regression analysis. To exclude potential bias from unidentified donor or graft characteristics, the results were subsequently validated in a subset of patients that had received paired kidneys.

\section{Materials and methods}

\section{Donation after cardiac death program}

DCD kidneys are procured after cardiac arrest and are categorized according to the Maastricht classification. ${ }^{34}$ The Maastricht DCD program includes category 2, 3 and 4 DCD donors from all hospitals (university as well as district) within its procurement area. Management of DCD donors has been reported in detail previously. ${ }^{35}$ Briefly, after declaration of death by an independent physician and a no-touch period, in situ perfusion of donor kidneys with HTK preservation solution is initiated by introduction of a double-balloon triple-lumen catheter via the femoral artery. This is allowed by Dutch law before consent for organ donation is obtained from the relatives and is the preservation method of choice, particularly for uncontrolled donors. Before 2003, a no-touch period of $10 \mathrm{~min}$ utes was applied according to our original DCD protocol $(\mathrm{N}=119)$. Later this period was reduced to 5 minutes according to the recommendations of the American Institute of Medicine and the Health Council of The Netherlands $(\mathrm{N}=58) .{ }^{36}$ When consent for organ donation is obtained from the relatives, the donor is transferred to the operating room for organ procurement. Most of the kidneys are subsequently preserved with $500 \mathrm{~mL}$ UW-MPS on Gambro-PF3B perfusion units until transplantation using standard surgical techniques. Before reperfusion of the graft, $200 \mathrm{~mL}$ of mannitol $20 \%$ is intravenously administered to the recipient. Kidneys were allocated according to the Eurotransplant policy. ${ }^{37}$ Sixty-four percent of the grafts in this study were locally procured according to this protocol; the other grafts were imported from other procurement areas that used similar DCD protocols.

The immunosuppressive regimen evolved over the study period as different trials were conducted. Immunosuppression was mainly based on a combination of prednisolone and a calcineurin inhibitor (cyclosporine or tacrolimus). 
Table 8.1 Transplantation characteristics

\begin{tabular}{|c|c|}
\hline & Case $\operatorname{mix}(\mathrm{N}=177)$ \\
\hline \multicolumn{2}{|l|}{ Donor characteristics } \\
\hline Age (years) & $47 \pm 16$ \\
\hline Sex (male) & $59 \%$ \\
\hline Creatinine $(\mu \mathrm{mol} / \mathrm{L})$ & $97 \pm 41$ \\
\hline Maastricht category (DCD-2 / DCD-3) & 37 / 63\% \\
\hline Cause of death (vascular / neurological / trauma / other) & $60 / 12 / 22 / 7 \%$ \\
\hline Procurement center (local) & $64 \%$ \\
\hline \multicolumn{2}{|l|}{ Graft characteristics } \\
\hline Kidney weight (g) & $236 \pm 62$ \\
\hline Warm ischemia time (min) & $27 \pm 11$ \\
\hline Cold ischemia time $(\mathrm{h})$ & $26 \pm 6$ \\
\hline Anastomosis time (min) & $37 \pm 15$ \\
\hline \multicolumn{2}{|l|}{ Recipient characteristics } \\
\hline Age (years) & $53 \pm 13$ \\
\hline Sex (male) & $62 \%$ \\
\hline \multicolumn{2}{|l|}{ Kidney disease } \\
\hline Glomerulonephritis & $36 \%$ \\
\hline Hypertension & $14 \%$ \\
\hline Diabetes & $4 \%$ \\
\hline Pyelonephritis & $13 \%$ \\
\hline Polycystic & $19 \%$ \\
\hline Other & $14 \%$ \\
\hline Dialysis time (years) & $3.7 \pm 3.4$ \\
\hline Dialysis type (hemodialysis) & $62 \%$ \\
\hline BMI $\left(\mathrm{kg} / \mathrm{m}^{2}\right)$ & $25 \pm 4$ \\
\hline Diabetes mellitus & $13 \%$ \\
\hline Cardiovascular events & $29 \%$ \\
\hline Framingham score (\%) & $11 \pm 8$ \\
\hline Retransplantation & $11 \%$ \\
\hline HLA mismatches & $2.5 \pm 1.0$ \\
\hline \multicolumn{2}{|l|}{ Immunosuppression } \\
\hline Tacrolimus / Cyclosporine / None & $83 / 11 / 6 \%$ \\
\hline Mycophenolate mofetil & $33 \%$ \\
\hline Sirolimus & $39 \%$ \\
\hline Daclizumab & $6 \%$ \\
\hline
\end{tabular}


Depending on the protocol at the time, these were combined with azathioprine, mycophenolate mofetil (MMF), sirolimus, or daclizumab in recipients with an increased immunological risk (e.g. HLA immunization and retransplants). Twenty percent of patients experienced an episode of biopsy-proven acute rejection. Patients with tubulo-interstitial rejection were given methylprednisolone; vascular and steroid-resistant rejections were treated with anti-thymocyte globulins.

\section{Patient inclusion}

All DCD kidney transplantations performed at our institution between January $1^{\text {st }}, 1993$ and July 1 $1^{\text {st }}, 2005$ were selected for this study. Donor, graft and recipient characteristics and transplant outcome were extracted from our prospectively recorded DCD database. Additional data on hemodynamic status during transplant surgery were obtained from a quality control database with retrospective data on anesthesiology. 19 recipients (10\%) were excluded because data were incomplete. For 3 recipients, primary graft function could not be determined because the recipient died of myocardial infarction $(\mathrm{N}=2)$ or transplantectomy was performed because malignancy was detected during donor autopsy $(\mathrm{N}=1)$. The remaining 177 DCD kidney transplantations were included in a multivariable regression analysis. Excluded cases were more likely to receive kidneys from male donors; other transplant characteristics, including post-operative graft function, were similar to included cases. Seventy transplants were available for paired kidney analysis since both kidneys from the same donor were transplanted at our institution.

Our study was performed in agreement with the code of conduct 'Use of data in health research' put forward by the federation of Dutch medical scientific societies (http://www.federa.org). According to Dutch law, institutional review board approval is not mandatory for scientific analysis of anonymous data.

\section{Risk factors and outcome measures}

The following risk factors for primary non-function were included in the analysis: donor age, sex, Maastricht category, cause of death, terminal creatinine, warm ischemia time (excluding resuscitation time), cold ischemia time, procurement center, flow rate $(\mathrm{mL} / \mathrm{min} / 100 \mathrm{~g}$ kidney mass) and resistive index $(\mathrm{mmHg} / \mathrm{mL} / \mathrm{min})$ during machine perfusion, recipient age, sex, kidney disease, dialysis type, time on dialysis, retransplantation, HLA mismatches, immunosuppressive regimen, body-mass index (BMI), diabetes mellitus, previous cardiovascular events, Framingham score ${ }^{38}$ pre-operative blood pressure (BP) and hema- 
tocrit, average and lowest intra-operative $\mathrm{BP}$ and central venous pressure (CVP) and BP drop during surgery. Intra-operative CVP was measured with a jugular central venous line at $5 \mathrm{cmH}_{2} \mathrm{O}$ positive end-expiratory pressure (PEEP) and was corrected for patient position. Blood pressures were recorded every 10 minutes and the arrhythmic mean of these measurements is reported as average intraoperative blood pressure; systolic and diastolic blood pressure as well as mean arterial pressure are reported. The time of reperfusion was documented in the anaesthesiology charts of 100 recipients. For these patients, blood pressure measurements in relation to reperfusion time are reported separately. Initial graft function was categorized as immediate function (IF: post-operative dialysis was not necessary), delayed graft function (DGF: dialysis was required in the first week post-transplant but life-supporting graft function was eventually achieved), or primary non-function (PNF: dialysis could never be discontinued). Glomerular filtration rate (GFR) was estimated by the abbreviated MDRD formula. ${ }^{39}$

\section{Statistical analysis}

Continuous variables are presented as means \pm standard deviation; categorical variables are presented as percentages. Differences between groups of patients were compared with the Pearson $\chi^{2}$ test for categorical variables, with the Student's t-test for normally distributed continuous variables, and with the MannWhitney U-test for continuous variables that were not normally distributed. Correlation of potential risk factors with PNF was tested with univariable logistic regression. For this analysis, all continuous variables were categorized with cutoffs that were chosen by inspection of histograms with the intention to assign approximately one third of the patients to the presumed high-risk group. All potential risk factors with P-values below 0.20 were selected for further analysis in a multivariable backward-stepwise logistic regression model (removal at $P \geq 0.10$ ). The Nagelkerke $R^{2}$ estimate of this model is reported and represents the proportion of observed variation in graft viability that is explained by the included variables. The same risk factors were analyzed for predictive value of DGF. Machine perfusion parameters were analyzed separately to prevent exclusion of kidneys that were preserved by static cold storage from the multivariable analysis. Subsequently, the statistically significant independent predictors of PNF were evaluated with a paired kidney analysis to exclude potential bias from unidentified donor characteristics. For example, for each pair of patients that had received kidneys from one donor, the recipient with the lower CVP was assigned to the high-risk group, whereas the other recipient (with the higher CVP) was 
Table 8.2 Hemodynamic measurements according to initial graft function ${ }^{\mathrm{a}}$

\begin{tabular}{|c|c|c|c|}
\hline & $\begin{array}{l}\text { Immediate / } \\
\text { delayed function } \\
\mathrm{N}=140\end{array}$ & $\begin{array}{c}\text { Primary non- } \\
\text { function } \\
\mathrm{N}=37\end{array}$ & $\mathrm{P}$ \\
\hline \multicolumn{4}{|l|}{ Pre-operative blood pressure } \\
\hline Systolic (mmHg) & $145 \pm 25$ & $137 \pm 26$ & 0.08 \\
\hline Diastolic (mmHg) & $83 \pm 13$ & $79 \pm 13$ & 0.03 \\
\hline Mean arterial pressure (mmHg) & $104 \pm 15$ & $98 \pm 15$ & 0.04 \\
\hline \multicolumn{4}{|l|}{ Average intra-operative blood pressure } \\
\hline Systolic (mmHg) & $122 \pm 16$ & $116 \pm 15$ & 0.04 \\
\hline Diastolic (mmHg) & $63 \pm 11$ & $61 \pm 9$ & 0.16 \\
\hline Mean arterial pressure (mmHg) & $83 \pm 12$ & $79 \pm 11$ & 0.08 \\
\hline Central venous pressure $\left(\mathrm{cmH}_{2} \mathrm{O}\right)$ & $7.7 \pm 3.0$ & $6.9 \pm 4.1$ & 0.05 \\
\hline \multicolumn{4}{|l|}{ Lowest intra-operative blood pressure } \\
\hline Systolic (mmHg) & $93 \pm 15$ & $85 \pm 14$ & 0.004 \\
\hline Diastolic (mmHg) & $46 \pm 12$ & $43 \pm 11$ & 0.19 \\
\hline Central venous pressure $\left(\mathrm{cmH}_{2} \mathrm{O}\right)$ & $2.1 \pm 3.1$ & $1.3 \pm 3.9$ & 0.15 \\
\hline Systolic drop (\%) & $34 \pm 15$ & $36 \pm 15$ & 0.52 \\
\hline Diastolic drop (\%) & $43 \pm 16$ & $44 \pm 16$ & 0.87 \\
\hline \multirow[t]{2}{*}{ Hematocrit } & $0.37 \pm 0.05$ & $0.36 \pm 0.05$ & 0.50 \\
\hline & $\mathrm{N}=85$ & $\mathrm{~N}=15$ & \\
\hline \multicolumn{4}{|l|}{ Blood pressure at reperfusion } \\
\hline Systolic (mmHg) & $113 \pm 18$ & $108 \pm 20$ & 0.32 \\
\hline Diastolic (mmHg) & $59 \pm 13$ & $55 \pm 10$ & 0.32 \\
\hline Mean arterial pressure (mmHg) & $77 \pm 13$ & $73 \pm 12$ & 0.27 \\
\hline Central venous pressure $\left(\mathrm{cmH}_{2} \mathrm{O}\right)$ & $11 \pm 4.3$ & $10 \pm 3.4$ & 0.47 \\
\hline \multicolumn{4}{|l|}{ Blood pressure 10 minutes after reperfusion } \\
\hline Systolic (mmHg) & $111 \pm 21$ & $105 \pm 18$ & 0.34 \\
\hline Diastolic (mmHg) & $57 \pm 14$ & $53 \pm 13$ & 0.33 \\
\hline Mean arterial pressure (mmHg) & $75 \pm 15$ & $71 \pm 13$ & 0.31 \\
\hline Central venous pressure $\left(\mathrm{cmH}_{2} \mathrm{O}\right)$ & $12 \pm 3.9$ & $11 \pm 4.4$ & 0.28 \\
\hline \multicolumn{4}{|l|}{ Average blood pressure after reperfusion } \\
\hline Systolic (mmHg) & $128 \pm 17$ & $123 \pm 21$ & 0.29 \\
\hline Diastolic (mmHg) & $67 \pm 12$ & $60 \pm 12$ & 0.08 \\
\hline Mean arterial pressure (mmHg) & $88 \pm 13$ & $81 \pm 15$ & 0.11 \\
\hline Central venous pressure $\left(\mathrm{cmH}_{2} \mathrm{O}\right)$ & $7.4 \pm 3.2$ & $6.3 \pm 3.4$ & 0.27 \\
\hline
\end{tabular}

a Data are presented as mean (standard deviation) or as percentages. Differences between means are tested with Student's t-test or Mann-Whitney U-test. For 100 patients, reperfusion time was recorded in the anesthesiology charts. Blood pressures related to reperfusion time are reported for these patients. 
assigned to the low-risk group. Ties were excluded. Due to the paired kidney design, these two groups were identical with respect to donor and graft characteristics. Long-term graft survival was calculated using Kaplan-Meier curves and compared with the log-rank test. Graft survival was censored for recipient death with functioning graft and PNF to study graft loss after the immediate postoperative period. P-values below 0.05 were considered statistically significant. Statistical analysis was performed with SPSS for Windows version 12.0.1.

\section{Results}

\section{Hemodynamic status during transplant surgery}

Donor, graft and recipient characteristics are summarized in Table 8.1. Postoperative graft function was immediate in 30 patients (17\%), delayed in 110 patients $(61 \%)$, and primary non-function in 37 patients (21\%). Data on hemodynamic status during transplant surgery grouped according to post-transplant graft function are presented in Table 8.2. In general, recipients with primary non-function had lower BP and CVP than recipients with delayed or immediate graft function. These differences were statistically significant for pre-operative diastolic BP and mean arterial pressure (MAP), for lowest and average systolic BP during surgery, and for average intra-operative central venous pressure. Preoperative diastolic blood pressure and mean arterial pressure of patients that subsequently developed PNF were $79 \pm 13$ and $98 \pm 15 \mathrm{mmHg}$ compared to $83 \pm 13$ and $104 \pm 15 \mathrm{mmHg}$ for patients with eventual graft function $(\mathrm{P}=0.03$ and $\mathrm{P}=0.04$, respectively). Similarly, lowest and average intra-operative systolic blood pressure in recipients with PNF were $85 \pm 14$ and $116 \pm 15 \mathrm{mmHg}$, both significantly lower than in recipients of functioning grafts $(93 \pm 15 \mathrm{mmHg}(\mathrm{P}=0.004)$ and $122 \pm 16(\mathrm{P}=0.04)$, respectively). Furthermore, intra-operative CVP was $6.9 \pm 4.1$ $\mathrm{cmH}_{2} \mathrm{O}$ in patients with primary non-function compared to $7.7 \pm 3.0 \mathrm{cmH}_{2} \mathrm{O}$ for recipients of functioning grafts $(\mathrm{P}=0.05)$. Pre-operative hematocrit levels were similar among groups of recipients with different post-operative graft function.

\section{Multivariable regression analysis}

Unadjusted odds ratios for the potential risk factors for primary non-function are presented in Figure 8.1. Recipient kidney disease is not presented since this 
\begin{tabular}{ll|ll}
172 & C H A P T E R & 8
\end{tabular} 
variable has multiple categories; however, none of these disease categories was associated with PNF. All potential risk factors associated with PNF with P-values below 0.20 were further studied by multivariable logistic regression analysis with backward-stepwise exclusion of variables at $P \geq 0.10$. The variables included in the resulting model are independently associated with primary non-function. We identified three variables that were statistically significant risk factors for PNF (Table 8.3). Average intra-operative central venous pressure below $6 \mathrm{cmH}_{2} \mathrm{O}$ increased the odds of PNF 3.1 times (95\% CI: 1.4-7.1, P=0.007) compared to higher intra-operative CVP. Similarly, average systolic BP below $110 \mathrm{mmHg}$ during transplant surgery and pre-operative diastolic BP below $80 \mathrm{mmHg}$ increased the odds of PNF 2.6 times (95\% CI: 1.1-5.9, $\mathrm{P}=0.03)$ and 2.4 times $(95 \%$ CI: 1.0-5.9, $\mathrm{P}=0.05)$, respectively, compared to higher blood pressures. These three independent risk factors explain approximately $16 \%$ of the observed variation in graft viability (Nagelkerke $\mathrm{R}^{2}$ ). Donor characteristics that were associated with PNF in the univariable analysis (donor age, type, warm ischemia time, cause of death, and procurement center) were not included in the multivariable model. Three patients experienced PNF due to vascular rejection, which is clinically unlikely to be related to intra-operative hemodynamic status. The findings of the multivariable analysis did not change when these patients were excluded. Machine perfusion parameters were analyzed separately to prevent exclusion of kidneys that were preserved by cold static storage $(\mathrm{N}=45)$ from the multivariable analysis. Flow rate below $70 \mathrm{~mL} / \mathrm{min} / 100 \mathrm{~g}$ kidney mass and resistive index above $0.45 \mathrm{mmHg} / \mathrm{mL} / \mathrm{min}$ were not associated with PNF with statistical significance (OR 1.7 (95\% CI 0.64-4.7, $\mathrm{P}=0.28$ ) and OR 1.8 (95\% CI 0.75-4.5, $\mathrm{P}=0.19$ ), respectively). Taken together, these findings indicate that recipient hemodynamics during transplant surgery may be more important predictors of primary nonfunction than DCD donor characteristics.

The potential risk factors for PNF were further analyzed for their correlation with delayed graft function. When PNF cases were excluded, average intra-operative systolic blood pressure below $110 \mathrm{mmHg}$ (AOR 3.2, $\mathrm{P}=0.08$ ), preoperative mean arterial pressure below $100 \mathrm{mmHg}$ (AOR 0.35, P=0.04), Maas-

Table 8.3 Multivariable regression analysis for primary non-function of DCD kidney transplants

\begin{tabular}{lcc}
\hline & Adjusted odds ratio (95\% CI) & P \\
\hline Average central venous pressure $(<6 \mathrm{cmH} 2 \mathrm{O})$ & $3.1(1.4-7.1)$ & 0.007 \\
Average intra-operative systolic $\mathrm{BP}(<110 \mathrm{mmHg})$ & $2.6(1.1-5.9)$ & 0.03 \\
Pre-operative diastolic BP $(<80 \mathrm{mmHg})$ & $2.4(1.0-5.9)$ & 0.05 \\
\hline
\end{tabular}


tricht category 2 DCD donors (AOR 4.8, $\mathrm{P}=0.03$ ), warm ischemia time over 30 minutes (AOR 6.0, $\mathrm{P}=0.03$ ) and local procurement ( $\mathrm{AOR}$ 0.40, $\mathrm{P}=0.08$ ) were independently associated with DGF. Thus, most hemodynamic variables were not associated with DGF and low pre-operative mean arterial pressure even reduced the risk of DGF. Low systolic blood pressure during transplantation was the only hemodynamic parameter predictive of DGF, although statistical significance was not reached. Whereas several hemodynamic parameters were independently associated with PNF, DGF was predicted by donor characteristics related to prolonged ischemic injury before procurement. This indicates that regardless of recipient hemodynamic management, most DCD kidneys undergo a period of delayed graft function because of warm ischemic injury before procurement.

\section{Paired kidney analysis}

To validate the results from the multivariable analysis, we selected a subset of recipients $(\mathrm{N}=70)$ who received kidneys from the same donor. For all pairs of recipients, the patients with the lower central venous pressure during transplant surgery were compared to their counterparts with higher CVP. This design ensures that donor and graft characteristics of the two groups are identical and therefore can not confound the findings of the study. ${ }^{40}$ Seven pairs were excluded from this analysis because CVP records were missing $(\mathrm{N}=3)$ or because average CVP of the two recipients was equal $(\mathrm{N}=4)$. As anticipated, average and lowest CVP during surgery were significantly lower in the low CVP group compared to the high CVP group $\left(5.5 \pm 2.5\right.$ vs. $8.8 \pm 1.9 \mathrm{cmH}_{2} \mathrm{O}(\mathrm{P}<0.001)$, and $0.50 \pm 3.0$ vs. $2.7 \pm 3.0 \mathrm{cmH}_{2} \mathrm{O}(\mathrm{P}=0.008)$, respectively). Besides these intended differences in CVP, the two study groups were similar with respect to machine perfusion parameters and most recipient and hemodynamic characteristics (Table 8.4). However, more patients in the high CVP group had received a previous allograft ( $0 \%$ vs. $11 \%, \mathrm{P}=0.08)$, and patients in the high CVP group had a higher pre-operative systolic blood pressure than the patients in the low CVP group ( $150 \pm 21$ vs. $141 \pm 16 \mathrm{mmHg}, \mathrm{P}=0.08$ ); both differences did not reach statistical significance. Furthermore, the distribution of kidney diseases was significantly different for these two groups, with more recipients suffering from glomerulonephritis in the high CVP group and more patients with hypertensive kidney disease in the low CVP group $(\mathrm{P}=0.05)$.

Even though the two groups of patients received kidneys from the same donors, the percentage of PNF was $11 \%$ in the high CVP group compared to $29 \%$ 
Table 8.4 Recipient characteristics and graft outcome in paired kidney analysis ${ }^{\mathrm{a}}$

\begin{tabular}{|c|c|c|c|}
\hline & $\begin{array}{l}\text { Low CVP group } \\
\quad(\mathrm{N}=28)\end{array}$ & $\begin{array}{l}\text { High CVP group } \\
\qquad(\mathrm{N}=28)\end{array}$ & $\mathrm{P}$ \\
\hline \multicolumn{4}{|l|}{ Perfusion characteristics } \\
\hline Flow rate (mL/min/100g kidney mass) & $62 \pm 22$ & $56 \pm 19$ & 0.27 \\
\hline Resistive index $(\mathrm{mmHg} / \mathrm{mL} / \mathrm{min})$ & $0.39 \pm 0.15$ & $0.39 \pm 0.15$ & 0.80 \\
\hline \multicolumn{4}{|l|}{ Recipient characteristics } \\
\hline Cold ischemia time (h) & $27 \pm 5.5$ & $28 \pm 5.9$ & 0.48 \\
\hline Recipient age (yrs) & $55 \pm 13$ & $53 \pm 14$ & 0.65 \\
\hline Recipient sex (male) & $57 \%$ & $61 \%$ & 0.79 \\
\hline Dialysis time (yrs) & $3.5 \pm 3.3$ & $3.2 \pm 2.2$ & 0.61 \\
\hline Dialysis type (hemodialysis) & $75 \%$ & $57 \%$ & 0.16 \\
\hline Previous cardiovascular events & $32 \%$ & $18 \%$ & 0.22 \\
\hline BMI $\left(\mathrm{kg} / \mathrm{m}^{2}\right)$ & $25 \pm 4.1$ & $25 \pm 3.0$ & 0.89 \\
\hline Diabetes mellitus & $7 \%$ & $14 \%$ & 0.39 \\
\hline Framingham score (\%) & $12 \pm 9.0$ & $11 \pm 7.8$ & 0.93 \\
\hline HLA mismatches & $3.0 \pm 1.1$ & $3.0 \pm 0.9$ & 0.89 \\
\hline Re-transplantation & $0 \%$ & $11 \%$ & 0.08 \\
\hline \multicolumn{4}{|l|}{ Immunosuppression } \\
\hline Tacrolimus / Cyclosporin / None & $82 / 18 / 0 \%$ & $82 / 14 / 4 \%$ & 0.76 \\
\hline Induction therapy & $4 \%$ & $4 \%$ & 1.00 \\
\hline Mycophenolate mofetil & $39 \%$ & $39 \%$ & 1.00 \\
\hline Sirolimus & $18 \%$ & $14 \%$ & 0.72 \\
\hline \multicolumn{4}{|l|}{ Hemodynamic measurements } \\
\hline Pre-transplant systolic BP (mmHg) & $141 \pm 16$ & $150 \pm 21$ & 0.08 \\
\hline Pre-transplant diastolic BP (mmHg) & $82 \pm 9.5$ & $85 \pm 13$ & 0.38 \\
\hline Intra-operative average systolic $\mathrm{BP}(\mathrm{mmHg})$ & $123 \pm 17$ & $127 \pm 16$ & 0.30 \\
\hline Average CVP $\left(\mathrm{cmH}_{2} \mathrm{O}\right)$ & $5.5 \pm 2.5$ & $8.8 \pm 1.9$ & $<0.001$ \\
\hline Lowest $\mathrm{CVP}\left(\mathrm{cmH}_{2} \mathrm{O}\right)$ & $0.50 \pm 3.0$ & $2.7 \pm 3.0$ & 0.008 \\
\hline \multicolumn{4}{|l|}{ Graft outcome } \\
\hline Immediate function & $14 \%$ & $18 \%$ & 0.72 \\
\hline Delayed graft function & $57 \%$ & $71 \%$ & 0.27 \\
\hline Primary non-function & $29 \%$ & $11 \%$ & 0.09 \\
\hline GFR at $1 \mathrm{yr}(\mathrm{mL} / \mathrm{min})$ & $43 \pm 16$ & $40 \pm 14$ & 0.57 \\
\hline Graft survival at 5 yrs & $94 \%$ & $95 \%$ & 0.75 \\
\hline
\end{tabular}

a Data are presented as means \pm standard deviations or as percentage. Pairs were split according to average intraoperative central venous pressure. Ties were excluded. Graft survival was censored for recipient death with functioning graft and PNF. 
in the low CVP group (Figure 8.2). This difference is clinically important and showed a trend towards statistical significance $(\mathrm{P}=0.09)$. Causes of primary nonfunction were thrombosis $(\mathrm{N}=4)$, vascular rejection $(\mathrm{N}=2)$, permanent nonfunction $(\mathrm{N}=1)$ and unknown $(\mathrm{N}=1)$ for the low CVP group, and thrombosis $(\mathrm{N}=1)$, hyperacute rejection $(\mathrm{N}=1)$ and permanent non-function $(\mathrm{N}=1)$ for the high CVP group. Delayed graft function occurred in $71 \%$ of transplantations in the high CVP group compared to $56 \%$ in the low CVP group ( $\mathrm{P}=0.27)$, whereas immediate function occurred in $18 \%$ and $14 \%$ of patients, respectively $(\mathrm{P}=0.72)$. GFR at one year post-transplant $(43 \pm 16$ vs. $40 \pm 14 \mathrm{~mL} / \mathrm{min}, \mathrm{P}=0.57)$ and longterm death-censored graft survival excluding PNF (94\% vs. 95\% at five years post-transplant, $\mathrm{P}=0.75$ ) were similar for the two groups of patients. Taken together, the paired kidney analysis shows that recipients with lower CVP during surgery are approximately three times more likely to experience PNF, confirming the results of the multivariable regression analysis. Furthermore, the increased risk of graft failure in the early post-operative period for patients with lower CVP did not pass on to later years.

Paired recipients were also split into two groups according to the other statistically significant independent risk factors for PNF, i.e. average systolic BP during surgery and pre-operative diastolic BP. Primary non-function rates were

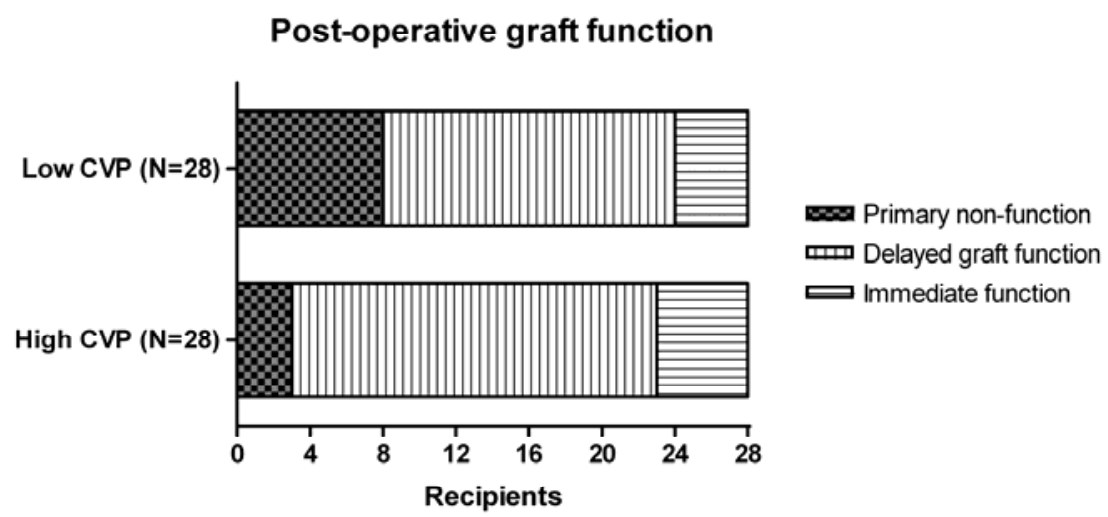

Figure 8.2 Post-operative graft function according to average intra-operative central venous pressure in an analysis of paired kidneys. For each pair of patients that had received the kidneys from one donor, the recipient with the lower CVP was assigned to the low CVP group, whereas the other recipient (with the higher CVP) was assigned to the high CVP group. Ties were excluded. Due to the paired kidney design, the two groups are identical with respect to donor and graft characteristics. 
similar for these groups of paired recipients (21\% vs. $17 \%$ PNF for lower and higher pre-operative diastolic BP ( $\mathrm{P}=0.74), 14 \%$ vs. $23 \%$ PNF for lower and higher systolic $\mathrm{BP}$ during surgery $(\mathrm{P}=0.36))$.

\section{Discussion}

Kidneys from donors after cardiac death hold great potential to expand the donor pool but have not yet been fully utilized, in part because of concerns about initial graft dysfunction. Previous studies on kidneys from donors after brain death have shown that poor hemodynamic management of the recipient may result in delayed graft function. Although this is not the ideal outcome of kidney transplantation, it will still provide the recipient with a functioning graft. In contrast, most DCD kidneys go through a period of acute tubular necrosis as a consequence of warm ischemic injury at procurement. This ischemic damage shifts the expected outcome of DCD kidneys from immediate function towards delayed graft function and puts these kidneys at risk of primary non-function. Therefore, additional ischemic injury to DCD kidneys at the time of transplantation due to impaired hemodynamic status may result in PNF, whereas a similar hit to undamaged DBD kidneys would lead to temporary graft dysfunction.

Our study shows that recipient hemodynamic status during DCD kidney transplantation is a major risk factor for PNF. Average intra-operative central venous pressure below $6 \mathrm{cmH}_{2} \mathrm{O}$, average intra-operative systolic blood pressure below $110 \mathrm{mmHg}$, and pre-operative diastolic blood pressure below $80 \mathrm{mmHg}$ all increased the odds of primary non-function approximately three times $(\mathrm{P} \leq 0.05$ for all). In a subgroup of recipients of paired kidneys, $29 \%$ of the recipients with the lower CVP of the pair experienced PNF compared with $11 \%$ of their counterparts with higher CVP, even though the kidneys were retrieved from the same donors $(\mathrm{P}=0.09)$. This difference is clinically important; statistical significance probably was not reached because of the small sample size. Of note, hemodynamic variables had the highest odds ratios of all potential risk factors included in our study in both the univariable and multivariable analyses. In fact, all donor characteristics were excluded from the multivariable model and were not independently associated with PNF $(\mathrm{P}>0.10)$. This implies that recipient hemodynamics during transplant surgery may be more important predictors of PNF than the donor characteristics of the DCD kidneys we have transplanted.

This study is not a randomized clinical trial in which recipients of DCD kidneys were randomly assigned to intravascular volume expansion to raise 
central venous and arterial blood pressures during transplant surgery. Such a randomized clinical trial would not have been ethically justifiable since studies on DBD kidneys have shown that intravascular fluid expansion is associated with improved transplant outcomes. Therefore, a formal causal relationship between intra-operative hemodynamics and graft outcome can not be inferred. However, we have carefully avoided potential confounders with multivariable and paired kidney analyses. Although we were able to adjust for several cardiovascular risk factors and previous cardiovascular events in our analysis, data on left ventricular function of the recipients were not available. Therefore, it is possible that low blood pressures during transplant surgery were caused by poor cardiac function rather than depletion of the intravascular volume. However, patients suffering from heart failure usually have high CVP whereas we observed that low CVP was associated with increased risk of primary non-function. The results from our study therefore strongly suggest a deleterious effect of low central venous and arterial pressures on the viability of DCD kidneys. The advantage of our uncontrolled study design is that anesthesia was not standardized and reflects actual clinical practice. The incidence of primary non-function in our study was $21 \%$, which is higher than previously reported by our group. ${ }^{7}$ This reflects the acceptance of more marginal kidneys as a result of the increasing organ shortage and our favorable initial experience with DCD kidneys.

In general, our findings are in line with other studies that report a higher incidence of post-operative graft dysfunction of DBD and living donor kidneys in recipients with impaired hemodynamic status. ${ }^{17-33}$ In a single-center study of 121 DBD kidney transplantations, post-operative urine output was proportional to MAP five minutes before reperfusion. On the first day after transplantation, serum creatinine concentration decreased in patients with MAP above $100 \mathrm{mmHg}$, whereas it remained stable in patients with MAP of 80-100 $\mathrm{mmHg}$ and increased in patients with MAP below $80 \mathrm{mmHg} .{ }^{30}$ Another singlecenter study of 734 DBD kidney transplants reported that recipients with MAP below $100 \mathrm{mmHg}$ before transplantation had twice the risk of DGF compared to patients with higher MAP. ${ }^{31}$ Carlier and co-workers established a protocol of maximal fluid loading guided by pulmonary arterial pressure and showed that $36 \%$ of recipients with mean pulmonary arterial pressures below $20 \mathrm{mmHg}$ experienced DGF compared to $6 \%$ of patients with higher pressures. ${ }^{28}$ Furthermore, $14 \%$ of recipients with fluid loading experienced DGF, whereas the incidence of DGF of contralateral kidneys that were transplanted in other centers without fluid loading was $41 \%$, even though cold ischemia time was longer in the fluid-loaded patients. ${ }^{22}$ The efficacy of additional hydration of transplant 
recipients has been confirmed by several other centers. ${ }^{21,24,25}$ In particular, Dawidson and co-workers showed that recipients of living donor kidneys lost more serum albumin during surgery than their donors, resulting in decreased plasma volume that was associated with reduced post-operative urine output. Therefore, the authors recommended the administration of colloids to replace the additional loss of albumin during transplant surgery. ${ }^{29}$ In a subsequent single-center observational study of $438 \mathrm{DBD}$ kidney transplants, $12 \%$ of patients that received at least $0.8 \mathrm{mg} / \mathrm{kg}$ albumin during surgery experienced DGF compared to $34 \%$ of patients that received lower doses of albumin. ${ }^{26}$ Taken together, these studies indicate that poor hemodynamic status of recipients of DBD kidneys may result in impaired post-operative graft function, which is in line with our observations in DCD kidney transplantations. A major difference relates to the outcome measure of interest, which is PNF in our study and DGF in previous studies. Regardless of recipient hemodynamic management, most DCD kidneys undergo a period of delayed graft function that is attributed to warm ischemic injury before procurement. Indeed, we found that donor characteristics such as Maastricht category 2 DCD type and prolonged warm ischemia time were strongly predictive of DGF, whereas recipient hemodynamic parameters were not associated with increased risk of DGF. While undamaged DBD kidneys respond to poor hemodynamic status at transplant surgery by temporary graft dysfunction, additional ischemic injury in the peri-operative period is poorly tolerated by DCD kidneys that have already suffered ischemic injury before procurement. This substantially increases the risk of transplanting non-viable grafts, leaving the recipient on dialysis with worse chances of a subsequent transplant due to immunological sensitization.

In the normal kidney, vasodilation of the afferent arterioles ensures stable renal blood flow over a range of perfusion pressures. This autoregulatory mechanism is absent in experimental models of ischemic acute renal failure and calcineurin inhibitor nephrotoxicity. ${ }^{41-45}$ Therefore, the ischemic kidney is vulnerable to minor reductions in arterial blood pressure that may occur during hemodialysis or surgery. ${ }^{46}$ DCD kidneys suffer extensive ischemia-reperfusion injury and autoregulation of these kidneys may therefore be particularly impaired. This may explain why the effects of low arterial and central venous pressure on graft viability in DCD kidney transplantation are more profound than previously reported for DBD kidneys. Additionally, poor renal perfusion may exacerbate the no reflow phenomenon and cause additional ischemic damage. ${ }^{47-49}$ In an experimental study, increased perfusion pressure reduced vascular congestion and stasis of erythrocytes in the outer medulla. This completely 
restored renal blood flow and partially improved kidney function after a period of renal artery clamping..$^{50}$

Our study identifies low central venous pressure, low intra-operative systolic BP and low pre-operative diastolic BP as major risk factors for primary non-function of DCD kidneys. Therefore, we strongly recommend expansion of the intravascular volume with crystalloid (preferably lactated Ringer's) ${ }^{51}$ and colloid solutions to reach a CVP of at least $10 \mathrm{cmH}_{2} \mathrm{O}$ (at $5 \mathrm{cmH}_{2} \mathrm{O}$ PEEP) and a systolic BP of at least $120 \mathrm{mmHg}$ during transplant surgery. Since patients with chronic kidney disease have a high incidence of cardiovascular disease, expansion of the intravascular volume may cause cardiac ischemia and pulmonary edema. In a recent series of 90 transplant recipients at high cardiovascular risk, satisfactory graft function has been reported with a target CVP of 7-9 $\mathrm{cmH}_{2} \mathrm{O}$ during surgery. ${ }^{52}$ This target level is still higher than our $6 \mathrm{cmH}_{2} \mathrm{O}$ cut-off value for high risk of primary non-function and therefore reasonably balances the risks of PNF and cardiac decompensation in these high-risk patients. Next to intravascular volume expansion during surgery, we recommend post-operative hemodynamic monitoring of the recipient since the post-ischemic kidney is not able to compensate for reductions in perfusion pressure and therefore is at risk of additional ischemic injury due to relatively small decreases in arterial blood pressure.

In conclusion, DCD kidneys may substantially expand the donor pool but the relatively high incidence of primary graft failure impedes full utilization of this donor source. Our study shows that excellent intra-operative hemodynamic status of the recipient greatly increases the probability of transplanting viable grafts. We suggest that ischemically injured DCD kidneys are particularly vulnerable to additional ischemic events at the time of transplantation, whereas undamaged DBD kidneys respond to similar circumstances with temporary graft dysfunction that will eventually recover. Therefore, extra attention to recipient hemodynamic management by expansion of the intravascular volume may reduce the incidence of PNF and improve the outcome of DCD kidney transplantations. Our study sheds new light on recipient hemodynamic management as an opportunity to improve the outcome of marginal donor kidneys that are increasingly being used to meet the rising demands for kidney transplantation. 


\section{References}

1. Wolfe RA, Ashby VB, Milford EL, et al. Comparison of mortality in all patients on dialysis, patients on dialysis awaiting transplantation, and recipients of a first cadaveric transplant. $\mathrm{N}$ Engl J Med 1999; 341:1725-1730.

2. Evans RW, Manninen DL, Garrison LP, Jr., et al. The quality of life of patients with end-stage renal disease. N Engl J Med 1985; 312:553-559.

3. Terasaki PI, Cecka JM, Gjertson DW, Takemoto S. High survival rates of kidney transplants from spousal and living unrelated donors. N Engl J Med 1995; 333:333-336.

4. Port FK, Bragg-Gresham JL, Metzger RA, et al. Donor characteristics associated with reduced graft survival: an approach to expanding the pool of kidney donors. Transplantation 2002; 74:1281-1286.

5. Daemen JW, Oomen AP, Kelders WP, Kootstra G. The potential pool of non-heart-beating kidney donors. Clin Transplant 1997; 11:149-154.

6. Terasaki PI, Cho YW, Cecka JM. Strategy for eliminating the kidney shortage. Clin Transpl 1997:265-267.

7. Wijnen RM, Booster MH, Stubenitsky BM, de Boer J, Heineman E, Kootstra G. Outcome of transplantation of non-heart-beating donor kidneys. Lancet 1995; 345:1067-1070.

8. Cho YW, Terasaki PI, Cecka JM, Gjertson DW. Transplantation of kidneys from donors whose hearts have stopped beating. N Engl J Med 1998; 338:221-225.

9. Nicholson ML, Metcalfe MS, White SA, et al. A comparison of the results of renal transplantation from non-heart-beating, conventional cadaveric, and living donors. Kidney Int 2000; 58:2585-2591.

10. Gok MA, Buckley PE, Shenton BK, et al. Long-term renal function in kidneys from non-heartbeating donors: A single-center experience. Transplantation 2002; 74:664-669.

11. Weber M, Dindo D, Demartines N, Ambuhl PM, Clavien PA. Kidney transplantation from donors without a heartbeat. N Engl J Med 2002; 347:248-255.

12. Rudich SM, Kaplan B, Magee JC, et al. Renal transplantations performed using non-heartbeating organ donors: going back to the future? Transplantation 2002; 74:1715-1720.

13. Sanchez-Fructuoso AI, Marques M, Prats D, et al. Victims of cardiac arrest occurring outside the hospital: a source of transplantable kidneys. Ann Intern Med 2006; 145:157-164.

14. Keizer KM, de Fijter JW, Haase-Kromwijk BJ, Weimar W. Non-heart-beating donor kidneys in the Netherlands: allocation and outcome of transplantation. Transplantation 2005; 79:11951199 .

15. Daemen JW, Oomen AP, Janssen MA, et al. Glutathione S-transferase as predictor of functional outcome in transplantation of machine-preserved non-heart-beating donor kidneys. Transplantation 1997; 63:89-93.

16. de Vries B, Snoeijs MG, von Bonsdorff L, Ernest van Heurn LW, Parkkinen J, Buurman WA. Redox-active iron released during machine perfusion predicts viability of ischemically injured deceased donor kidneys. Am J Transplant 2006; 6:2686-2693.

17. Van Loo AA, Vanholder RC, Bernaert PR, Vermassen FE, Van der Vennet M, Lameire NH. Pretransplantation hemodialysis strategy influences early renal graft function. J Am Soc Nephrol 1998; 9:473-481. 
18. Snyder JJ, Kasiske BL, Gilbertson DT, Collins AJ. A comparison of transplant outcomes in peritoneal and hemodialysis patients. Kidney Int 2002; 62:1423-1430.

19. Turcotte JG, Herrmann TJ, Haig O, O'Dell C, Jr., Cerny J, Greene JA, Jr. Oliguria following transplantation of kidneys donated by blood relatives. Surg Gynecol Obstet 1970; 130:29-36.

20. McCormick BB, Pierratos A, Fenton S, Jain V, Zaltzman J, Chan CT. Review of clinical outcomes in nocturnal haemodialysis patients after renal transplantation. Nephrol Dial Transplant 2004; 19:714-719.

21. Luciani J, Frantz $P$, Thibault $P$, et al. Early anuria prevention in human kidney transplantation. Advantage of fluid load under pulmonary arterial pressure monitoring during surgical period. Transplantation 1979; 28:308-312.

22. Carlier M, Squifflet JP, Pirson Y, Decocq L, Gribomont B, Alexandre GP. Confirmation of the crucial role of the recipient's maximal hydration on early diuresis of the human cadaver renal allograft. Transplantation 1983; 36:455-456.

23. Tiggeler RG, Berden JH, Hoitsma AJ, Koene RA. Prevention of acute tubular necrosis in cadaveric kidney transplantation by the combined use of mannitol and moderate hydration. Ann Surg 1985; 201:246-251.

24. Rajagopalan PR, Kay NA, Fitts CT, Majeski JA. Prevention of acute tubular necrosis after transplantation: effect of pretransplantation volume expansion. South Med J 1986; 79:972-974.

25. Thomsen HS, Lokkegaard H, Munck O. Influence of normal central venous pressure on onset of function in renal allografts. Scand J Urol Nephrol 1987; 21:143-145.

26. Dawidson IJ, Sandor ZF, Coorpender L, et al. Intraoperative albumin administration affects the outcome of cadaver renal transplantation. Transplantation 1992; 53:774-782.

27. Shackleton CR, Keown PA, McLoughlin MG, et al. Cadaver kidney transplantation with minimal delayed function: experience with perioperative strategies to enhance initial renal allograft function. Transplant Proc 1995; 27:1075-1077.

28. Carlier M, Squifflet JP, Pirson Y, Gribomont B, Alexandre GP. Maximal hydration during anesthesia increases pulmonary arterial pressures and improves early function of human renal transplants. Transplantation 1982; 34:201-204.

29. Dawidson I, Berglin E, Brynger H, Reisch J. Intravascular volumes and colloid dynamics in relation to fluid management in living related kidney donors and recipients. Crit Care Med 1987; 15:631-636.

30. Toth M, Reti V, Gondos T. Effect of recipients' peri-operative parameters on the outcome of kidney transplantation. Clin Transplant 1998; 12:511-517.

31. Boom H, Mallat MJ, de Fijter JW, Zwinderman AH, Paul LC. Delayed graft function influences renal function, but not survival. Kidney Int 2000; 58:859-866.

32. Hollenberg NK, Birtch A, Rashid A, et al. Relationships between intrarenal perfusion and function: serial hemodynamic studies in the transplanted human kidney. Medicine (Baltimore) 1972; 51:95-106.

33. Anderson CB, Etheredge EE. Human renal allograft blood flow and early renal function. Ann Surg 1977; 186:564-567.

34. Kootstra G, Daemen JH, Oomen AP. Categories of non-heart-beating donors. Transplant Proc 1995; 27:2893-2894.

35. Heineman E, Daemen JH, Kootstra G. Non-heart-beating donors: methods and techniques. Transplant Proc 1995; 27:2895-2896; discussion 2896-2897.

36. Institute of Medicine Division of Health Care Services. Non-heart-beating Organ Transplantation: Medical and Ethical Issues in Procurement. Washington D.C.: National Acadamy Press; 1997. 
37. Persijn GG. Allocation of organs, particularly kidneys, within Eurotransplant. Hum Immunol 2006; 67:419-423.

38. Wilson PW, D'Agostino RB, Levy D, Belanger AM, Silbershatz H, Kannel WB. Prediction of coronary heart disease using risk factor categories. Circulation 1998; 97:1837-1847.

39. Levey AS, Bosch JP, Lewis JB, Greene T, Rogers N, Roth D. A more accurate method to estimate glomerular filtration rate from serum creatinine: a new prediction equation. Modification of Diet in Renal Disease Study Group. Ann Intern Med 1999; 130:461-470.

40. Gourishankar S, Jhangri GS, Cockfield SM, Halloran PF. Donor tissue characteristics influence cadaver kidney transplant function and graft survival but not rejection. J Am Soc Nephrol 2003; 14:493-499.

41. Adams PL, Adams FF, Bell PD, Navar LG. Impaired renal blood flow autoregulation in ischemic acute renal failure. Kidney Int 1980; 18:68-76.

42. Williams RH, Thomas CE, Navar LG, Evan AP. Hemodynamic and single nephron function during the maintenance phase of ischemic acute renal failure in the dog. Kidney Int 1981; 19:503-515.

43. Matthys E, Patton MK, Osgood RW, Venkatachalam MA, Stein JH. Alterations in vascular function and morphology in acute ischemic renal failure. Kidney Int 1983; 23:717-724.

44. Conger JD, Robinette JB, Hammond WS. Differences in vascular reactivity in models of ischemic acute renal failure. Kidney Int 1991; 39:1087-1097.

45. Verbeke M, Van de Voorde J, de Ridder L, Lameire N. Beneficial effect of serotonin 5-HT2receptor antagonism on renal blood flow autoregulation in cyclosporin-treated rats. J Am Soc Nephrol 1999; 10:28-34.

46. Conger JD, Schultz MF, Miller F, Robinette JB. Responses to hemorrhagic arterial pressure reduction in different ischemic renal failure models. Kidney Int 1994; 46:318-323.

47. Summers WK, Jamison RL. The no reflow phenomenon in renal ischemia. Lab Invest 1971; 25:635-643.

48. Flores J, DiBona DR, Beck CH, Leaf A. The role of cell swelling in ischemic renal damage and the protective effect of hypertonic solute. J Clin Invest 1972; 51:118-126.

49. Johnston WH, Latta H. Glomerular mesangial and endothelial cell swelling following temporary renal ischemia and its role in the no-reflow phenomenon. Am J Pathol 1977; 89:153-166.

50. Mason J, Welsch J, Torhorst J. The contribution of vascular obstruction to the functional defect that follows renal ischemia. Kidney Int 1987; 31:65-71.

51. O'Malley CM, Frumento RJ, Hardy MA, et al. A randomized, double-blind comparison of lactated Ringer's solution and $0.9 \% \mathrm{NaCl}$ during renal transplantation. Anesth Analg 2005; 100:1518-1524.

52. De Gasperi A, Narcisi S, Mazza E, et al. Perioperative fluid management in kidney transplantation: is volume overload still mandatory for graft function? Transplant Proc 2006; 38:807-809. 
184 | 


\title{
Chapter 9
}

\author{
Acute ischemic injury to \\ the renal microvasculature in \\ human kidney transplantation
}




\begin{abstract}
Background: Increased understanding of the pathophysiology of ischemic acute kidney injury in renal transplantation may lead to novel therapies that improve early graft function and allow expansion of the donor pool with kidneys that have suffered prolonged ischemia. Therefore, we studied the effects of ischemia and reperfusion on the human renal microcirculation by comparing ischemically injured kidneys from donors after cardiac death (DCD) to a control group of kidneys from living donors with minimal ischemia.

Methods: During transplant surgery, cortical peritubular capillaries were directly visualized by sidestream dark-field imaging and renal arteriovenous gradients of the main constituents of the endothelial glycocalyx (syndecan-1 and heparan sulfate) were measured.
\end{abstract}

Findings: Despite a profound reduction in creatinine clearance, total renovascular resistance of DCD kidneys was similar to that of living donor kidneys. In contrast, renal microvascular perfusion in the early reperfusion period was $42 \%$ lower in DCD compared to living donor kidneys, which was accounted for by smaller blood vessel diameters in DCD kidneys. Furthermore, DCD kidneys were characterized by smaller red blood cell exclusion zones in peritubular capillaries and by greater arteriovenous gradients of syndecan-1 and heparan sulfate compared to living donor kidneys, providing strong evidence for degradation of the endothelial glycocalyx in these kidneys.

Interpretation: Renal ischemia and reperfusion is associated with reduced capillary blood flow and loss of glycocalyx integrity. These findings form the basis for development of novel interventions to prevention ischemic acute kidney injury.

\title{
Published as
}

Snoeijs MG, Vink H, Voesten N, Christiaans MH, Daemen JH, Peppelenbosch AG, Tordoir JH, Buurman WA, Schurink GW, van Heurn LW. Acute ischemic injury to the renal microvasculature in human kidney transplantation. Am J Phys, in revision. 


\section{Introduction}

Kidney transplantation is inevitably associated with ischemia and reperfusion injury. Depending on the severity of injury, $20-80 \%$ of recipients of deceased donor kidneys require dialysis treatment in the first week after transplantation, which is referred to as delayed graft function. ${ }^{1}$ This condition complicates patient management and is associated with a $40 \%$ increased rate of graft loss in kidneys from donors after brain death. ${ }^{2}$ Liberal use of donation after cardiac death greatly expands the number of available donor kidneys and may even eliminate transplant waiting lists. ${ }^{3}$ However, kidneys from these donors suffer extensive ischemic injury from circulatory arrest until organ preservation, which almost invariably leads to delayed graft function after transplantation. More importantly, up to $15-25 \%$ of these kidneys will never regain function, unnecessarily exposing recipients to the risks of major surgery and immunological sensitization. ${ }^{4}$

Adequate reperfusion is essential for functional recovery of donor kidneys and prevents ongoing ischemic tissue injury after revascularization. In rodent models of ischemic acute kidney injury, it has been demonstrated that the peritubular microcirculation suffers endothelial injury and functional impairment after reperfusion, ${ }^{5,6}$ which has recently been observed in man as well. ${ }^{7-9}$ The endothelium is covered by the glycocalyx, a dynamic network of proteoglycans and glycoproteins that determines vascular permeability, transduces shear stress to the endothelium and prevents interaction of leukocytes and platelets with the vascular wall. ${ }^{10}$ Loss of endothelial glycocalyx integrity after ischemia and reperfusion has been observed in experimental models ${ }^{11-13}$ and in patients undergoing aortic surgery. ${ }^{14}$ Degradation of the endothelial glycocalyx by infusion of hyaluronidase causes capillary perfusion defects in rodents. ${ }^{15}$ Taken together, ischemic injury to endothelial cells and glycocalyx of peritubular capillaries may play a major role in the pathophysiology of acute kidney injury by reducing tissue perfusion and propagating inflammation in the reperfused kidney.

In the current chapter, we studied the human renal microcirculation after clinical kidney transplantation by direct visualization of cortical peritubular capillaries and by measuring renal arteriovenous gradients of the main constituents of the endothelial glycocalyx. We found that ischemically injured kidneys from donors after cardiac death (DCD) were characterized by reduction of 
capillary blood flow and loss of glycocalyx integrity in comparison to a control group of kidneys from living donors with minimal ischemic injury. These findings form the basis for development of interventions that increase microvascular perfusion and protect the endothelial glycocalyx.

\section{Materials and methods}

\section{Study design}

In this observational study, eight consecutive recipients of ischemically injured kidneys from donors after cardiac death were compared to eight recipients of living donor kidneys that suffered minimal ischemic injury. All patients received dialysis therapy and were 18 years or older. The kidneys were recovered from separate donors between 16 and 60 years of age to reduce the possibility of perfusion abnormalities as a result of small pediatric grafts or atherosclerotic blood vessels. At transplantation, renovascular resistance, microvascular perfusion and endothelial glycocalyx integrity were assessed immediately after reperfusion. Patients were observed for 10 days after transplantation to measure early graft function. The study was approved by the local institutional review board (MEC 07-2-025) and all patients gave written informed consent for participation in this study.

\section{Kidney transplantation}

Living donor kidneys ( $\mathrm{N}=8$ ) were recovered by open mini-incision donor nephrectomy and were cold-stored in HTK preservation solution (Dr. F. Köhler Chemie, Bensheim, Germany). DCD kidneys were recovered after in situ perfusion for uncontrolled donation after failed cardiopulmonary resuscitation in the emergency department $(\mathrm{N}=3)$ or after rapid laparotomy and direct aortic cannulation for controlled donation after scheduled withdrawal of supportive treatment in the intensive care unit $(\mathrm{N}=5) .{ }^{16}$ DCD kidneys were preserved by cold storage in HTK solution or by machine perfusion (LifePort; Organ Recovery Systems, Des Plaines, IL).

After obtaining negative cross-matches, kidneys were transplanted by end-to-side anastomoses of the renal artery and vein to the common or external iliac artery and vein. Heparin was not routinely administered and none of the patients received blood transfusions during surgery. Recipient hemodynamic management was targeted at a central venous pressure of $10-15 \mathrm{mmHg}$ during 
transplant surgery. Renal artery blood flow was measured at 5 and 30 minutes after reperfusion using perivascular flow probes (Transonic Systems Inc., Ithaca, $\mathrm{NY}$ ). Immunosuppression was started before surgery and consisted of corticosteroids, tacrolimus and mycophenolic acid or sirolimus. In the first 10 days after transplantation, graft function was assessed daily by measuring creatinine clearance using 24-hour urine collections.

\section{Sidestream dark-field imaging}

The cortical peritubular microcirculation was directly visualized at $5 \mathrm{x}$ magnification by sidestream dark-field imaging (MicroScan, Amsterdam, The Netherlands) at a frame rate of $25 \mathrm{~Hz}$ and a resolution of 720x576 pixels. After reperfusion, the renal capsule was removed from the kidney over an area of approximately $2 \mathrm{~cm}^{2}$. Subsequently, the imaging probe was manually positioned on the kidney using saline irrigation to obtain a bloodless surface. At 5 and 30 minutes after reperfusion, three continuous image sequences of 20 seconds were digitally stored. At each time point, stable and sharp fragments of approximately 5 seconds were selected for off-line analysis. The imaging studies were done by the same investigator.

Characteristics of the cortical peritubular microcirculation were quantified using Automated Vascular Analysis software (MicroScan). After calibration and image stabilization by linear transformation, blood vessels were manually identified in an averaged frame and the vascular density was calculated. Blood vessel diameter was defined as the median diameter of the red blood cell column. For blood vessels up to $25 \mu \mathrm{m}$ in diameter, blood flow velocity was measured by manual tracing of leukocytes and plasma gaps along the vessel centreline in space-time diagrams. ${ }^{17}$ Centreline velocity was multiplied by 0.7 to account for the velocity distribution over the cross-sectional area of the vessels. ${ }^{18}$ Assuming a cylindrical shape of the blood vessels, volumetric blood flow in each vessel was calculated as $(\pi / 4) \times$ (diameter) $)^{2} \mathrm{x}$ (blood flow velocity). Total microvascular blood flow was calculated as the sum of the individual vessels. The analyses were done by a single investigator who was blinded to donor type.

Glycocalyx dimensions were quantified by measuring erythrocyte column width at approximately 200-300 sites in the peritubular microcirculation in each video fragment using Image-Pro Plus software (Media Cybernetics, Bethesda, MD). Infrequently, erythrocytes are able to transiently penetrate the endothelial glycocalyx, contributing to the dynamic range of erythrocyte column width. Reduced dynamic range of erythrocyte column width was therefore interpreted as a reduction of glycocalyx dimension. At each measurement site, 
erythrocyte column width was automatically determined from $50 \mu \mathrm{m}$ radial lineintensity profiles at 20 locations distributed over a $10 \mu \mathrm{m}$ longitudinal distance in 40 sequential frames, resulting in 800 measurements of erythrocyte column width. The dynamic range of erythrocyte column width was determined at each measurement site as the difference between median and maximal erythrocyte column width $\left(50^{\text {th }}\right.$ and $99^{\text {th }}$ percentiles of erythrocyte column width distribution, respectively). Glycocalyx dimensions were compared by calculating differences in the median dynamic range of erythrocyte column width of differently sized microvessels (maximal erythrocyte column width between 10 and $25 \mu \mathrm{m}$, classified into $1 \mu \mathrm{m}$ intervals).

\section{Measurement of glycocalyx constituents in plasma}

Systemic blood was drawn from a radial artery catheter at the start of surgery, just before reperfusion and at 5 and 30 minutes after reperfusion. Renal venous blood was drawn at 5 and 30 minutes after reperfusion. Blood was immediately transferred to EDTA tubes and centrifuged at $900 \mathrm{~g}$ at $4^{\circ} \mathrm{C}$ for 10 minutes. Plasma was kept on ice until storage at $-80^{\circ} \mathrm{C}$. Plasma syndecan- 1 and heparan sulfate concentrations were measured using enzyme immunoassays (Diaclone Research, Besancon, France and Seikagaku Corp, Tokyo, Japan, respectively) according to manufacturer's instructions. Before measurement of heparan sulfate concentrations, samples were treated with actinase E to digest plasma proteins (SigmaAldrich, St. Louis, MO). Measurements from blood sampled during surgery were adjusted for hemodilution using hemoglobin and hematocrit to calculate relative increases in plasma volume. ${ }^{19}$ Renal fluxes of syndecan-1 and heparan sulfate were calculated by multiplying the arteriovenous concentration differences with total renal plasma flow which was measured simultaneously and adjusted for kidney weight.

\section{Statistical methods}

Continuous variables were expressed as means with standard errors and categorical variables as percentages. For continuous variables, differences between groups were compared with independent samples t-tests and differences within groups with paired samples t-tests. For categorical variables, differences between groups were compared with Fisher exact tests. Correlations between continuous variables were assessed with Pearson correlation coefficients and with multivariable linear regression. Results with $\mathrm{P}<0.05$ were considered statistically significant. 


\section{Results}

\section{Patient characteristics}

The effects of ischemia and reperfusion on the human renal microcirculation were studied by comparing kidneys from donors after cardiac death $(\mathrm{N}=8)$ with living donor kidneys $(\mathrm{N}=8)$. Transplant characteristics of the two study groups are presented in Table 9.1. Baseline characteristics of the two types of organ donors were comparable. As intended by study design, warm and cold ischemia times were significantly longer for DCD kidneys than for living donor kidneys. Furthermore, recipients of DCD kidneys were significantly older, had spent more time on dialysis and received grafts with increased weight as compared to recipients of living donor kidneys. Other transplant characteristics were similar between the two study groups.

Table 9.1 Transplant characteristics ${ }^{\mathrm{a}}$

\begin{tabular}{lccc}
\hline & $\begin{array}{c}\text { Living donors } \\
(\mathrm{N}=8)\end{array}$ & $\begin{array}{c}\text { DCD donors } \\
(\mathrm{N}=8)\end{array}$ & $\mathrm{P}$ \\
\hline Donor & & & \\
\hline \multicolumn{1}{|l}{ Age (years) } & $40(4)$ & $45(5)$ & 0.44 \\
\hline Sex (male) & 5 & 4 & 0.61 \\
\hline Serum creatinine ( $\mu$ mol/L) & $91(4)$ & $93(21)$ & 0.91 \\
\hline Hypertension (yes) & 0 & 2 & 0.20 \\
\hline Recipient & & & \\
\hline Age (years) & $44(4)$ & $60(2)$ & 0.005 \\
\hline Sex (male) & 5 & 5 & 1.00 \\
\hline Dialysis time (years) & $1.4(0.4)$ & $5.2(0.7)$ & $<0.001$ \\
\hline Dialysis type (HD / PD) & $6 / 2$ & $5 / 3$ & 1.00 \\
\hline Diuresis (mL/day) & $750(206)$ & $588(351)$ & 0.70 \\
\hline Immunosuppression (sirolimus / MMF) & $4 / 4$ & $5 / 3$ & 1.00 \\
\hline Graft & & & \\
\hline Warm ischemia time (min) & $4(1)$ & $39(11)$ & 0.006 \\
\hline Cold ischemia time (hours) & $2.4(0.1)$ & $22(1.8)$ & $<0.001$ \\
\hline Anastomosis time (min) & $34(6)$ & $39(3)$ & 0.48 \\
\hline Preservation (cold storage / machine) & 8 & $5 / 3$ & 0.20 \\
\hline Kidney weight (g) & $172(14)$ & $229(17)$ & 0.03 \\
\hline
\end{tabular}

a Data are presented as means (standard errors) or as counts and are compared with independent samples t-tests or Fisher exact tests. DCD: donation after cardiac death, HD: hemodialysis, PD: peritoneal dialysis, MMF: mycophenolate mofetil. 


\section{Kidney function}

All kidney transplantations were technically successful and eventually resulted in cessation of dialysis therapy. After transplantation, 6 (75\%) DCD kidney recipients and none $(0 \%)$ of the recipients of living donor kidneys required temporary continuation of dialysis treatment $(\mathrm{P}=0.01)$. Kidney function in the first 10 days after transplantation was assessed by daily measurements of creatinine clearance from 24-hour urine collections (Figure 9.1). On each day, creatinine clearance of DCD kidneys was significantly lower than that of living donor kidneys $(\mathrm{P}<0.05)$. These findings indicate that the extensive ischemic injury suffered by DCD kidneys was associated with a profound reduction in graft function in the early postoperative period.

\section{Renal macrovascular perfusion}

At reperfusion of the transplanted kidney, mean arterial pressure and central venous pressure in DCD kidney recipients were similar to those in recipients of living donor kidneys $(\mathrm{P}=0.45$ and $\mathrm{P}=0.10$, respectively, Table 9.2). Volumetric blood flow through the transplant renal artery was measured with perivascular flow probes and adjusted for perfusion pressure and kidney weight to assess vascular resistance. At 5 and 30 minutes after reperfusion, total vascular resistance of DCD kidneys was comparable to that of living donor kidneys ( $\mathrm{P}=0.99$ and $\mathrm{P}=0.27$, respectively). Recipients of living donor kidneys were loaded with immunosuppressive drugs before transplantation and therefore had higher

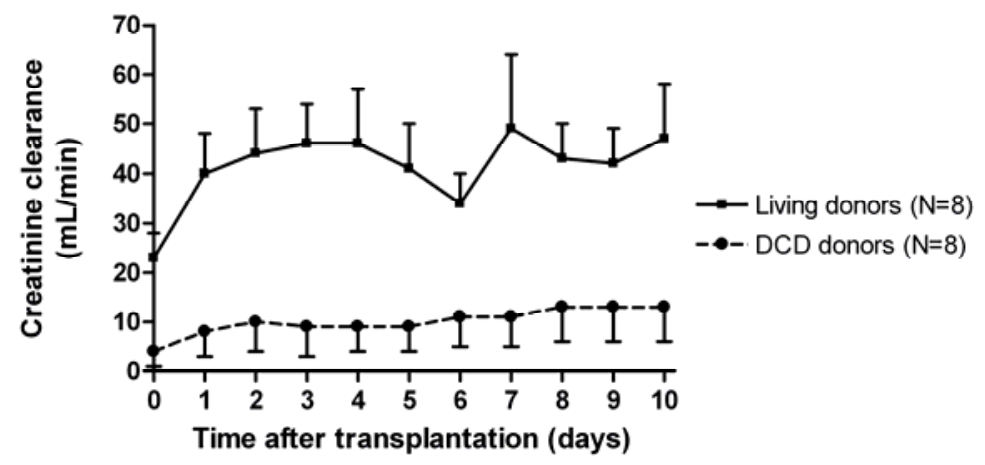

Figure 9.1 Kidney function in the first 10 days after transplantation assessed by daily measurements of creatinine clearance from 24-hour urine collections. On each day, creatinine clearance of kidneys from donors after cardiac death (DCD, $N=8$ ) was significantly lower than that of living donor kidneys $(\mathrm{N}=8, \mathrm{P}<0.05)$. Data are presented as means and standard errors. 
Table 9.2 Renal macrovascular perfusion ${ }^{\mathrm{a}}$

\begin{tabular}{lccc}
\hline & Living donors & DCD donors & \\
& $(\mathbf{N}=8)$ & $(\mathbf{N}=8)$ & P \\
\hline MAP at reperfusion $(\mathrm{mmHg})$ & $70(4)$ & $66(3)$ & 0.45 \\
CVP at reperfusion $\left(\mathrm{cmH}_{2} \mathrm{O}\right)$ & $15(3)$ & $10(1)$ & 0.10 \\
Resistance at $5 \mathrm{~min}(\mathrm{mmHg} / \mathrm{mL} / \mathrm{min} / 100 \mathrm{~g})$ & $0.25(0.07)$ & $0.25(0.05)$ & 0.99 \\
Resistance at $30 \mathrm{~min}(\mathrm{mmHg} / \mathrm{mL} / \mathrm{min} / 100 \mathrm{~g})$ & $0.16(0.03)$ & $0.26(0.09)$ & 0.27 \\
Tacrolimus concentration at reperfusion $(\mu \mathrm{g} / \mathrm{L})$ & $24(3)$ & $10(3)$ & 0.003 \\
\hline
\end{tabular}

${ }^{a}$ Data are presented as means (standard errors) and are compared with independent samples t-tests. DCD: donation after cardiac death, MAP: mean arterial pressure, CVP: central venous pressure.

tacrolimus levels at reperfusion than DCD kidney recipients. Since calcineurin inhibitors have been reported to cause renal vasoconstriction, ${ }^{20}$ we used multivariable linear regression to account for tacrolimus concentrations at reperfusion of the kidney. After elimination of this potential confounder, kidney type remained unrelated to renovascular resistance at 5 and 30 minutes after reperfusion $(\mathrm{P}=0.31$ and $\mathrm{P}=0.66$, respectively). Taken together, ischemic injury to donor kidneys did not affect the renal macrovascular resistance to reperfusion.

\section{Cortical peritubular microcirculation}

Peritubular capillaries in the renal cortex were directly visualized by sidestream dark-field imaging at 5 and 30 minutes after reperfusion. Transplanted kidneys typically showed continuous flow through the vast majority of blood vessels (Video 9.1, included on CD). In some cases, however, several non-perfused capillaries with stagnant or oscillating blood flow were observed (Video 9.2, included on CD). To compare the cortical microcirculation between kidney types, peritubular microvascular perfusion was quantified off-line. The cortical area, vascular density and fraction of vessel length that could be analyzed were similar for the video fragments of DCD and living donor kidneys (Table 9.3). At 5 minutes after reperfusion, mean blood vessel diameter in DCD kidneys was significantly smaller than that in kidneys from living donors $(\mathrm{P}=0.02)$. Since mean microvascular blood flow velocity was comparable, the smaller diameter resulted in a significant $42 \%$ reduction of total blood volume flowing through the peritubular capillary network of DCD compared to living donor kidneys $(\mathrm{P}=0.007)$. At 30 minutes after reperfusion, this difference in volumetric blood flow persisted but was no longer statistically significant $(\mathrm{P}=0.24)$. Renal perfusion pressure at the time of imaging was comparable between the two study groups 
Table 9.3 Cortical peritubular microcirculation ${ }^{\mathrm{a}}$

\begin{tabular}{lccc}
\hline & $\begin{array}{c}\text { Living donors } \\
(\mathrm{N}=8)\end{array}$ & $\begin{array}{c}\text { DCD donors } \\
(\mathrm{N}=8)\end{array}$ & $\mathrm{P}$ \\
\hline 5 MIN AFTER REPERFUSION & & & \\
\hline Cortical area $\left(\mathrm{mm}^{2}\right)$ & $0.60(0.02)$ & $0.50(0.06)$ & 0.20 \\
Vessel length analyzed $(\%)$ & $85(1)$ & $87(2)$ & 0.30 \\
Vascular density $\left(\mathrm{mm} / \mathrm{mm}^{2}\right)$ & $16(1.2)$ & $15(2.1)$ & 0.62 \\
Mean blood vessel diameter $(\mu \mathrm{m})$ & $12(0.4)$ & $11(0.4)$ & 0.02 \\
Mean blood flow velocity $(\mu \mathrm{m} / \mathrm{sec})$ & $244(24)$ & $275(40)$ & 0.56 \\
Total microvascular blood flow $(\mathrm{pL} / \mathrm{min})$ & $87(6)$ & $51(9)$ & 0.007 \\
\hline 30 MIN AFTER REPERFUSION & & & \\
Cortical area (mm $\left.{ }^{2}\right)$ & $0.57(0.05)$ & $0.59(0.03)$ & 0.72 \\
Vessel length analyzed $(\%)$ & $86(2)$ & $88(2)$ & 0.40 \\
Vascular density (mm/mm $\left.{ }^{2}\right)$ & $16(1.9)$ & $16(1.4)$ & 0.88 \\
Mean blood vessel diameter $(\mu \mathrm{m})$ & $11(0.8)$ & $11(0.5)$ & 0.33 \\
Mean blood flow velocity $(\mu \mathrm{m} / \mathrm{sec})$ & $356(57)$ & $337(54)$ & 0.82 \\
Total microvascular blood flow $(\mathrm{pL} / \mathrm{min})$ & $108(33)$ & $68(8)$ & 0.24 \\
\hline
\end{tabular}

a Data are presented as means (standard errors) and are compared with independent samples t-tests. Peritubular blood vessels up to $25 \mu \mathrm{m}$ in diameter were analyzed. DCD: donation after cardiac death.

(data not shown). These findings indicate that ischemic acute kidney injury is associated with reduced cortical microvascular blood flow in the early reperfusion period.

\section{Endothelial glycocalyx}

The luminal surface of the capillary endothelium is covered by the glycocalyx, a dynamic network of proteoglycans and glycoproteins that contributes to endothelial function and microvascular perfusion. ${ }^{10,15}$ To investigate whether the glycocalyx was disrupted by ischemia and reperfusion, we measured red blood cell exclusion zones in the cortical peritubular microcirculation of transplanted kidneys using sidestream dark-field imaging. At 5 minutes after reperfusion, red blood cell exclusion zones in DCD kidneys were $0.16 \pm 0.06 \mu \mathrm{m}$ smaller than those in living donor kidneys ( $\mathrm{P}=0.02$, Figure 9.2), indicating significant loss of glycocalyx in ischemically injured kidneys. Although glycocalyx thickness increased during the early reperfusion period $(\mathrm{P}<0.05)$, differences between the two kidney types persisted until 30 minutes after reperfusion, but were no longer statistically significant at that time $(\mathrm{P}=0.20)$. 
Degradation of the endothelial glycocalyx was confirmed by measuring renal arteriovenous gradients of the main glycocalyx constituents syndecan-1 and heparan sulfate. At 5 minutes after reperfusion of DCD kidneys, concentrations of syndecan-1 and heparan sulfate in the transplant renal vein were higher than those in arterial blood ( $\mathrm{P}=0.02$ and $\mathrm{P}=0.06$, respectively, Figure 9.3). In contrast, no arteriovenous differences in syndecan- 1 and heparan sulfate concentrations were observed in living donor kidneys $(\mathrm{P}=0.38$ and $\mathrm{P}=0.78)$. The renal flux of syndecan-1, but not of heparan sulfate, was significantly greater in DCD kidneys than in kidneys from living donors $(2.6 \pm 1.0 \mathrm{vs}-0.2 \pm 0.5 \mu \mathrm{g} / \mathrm{min} / 100 \mathrm{~g}, \mathrm{P}=0.02$ for syndecan- 1 , and $57 \pm 32$ vs $114 \pm 85 \mu \mathrm{g} / \mathrm{min} / 100 \mathrm{~g}, \mathrm{P}=0.59$ for heparan sulfate). Moreover, creatinine clearance on the first day after transplantation was inversely correlated to the renal flux of syndecan- 1 at 5 minutes after reperfusion $(\mathrm{R}=-0.77, \mathrm{P}=0.001)$. Renal arteriovenous differences of syndecan- 1 and heparan sulfate had dissipated at 30 minutes after reperfusion (data not shown). Taken together, these findings provide strong evidence for glycocalyx disruption in the cortical peritubular microcirculation of ischemically injured kidneys.

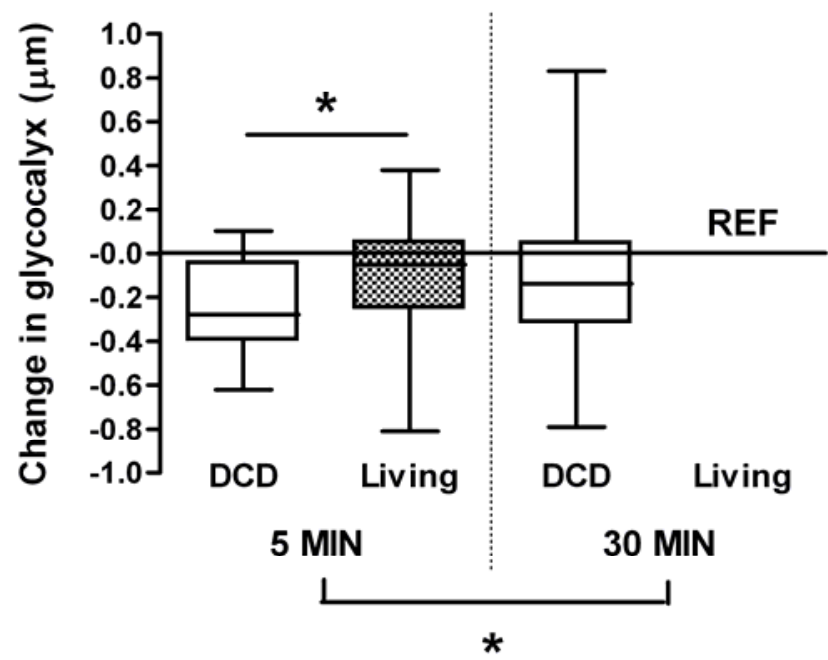

Figure 9.2 Endothelial glycocalyx dimensions in the cortical peritubular microcirculation of donor kidneys assessed by measuring red blood cell exclusion zones using sidestream dark-field imaging. At 5 minutes after reperfusion, the glycocalyx of kidneys from donors after cardiac death (DCD) was significantly smaller than that of living donor kidneys $(\mathrm{P}=0.02)$. Glycocalyx thickness increased from 5 to 30 minutes after reperfusion $(\mathrm{P}<0.05)$. Data are presented as median, interquartile range, minimal and maximal glycocalyx dimensions relative to living donor kidneys at 30 minutes after reperfusion. Asterisks denote statistical significance. 

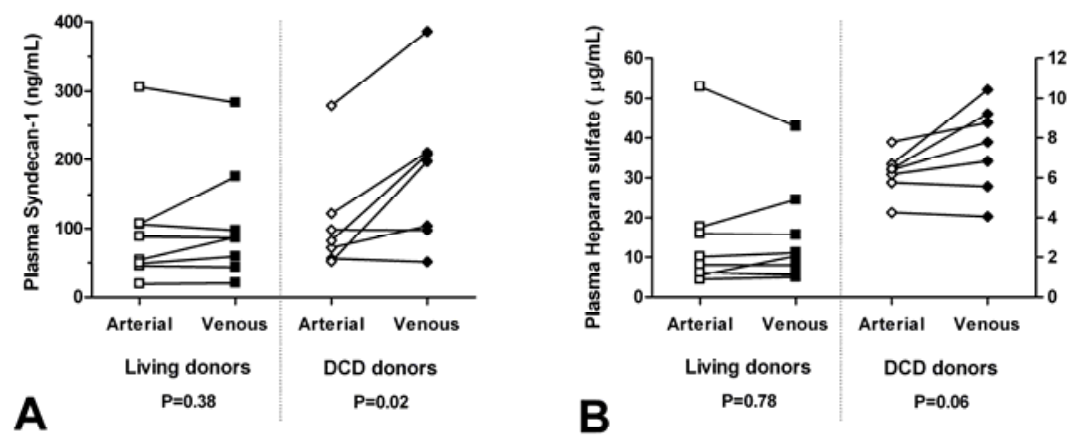

Figure 9.3 Endothelial glycocalyx degradation assessed by measuring the renal arteriovenous gradients of the glycocalyx constituents (A) syndecan-1 and (B) heparan sulfate at 5 minutes after reperfusion. Syndecan-1 and heparan sulfate were released from kidneys from donors after cardiac death (DCD, $N=7$ ) but not from living donor kidneys $(\mathrm{N}=8)$. One DCD kidney was excluded from analysis because the transplant renal vein was positioned too deeply for safe blood sampling.

\section{Discussion}

Kidney transplantation is inevitably associated with renal ischemia and reperfusion, leading to a transient reduction in glomerular filtration rate due to tubular obstruction, afferent arteriolar vasoconstriction and transtubular backleak of ultrafiltrate. ${ }^{21}$ Furthermore, renal ischemia and reperfusion results in upregulation of genes involved in cellular injury and repair (particularly genes regulating oxidative stress and apoptosis) and inflammation (particularly toll-like receptors, complement components, chemokines and adhesion molecules). In animal studies, each of these pathways has been shown to contribute to ischemic acute kidney injury. Despite these advances, specific pharmacological interventions to protect the human donor kidney from ischemia and reperfusion injury have not been found. It is therefore important to further study the pathophysiology of ischemic acute kidney injury to guide the development of more effective therapies.

In the current study, we report on the effects of acute ischemic injury on the renal microcirculation in human kidney transplantation. We took advantage of the unique accessibility of the kidney during transplant surgery to perform invasive renal hemodynamic measurements in the early reperfusion period. Two 
groups of donor kidneys were compared with highly different levels of ischemic injury but with similar baseline characteristics: (1) kidneys from donors after cardiac death (DCD) that suffer extensive ischemic injury from circulatory arrest until organ preservation, and (2) kidneys from living donors that suffer minimal warm and cold ischemic injury.

The creatinine clearance of DCD kidneys was much lower than that of kidneys from living donors in the first ten days after transplantation, illustrating the impact of acute ischemic injury on early graft function. Despite the profound reduction in glomerular filtration rate, total renovascular resistance of DCD kidneys was similar to that of living donor kidneys in the early reperfusion period. This finding seems to contradict previous publications that have shown a correlation between volumetric renal blood flow and early graft function. ${ }^{22-24}$ However, such studies are scarce and typically did not adjust for perfusion pressure and kidney weight, which may result in a confounded impression of renal hemodynamics.

In contrast to the similarity of macrovascular characteristics between DCD and living donor kidneys, microvascular perfusion of DCD kidneys was significantly reduced by $42 \%$ in the early reperfusion period. Since vascular density and blood flow velocity of the study groups were comparable, the reduction in microvascular perfusion was most likely accounted for by the significantly smaller blood vessel diameter of DCD compared to living donor kidneys. These findings are supported by previous reports of abnormalities in peritubular capillary perfusion after renal ischemia and reperfusion in rats and in human kidney transplantation..$^{5-8,25}$ Moreover, microvascular dysfunction after renal ischemia and reperfusion is associated with permanent loss of up to $50 \%$ of peritubular capillaries in rats, predisposing the kidney to interstitial fibrosis and tubular atrophy. ${ }^{26,27}$ Since sidestream dark-field imaging has a penetration depth of $300-500 \mu \mathrm{m},{ }^{28}$ our microcirculatory measurements were confined to the cortical peritubular microcirculation at the renal surface. As the proximal tubular epithelium in the outer medulla is considered to be most vulnerable to ischemia and reperfusion injury, studies of the medullary microcirculation in human kidney transplantation may be performed as new imaging techniques become available. $^{29}$

In the current study, we show for the first time that the endothelial glycocalyx is rapidly degraded after transplantation of ischemically injured kidneys. This novel finding is in line with previous observations on glycocalyx disruption by ischemia and reperfusion in animal models and in human cardiovascular surgery. ${ }^{11-14}$ We used two complementary methods to measure the integrity of 
the endothelial glycocalyx in the early reperfusion period during human kidney transplantation. First, smaller red blood cell exclusion zones were observed in sidestream dark-field images of the peritubular capillaries of ischemically injured DCD kidneys. Second, renal arteriovenous gradients of syndecan-1 and heparan sulfate - the main constituents of the endothelial glycocalyx - were greater in DCD kidneys than in kidneys from living donors. Red blood cell exclusion zones increased and release of glycocalyx constituents decreased during the first half hour of reperfusion, suggesting a rapid restoration of degraded endothelial glycocalyx. Together, these findings demonstrate that damage to endothelial glycocalyx develops early in the course of renal ischemia and reperfusion.

Glycocalyx injury may have major implications for graft function. Disruption of the endothelial glycocalyx results in vascular permeability, interstitial edema and endothelial cell swelling. ${ }^{30-32}$ In addition, the glycocalyx acts by transducing shear stress to the underlying endothelium which in turn responds by production of the vasodilator nitric oxide. ${ }^{33-36}$ Glycocalyx loss in ischemically injured kidneys is therefore expected to result in reduced nitric oxide production, which has indeed been observed in human kidney transplantations with delayed graft function. ${ }^{37}$ Impaired flow-induced vasodilation and capillary compression by interstitial edema as a result of glycocalyx degradation may both account for the smaller capillary diameters observed in DCD compared to living donor kidneys. Furthermore, the intact glycocalyx prevents direct contact of blood cells with the endothelium. Disruption of the glycocalyx uncovers adhesion molecules at the endothelial surface and increases leukocyte and platelet binding to the vascular wall. ${ }^{38,39}$ In addition, several constituents of the glycocalyx (hyaluronan fragments, heparan sulfate and biglycan) have been shown to activate innate and adaptive immunity by signalling through toll-like receptors when shed from the extracellular matrix.40-44 Degradation of the endothelial glycocalyx may therefore contribute to the excessive inflammatory response following renal ischemia and reperfusion.

In conclusion, our study demonstrates that ischemically injured kidneys from donors after cardiac death are characterized by reduced microvascular blood flow and loss of glycocalyx integrity in comparison to a control group of intact kidneys from living donors. These findings may apply more generally to other conditions associated with ischemia and reperfusion injury such as acute myocardial infarction, stroke and liver resection. Interventions aimed at increasing microvascular perfusion and restoring the endothelial glycocalyx may improve early graft function and enable expansion of the donor pool with kidneys that suffered prolonged ischemia. 


\section{References}

1. Perico N, Cattaneo D, Sayegh MH, Remuzzi G. Delayed graft function in kidney transplantation. Lancet 2004; 364:1814-1827.

2. Yarlagadda SG, Coca SG, Formica RN, Jr., Poggio ED, Parikh CR. Association between delayed graft function and allograft and patient survival: a systematic review and meta-analysis. Nephrol Dial Transplant 2009; 24:1039-1047.

3. Terasaki PI, Cho YW, Cecka JM. Strategy for eliminating the kidney shortage. Clin Transpl 1997:265-267.

4. Wijnen RM, Booster MH, Stubenitsky BM, de Boer J, Heineman E, Kootstra G. Outcome of transplantation of non-heart-beating donor kidneys. Lancet 1995; 345:1067-1070.

5. Yamamoto T, Tada T, Brodsky SV, et al. Intravital videomicroscopy of peritubular capillaries in renal ischemia. Am J Physiol Renal Physiol 2002; 282:F1150-1155.

6. Brodsky SV, Yamamoto T, Tada T, et al. Endothelial dysfunction in ischemic acute renal failure: rescue by transplanted endothelial cells. Am J Physiol Renal Physiol 2002; 282:F11401149 .

7. Hattori R, Ono Y, Kato M, Komatsu T, Matsukawa Y, Yamamoto T. Direct visualization of cortical peritubular capillary of transplanted human kidney with reperfusion injury using a magnifying endoscopy. Transplantation 2005; 79:1190-1194.

8. Schmitz V, Schaser KD, Olschewski P, Neuhaus P, Puhl G. In vivo Visualization of Early Microcirculatory Changes following Ischemia/Reperfusion Injury in Human Kidney Transplantation. Eur Surg Res 2007; 40:19-25.

9. Kwon O, Hong SM, Sutton TA, Temm CJ. Preservation of peritubular capillary endothelial integrity and increasing pericytes may be critical to recovery from postischemic acute kidney injury. Am J Physiol Renal Physiol 2008; 295:F351-359.

10. Reitsma S, Slaaf DW, Vink H, van Zandvoort MA, oude Egbrink MG. The endothelial glycocalyx: composition, functions, and visualization. Pflugers Arch 2007; 454:345-359.

11. Platts SH, Linden J, Duling BR. Rapid modification of the glycocalyx caused by ischemiareperfusion is inhibited by adenosine A2A receptor activation. Am J Physiol Heart Circ Physiol 2003; 284:H2360-2367.

12. Mulivor AW, Lipowsky HH. Inflammation- and ischemia-induced shedding of venular glycocalyx. Am J Physiol Heart Circ Physiol 2004; 286:H1672-1680.

13. Chappell D, Jacob M, Hofmann-Kiefer K, et al. Antithrombin reduces shedding of the endothelial glycocalyx following ischaemia/reperfusion. Cardiovasc Res 2009; 83:388-396.

14. Rehm M, Bruegger D, Christ F, et al. Shedding of the endothelial glycocalyx in patients undergoing major vascular surgery with global and regional ischemia. Circulation 2007; 116:1896-1906.

15. Cabrales P, Vazquez BY, Tsai AG, Intaglietta M. Microvascular and capillary perfusion following glycocalyx degradation. J Appl Physiol 2007; 102:2251-2259.

16. Snoeijs MG, Dekkers AJ, Buurman WA, et al. In Situ Preservation of Kidneys From Donors After Cardiac Death: Results and Complications. Ann Surg 2007; 246:844-852.

17. Ellis CG, Ellsworth ML, Pittman RN, Burgess WL. Application of image analysis for evaluation of red blood cell dynamics in capillaries. Microvasc Res 1992; 44:214-225. 
18. Tangelder GJ, Slaaf DW, Muijtjens AM, Arts T, oude Egbrink MG, Reneman RS. Velocity profiles of blood platelets and red blood cells flowing in arterioles of the rabbit mesentery. Circ Res 1986; 59:505-514.

19. Dill DB, Costill DL. Calculation of percentage changes in volumes of blood, plasma, and red cells in dehydration. J Appl Physiol 1974; 37:247-248.

20. Nankivell BJ, Chapman JR, Bonovas G, Gruenewald SM. Oral cyclosporine but not tacrolimus reduces renal transplant blood flow. Transplantation 2004; 77:1457-1459.

21. Snoeijs MG, van Heurn LW, Buurman WA. Biological modulation of renal ischemiareperfusion injury. Curr Opin Organ Transplant 2010; 15:190-199.

22. Anderson CB, Etheredge EE. Human renal allograft blood flow and early renal function. Ann Surg 1977; 186:564-567.

23. Alejandro V, Scandling JD, Jr., Sibley RK, et al. Mechanisms of filtration failure during postischemic injury of the human kidney. A study of the reperfused renal allograft. J Clin Invest 1995; 95:820-831.

24. Lundell A, Persson NH, Kallen R, Ekberg H. Impaired renal artery blood flow at transplantation is correlated to delayed onset of graft function. Transpl Int 1996; 9:57-61.

25. Angelescu M, Kraus T, Wiesel M, Hergesell O, Haberkorn U, Klar E. Assessment of renal graft function by perioperative monitoring of cortical microcirculation in kidney transplantation. Transplantation 2003; 75:1190-1196.

26. Basile DP, Donohoe D, Roethe K, Osborn JL. Renal ischemic injury results in permanent damage to peritubular capillaries and influences long-term function. Am J Physiol Renal Physiol 2001; 281:F887-899.

27. Higgins DF, Kimura K, Bernhardt WM, et al. Hypoxia promotes fibrogenesis in vivo via HIF-1 stimulation of epithelial-to-mesenchymal transition. J Clin Invest 2007; 117:3810-3820.

28. Groner W, Winkelman JW, Harris AG, et al. Orthogonal polarization spectral imaging: a new method for study of the microcirculation. Nat Med 1999; 5:1209-1212.

29. Schrier RW, Wang W, Poole B, Mitra A. Acute renal failure: definitions, diagnosis, pathogenesis, and therapy. J Clin Invest 2004; 114:5-14.

30. Henry CB, Duling BR. Permeation of the luminal capillary glycocalyx is determined by hyaluronan. Am J Physiol 1999; 277:H508-514.

31. Vink H, Duling BR. Capillary endothelial surface layer selectively reduces plasma solute distribution volume. Am J Physiol Heart Circ Physiol 2000; 278:H285-289.

32. van den Berg BM, Vink H, Spaan JA. The endothelial glycocalyx protects against myocardial edema. Circ Res 2003; 92:592-594.

33. Hecker M, Mulsch A, Bassenge E, Busse R. Vasoconstriction and increased flow: two principal mechanisms of shear stress-dependent endothelial autacoid release. Am J Physiol 1993; 265:H828-833.

34. Mochizuki S, Vink H, Hiramatsu O, et al. Role of hyaluronic acid glycosaminoglycans in shearinduced endothelium-derived nitric oxide release. Am J Physiol Heart Circ Physiol 2003; 285:H722-726.

35. VanTeeffelen JW, Brands J, Jansen C, Spaan JA, Vink H. Heparin impairs glycocalyx barrier properties and attenuates shear dependent vasodilation in mice. Hypertension 2007; 50:261267.

36. Kumagai R, Lu X, Kassab GS. Role of glycocalyx in flow-induced production of nitric oxide and reactive oxygen species. Free Radic Biol Med 2009; 47:600-607. 
37. Kwon O, Hong SM, Ramesh G. Diminished NO generation by injured endothelium and loss of macula densa nNOS may contribute to sustained acute kidney injury after ischemiareperfusion. Am J Physiol Renal Physiol 2009; 296:F25-33.

38. Vink H, Constantinescu AA, Spaan JA. Oxidized lipoproteins degrade the endothelial surface layer : implications for platelet-endothelial cell adhesion. Circulation 2000; 101:1500-1502.

39. Constantinescu AA, Vink H, Spaan JA. Endothelial cell glycocalyx modulates immobilization of leukocytes at the endothelial surface. Arterioscler Thromb Vasc Biol 2003; 23:1541-1547.

40. Termeer C, Benedix F, Sleeman J, et al. Oligosaccharides of Hyaluronan activate dendritic cells via toll-like receptor 4. J Exp Med 2002; 195:99-111.

41. Taylor KR, Trowbridge JM, Rudisill JA, Termeer CC, Simon JC, Gallo RL. Hyaluronan fragments stimulate endothelial recognition of injury through TLR4. J Biol Chem 2004; 279:1707917084.

42. Scheibner KA, Lutz MA, Boodoo S, Fenton MJ, Powell JD, Horton MR. Hyaluronan fragments act as an endogenous danger signal by engaging TLR2. J Immunol 2006; 177:1272-1281.

43. Johnson GB, Brunn GJ, Kodaira Y, Platt JL. Receptor-mediated monitoring of tissue well-being via detection of soluble heparan sulfate by Toll-like receptor 4. J Immunol 2002; 168:52335239.

44. Schaefer L, Babelova A, Kiss E, et al. The matrix component biglycan is proinflammatory and signals through Toll-like receptors 4 and 2 in macrophages. J Clin Invest 2005; 115:2223-2233. 
202 


\section{Chapter 10}

\section{Tubular epithelial injury}

and inflammation after ischemia and reperfusion in human kidney transplantation 


\begin{abstract}
Background: Tissue injury due to ischemia and reperfusion is an inevitable consequence of kidney transplantation. Tubular epithelial injury, inflammation and oxidative stress play major roles in the pathophysiology of acute kidney injury in small animals, but it remains to be established whether this paradigm holds true for human kidney transplantation.

Methods: To address this issue, markers of tubular injury, inflammation and oxidative stress were compared between recipients of kidneys from donors after cardiac death ( $\mathrm{DCD} ; \mathrm{N}=8$ ) with prolonged ischemia and recipients of living donor kidneys with minimal ischemia $(\mathrm{N}=8)$.

Findings: In the early postoperative period, creatinine clearance and tubular sodium reabsorption were profoundly reduced in DCD kidneys, coinciding with significantly increased urinary concentrations of tubular injury markers (NGAL, NAG and cystatin C) and an 18-fold increase in renal production of cytokeratin18 , indicating extensive necrotic cell death. Tubular injury in DCD kidneys was followed by greater systemic inflammatory activity and oxidative stress in the postoperative period (measured with 17-plex cytokine arrays and as plasma $\mathrm{F}_{2}$ isoprostanes, respectively). In contrast, no evidence of oxidative damage to either of the two kidney types was found in the early reperfusion period.

Interpretation: These findings establish the relevance of observations in animal models for human kidney transplantation and form the basis for development of novel therapies to improve early graft function and expand the use of donor kidneys with prolonged ischemia.
\end{abstract}

\title{
Published as
}

Snoeijs MG, van Bijnen A, Swennen E, Haenen GR, Roberts LJ, Christiaans MH, Peppelenbosch AG, Buurman WA, van Heurn LW. Tubular epithelial injury and inflammation after ischemia and reperfusion in human kidney transplantation. Ann Surg, in revision. 


\section{Introduction}

Kidney transplantation results in acute kidney injury due to ischemia and reperfusion. Depending on the extent of injury, $20-80 \%$ of kidneys from deceased donors have delayed graft function, which is defined as the requirement for dialysis treatment in the first week after transplantation. ${ }^{1}$ Delayed graft function obscures postoperative complications such as acute rejection and results in a $40 \%$ increase in the rate of graft loss in kidneys from brain-dead donors. ${ }^{2}$ Liberal use of organs from donors after cardiac death (DCD) greatly expands the number of kidney transplantations and may even be sufficient to eliminate transplant waiting lists. ${ }^{3}$ However, DCD kidneys undergo prolonged warm ischemia after circulatory arrest, causing delayed graft function in the majority of transplanted kidneys. Furthermore, up to $15-25 \%$ of these grafts do not recover function, exposing recipients to the risks of surgery and immunological sensitization without delivering the benefit of dialysis independence. ${ }^{4}$

Generation of reactive oxygen species at reperfusion of the kidney is considered to be a major cause of tubular epithelial injury, since administration of various anti-oxidants attenuates tubular injury and renal dysfunction in rodent models. ${ }^{5-7}$ Following renal ischemia and reperfusion, tubular epithelial cell death induces inflammation by activating the innate immune system. ${ }^{8}$ In the context of sterile tissue injury, inflammation does not restore homeostasis but rather exacerbates renal damage. Inhibition of various inflammatory pathways (e.g. complement activation, cytokine production and adhesion molecule expression) reduces tissue injury and kidney dysfunction after renal ischemia and reperfusion in rodents. ${ }^{9-11}$ Therefore, tubular epithelial injury and the subsequent inflammatory response play a major role in the pathophysiology of ischemic acute kidney injury in small animals.

Extensive necrosis of the tubular epithelium with dramatic leukocyte infiltration observed in rodent models of renal ischemia and reperfusion bears little resemblance to the subtle histological changes in human acute kidney injury. ${ }^{12}$ Therefore, it is unclear to which extent the concept of tubular epithelial cell death and inflammation following ischemic injury applies to human kidney transplantation. The limited number of studies in human kidney transplantation are generally in support of this paradigm, as neutrophil infiltration and necrotic and apoptotic cell death have been observed in renal transplant biopsies and were correlated to the extent of ischemic injury. ${ }^{13-15}$ In the current study, we 
further address this issue by providing an integrated insight into the kinetics of tubular epithelial injury, inflammation and oxidative stress following clinical transplantation of DCD kidneys that suffer prolonged ischemia as compared to kidneys from living donors with minimal ischemia.

\section{Materials and methods}

\section{Study design}

In this observational study, eight consecutive recipients of ischemically injured DCD kidneys were compared to eight recipients of kidneys from living donors with minimal ischemic injury. Kidneys were recovered from separate donors between 16 and 60 years. Recipients were 18 years or older, received maintenance dialysis therapy and did not smoke in order to avoid major differences in baseline oxidative stress between patients. ${ }^{16,17}$ After kidney transplantation, early graft function and biomarkers of tubular injury, inflammation and oxidative stress were measured in blood and urine. The study was approved by the local institutional review board (MEC 07-2-025) and all patients gave written informed consent for participating in the study.

\section{Kidney transplantation}

Kidneys from living donors $(\mathrm{N}=8)$ were recovered through open mini-incision donor nephrectomy and were cold-stored in histidine tryptophan ketoglutarate preservation solution (HTK; Dr. F. Köhler Chemie, Bensheim, Germany). Kidneys from donors after cardiac death were recovered after in situ perfusion for uncontrolled donations after failed cardiopulmonary resuscitation $(\mathrm{N}=3)$ or after rapid laparotomy and direct aortic cannulation for controlled donation after scheduled withdrawal of supportive treatment $(\mathrm{N}=5) .{ }^{18}$ DCD kidneys were preserved by cold storage in HTK solution or by machine perfusion (LifePort; Organ Recovery Systems, Des Plaines, IL).

After having obtained a negative cross-match, the kidneys were transplanted by end-to-side anastomoses to the recipient common or external iliac artery and vein. No patients received blood transfusions during surgery. Intraoperative recipient hemodynamics were targeted at central venous pressures of 10-15 mmHg. Renal blood flow was measured at 5 and 30 minutes after reperfusion with perivascular flow probes (Transonic Systems, Ithaca, NY). Immunosuppressive regimen was started before surgery and consisted of corticosteroids, 
tacrolimus and mycophenolic acid or sirolimus. In the first 10 days after transplantation, graft function was estimated daily by measuring creatinine clearance in 24-hour urine collections and fractional excretion of sodium in spot urine samples. ${ }^{19}$

\section{Measurement of plasma and urine markers}

At transplantation, systemic blood was drawn from a radial artery catheter at the start of surgery, just before reperfusion and at 5 and 30 minutes after reperfusion. Transplant renal venous blood was drawn at 5 and 30 minutes after reperfusion. After surgery, systemic blood was drawn from a central venous access and spot urine samples were collected at 6 and 24 hours after reperfusion and on postoperative day 2 and 4 . Blood was immediately transferred to EDTA tubes and blood and urine samples were centrifuged at $900 \mathrm{~g}$ at $4^{\circ} \mathrm{C}$ for 10 minutes. Plasma and urine were kept on ice until storage at $-80^{\circ} \mathrm{C}$.

Plasma concentrations of soluble cytokeratin-18 (CK-18) and its fragments (CK-18-NEO) were measured using enzyme immunoassays (M65 and M30 Apoptosense ELISA kit, respectively; Peviva, Bromma, Sweden) according to manufacturer's instructions. Plasma cytokine concentrations were measured with the Bio-Plex human cytokine 17-plex panel (including IL-1 $\beta$, IL-2, IL-4, IL-5, IL6, IL-7, IL-8, IL-10, IL-12p70, IL-13, IL-17, G-CSF, GM-CSF, IFN- $\gamma$, MCP-1, MIP-1 $\beta$ and TNF; Bio-Rad Laboratories, Hercules, CA) on a Luminex 100 IS 2.3 system (Luminex, Austin, TX) according to manufacturer's instructions. Luminex results were analyzed off-line using Bio-Plex Manager 4.1.1 software (Bio-Rad Laboratories). Measurements from blood sampled during surgery were adjusted for hemodilution using hemoglobin and hematocrit. ${ }^{20}$ Renal fluxes were calculated by multiplying arteriovenous concentration gradients with simultaneously measured total transplant renal plasma flow and were adjusted for kidney weight. Urine concentrations of neutrophil gelatinase-associated lipocalin (NGAL), $\mathrm{N}$-acetyl- $\beta$-D-glucosaminidase (NAG) and cystatin $\mathrm{C}$ were measured using commercially available assays (human NGAL ELISA kit from Hycult Biotech, Uden, The Netherlands; NAG assay from Haemoscan, Groningen, The Netherlands; human cystatin C ELISA kit from R\&D Systems, Minneapolis, MN) according to manufacturer's instructions and were adjusted for urinary creatinine concentrations.

\section{Oxidative stress markers}

F2-isoprostanes were eluted from silica Sep-Pak (Waters Associates, Milford, MA) with $5 \mathrm{~mL}$ of ethyl acetate: methanol $(50: 50 \mathrm{v} / \mathrm{v})$. The eluate was evaporated 
under nitrogen at $37^{\circ} \mathrm{C}$ until dry. The samples were resuspended in $50 \mu \mathrm{L}$ methanol and subjected to thin layer chromatography (TLC) using solvent composed of chloroform: methanol: acetic acid: water (86:14:1.0:0.8 v/v). The TLC plates were pre-washed in ethyl acetate: ethanol $(90: 10 \mathrm{v} / \mathrm{v})$, oven dried at $105^{\circ} \mathrm{C}$ for 10 minutes and cooled to room temperature in a desiccator. Plates were spotted with resuspended samples or $5 \mu \mathrm{g}$ free acid $\mathrm{PGF}_{2 \alpha}$ TLC standard and run in the TLC tank for $13 \mathrm{~cm}$. After chromatography, the standard was visualized by lightly spraying its lane with $10 \%$ phosphomolybdic acid in ethanol and placing it on a hot plate to reveal the standard band. The region $0.5 \mathrm{~cm}$ above the band to $1.5 \mathrm{~cm}$ below the top of the $\mathrm{PGF}_{2 \alpha}$ free acid band $\left(\mathrm{R}_{\mathrm{f}} \sim 4.6\right)$ was scraped for all samples. The samples were extracted from the silica with $1 \mathrm{~mL}$ ethyl acetate: ethanol $(50: 50 \mathrm{v} / \mathrm{v})$ and dried at $37^{\circ} \mathrm{C}$ under nitrogen. Once completely dry, the samples were treated with $20 \mu \mathrm{L}$ of $10 \% \mathrm{~N}, \mathrm{~N}$-diisopropylethylamine in acetonitrile and $10 \%$ pentafluorobenzyl bromide in acetonitrile at $37^{\circ} \mathrm{C}$ for 30 minutes and then treated according to previously described $\mathrm{F}_{2}$-isoprostanes purification protocols. $^{21}$

Trolox-equivalent antioxidant capacity (TEAC) represents the amount of 2,2'-azino-bis(3-ethylbenzthiazoline-6-sulfonic acid) diammonium salt (ABTS) radicals that can be scavenged by plasma relative to the reference anti-oxidant trolox. Plasma was deprotinated with 5\% trichloroacetic acid. ${ }^{22}$ Samples were incubated with ABTS radical solution for 5 minutes. Subsequently, the reduction in absorbance at $734 \mathrm{~nm}$ was quantified, reflecting the amount of radicals being scavenged.

Vitamin $\mathrm{E}$ was extracted from $250 \mu \mathrm{L}$ plasma using hexane after adding vitamin E nicotinate as internal standard. The hexane layer was separated and evaporated. The residue was dissolved in $250 \mu \mathrm{L}$ iso-propanol. $20 \mu \mathrm{L}$ was injected on a Hypersil BDS C-18 end-capped column (Agilent, Palo Alto, CA) using methanol: water $(98: 2 \mathrm{v} / \mathrm{v})$ as the mobile phase and UV detection at a wavelength of $295 \mathrm{~nm}$.

To measure vitamin C concentrations, $800 \mu \mathrm{L} 5 \%$ trichloroacetic acid solution was added to $200 \mu \mathrm{L}$ blood. Resulting samples were stored at $-80^{\circ} \mathrm{C}$ until analysis. After adding $50 \mu \mathrm{L}$ of $4.5 \mathrm{M}$ sodium acetate buffer (pH 6.2), samples were incubated with ascorbate-oxidase spatulas at $37^{\circ} \mathrm{C}$ for 5 minutes. Subsequently, samples were incubated with $65 \mu \mathrm{L} o$-phenylene diamine $(0.1 \% \mathrm{w} / \mathrm{v}$, made fresh) at $37^{\circ} \mathrm{C}$ in the dark for 30 minutes. $25 \mu \mathrm{L}$ was injected on a Hypersil BDS C-18 end-capped column (Agilent) using methanol: $80 \mathrm{mM}$ phosphate buffer $(\mathrm{pH} 7.8,20: 80 \mathrm{v} / \mathrm{v})$ as the mobile phase and fluorescence detection at excitation and emission wavelengths of 355 and $425 \mathrm{~nm}$, respectively. 
Table 10.1 Transplant characteristics ${ }^{\mathrm{a}}$

\begin{tabular}{|c|c|c|c|}
\hline & $\begin{array}{c}\text { DCD donors } \\
\qquad(\mathrm{N}=8)\end{array}$ & $\begin{array}{l}\text { Living donors } \\
\qquad(\mathrm{N}=8)\end{array}$ & $\mathrm{P}$ \\
\hline \multicolumn{4}{|l|}{ Donor } \\
\hline Age (years) & $45(5)$ & $40(4)$ & 0.44 \\
\hline Sex (male / female) & $4 / 4$ & $6 / 2$ & 0.61 \\
\hline Serum creatinine $(\mu \mathrm{mol} / \mathrm{L})$ & $93(21)$ & $91(4)$ & 0.91 \\
\hline Hypertension & 2 & 0 & 0.20 \\
\hline \multicolumn{4}{|l|}{ Graft } \\
\hline Warm ischemia time (min) & $39(11)$ & $4(1)$ & 0.006 \\
\hline Cold ischemia time (hours) & $22(1.8)$ & $2.4(0.1)$ & $<0.001$ \\
\hline Anastomosis time (min) & $39(3)$ & $34(6)$ & 0.48 \\
\hline Preservation (cold storage / machine) & $5 / 3$ & $8 / 0$ & 0.20 \\
\hline \multicolumn{4}{|l|}{ Recipient } \\
\hline Age (years) & $60(2)$ & $44(4)$ & 0.005 \\
\hline Sex (male / female) & $5 / 3$ & $5 / 3$ & 1.00 \\
\hline Dialysis time (years) & $5.2(0.7)$ & $1.4(0.4)$ & $<0.001$ \\
\hline Dialysis type (HD / PD) & $5 / 3$ & $6 / 2$ & 1.00 \\
\hline Diuresis (mL/day) & $588(351)$ & $750(206)$ & 0.70 \\
\hline Immunosuppression (sirolimus / MMF) & $5 / 3$ & $4 / 4$ & 1.00 \\
\hline \multicolumn{4}{|l|}{ Graft outcome } \\
\hline Early function (immediate / delayed) & $2 / 6$ & $8 / 0$ & 0.01 \\
\hline GFR at 3 months $\left(\mathrm{mL} / \mathrm{min} / 1.73 \mathrm{~m}^{2}\right)^{\mathrm{b}}$ & $32(2)$ & $50(4)$ & 0.004 \\
\hline GFR at 1 year $\left(\mathrm{mL} / \mathrm{min} / 1.73 \mathrm{~m}^{2}\right)^{\mathrm{b}}$ & $33(4)$ & $49(5)$ & 0.02 \\
\hline Acute rejection (yes / no) & $2 / 6$ & $3 / 5$ & 1.00 \\
\hline
\end{tabular}

a Data are presented as means (standard errors) or as counts and are compared with independent samples t-tests or Fisher exact tests. DCD: donation after cardiac death, HD: hemodialysis, PD: peritoneal dialysis, MMF: mycophenolate mofetil.

To measure glutathione concentrations, $800 \mu \mathrm{L}$ water was added to $200 \mu \mathrm{L}$ blood. After mixing, $110 \mu \mathrm{L}$ of $13 \% 5$-sulfosalicyl acid in $100 \mathrm{mM} \mathrm{HCl}$ was added. Samples were centrifuged at $10.000 \mathrm{~g}$ at $4^{\circ} \mathrm{C}$ for 5 minutes and the supernatants were stored at $-80^{\circ} \mathrm{C}$. For measurement of total glutathione concentrations, 100 $\mu \mathrm{L}$ of $0.6 \mathrm{mM}$ DTNB and $0.8 \mathrm{mM}$ NADPH in $143 \mathrm{mM}$ phosphate buffer ( $\mathrm{pH} 7.4)$ was added to $50 \mu \mathrm{L}$ of $10 \mathrm{x}$ diluted samples at $37^{\circ} \mathrm{C}$. Subsequently, $50 \mu \mathrm{L}$ GSSG reductase $(4 \mathrm{U} / \mathrm{mL})$ was added and absorbance at $412 \mathrm{~nm}$ was measured for 3 minutes. For measurement of glutathione disulphide (GSSG), $50 \mu \mathrm{L}$ of the undi- 
luted samples were incubated with $10 \mu \mathrm{L}$ of vinyl pyridine: ethanol (33:67 v/v) at room temperature for 1 hour before proceeding with the protocol. The concentrations of reduced glutathione (GSH) and GSSG were calculated using calibrators.

\section{Statistical methods}

Continuous variables were expressed as means with standard errors and categorical variables as percentages. For statistical analysis, continuous variables with repeated measurements in the same individuals were summarized as areas under the curve. ${ }^{23}$ For continuous variables, differences between groups were compared with independent samples t-tests and differences within groups with paired samples t-tests. To compare overall inflammation between the two kidney types, standardized between-group differences of each cytokine were tested against zero using one-sample t-tests. For categorical variables, differences between groups were compared with Fisher exact tests. Results with $\mathrm{P}<0.05$ were considered statistically significant.

\section{Results}

\section{Patient characteristics}

The effects of renal ischemia and reperfusion on tubular injury and inflammation were studied by comparing recipients of DCD kidneys $(\mathrm{N}=8)$ with patients who received kidneys from living donors $(\mathrm{N}=8)$. Characteristics of the study groups are presented in Table 10.1. Baseline characteristics of the two donor types were similar. As intended by the design of the study, ischemia times of DCD kidneys were significantly longer than those of living donor kidneys. Furthermore, recipients of DCD kidneys were significantly older and had spent more time on dialysis than recipients of living donor kidneys. Other transplant characteristics were comparable between the study groups.

\section{Kidney function}

All kidneys were successfully transplanted and eventually provided lifesustaining function. After transplantation, 6 (75\%) recipients of DCD kidneys and none of the patients who received living donor kidneys required temporary dialysis treatment $(\mathrm{P}=0.01)$. Dialysis treatment was typically started after the 
second postoperative day and therefore did not influence biomarker concentrations in the early postoperative period. In the first 10 days after transplantation, glomerular and tubular function were assessed daily by measuring creatinine clearance in 24-hour urine collections and fractional excretion of sodium in spot urine samples, respectively (Figure 10.1). Creatinine clearance of DCD kidneys was significantly lower than that of living donor kidneys $(\mathrm{P}=0.004)$, whereas the fractional excretion of sodium of DCD kidneys was significantly greater $(\mathrm{P}=0.03)$. These findings indicate that the prolonged ischemia suffered by DCD kidneys was associated with a profound reduction in glomerular and tubular function in the early postoperative period.

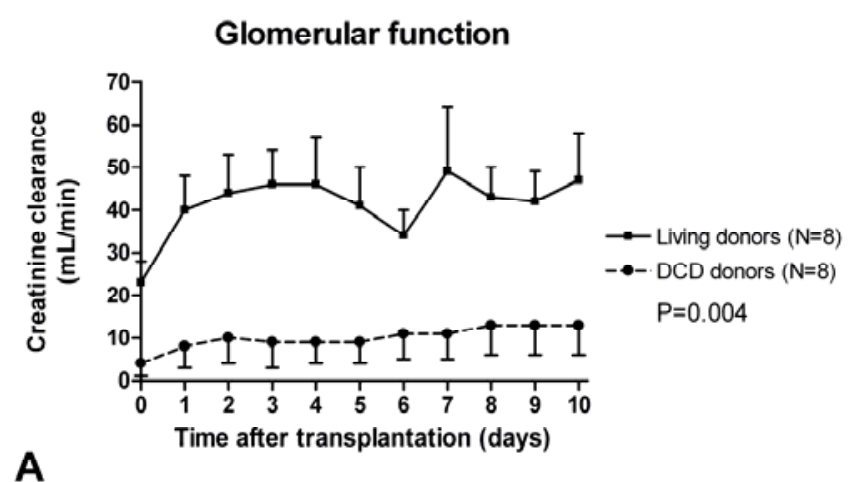

A

Tubular function

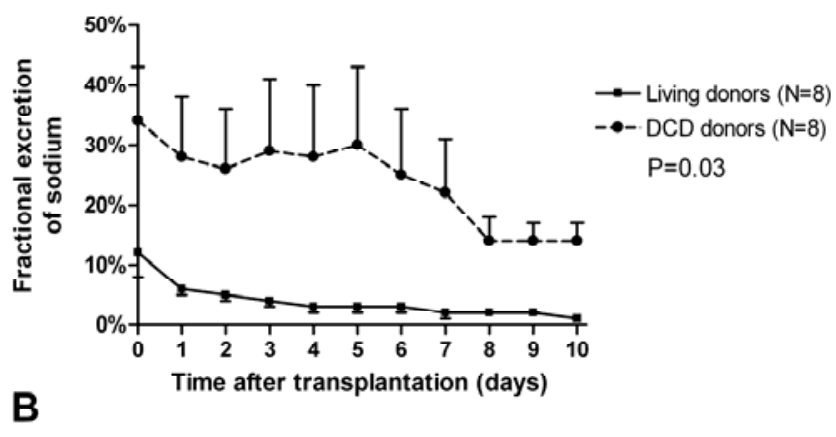

Figure 10.1 Glomerular and tubular function were assessed by daily measurements of creatinine clearances in 24-hour urine collections (A) and of fractional excretion of sodium in spot urine samples (B). Creatinine clearance of kidneys from donors after cardiac death (DCD) was significantly lower than that of living donor kidneys, whereas fractional excretion of sodium was significantly greater in DCD kidneys. Data are presented as means and standard errors. 


\section{Tubular epithelial injury}

After kidney transplantation, biomarkers of tubular epithelial injury were measured in spot urine samples (Figure 10.2). Injured tubular epithelial cells produce and secrete NGAL, which was present in higher concentrations in the urine of DCD kidney recipients than in patients who received living donor kidneys $(\mathrm{P}=0.06){ }^{24} \mathrm{NAG}$ is expressed in the proximal tubular epithelium and is passively released as a result of cellular injury. ${ }^{25}$ Urinary NAG activity was higher in patients who received DCD kidneys than in recipients of living donor kidneys; however, the difference was not statistically significant $(\mathrm{P}=0.14)$. Finally, cellular injury disturbs the degradation of filtered cystatin $\mathrm{C}$ by the tubular epithelium. ${ }^{26}$ Urinary cystatin $C$ concentrations were significantly higher in recipients of DCD kidneys than in patients who received living donor kidneys $(\mathrm{P}<0.05)$. Interestingly, the two recipients of DCD kidneys with immediate graft function had low concentrations of all tubular injury markers (data not shown).

Tubular epithelial cell death was detected by measuring renal fluxes of soluble cytokeratin-18, which is released from the cytoplasm of necrotic epithelial cells. ${ }^{27}$ During apoptosis, protein cleavage by activated caspases gives rise to cytokeratin-18 fragments with neo-epitopes that are detected by specific antibodies. At reperfusion, renal fluxes of soluble cytokeratin-18 in DCD kidneys were 12 to 18 -fold greater than those in living donor kidneys $(\mathrm{P}=0.03$, Table 10.2). This biomarker of necrotic cell death accumulated to a greater extent in

\section{Tubular epithelial injury}

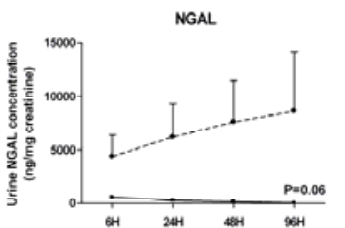

A

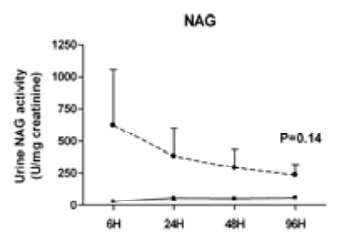

B

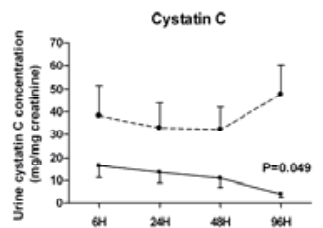

C

Figure 10.2 Urinary biomarkers of tubular epithelial injury were measured at different time points after kidney transplantation. Kidneys from donors after cardiac death (DCD) had higher concentrations of neutrophil gelatinase-associated lipocalin (NGAL; Panel A), N-acetyl- $\beta$-D-glucosaminidase (NAG; Panel B) and cystatin C (Panel C) as compared to living donor kidneys. Data are presented as means and standard errors. P-values are derived from comparison of the mean area under the curve between the study groups. 
Table 10.2 Renal fluxes of biomarkers of cell death and oxidative stress ${ }^{\mathrm{a}}$

\begin{tabular}{llccc}
\hline & & $\begin{array}{c}\text { DCD donors } \\
(\mathrm{N}=8)\end{array}$ & $\begin{array}{c}\text { Living donors } \\
(\mathrm{N}=8)\end{array}$ & P \\
\hline & & & & \\
\hline \multirow{2}{*}{ CELL DEATH } & Soluble CK-18 (U/min/100g) & $260(115)$ & $21(4)$ & 0.03 \\
& CK-18-NEO (U/min/100g) & $3.0(1.6)$ & $0.0(0.3)$ & 0.05 \\
OXIDATIVE & F2-isoprostanes (pg/min/100g) & $5173(5149)$ & $4(174)$ & 0.24 \\
STRESS & Vitamin E (ng/min/100g) & $-55(30)$ & $24(20)$ & 0.04 \\
& Vitamin C (ng/min/100g) & $146(28)$ & $150(171)$ & 0.99 \\
\hline \multirow{2}{*}{ CELL DEATH } & 30 MIN AFTER REPERFUSION & & & \\
& Soluble CK-18 (U/min/100g) & $362(112)$ & $20(23)$ & 0.005 \\
OXIDATIVE & CK-18-NEO (U/min/100g) & $3.9(2.7)$ & $2.1(5.0)$ & 0.77 \\
STRESS & F2-isoprostanes (pg/min/100g) & $-1115(1773)$ & $-722(388)$ & 0.78 \\
& Vitamin E (ng/min/100g) & $-149(111)$ & $15(122)$ & 0.36 \\
& Vitamin C (ng/min/100g) & $-31(112)$ & $185(142)$ & 0.29 \\
\hline
\end{tabular}

a Data are presented as means (standard errors) and are compared with independent samples t-tests. Positive fluxes indicate renal production, whereas negative fluxes indicate consumption. DCD: donation after cardiac death, CK18: cytokeratin-18, NEO: neo-epitope.

systemic blood of DCD kidney recipients during the first postoperative day as compared to patients who received living donor kidneys $(2.8 \pm 0.9$ and $1.0 \pm 2.5$ $\mathrm{U} / \mathrm{mL}, \mathrm{P}=0.01$ ). In addition, the renal flux of soluble cytokeratin-18 correlated with fractional excretion of sodium after kidney transplantation $(\mathrm{R}=0.71$, $\mathrm{P}=0.009$ ). Renal fluxes of caspase-cleaved cytokeratin-18 fragments were greater in DCD kidneys than in kidneys from living donors immediately after reperfusion $(\mathrm{P}=0.05$, Table 10.2). During the first postoperative day, however, systemic concentrations of this biomarker of apoptotic cell death were comparable between recipients of DCD and living donor kidneys $(0.15 \pm 0.02$ and $0.17 \pm 0.04$ $\mathrm{U} / \mathrm{mL}, \mathrm{P}=0.64)$. The ratio of full-length to cleaved cytokeratin-18 levels was statistically significantly greater after transplantation of DCD kidneys compared to kidneys from living donors $(93 \pm 1$ and $84 \pm 1 \%, P<0.001)$. Taken together, these findings show that DCD kidneys with prolonged ischemia are characterized by tubular epithelial injury and cell death.

\section{Inflammation}

To investigate whether tubular epithelial injury in donor kidneys leads to increased inflammatory activation, we measured local and systemic concentrations 
of a panel of 17 cytokines and chemokines after transplantation of DCD and living donor kidneys. Significantly smaller renal fluxes of IL-6 and MCP-1 were observed in DCD kidneys as compared to kidneys from living donors in the early reperfusion period $(\mathrm{P}=0.04$ and $\mathrm{P}=0.002$, respectively, Table 10.3), whereas renal fluxes of other cytokines were comparable between these kidneys. During the first days after transplantation, overall systemic cytokine concentrations were significantly higher in DCD kidney recipients than in patients who received living donor kidneys $(61 \pm 13 \%$ increase, $\mathrm{P}<0.001)$. Furthermore, plasma concentrations of the specific cytokines IL- 6 and IL- 8 were higher in recipients of DCD

Table 10.3 Renal fluxes and plasma concentrations of cytokines ${ }^{\mathrm{a}}$

\begin{tabular}{|c|c|c|c|c|c|c|}
\hline & \multicolumn{2}{|c|}{$\begin{array}{c}5 \text { MIN AFTER } \\
\text { REPERFUSION FLUX } \\
(\mathrm{pg} / \mathrm{min} / 100 \mathrm{~g})\end{array}$} & \multicolumn{2}{|c|}{$\begin{array}{c}30 \text { MIN AFTER } \\
\text { REPERFUSION FLUX } \\
(\mathrm{pg} / \mathrm{min} / 100 \mathrm{~g})\end{array}$} & \multicolumn{2}{|c|}{$\begin{array}{c}6 \text { HOURS - } 4 \text { DAYS } \\
\text { AFTER SURGERY } \\
\text { (AUC) }\end{array}$} \\
\hline & DCD & Living & DCD & Living & DCD & Living \\
\hline IL-1 $\beta$ & - & - & - & - & - & - \\
\hline IL-2 & $55(42)$ & $121(62)$ & $-134(164)$ & $-77(136)$ & $20(4)$ & $15(3)$ \\
\hline IL-4 & $2(6)$ & $-14(8)$ & $-4(9)$ & $11(24)$ & $5(1)$ & $3(1)$ \\
\hline IL-5 & $-1(16)$ & $21(20)$ & $-112(66)$ & $-38(32)$ & $18(5)$ & $12(2)$ \\
\hline IL-6 & $210(58)^{\mathrm{b}}$ & $801(217)^{\mathrm{b}}$ & $-303(465)^{b}$ & $3278(915)^{\mathrm{b}}$ & $290(72)^{c}$ & $143(19)^{c}$ \\
\hline IL-7 & $32(39)$ & $-34(13)$ & $-89(57)$ & $-95(29)$ & $21(3)$ & $18(0)$ \\
\hline IL-8 & $-3(40)$ & $48(37)$ & $22(86)$ & $553(433)$ & $81(17)^{\mathrm{b}}$ & $35(4)^{b}$ \\
\hline IL-10 & $70(66)$ & $30(30)$ & $-152(93)$ & $56(109)$ & $49(9)$ & $29(6)$ \\
\hline IL-12 & $69(23)$ & 77 (55) & $-296(127)$ & 87 (155) & $48(10)$ & $30(7)$ \\
\hline IL-13 & $-19(24)$ & $-25(9)$ & $-67(78)$ & $-41(35)$ & $24(7)$ & $12(1)$ \\
\hline IL-17 & $-154(118)$ & $-304(174)$ & $-274(140)$ & $-134(225)$ & $152(14)$ & $137(1)$ \\
\hline G-CSF & 364 (131) & $-269(456)$ & $-158(191)$ & $-378(1010)$ & $188(28)$ & $166(16)$ \\
\hline GM-CSF & 856 (1018) & $169(142)$ & $-2116(1686)$ & $-300(642)$ & $282(130)$ & $92(19)$ \\
\hline IFN- $\gamma$ & 939 (1056) & $-90(148)$ & $-2171(2096)$ & $-1090(1637)$ & 259 (83) & $156(23)$ \\
\hline MCP-1 & $67(316)^{b}$ & $1353(144)^{\mathrm{b}}$ & $-436(353)$ & 4214 (2248) & $227(31)$ & $171(26)$ \\
\hline MIP-1 $\beta$ & $98(165)^{c}$ & $2138(878)^{c}$ & $-476(454)^{\mathrm{c}}$ & $4155(1823)^{c}$ & $185(21)$ & $162(25)$ \\
\hline TNF & $61(188)$ & $116(164)$ & $-317(214)$ & $-133(609)$ & $131(20)$ & $101(15)$ \\
\hline
\end{tabular}

${ }^{a}$ Data are presented as means (standard errors) and are compared with independent samples t-tests. Positive fluxes indicate renal production, whereas negative fluxes indicate consumption. AUC: area under curve, DCD: donation after cardiac death, IL: interleukin, G-CSF: granulocyte colony-stimulating factor, GM-CSF: granulocyte macrophage colony-stimulating factor, IFN: interferon, MCP: monocyte chemoattractant protein, MIP: macrophage inflammatory protein, TNF: tumor necrosis factor.

${ }^{\mathrm{b}} \mathrm{P}<0.05$ for comparison of DCD and living donor kidneys.

c $\mathrm{P}<0.10$ for comparison of $\mathrm{DCD}$ and living donor kidneys. 
kidneys $(\mathrm{P}=0.07$ and $\mathrm{P}=0.02$, Figure $10.3 \mathrm{~A}$ and $10.3 \mathrm{~B})$. These findings indicate that transplantation of ischemically injured DCD kidneys gives rise to an increased pro-inflammatory environment in the early postoperative period.

\section{Oxidative stress}

Generation of reactive oxygen species at reperfusion of the kidney is generally considered to be the major cause of tubular epithelial injury. Peroxidation of arachidonic acid in cell membranes leads to formation of $\mathrm{F}_{2}$-isoprostanes, which are accurate biomarkers of oxidative damage. ${ }^{28}$ Before transplant surgery, plasma $\mathrm{F}_{2}$-isoprostanes concentrations in recipients of $\mathrm{DCD}$ and living donor kidneys were similar $(49 \pm 10$ and $31 \pm 5 \mathrm{pg} / \mathrm{mL}$, respectively, $\mathrm{P}=0.14)$. After reperfusion, renal fluxes of $\mathrm{F}_{2}$-isoprostanes were comparable between the two kidney types $(\mathrm{P}=0.24$, Table 10.2). In contrast, DCD kidneys consumed significantly more vitamin $\mathrm{E}$ - the major anti-oxidant in lipid membranes - than living donor kidneys $(\mathrm{P}=0.04)$. Other anti-oxidant defences were not affected by reperfusion of the kidney, since we observed neither consumption of vitamin $\mathrm{C}$ nor renal arteriovenous gradients of GSH/GSSG ratio and total anti-oxidant capacity with either of the two kidney types (Table 10.2 and data not shown). In contrast to the absence of biomarkers for oxidative injury at reperfusion, plasma concentrations of $\mathrm{F}_{2}$-isoprostanes in DCD kidney recipients were significantly higher than those in patients who received kidneys from living donors during the first postopera-

\section{Inflammation and oxidative stress after kidney transplantation}
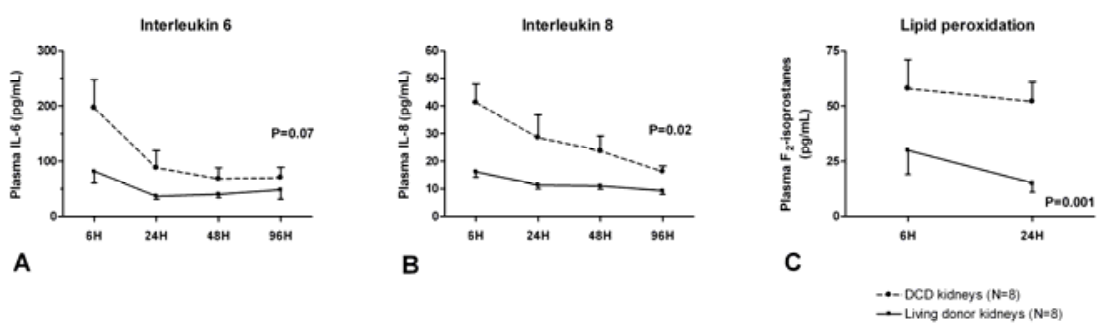

Figure 10.2 Cytokines and biomarkers of oxidative stress were measured at different time points after kidney transplantation. Kidneys from donors after cardiac death (DCD) had higher systemic plasma concentrations of interleukin-6 (A), interleukin-8 (B) and $F_{2}$-isoprostanes (C) as compared to living donor kidneys. Data are presented as means and standard errors. P-values are derived from comparison of the mean area under the curve between the study groups. 
tive day $(\mathrm{P}=0.001$, Figure $10.3 \mathrm{C})$. This indicates that systemic oxidative stress was increased in patients who received ischemically injured DCD kidneys.

\section{Discussion}

Ischemia and reperfusion of the donor kidney is an inevitable consequence of renal transplantation. Prevention of the resulting renal injury holds the potential to improve early graft function and allow expansion of the donor pool with kidneys that suffered prolonged ischemia. Until now, pharmacological protection of the donor kidney from ischemia and reperfusion injury has remained elusive. Further investigations into the pathophysiology of ischemic acute renal injury in human kidney transplantation are therefore needed to guide the development of more effective interventions.

In the current study, we investigated the effects of ischemia and reperfusion on the renal tubular epithelium by comparing two groups of donor kidneys with highly different ischemic periods but with similar baseline characteristics: DCD kidneys that suffer prolonged ischemia from circulatory arrest, and living donor kidneys that suffer minimal warm and cold ischemia. Although all kidney transplants eventually allowed cessation of dialysis therapy, the impact of prolonged ischemia on early graft function was evident from the profoundly reduced creatinine clearance of DCD kidneys as compared to living donor kidneys. Similarly, function of the renal tubular epithelium of DCD kidneys was impaired in the early postoperative period, as indicated by reduced sodium reabsorption. ${ }^{19}$

Functional impairment of DCD kidneys coincided with increased urine levels of NGAL, NAG and cystatin C, supporting previous observations in kidneys from brain-dead donors. ${ }^{29-31}$ These biomarkers of tubular injury accumulate in urine through distinct mechanisms: NGAL is produced by injured tubular cells, NAG passively leaks from damaged tubular epithelium and filtered cystatin $C$ fails to be degraded following tubular injury. ${ }^{24-26}$ The combination of these markers may therefore constitute a clinically useful panel for early detection of ischemic acute kidney injury.

The extent and mode of tubular epithelial cell death following human kidney transplantation was investigated by quantification of full-length and caspase-cleaved fragments of soluble cytokeratin-18 (biomarkers for necrotic and apoptotic cell death, respectively) in systemic and transplant renal venous blood samples. ${ }^{27}$ Release of full-length cytokeratin-18 by DCD kidneys was an order of magnitude greater than that by living donor kidneys, whereas release of caspase- 
cleaved fragments of cytokeratin-18 was only slightly increased in DCD kidneys immediately after reperfusion. DCD kidneys with prolonged ischemia are therefore characterized by extensive tubular epithelial cell death that is only marginally accounted for by apoptosis. This finding contrasts with observations in renal transplant biopsies taken at reperfusion. ${ }^{14,32,33}$ However, histological evidence of apoptosis and necrosis in renal biopsies may be obscured by rapid clearance of cell debris by phagocytes and quick restoration of epithelial continuity by flattening of neighbouring cells. ${ }^{34}$ The specific mechanisms of cell death following human kidney transplantation remain to be determined. ${ }^{35}$ The marked increase of soluble cytokeratin-18 very early after reperfusion indicates that this biomarker may be useful for assessment of the extent of ischemic acute kidney injury. In particular, measurement of cytokeratin-18 may qualify as a surrogate endpoint for clinical trials aiming to reduce tubular cell death in kidney transplantation, e.g. by improving organ preservation.

Necrotic cell death leads to spillage of intracellular contents, activating pattern recognition receptors such as toll-like receptor 4 on nearby leukocytes and tubular cells. Signalling through these receptors stimulates innate and adaptive immunity and exacerbates renal dysfunction following ischemia and reperfusion of the kidney. ${ }^{36-38}$ Surprisingly, we found that DCD kidneys produced significantly less IL-6 and MCP-1 than kidneys from living donors in the early reperfusion period. Upregulation of cytokine production in response to tissue injury takes time, however, and was not expected immediately after reperfusion. In the early postoperative period, recipients of ischemically injured DCD kidneys were characterized by increased inflammatory activity as compared to patients who received kidneys from living donors. Specifically, plasma concentrations of the cytokines IL- 6 and IL-8 were increased in DCD kidney recipients, which is in line with a previous observation of increased urinary IL-6 and IL-8 levels in kidneys with impaired graft function. ${ }^{39}$ IL-6 exacerbates tubular injury and renal dysfunction in animal models of ischemic acute kidney injury and shifts $\mathrm{T}$ cell differentiation from the regulatory towards the Th17 subtype causing allograft rejection. ${ }^{40,41} \mathrm{IL}-8$ is a major chemoattractant for neutrophils that intensify acute kidney injury through local secretion of proteases and reactive oxygen species. ${ }^{42}$

Generation of reactive oxygen species at reperfusion is often cited as a major cause of tubular epithelial injury after kidney transplantation. However, randomized clinical trials on the effect of anti-oxidant supplementation on early graft function after kidney transplantation have yielded conflicting results. ${ }^{43-48}$ In the current study, we did not observe significant renal production of $F_{2}$ isoprostanes - the gold standard biomarker for assessment of oxidative injury ${ }^{28}$ 
in either of the two kidney types. Nevertheless, DCD kidneys consumed significantly more vitamin $\mathrm{E}$ in the early reperfusion period as compared to living donor kidneys. These findings suggest that more reactive oxygen species are being formed in ischemically injured DCD kidneys, but that endogenous antioxidant defence is sufficient to prevent lipid peroxidation at reperfusion. In contrast, systemic $\mathrm{F}_{2}$-isoprostanes concentrations were increased in recipients of DCD kidneys in the postoperative period, coinciding with heightened inflammatory activity. Since activated leukocytes produce reactive oxygen species, increased oxidative stress may be consequence rather than cause of tubular injury and inflammation after kidney transplantation.

The current study provides a unique and integrated insight into the kinetics of tubular epithelial injury, inflammation and oxidative stress following human kidney transplantation. The small sample size of the study precludes multivariable analyses to adjust for potential confounders. However, the difference in early graft function between the two study groups was profound, and any associated differences in epithelial injury, inflammation and oxidative stress were therefore expected to be large enough to result in statistical significance with a relatively small sample size. Furthermore, the large number of inflammatory cytokines measured raises the issue of multiple comparisons, which was partly addressed by using summary measures such as area under the curve to reduce the number of comparisons being made. A statistically significant difference in cytokine concentrations was observed when considering all cytokines together. The diagnostic and prognostic value of specific parameters studied should be validated in a separate cohort of transplant recipients.

In conclusion, DCD kidneys that suffer prolonged ischemia are characterized by early necrotic tubular epithelial cell death that is significantly increased in comparison to living donor kidneys that suffer minimal ischemia. Tubular epithelial injury in DCD kidneys is follow-ed by reduced renal function and increased systemic inflammation in the postoperative period, in line with observations in rodent models of acute kidney injury. In contrast, we found no evidence of oxidative damage in the early reperfusion period. These findings may form the basis for the development of novel interventions to prevent tubular injury and inflammation, improving early graft function and thereby encouraging the use of donor kidneys with prolonged ischemia. 


\section{References}

1. Perico N, Cattaneo D, Sayegh MH, Remuzzi G. Delayed graft function in kidney transplantation. Lancet 2004; 364:1814-1827.

2. Yarlagadda SG, Coca SG, Formica RN, Jr., Poggio ED, Parikh CR. Association between delayed graft function and allograft and patient survival: a systematic review and meta-analysis. Nephrol Dial Transplant 2009; 24:1039-1047.

3. Terasaki PI, Cho YW, Cecka JM. Strategy for eliminating the kidney shortage. Clin Transpl 1997:265-267.

4. Wijnen RM, Booster MH, Stubenitsky BM, de Boer J, Heineman E, Kootstra G. Outcome of transplantation of non-heart-beating donor kidneys. Lancet 1995; 345:1067-1070.

5. Paller MS, Hoidal JR, Ferris TF. Oxygen free radicals in ischemic acute renal failure in the rat. J Clin Invest 1984; 74:1156-1164.

6. Baker GL, Corry RJ, Autor AP. Oxygen free radical induced damage in kidneys subjected to warm ischemia and reperfusion. Protective effect of superoxide dismutase. Ann Surg 1985; 202:628-641.

7. Paller MS, Hedlund BE. Role of iron in postischemic renal injury in the rat. Kidney Int 1988; 34:474-480.

8. Bonventre JV, Zuk A. Ischemic acute renal failure: an inflammatory disease? Kidney Int 2004; 66:480-485.

9. Zhou W, Farrar CA, Abe K, et al. Predominant role for C5b-9 in renal ischemia/reperfusion injury. J Clin Invest 2000; 105:1363-1371.

10. De Vries B, Matthijsen RA, Wolfs TG, Van Bijnen AA, Heeringa P, Buurman WA. Inhibition of complement factor C5 protects against renal ischemia-reperfusion injury: inhibition of late apoptosis and inflammation. Transplantation 2003; 75:375-382.

11. Kelly KJ, Williams WW, Jr., Colvin RB, et al. Intercellular adhesion molecule-1-deficient mice are protected against ischemic renal injury. J Clin Invest 1996; 97:1056-1063.

12. Rosen S, Stillman IE. Acute tubular necrosis is a syndrome of physiologic and pathologic dissociation. J Am Soc Nephrol 2008; 19:871-875.

13. Solez K, Racusen LC, Marcussen N, et al. Morphology of ischemic acute renal failure, normal function, and cyclosporine toxicity in cyclosporine-treated renal allograft recipients. Kidney Int 1993; 43:1058-1067.

14. Burns AT, Davies DR, McLaren AJ, Cerundolo L, Morris PJ, Fuggle SV. Apoptosis in ischemia/reperfusion injury of human renal allografts. Transplantation 1998; 66:872-876.

15. Koo DD, Welsh KI, Roake JA, Morris PJ, Fuggle SV. Ischemia/reperfusion injury in human kidney transplantation: an immunohistochemical analysis of changes after reperfusion. Am J Pathol 1998; 153:557-566.

16. Morrow JD, Frei B, Longmire AW, et al. Increase in circulating products of lipid peroxidation (F2-isoprostanes) in smokers. Smoking as a cause of oxidative damage. N Engl J Med 1995; 332:1198-1203.

17. Handelman GJ, Walter MF, Adhikarla R, et al. Elevated plasma F2-isoprostanes in patients on long-term hemodialysis. Kidney Int 2001; 59:1960-1966.

18. Snoeijs MG, Dekkers AJ, Buurman WA, et al. In Situ Preservation of Kidneys From Donors After Cardiac Death: Results and Complications. Ann Surg 2007; 246:844-852. 
19. Espinel CH. The FENa test. Use in the differential diagnosis of acute renal failure. Jama 1976; 236:579-581.

20. Dill DB, Costill DL. Calculation of percentage changes in volumes of blood, plasma, and red cells in dehydration. J Appl Physiol 1974; 37:247-248.

21. Milne GL, Yin H, Brooks JD, Sanchez S, Jackson Roberts L, 2nd, Morrow JD. Quantification of F2-isoprostanes in biological fluids and tissues as a measure of oxidant stress. Methods Enzymol 2007; 433:113-126.

22. Fischer MA, Gransier TJ, Beckers LM, Bekers O, Bast A, Haenen GR. Determination of the antioxidant capacity in blood. Clin Chem Lab Med 2005; 43:735-740.

23. Matthews JN, Altman DG, Campbell MJ, Royston P. Analysis of serial measurements in medical research. Bmj 1990; 300:230-235.

24. Mishra J, Ma Q Prada A, et al. Identification of neutrophil gelatinase-associated lipocalin as a novel early urinary biomarker for ischemic renal injury. J Am Soc Nephrol 2003; 14:2534-2543.

25. Wellwood JM, Ellis BG, Price RG, Hammond K, Thompson AE, Jones NF. Urinary N-acetylbeta-D-glucosaminidase activities in patients with renal disease. Br Med J 1975; 3:408-411.

26. Koyner JL, Bennett MR, Worcester EM, et al. Urinary cystatin C as an early biomarker of acute kidney injury following adult cardiothoracic surgery. Kidney Int 2008; 74:1059-1069.

27. Kramer G, Erdal H, Mertens HJ, et al. Differentiation between cell death modes using measurements of different soluble forms of extracellular cytokeratin 18. Cancer Res 2004; 64:17511756.

28. Kadiiska MB, Gladen BC, Baird DD, et al. Biomarkers of oxidative stress study II: are oxidation products of lipids, proteins, and DNA markers of CCl4 poisoning? Free Radic Biol Med 2005; 38:698-710.

29. Parikh CR, Jani A, Mishra J, et al. Urine NGAL and IL-18 are predictive biomarkers for delayed graft function following kidney transplantation. Am J Transplant 2006; 6:1639-1645.

30. Hall IE, Yarlagadda SG, Coca SG, et al. IL-18 and Urinary NGAL Predict Dialysis and Graft Recovery after Kidney Transplantation. J Am Soc Nephrol 2009.

31. Wellwood JM, Davies D, Leighton M, Thompson AE. Urinary N-acetyl-beta-Dglucosaminidase assay in renal transplant recipients. Transplantation 1978; 26:396-400.

32. Oberbauer R, Rohrmoser M, Regele H, Muhlbacher F, Mayer G. Apoptosis of tubular epithelial cells in donor kidney biopsies predicts early renal allograft function. J Am Soc Nephrol 1999; 10:2006-2013.

33. Castaneda MP, Swiatecka-Urban A, Mitsnefes MM, et al. Activation of mitochondrial apoptotic pathways in human renal allografts after ischemiareperfusion injury. Transplantation 2003; 76:50-54.

34. Bonventre JV. Dedifferentiation and proliferation of surviving epithelial cells in acute renal failure. J Am Soc Nephrol 2003; 14 Suppl 1:S55-61.

35. Hotchkiss RS, Strasser A, McDunn JE, Swanson PE. Cell death. N Engl J Med 2009; 361:15701583.

36. Leemans JC, Stokman G, Claessen N, et al. Renal-associated TLR2 mediates ischemia/reperfusion injury in the kidney. J Clin Invest 2005; 115:2894-2903.

37. Wu H, Chen G, Wyburn KR, et al. TLR4 activation mediates kidney ischemia/reperfusion injury. J Clin Invest 2007; 117:2847-2859.

38. Kruger B, Krick S, Dhillon N, et al. Donor Toll-like receptor 4 contributes to ischemia and reperfusion injury following human kidney transplantation. Proc Natl Acad Sci U S A 2009; 106:3390-3395. 
39. Kwon O, Molitoris BA, Pescovitz M, Kelly KJ. Urinary actin, interleukin-6, and interleukin-8 may predict sustained ARF after ischemic injury in renal allografts. Am J Kidney Dis 2003; 41:1074-1087.

40. Nechemia-Arbely Y, Barkan D, Pizov G, et al. IL-6/IL-6R axis plays a critical role in acute kidney injury. J Am Soc Nephrol 2008; 19:1106-1115.

41. Chen L, Ahmed E, Wang T, et al. TLR signals promote IL-6/IL-17-dependent transplant rejection. J Immunol 2009; 182:6217-6225.

42. Matthijsen RA, Huugen D, Hoebers NT, et al. Myeloperoxidase is critically involved in the induction of organ damage after renal ischemia reperfusion. Am J Pathol 2007; 171:1743-1752.

43. Pollak R, Andrisevic JH, Maddux MS, Gruber SA, Paller MS. A randomized double-blind trial of the use of human recombinant superoxide dismutase in renal transplantation. Transplantation 1993; 55:57-60.

44. Rabl H, Khoschsorur G, Colombo T, et al. A multivitamin infusion prevents lipid peroxidation and improves transplantation performance. Kidney Int 1993; 43:912-917.

45. Land W, Schneeberger H, Schleibner S, et al. The beneficial effect of human recombinant superoxide dismutase on acute and chronic rejection events in recipients of cadaveric renal transplants. Transplantation 1994; 57:211-217.

46. Shoskes D, Lapierre C, Cruz-Corerra M, et al. Beneficial effects of the bioflavonoids curcumin and quercetin on early function in cadaveric renal transplantation: a randomized placebo controlled trial. Transplantation 2005; 80:1556-1559.

47. Norio K, Wikstrom M, Salmela K, Kyllonen L, Lindgren L. Ascorbic acid against reperfusion injury in human renal transplantation. Transpl Int 2003; 16:480-485.

48. Hower R, Minor $\mathrm{T}$, Schneeberger $\mathrm{H}$, et al. Assessment of oxygen radicals during kidney transplantation--effect of radical scavenger. Transpl Int 1996; 9 Suppl 1:S479-482. 
222 


\section{Chapter 11}

Autologous transplantation of ischemically injured kidneys in pigs 


\begin{abstract}
Background: Expansion of the organ donor pool can be obtained through novel interventions attenuating ischemic acute kidney injury which will enable the use of kidneys that suffered prolonged ischemia. In basic science, new therapeutic targets are identified that should be tested in a relevant large animal model before use in human kidney transplantation.

Methods: The current paper provides a detailed description of the technique of autologous transplantation of ischemically injured kidneys in pigs with special emphasis on peri-operative care.

Findings: The animal model was validated by showing that renal function after transplantation was proportional to the duration of warm ischemia before organ recovery. The extent of renal dysfunction was reproducible following kidney transplantations with the same warm ischemia time.

Interpretation: Our experience may shorten the learning curves of other research groups taking an interest in the model and improve preclinical testing of novel interventions that modulate renal ischemia and reperfusion injury in kidney transplantation.
\end{abstract}

\title{
Published as
}

Snoeijs MG, Matthijsen RA, Seeldrayers S, Marcus MA, Daemen JH, Buurman WA, Schurink GW, van Heurn LW. Autologous transplantation of ischemically injured kidneys in pigs. J Surg Res, in revision. 


\section{Introduction}

A major challenge in the field of renal transplantation is expansion of the organ donor pool. ${ }^{1}$ Liberal utilization of donation after cardiac death (DCD) may expand the supply of kidney grafts sufficiently to reduce or even eliminate the waiting lists for transplantation. ${ }^{2}$ However, kidneys from DCD donors suffer ischemic injury from circulatory arrest until organ preservation, which results in a high incidence of early graft dysfunction after transplantation. ${ }^{3}$ Importantly, up to $15-25 \%$ of DCD kidneys will never recover function, unnecessarily exposing their recipients to the risks of major surgery and immunological sensitization. ${ }^{3}$ It is therefore of critical importance to develop novel interventions that attenuate ischemic acute kidney injury and allow increased use of DCD kidneys for transplantation.

Over the past decade, a vast array of therapeutic targets for ischemic acute kidney injury have been identified in rodent models. Translation of these experimental findings into effective interventions in human kidney transplantation requires clinically relevant large animal models. In this respect, pigs are highly useful because of their limited genetic variation and the close similarity of the renal anatomy and physiology between pigs and men. ${ }^{4}$

In the current paper, we provide a detailed description of the technique of autotransplantation of ischemically injured kidneys in the pig with special emphasis on peri-operative management. Our experience may facilitate others to investigate interventions that reduce ischemic damage in a clinically relevant model of kidney transplantation in order to eventually improve the outcome of clinical transplantation of ischemically injured kidneys.

\section{Materials and methods}

\section{Study design}

This observational study compares the outcome of porcine renal autotransplantation using kidneys exposed to different warm ischemia times $(0[\mathrm{~N}=1], 30[\mathrm{~N}=4]$ and $45[\mathrm{~N}=10]$ minutes). In vivo experiments were approved by the local laboratory animal review board (DEC 2005-057 and 2006-173) and were conducted in accordance with the NIH principles of laboratory animal care. 


\section{Animals}

Male white pigs (Dutch landrace $\mathrm{x}$ Yorkshire crossbreed) of $35-45 \mathrm{~kg}$ and aged 16-20 weeks were obtained from a commercial farm. The animals tested negative for infection with porcine reproductive and respiratory syndrome virus, actinobacillus pleuropneumonia and mycoplasma. One week before surgery, pigs were allowed to adapt to their housing $(2 \times 3 \mathrm{~m})$. Animals had free access to water and were fed $500 \mathrm{~g}$ of pellets for adult sows twice a day to limit their growth during the experiments. Pigs were kept in an environment at a temperature of $20^{\circ} \mathrm{C}$, at a humidity level of $55 \%$ and with 12 hours of light per day. Environmental enrichment was provided by a ball and straw floor isolation. After surgery, the animals were housed individually.

\section{Donor nephrectomy}

The abdomen and neck were shaved and washed with chlorhexidine before gently restraining the legs to obtain adequate surgical access. After topical application of iodine, a long midline abdominal incision was made running alongside the nipple line below the umbilicus to avoid injury to the penis. The peritoneum was opened, a retractor was placed and the bowel was packed in a wet towel and gently retracted by an assistant to expose the left kidney. The kidney was then mobilized and stripped of perirenal tissue. The renal vessels were gently dissected free up to the aorta and vena cava while dividing lumbar venous branches between ligatures; dissection of the renal hilum and ureter was avoided. The ureter was ligated and divided distally. Subsequently, the renal artery and vein were ligated and divided close to the aorta and vena cava. The renal artery was ligated first to allow drainage of blood from the kidney. The kidney was left in the abdomen to obtain adequate warm ischemic injury. Induction of warm ischemia by clamping the renal artery and vein without transection resulted in extensive thrombosis.

Baseline 16G needle biopsies (TSK Laboratory, Tochigi, Japan) were taken from the contralateral kidney to avoid injury to the donor kidney. The bowel was carefully placed back into the abdomen taking care not to twist the small bowel. The abdomen was then partly closed in two layers (fascia and skin) with multifilament polyester sutures to prevent heat and fluid loss during the warm ischemic period. Subsequently, a small right paratracheal incision was made and the internal carotid artery and internal jugular vein were exposed by blunt dissection. Tygon catheters (inner diameter $1.16 \mathrm{~mm}$, outer diameter 1.78 $\mathrm{mm}$, length $80 \mathrm{~cm}$; Norton Co., Akron, $\mathrm{OH}$ ) were advanced $10 \mathrm{~cm}$ into both vessels, were carefully secured with sutures and then subcutaneously tunnelled, 
exiting the skin behind the left ear. The neck incision was closed in two layers (subcutaneous tissue and skin) with multifilament polyester sutures. The catheters were filled with a mixture of gentamycin $(20 \mathrm{mg} / \mathrm{mL})$ and $\alpha$-chymotrypsin (225 U/mL; Merck, Darmstadt, Germany) in saline. ${ }^{5}$

At the end of the warm ischemic period, the kidney was recovered from the abdomen and the renal artery was cannulated with a luerlock adapter (VBM Medizintechnik, Sulz am Neckar, Germany). The kidney was then weighed and flushed with $300 \mathrm{~mL}$ histidine tryptophan ketoglutarate preservation solution (Dr. F. Köhler Chemie, Bensheim, Germany) per $100 \mathrm{~g}$ of kidney weight at a pressure of $100 \mathrm{cmH}_{2} \mathrm{O}$ without topical cooling while the abdomen was being closed. The kidney was weighed again and connected to a PF-3B perfusion machine (Gambro, Lund, Sweden) primed with $500 \mathrm{~mL}$ UW-MPS (Organ Recovery Systems, Des Plaines, IL). Systolic perfusion pressure was kept at $55 \mathrm{mmHg}$ during the first hour of perfusion and perfusate flow was kept constant afterwards.

\section{Orthotopic kidney transplantation}

24 hours after the start of the first operation, animals were anesthetized again and the midline abdominal incision was reopened. A retractor was placed and the bowel was packed in a wet towel to be gently retracted by an assistant in order to expose the right kidney, taking care not to induce bowel ischemia. The vessels of the contralateral kidney were dissected free and the ureter was divided at the renal pelvis. The renal artery and vein were clamped at the aorta and vena cava. The vessels were divided in the renal hilum and the right kidney was retrieved. The right renal artery was now enlarged by transecting the inner curve of its bifurcation, allowing a wide anastomosis with the artery of the transplanted left kidney to be made.

The donor kidney was then removed from the perfusion machine and grafted orthotopically at the contralateral site. The donor vein was anastomosed end-to-end to the contralateral renal vein. Two stay sutures were placed at the superior and inferior edges of the renal vein of the donor kidney. The posterior wall of the anastomosis was completed first with a running polypropylene 6-0 suture, everting the edge. Then, the anterior wall anastomosis was completed. Subsequently, the donor artery was anastomosed end-to-end to the contralateral renal artery using the same technique. Before closure of the anastomoses, the vessel lumina were flushed with saline to prevent thrombosis. The venous clamp was removed before the arterial clamp and reperfusion of the kidney was observed. If present, minor blood loss from the renal hilum resolved spontaneously 
after packing the kidney with gauze swabs for some minutes. Major or continuing blood loss from the kidney required additional individual stitches without clamping the vessels to maintain standard experimental conditions.

The proximal donor ureter was shortened and anastomosed end-to-end to the contralateral ureter with a running polypropylene 5-0 suture. A double-J catheter $(26 \mathrm{~cm}$, Ch4.8; Rüsch, Kernen-Rommelshausen, Germany) was placed in the ureter to prevent obstruction. The catheter was secured with a suture to prevent it from dislodging into the bladder. 16G needle biopsies were taken from the kidney for histological assessment of early reperfusion injury. Biopsy holes were closed with a gently tied purse string suture. The abdomen was again closed in two layers and the animals were left to recover from surgery.

\section{Peri-operative management and anesthesia}

The animals were starved 12 hours before surgery but had free access to water. Before induction of anesthesia, pigs were sedated with azaperone $4 \mathrm{mg} / \mathrm{kg}$ and ketamine $15 \mathrm{mg} / \mathrm{kg}$ i.m. to allow ear vein cannulation. A baseline blood sample was drawn and anesthesia was induced by thiopental $6 \mathrm{mg} / \mathrm{kg}$ and fentanyl 8 $\mu \mathrm{g} / \mathrm{kg}$ i.v. The animals were then intubated and ventilated with $1 \%$ isoflurane and $40 \%$ oxygen in room air. These concentrations should not be changed during surgery since both isoflurane and oxygen may affect the course of renal ischemia and reperfusion injury.6,7 Animals were ventilated with tidal volumes of 10 $\mathrm{mL} / \mathrm{kg}$ at frequencies of 17 breaths/min to obtain end-tidal $\mathrm{CO}_{2}$ concentrations of 4-5 $\mathrm{kPa}$. Atropine $10 \mu \mathrm{g} / \mathrm{kg}$ i.v. was administered at the start of surgery and was maintained with $5 \mu \mathrm{g} / \mathrm{kg}$ i.v. every 45 minutes thereafter. During surgery, fentanyl $8 \mu \mathrm{g} / \mathrm{kg} / \mathrm{h}$ i.v. was administered by continuous infusion.

Animals were monitored by oxymeter (saturation $>95 \%$ and heart rate $<100 \mathrm{bpm})$ and rectal thermometer $\left(>36^{\circ} \mathrm{C}\right)$. Body temperature was maintained by infusion heaters and heat pads on the operating table; room temperature was $22^{\circ} \mathrm{C}$. During donor nephrectomy, $40 \mathrm{~mL} / \mathrm{kg}$ Ringer's lactate i.v. was administered. During kidney transplantation, $10 \mathrm{~mL} / \mathrm{kg}$ gelofusine and Ringer's lactacte as needed i.v. were administered in order to achieve central venous pressures (CVP) of $10 \mathrm{mmHg}$ and mean arterial pressures of $70-80 \mathrm{mmHg}$ at reperfusion of the kidney. Blood pressure and CVP were continuously monitored by pressure transducers on the central arterial and venous lines. Before reperfusion of the kidney, $100 \mathrm{~mL}$ mannitol $20 \%$ i.v. was administered. ${ }^{8}$

To maintain adequate hydration in the postoperative period, animals received $20 \mathrm{~mL} / \mathrm{kg}$ Ringer's lactate i.v. overnight after surgery and $10 \mathrm{~mL} / \mathrm{kg}$ Ringer's lactate i.v. twice a day during the first two postoperative days. For analgesia, 
$30 \mu \mathrm{g} / \mathrm{kg}$ buprenorphine i.v. was administered immediately after surgery and every 12 hours on the first two days after surgery (half dose at the second postoperative day). Antibiotic prophylaxis was provided by 1000/200 mg amoxicillin/clavulanate i.v. during donor nephrectomy and 500/100 mg (adjustment for reduced renal clearance) on the next three days. After transplant surgery, food was gradually restarted in order not to overfeed the animals. Rectal temperature was measured daily to check for infectious disease. Pigs were kept for 10 days after transplantation and blood was taken every day for serum creatinine and blood urea nitrogen (BUN) measurements.

\section{Statistics}

Continuous variables were presented as mean (standard error). For comparisons of continuous variables between groups, independent samples t-tests were used. Coefficient of variation was calculated as standard deviation divided by mean. Sample size was calculated at a power of $80 \%$ according to Campbell et al. ${ }^{9}$ Results with $\mathrm{P}<0.05$ were considered statistically significant.

\section{Kidney function after transplantation}

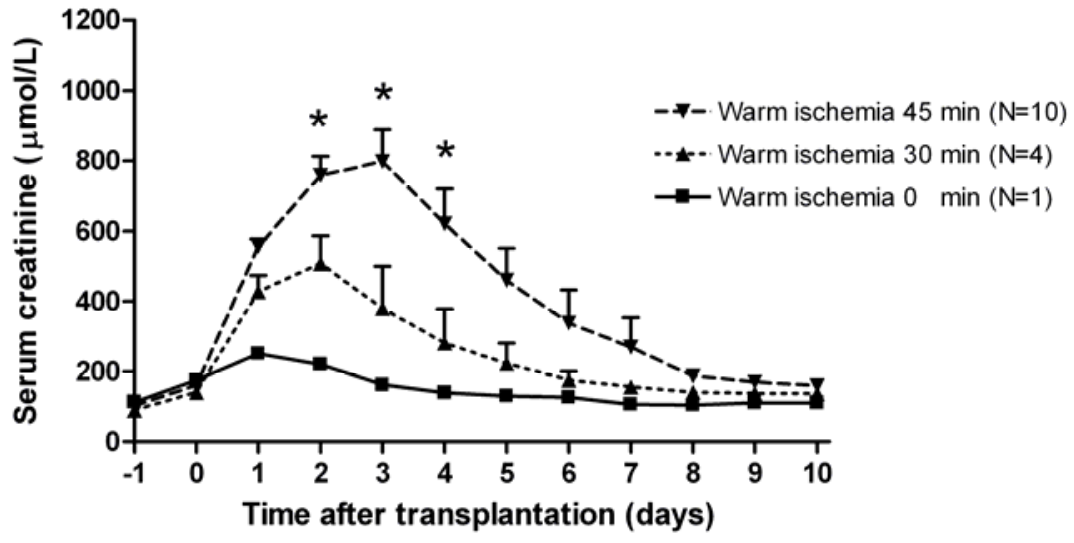

Figure 11.1 Serum creatinine over time for groups of kidneys with different warm ischemia times. Increased duration of warm ischemia before hypothermic organ preservation results in greater impairment of renal function after autologous kidney transplantation in pigs. Data are presented as means and standard errors. The asterisk denotes statistically significant differences between the 30 and 45 minutes warm ischemia group ( $\mathrm{P}=0.01$ at day $2, \mathrm{P}=0.03$ at day 3 and $\mathrm{P}=0.03$ at day 4$)$. 


\section{Results}

All animals survived until the end of the observation period. Duration of nephrectomy was $87 \pm 4$ minutes, whereas autologous kidney transplantation took $98 \pm 4$ minutes. Mean anastomosis time was $27 \pm 1$ minutes.

Autologous transplantation of ischemically injured kidneys in pigs was followed by severe renal dysfunction as indicated by a temporary rise in serum creatinine in the first 10 days after transplantation (Figure 11.1). Kidneys subjected to 45 minutes of warm ischemia before hypothermic organ preservation were associated with significantly higher serum creatinine concentrations than kidneys with 30 minutes of warm ischemia ( $\mathrm{P}=0.01$ at day $2, \mathrm{P}=0.03$ at day 3 and $\mathrm{P}=0.03$ at day 4, Figure 11.1). This was also observed with BUN concentrations, but the differences between groups did not reach statistical significance (data not shown). As a reference, one animal that received a kidney without warm ischemia showed a minor and transient rise in serum creatinine concentration that peaked on the first day after transplantation. These findings indicate that the duration of warm ischemia is closely related to the extent of renal dysfunction

\section{Variation in graft function between animals}

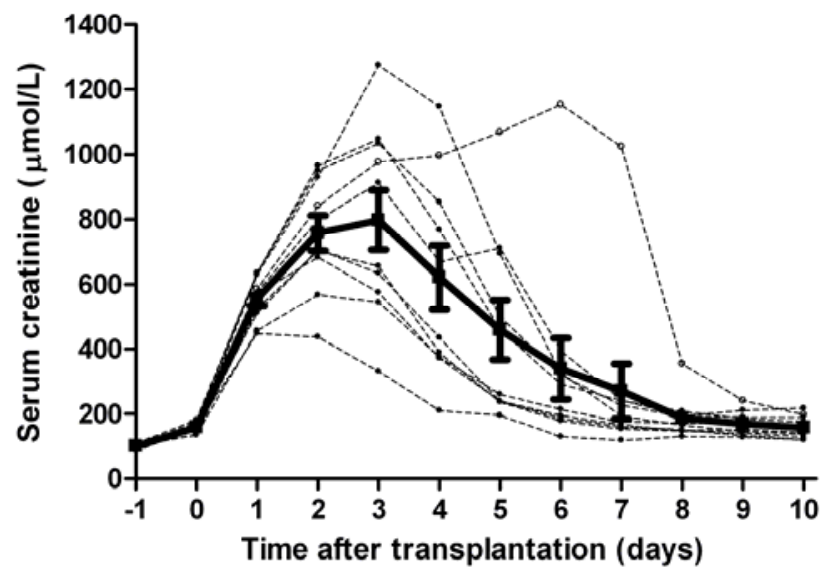

Figure 11.2 Variation in kidney function after autologous transplantation of porcine kidneys with 45 minutes of warm ischemia time $(\mathrm{N}=10)$. The solid line denotes the mean and standard error of serum creatinine concentrations over time, whereas the dashed lines denote serum creatinine concentrations over time for the individual animals. The line with open rounds is an outlier that was removed for analysis of reproducibility. 
after autologous kidney transplantation in pigs.

The variation in graft function between animals with a warm ischemia time of 45 minutes was evaluated (Figure 11.2). After removal of a single outlier, the mean coefficient of variation for the daily serum creatinine measurements was $26 \%$. With this variation, 5 animals per group are required to detect a difference of $50 \%$ between treatment and controls with statistical significance. This indicates that the model can be used efficiently for preclinical testing of novel interventions for ischemic acute kidney injury in renal transplantation.

\section{Discussion}

Pigs have been used as a large animal model for kidney transplantation since the early 1970s. ${ }^{10-14}$ In line with the major immunological challenges facing organ transplantation at that time, these early studies largely focussed on prevention of acute rejection after allogeneic transplantation of kidneys with minimal ischemic injury. With the advent of more effective immunosuppressive drugs and the increasing disparity between supply and demand of donor kidneys, scientific interest has shifted towards modulation of ischemic acute renal injury in order to enable transplantation of kidneys that have suffered prolonged ischemia. This interest is most readily addressed by autologous kidney transplantation models, which allow the study of ischemia and reperfusion injury without the potential for confounding by acute rejection or immunosuppressive drugs. ${ }^{15-19}$

Autologous kidney transplantation in pigs compares favourably to other animal models of ischemic acute kidney injury. Temporary renal artery occlusion in mice or rats, the most frequently used small animal model, ${ }^{20}$ is followed by extensive necrosis of proximal tubules which does not correspond to the much milder histological changes in renal biopsies during human acute kidney injury. ${ }^{21}$ Therefore, large animal models of autologous kidney transplantation in pigs and dogs have been used to more accurately simulate the clinical situation. Canine kidneys are able to function immediately even after 5 to 6 days of hypothermic organ preservation, ${ }^{22,23}$ indicating that these kidneys are less vulnerable to ischemia and reperfusion injury than those of humans and pigs. In addition, public opinion has shifted against the use of dogs in laboratory experiments. Therefore, we consider the pig to be the most appropriate species for preclinical studies on renal transplantation with ischemically injured kidneys, in particular since their renal anatomy and physiology are highly comparable to humans and because inbred pigs have relatively little genetic variation. ${ }^{4}$ Still, these experiments are 
typically done in young and healthy animals that may not be entirely representative of wait-listed dialysis patients. In addition, large animal models of kidney transplantation are restricted by their considerable expense and complexity and by the limited availability of transgenic animals and reagents for immunological assays on plasma and tissue samples.

Critical steps in the protocol are the anastomoses of the renal blood vessels, the creation of permanent vascular access and the peri-operative hemodynamic management. When anastomosing the renal artery and vein, generous spatulation of the vessels is necessary to avoid constriction at the anastomotic site. Constricted arterial or venous lumina will increase the risk of graft thrombosis, in particular in the context of reduced renal blood flow after acute ischemic injury. After unfavorable pilot experiments with small pigs weighing 20-30 $\mathrm{kg}$ and with heterotopic transplantation in the iliac fossa, we improved surgical success rates by using animals of at least $35 \mathrm{~kg}$ and by grafting the kidney orthotopically. ${ }^{24}$ Orthotopic kidney transplantation has the additional advantage of preventing ischemia of the hind leg due to iliac artery clamping. Surgery was further facilitated by the absence of accessory renal arteries in our experience.

Permanent vascular access is essential for the experiments by enabling blood sampling and administration of fluids and drugs. To obtain vascular access, we implanted small handmade catheters in the internal carotid artery and jugular vein that were tunnelled subcutaneously and locked with antibiotics and proteases to prevent catheter obstruction and infection. ${ }^{5}$ Alternatively, a doublelumen Hickman catheter may be placed in the external jugular vein. Although the larger size of this catheter facilitates rapid administration of intravenous fluids, it is also more prone to infectious complications and is considerably more expensive.

When performing autologous transplantation of ischemically injured kidneys in pigs, careful hemodynamic management is critical since the animals are transplanted within 24 hours of the previous major surgery and optimal renal perfusion is required to prevent further ischemic injury to the graft. After pilot experiments with restricted administration of fluids to prevent overload due to renal dysfunction, we increased the survival rate of the animals by implementing a standardized and liberal fluid regimen to avoid dehydration in the early postoperative period. During transplant surgery, fluids were given as needed to maintain target mean arterial and central venous pressures. Administration of vasoactive drugs was not necessary in our experience, contributing to standardization of the experimental protocol. In general, we adopted interventions known to improve graft function in human kidney transplantation: machine perfusion, 
hemodynamic optimization and administration of mannitol at reperfusion. $8,25,26$ Renal function after kidney transplantation with this protocol was superior to previous reports from other laboratories, ${ }^{15-18}$ and was in line with expected results in human kidney transplantation from young organ donors. These findings indicate that results from this large animal model are highly applicable to clinical kidney transplantation.

Early graft function after autologous transplantation of ischemically injured kidneys was evaluated by measuring serum creatinine concentrations. In pigs, these concentrations are strongly correlated to glomerular filtration rates, in particular when adjusted for animal weight. ${ }^{27,28} \mathrm{~A}$ more accurate assessment of renal function can be obtained by measuring creatinine clearance and sodium reabsorption in timed urine collections, which requires ureterocutaneostomy or suprapubic catheterization..$^{29}$ Additional information on the extent of ischemic acute kidney injury may be obtained from histological assessment of renal biopsies. Although it is convenient to take open biopsies during transplant surgery, adequate assessment of renal injury and leukocyte infiltration requires biopsies to be taken at later time points. We therefore recommend to take percutaneous needle biopsies under ultrasound guidance and light anesthesia on the first or second day after transplantation, which we have done successfully in subsequent experiments.

In conclusion, the current paper provides a comprehensive description of a porcine model of autologous transplantation of ischemically injured kidneys with an emphasis on peri-operative care. The animal model was validated by showing that renal function after transplantation was proportional to the duration of warm ischemia before organ recovery. We consider the extent of renal dysfunction to be well reproducible between kidney transplantations with the same warm ischemia time, particularly when it is taken into account that small variations in creatinine clearance cause relatively large differences in serum creatinine concentrations in case of severely depressed kidney function. Our experience may improve preclinical testing of novel interventions that modulate renal ischemia and reperfusion injury and thereby enable more widespread use of kidneys from donors after cardiac death that have suffered prolonged ischemia. 


\section{References}

1. Lechler RI, Sykes M, Thomson AW, Turka LA. Organ transplantation--how much of the promise has been realized? Nat Med 2005; 11:605-613.

2. Terasaki PI, Cho YW, Cecka JM. Strategy for eliminating the kidney shortage. Clin Transpl 1997:265-267.

3. Wijnen RM, Booster MH, Stubenitsky BM, de Boer J, Heineman E, Kootstra G. Outcome of transplantation of non-heart-beating donor kidneys. Lancet 1995; 345:1067-1070.

4. Sachs DH. The pig as a potential xenograft donor. Vet Immunol Immunopathol 1994; 43:185191.

5. Palm U, Boemke W, Bayerl D, Schnoy N, Juhr NC, Reinhardt HW. Prevention of catheterrelated infections by a new, catheter-restricted antibiotic filling technique. Lab Anim 1991; 25:142-152.

6. Lee HT, Kim M, Kim N, Billings FTt, D'Agati VD, Emala CW, Sr. Isoflurane protects against renal ischemia and reperfusion injury and modulates leukocyte infiltration in mice. Am J Physiol Renal Physiol 2007; 293:F713-722.

7. Zwemer CF, Shoemaker JL, Jr., Hazard SW, 3rd, Davis RE, Bartoletti AG, Phillips CL. Hyperoxic reperfusion exacerbates postischemic renal dysfunction. Surgery 2000; 128:815-821.

8. Tiggeler RG, Berden JH, Hoitsma AJ, Koene RA. Prevention of acute tubular necrosis in cadaveric kidney transplantation by the combined use of mannitol and moderate hydration. Ann Surg 1985; 201:246-251.

9. Campbell MJ, Julious SA, Altman DG. Estimating sample sizes for binary, ordered categorical, and continuous outcomes in two group comparisons. Bmj 1995; 311:1145-1148.

10. Golby M, White HJ. The operation of orthotopic renal allografting in the pig and its complications. Br J Surg 1971; 58:287-288.

11. Calne RY, Sells RA, Marshall VC, et al. Multiple organ grafts in the pig. Techniques and results of pancreatic, hepatic, cardiac, and renal allografts. Br J Surg 1972; 59:969-977.

12. Terblanche J, Hickman R, Uys CJ. Renal transplantation in the unimmunosuppressed pig: an abnormal response. Br J Surg 1975; 62:474-479.

13. Kirkman RL, Colvin RB, Flye MW, et al. Transplantation in miniature swine. VI. Factors influencing survival of renal allografts. Transplantation 1979; 28:18-23.

14. Nerstrom B, Gyrd-Hansen N, Iversen Hansen R, Lokkegaard H. Renal autotransplantation in the pig: surgical aspects. Scand J Urol Nephrol 1972; 6:151-153.

15. Lodge JP, Perry SL, Skinner C, Potts DJ, Giles GR. Improved porcine renal preservation with a simple extracellular solution--PBS140. Transplantation 1991; 51:574-579.

16. Killion D, Canfield C, Norman J, Rosenthal JT. Exogenous epidermal growth factor fails to accelerate functional recovery in the autotransplanted ischemic pig kidney. J Urol 1993; 150:1551-1556

17. Nicholson ML, Hosgood SA, Metcalfe MS, Waller JR, Brook NR. A comparison of renal preservation by cold storage and machine perfusion using a porcine autotransplant model. Transplantation 2004; 78:333-337.

18. Maathuis MH, Manekeller S, van der Plaats A, et al. Improved Kidney Graft Function After Preservation Using a Novel Hypothermic Machine Perfusion Device. Ann Surg 2007; 246:982991. 
19. Hauet T, Goujon JM, Vandewalle A, et al. Trimetazidine reduces renal dysfunction by limiting the cold ischemia/reperfusion injury in autotransplanted pig kidneys. J Am Soc Nephrol 2000; 11:138-148.

20. Kennedy SE, Erlich JH. Murine renal ischaemia-reperfusion injury. Nephrology (Carlton) 2008; 13:390-396.

21. Rosen S, Heyman SN. Difficulties in understanding human "acute tubular necrosis": limited data and flawed animal models. Kidney Int 2001; 60:1220-1224.

22. McAnulty JF, Ploeg RJ, Southard JH, Belzer FO. Successful five-day perfusion preservation of the canine kidney. Transplantation 1989; 47:37-41.

23. Rijkmans BG, Buurman WA, Kootstra G. Six-day canine kidney preservation. Hypothermic perfusion combined with isolated blood perfusion. Transplantation 1984; 37:130-134.

24. Treckmann J, Nagelschmidt M, Saad S, et al. Decreasing surgical complications in porcine kidney autotransplantation by a new technique of implantation. J Exp Anim Sci 2007; 43:231236.

25. Moers C, Smits JM, Maathuis MH, et al. Machine perfusion or cold storage in deceased-donor kidney transplantation. N Engl J Med 2009; 360:7-19.

26. Snoeijs MG, Wiermans B, Christiaans MH, et al. Recipient hemodynamics during non-heartbeating donor kidney transplantation are major predictors of primary nonfunction. Am J Transplant 2007; 7:1158-1166.

27. Waldmann $\mathrm{KH}$, Wendt M, Bickhardt K. [Creatinine clearance as the foundation for clinical determination of kidney function in swine]. Tierarztl Prax 1991; 19:373-380.

28. Gofrit ON, Orvieto MA, Zorn KC, Steinberg GD, Zagaja GP, Shalhav AL. Serum creatinine can be used as a surrogate for glomerular filtration rate in single renal unit models. Can J Urol 2009; 16:4452-4457; discussion 4457.

29. Yanaga K, Makowka L, Shimada M, et al. Improved method of porcine renal allografting for transplantation research. J Invest Surg 1991; 4:231-236. 
236 


\section{Chapter 12}

Therapeutic effect of propofol-enriched preservation solution in experimental kidney transplantation 


\begin{abstract}
Background: Novel interventions that protect against ischemia and reperfusion injury are needed to improve early graft function of kidneys from donors after cardiac death that suffer prolonged ischemia before transplantation.

Methods: We used synthetic monophenolic anti-oxidants to protect proximal tubular epithelial cells from hypothermic injury in vitro and found that several compounds were highly effective. The monophenolic compound propofol was dissolved in water at high concentrations by inclusion into cyclodextrins and was added to organ preservation solutions in this form.

Findings: Machine perfusion of ischemically injured porcine kidneys with propofol-enriched preservation solution prevented lipid peroxidation and attenuated the increase in renovascular resistance in the early reperfusion period of autologous kidney transplantation. The anti-oxidant effects of propofol were followed by an improvement in renal function in the first 10 days after transplantation with a trend towards statistical significance. Treatment with propofol during organ preservation did not reduce tissue injury or neutrophil infiltration.

Interpretation: Given its excellent clinical safety record, we consider propofol to be a promising renoprotective agent that may attenuate ischemic acute kidney injury in renal transplantation.
\end{abstract}

\title{
Published as
}

Snoeijs MG, Vaahtera L, de Vries EE, Schurink GW, Haenen GR, Peutz-Kootstra CJ, Buurman WA, Parkkinen J, van Heurn LW. Therapeutic effect of propofol-enriched preservation solution in experimental kidney transplantation. Manuscript submitted. 


\section{Introduction}

The shortage of donor kidneys presents a major barrier for adequate treatment of patients with end-stage renal disease. ${ }^{1}$ Utilization of donors after cardiac death may substantially expand the supply of organs, but concerns about warm ischemic injury suffered from circulatory arrest until organ preservation has led to a reluctance to accept kidneys from these donors. ${ }^{2}$ This is particularly true for the large pool of uncontrolled donors who die after unsuccessful cardiopulmonary resuscitation and suffer prolonged periods of warm ischemia before organ recovery, greatly increasing the risks of delayed graft function and primary nonfunction after transplantation. ${ }^{3}$ Novel interventions that protect the kidney from ischemia and reperfusion injury may increase the utilization of kidneys from these donors and improve the treatment of wait-listed dialysis patients.

A major factor implicated in the pathophysiology of ischemic acute kidney injury is the increased formation of reactive oxygen species during cold ischemia and reperfusion. ${ }^{4}$ At reperfusion, oxygen is reintroduced into the ischemic tissue causing a burst of reactive oxygen species through the action of several enzymes (e.g. xanthine oxidase, cyclo-oxygenase and lipoxygenase), through leakiness of the mitochondrial electron transport chain and through iron-containing heme proteins such as cytochromes. ${ }^{5}$ Moreover, neutrophils and macrophages are attracted to the injured tissue and may contribute to the production of reactive oxygen species. If not effectively scavenged by anti-oxidants, these reactive oxygen species cause injury to lipids, proteins and DNA. Injury to poly-unsaturated fatty acids (lipid peroxidation) is particularly harmful since this may initiate a chain reaction of oxidation within cell membranes, leading to structural changes in membrane-associated proteins and loss of membrane fluidity and integrity. ${ }^{6}$ This chain reaction of lipid peroxidation can be controlled by phenolic anti-oxidants such as alpha-tocopherol (vitamin E) that reside in the cell membrane and react faster with peroxyl radicals than fatty acids do. ${ }^{7}$

We hypothesized that administration of phenolic anti-oxidants to the donor kidney would improve renal function after transplantation by protecting the graft against ischemia and reperfusion injury. Therefore, we studied the cytoprotective effects of the synthetic monophenolic compounds 2,6-diisopropylphenol (propofol), 2,6-dimetoxyphenol (DMP), 2,6-di-tert-butylphenol (DTB) and 2,6-di-tert-butyl-4-methylphenol (BHT) in porcine proximal tubular epithelial cells exposed to hypothermia and rewarming in vitro. Subsequently, we 
determined the feasibility of including these compounds into cyclodextrins in order to improve the delivery of hydrophobic monophenols from preservation solutions into the cell membranes of the kidney. ${ }^{8}$ Finally, ischemically injured donor kidneys were loaded with propofol during organ preservation by hypothermic machine perfusion in order to investigate its therapeutic effect in a preclinical porcine model of autologous kidney transplantation.

\section{Materials and methods}

\section{Preparation of monophenols}

$10 \mathrm{mM}$ stock solutions of DMP, DTB, BHT (all from Sigma-Aldrich, St. Louis, MO) and propofol (Cilag, Schaffhausen, Switzerland) were prepared in ethanol and stored at $-70^{\circ} \mathrm{C}$. For preparation of cyclodextrin-complexed propofol, $7.5 \mathrm{~g}$ of hydroxypropyl-beta-cyclodextrin (Cavasol ${ }^{\circledR}$ W7 HP Pharma; Wacker Chemie, München, Germany) was dissolved in $50 \mathrm{~mL}$ water. The solution was filtered to remove bioburden and endotoxins. $410 \mu \mathrm{L}$ of pure propofol was added to $40 \mathrm{~mL}$ of the filtered cyclodextrin solution, agitated until complete dissolution of propofol (24 hours), sterile filtered and stored frozen. The solution contained $52 \mathrm{mM}$ propofol and a 1.9-fold molar excess of cyclodextrin. Endotoxin concentration in the final solution was $<1 \mathrm{IU} / \mathrm{mL}$ as measured by a kinetic colorimetric method (Biovian, Turku, Finland).

\section{Cell culture and in vitro experiments}

Porcine proximal tubular epithelial cells (LLC-PK1; American Type Culture Collection, Manassas, VA) were cultured until confluence in 96-well plates (20,000 cells/well) in M199 cell culture medium supplemented with 5\% fetal calf serum, $100 \mathrm{units} / \mathrm{mL}$ penicillin and $100 \mu \mathrm{g} / \mathrm{mL}$ streptomycin at $37^{\circ} \mathrm{C}$ in a humidified atmosphere of 95\% air and 5\% $\mathrm{CO}_{2}$. After washing, pre-cooled UW solution $\left(V{ }^{\circ}{ }^{\circledR}{ }^{\circledR}\right.$; Bristol-Myers Squibb, New York, NY) with different concentrations of monophenols was added and cells were maintained for 20 hours at $4^{\circ} \mathrm{C}$. To assess hypothermic cell death, release of $\mathrm{LDH}$ into the medium was determined by the Cytotoxicity Detection Kit (Roche Applied Science, Indianapolis, IN). Total cellular LDH was determined after lysing with $1 \%$ Triton X-100. Mitochondrial metabolic activity was measured by tetrazolium conversion using the MTS assay (CellTiter $96^{\circledR}$ AQ One Solution Cell Proliferation Assay; Promega, 
Madison, WI) during 2 hours of rewarming in cell culture conditions. All experiments were repeated three times in four parallel wells.

\section{In vivo study design}

In a randomized and blinded fashion, propofol or an equal volume of saline (placebo) was added to the preservation solution of porcine kidneys to administer $40 \mu \mathrm{mol}$ propofol per $100 \mathrm{~g}$ kidney weight during flush-out and $32 \mu \mathrm{mol}$ propofol per $100 \mathrm{~g}$ kidney weight at one hour after initiation and one hour before termination of hypothermic machine perfusion. This dosing regimen was developed in pilot experiments with slaughterhouse kidneys in order to obtain a final tissue propofol concentration of $300 \mu \mathrm{mol} / \mathrm{kg}$. This tissue concentration was based on the most effective in vitro concentration of propofol (3-10 $\mu \mathrm{M})$ and on its tissueto-water partition coefficient of $50 .^{9}$

After kidney transplantation, serum creatinine concentrations were measured daily to determine the effect of treatment on early graft function. Assuming a standard deviation of serum creatinine of 30\% of the mean, 6 pigs per experimental group were necessary to detect a $50 \%$ difference between groups with statistical significance. Experiments were approved by the local laboratory animal review board (DEC 2006-173).

\section{Autologous kidney transplantation in pigs}

Male pigs (Dutch landrace x Yorkshire crossbreed) of 35-45 kg and aged 16-20 weeks were obtained from a commercial farm and housed individually. Using isoflurane and fentanyl anesthesia, the left kidney was recovered through a midline abdominal incision and was left in the abdomen for 45 minutes to induce warm ischemic injury. The kidney was flushed with $300 \mathrm{~mL}$ HTK preservation solution (Dr. F. Köhler Chemie, Bensheim, Germany) per 100 g kidney weight and connected to a PF-3B hypothermic perfusion machine (Gambro, Lund, Sweden) primed with $500 \mathrm{~mL}$ UW-MPS (Organ Recovery Systems, Des Plaines, IL) using $55 \mathrm{mmHg}$ systolic perfusion pressure during the first hour of perfusion and a constant perfusate flow thereafter. Permanent vascular access was obtained by cannulating the left internal carotid artery and jugular vein. After 24 hours, the animal was anesthetized again and the right kidney was removed. The left kidney was taken from the perfusion machine and grafted orthotopically by endto-end anastomoses to the right renal artery and vein (6/0 running sutures) and ureter (5/0 running suture with stent placement to prevent urinary obstruction). During surgery, mean arterial pressure and central venous pressure were maintained at $80 \mathrm{mmHg}$ and $10 \mathrm{mmHg}$, respectively, using $500 \mathrm{~mL}$ gelofusine, $100 \mathrm{~mL}$ 
$20 \%$ mannitol before reperfusion and lactated Ringer's solution as needed. Renal blood flow was measured using a $3 \mathrm{~mm}$ perivascular flow probe (Transonic Systems, Ithaca, NY) during the first 30 minutes after reperfusion. Up to two days after surgery, animals were given analgesia, prophylactic antibiotics and intravenous fluids to aid recovery. Animals were euthanized 10 days after transplantation; pigs with renal thrombosis or ureter obstruction were excluded from analysis.

\section{HPLC measurements}

Propofol was measured in renal biopsies taken after hypothermic organ preservation and in systemic plasma taken at 30 minutes after reperfusion. Renal biopsies were homogenized (1:5) in cold $150 \mathrm{mM}$ sodium chloride/acetonitrile (1:1) using a pellet pestle motor (Sigma-Aldrich) for 3 times 10 seconds on ice. After addition of tert-octylphenol (Sigma-Aldrich) as internal standard in an equal volume of acetonitrile and vortexing, samples were incubated on ice for 10 minutes and centrifuged for 10 minutes at $10,000 \mathrm{~g}$ at $4^{\circ} \mathrm{C}$. Propofol concentrations were determined by reverse phase HPLC using a Discovery BIO wide-pore column (250x4 mm, $5 \mu \mathrm{m}$ particle size; Supelco, Bellefonte, PA) eluted with 82\% methanol in water at a flow rate of $0.8 \mathrm{~mL} / \mathrm{min}$. Detection was performed by fluorescence using excitation at $276 \mathrm{~nm}$ and emission at $310 \mathrm{~nm}$.

Malondialdehyde (MDA) was measured from systemic blood samples drawn just before reperfusion and at 2, 10 and 30 minutes after reperfusion. Blood was immediately transferred to EDTA tubes and centrifuged for $10 \mathrm{~min}$ utes at $900 \mathrm{~g}$ at $4^{\circ} \mathrm{C}$. Plasma was snap frozen in liquid nitrogen and stored at $-80^{\circ} \mathrm{C} .100 \mu \mathrm{L}$ plasma was added to $900 \mu \mathrm{L}$ reagent (0.12 M 2-thiobarbituric acid, $0.32 \mathrm{M} o$-phosphoric acid, $0.68 \mathrm{mM}$ butylated hydroxytoluene, $0.01 \%$ EDTA) and incubated for 1 hour at $100^{\circ} \mathrm{C}$. MDA products were extracted with $500 \mu \mathrm{L}$ butanol and their concentrations were determined by HPLC using a Nucleosil C18 column (150x3.2 mm, $5 \mu$ m particle size; Supelco) eluted with 35\% methanol in $25 \mathrm{mM}$ phosphate buffer ( $\mathrm{pH}$ 4.8). Detection was done by fluorescence using excitation at $532 \mathrm{~nm}$ and emission at $553 \mathrm{~nm}$. Malonaldehyde bis(diethylacetal) was used as internal standard. ${ }^{10}$

\section{Histological assessment of renal biopsies}

$16 \mathrm{G}$ needle biopsies were taken from the kidney at baseline, after hypothermic organ preservation, at 30 minutes after reperfusion and after euthanasia. Biopsies were formalin-fixed and stained with periodic acid-Schiff for blinded assessment of renal injury by an experienced nephropathologist. Tubular dilation, casts and 
debris, brush border loss and necrosis were scored in 10 cortical fields at $400 \mathrm{x}$ magnification on a scale of 0 to 5 ( 0 is normal; 1 involves $<10 \%$ of cortex; 2 involves $10-25 \%$ of cortex; 3 involves $25-50 \%$ of cortex; 4 involves $50-75 \%$ of cortex; and 5 involves $>75 \%$ of cortex). ${ }^{11}$

For detection of neutrophils, tissue sections were incubated with polyclonal rabbit anti-human myeloperoxidase (MPO) antibodies (1:50 dilution; Hycult Biotechnology, Uden, The Netherlands) for 2 hours and with biotinylated polyclonal swine anti-rabbit IgG antibodies (1:500 dilution; Dako, Glostrup, Denmark) for 30 minutes. Endogenous peroxidase activity and non-specific binding were blocked with $0.6 \% \mathrm{H}_{2} \mathrm{O}_{2}$ and $10 \%$ normal pig serum. After incubation with streptavidin and horseradish peroxidase conjugated biotin (Dako), the slides were developed with $\mathrm{H}_{2} \mathrm{O}_{2}$ and AEC and were counterstained with hematoxylin. The number of positive cells were counted in 10 cortical fields at $400 \mathrm{x}$ magnification.

\section{Statistical methods}

Continuous variables are presented as mean \pm standard error. Independent samples t-tests were used to compare continuous variables between experimental groups. To compare changes in serum creatinine over time between groups, we used repeated-measures ANOVA with baseline animal weight as covariate and Greenhouse-Geisser correction in case sphericity was violated. Results with $\mathrm{P}<0.05$ were considered statistically significant. Statistical computing was done using SPSS version 16.0.

\section{Results}

\section{Protective effects of monophenolic compounds on hypothermic injury in vitro}

Storage of proximal tubular epithelial cells in UW solution for 20 hours at $4^{\circ} \mathrm{C}$ resulted in the release of $71 \pm 3 \%$ of total cellular LDH into the medium. After rewarming, cells kept in UW solution contained only $5 \pm 2 \%$ of the MTS activity of cells stored in UW solution containing $1 \mu \mathrm{M}$ BHT. Addition of DTB and BHT to UW solution significantly attenuated LDH release and increased MTS activity as compared to media alone at concentrations of $0.1 \mu \mathrm{M}$ or greater, whereas propofol provided statistically significant protection of a similar magnitude when added at concentrations of $1 \mu \mathrm{M}$ or greater (Figure 12.1). In contrast, DMP did 
Cell death during hypothermia
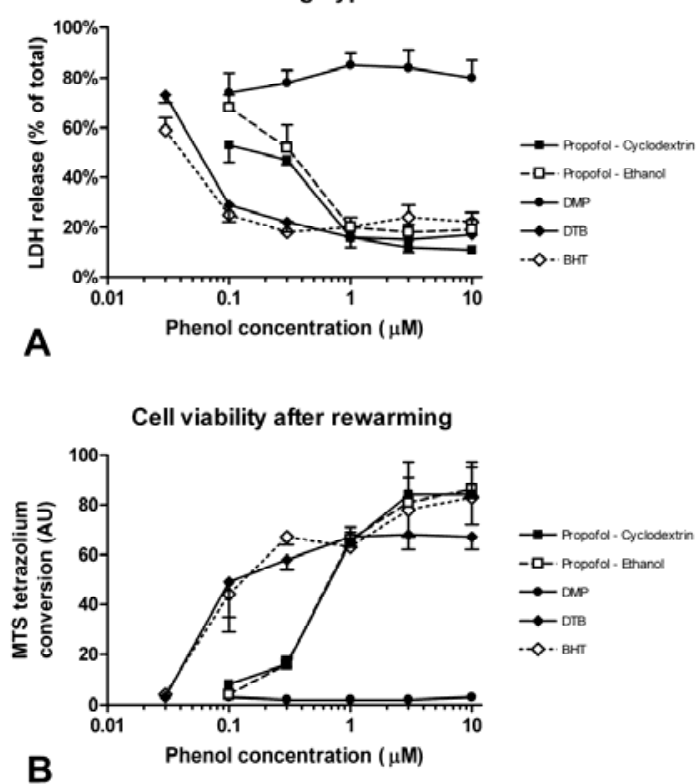

Figure 12.1 Addition of various monophenolic anti-oxidants protects proximal tubular epithelial cells (porcine LCC-PK1 cell line) from hypothermic injury in vitro. Cyclodextrin-complexed propofol has similar cytoprotective properties as propofol dissolved in ethanol. DMP does not protect against hypothermic injury. (A) Cell death after 20 hours of incubation in UW at $4^{\circ} \mathrm{C}$ was measured by LDH release into the medium. In untreated control cells, $71 \pm 3 \%$ of total LDH was released into the medium. (B) After 20 hours of incubation in UW at $4^{\circ} \mathrm{C}$, mitochondrial metabolic activity was measured by tetrazolium conversion using the MTS assay during 2 hours of rewarming in cell culture conditions. In untreated control cells, $3 \pm 1$ arbitrary units (AU) of tetrazolium were converted in the MTS assay. Data are presented as means and standard errors.

not significantly affect LDH release or MTS activity as compared to media alone at concentrations up to $10 \mu \mathrm{M}$.

\section{Preparation of water-soluble cyclodextrin inclusion complexes}

To enable the addition of water-insoluble phenolic compounds into preservation solutions without the use of organic solvents, an effort was made to prepare water-soluble, non-toxic formulations of the monophenols. Propofol could be dissolved at high concentrations in aqueous solution of cyclodextrin, which is in line with prior observations on inclusion complex formation of beta-cyclodextrin derivatives with propofol. ${ }^{12}$ The high solubility of cyclodextrin-complexed propofol allowed its addition at high concentrations to various organ preserva- 
tion solutions. No corresponding water-soluble formulations were obtained with the other monophenolic compounds tested. Importantly, cyclodextrin-complexed propofol had similar cytoprotective properties as propofol dissolved in 100\% ethanol (Figure 12.1). No toxicity was observed at levels up to $300 \mu \mathrm{M}$. Ethanol and cyclodextrin at concentrations used in cell culture had no effect on LDH release or MTS activity of the cells (data not shown). Because of the excellent protective efficacy of the cyclodextrin-complexed propofol against hypothermic injury in vitro and its high water-solubility, it was selected for further in vivo studies.

\section{Effect of propofol on oxidative stress in experimental kidney transplantation}

We investigated the therapeutic effect of propofol in a porcine model of autologous transplantation of kidneys subjected to 45 minutes of warm ischemia and 22

Table 12.1 Characteristics of autologous kidney transplantations in pigs $^{\mathrm{a}}$

\begin{tabular}{|c|c|c|c|}
\hline & $\begin{array}{c}\text { Propofol } \\
(\mathrm{N}=6)\end{array}$ & $\begin{array}{c}\text { Placebo } \\
(\mathrm{N}=6)\end{array}$ & $\mathbf{P}$ \\
\hline Pig weight (kg) & $40(2)$ & $39(2)$ & 0.76 \\
\hline Duration nephrectomy surgery (min) & $84(4)$ & $81(5)$ & 0.65 \\
\hline Duration transplant surgery (min) & $94(6)$ & $101(4)$ & 0.36 \\
\hline Cristalloid volume during transplantation $(\mathrm{mL})$ & $2025(294)$ & $2317(270)$ & 0.48 \\
\hline Warm ischemia time (min) & $45(0)$ & $46(1)$ & 0.52 \\
\hline Flush-out time (min) & $17(1)$ & $15(2)$ & 0.45 \\
\hline Machine perfusion time (hrs) & $23(0.2)$ & $23(0.1)$ & 0.69 \\
\hline Anastomosis time (min) & $25(2)$ & $27(2)$ & 0.54 \\
\hline Kidney weight at recovery (g) & $104(3)$ & $105(6)$ & 0.92 \\
\hline Kidney weight after flush-out (g) & $151(5)$ & $150(8)$ & 0.89 \\
\hline Kidney weight at implantation (g) & $168(6)$ & $169(10)$ & 0.98 \\
\hline Kidney weight at euthanasia (g) & $202(16)$ & $210(28)$ & 0.81 \\
\hline Perfusion pressure (mmHg) & $21(3)$ & $24(3)$ & 0.50 \\
\hline Perfusion flow rate $(\mathrm{mL} / \mathrm{min} / 100 \mathrm{~g})$ & $32(4)$ & $31(4)$ & 0.81 \\
\hline Resistance (mmHg/mL/min/100g) & $0.69(0.14)$ & $0.82(0.14)$ & 0.51 \\
\hline LDH concentration (IU/L/100g) & $190(18)$ & $192(18)$ & 0.93 \\
\hline Mean arterial pressure at reperfusion $(\mathrm{mmHg})$ & $92(4)$ & $87(5)$ & 0.48 \\
\hline Central venous pressure at reperfusion $(\mathrm{mmHg})$ & $11(1)$ & $10(1)$ & 0.17 \\
\hline Renal propofol concentration $(\mu \mathrm{mol} / \mathrm{kg})$ & $270(72)$ & $0(0)$ & 0.01 \\
\hline
\end{tabular}

${ }^{a}$ Data are presented as mean (standard error) and compared with independent samples t-tests. 
hours of hypothermic machine perfusion. Addition of cyclodextrin-complexed propofol to the organ preservation solution resulted in mean propofol tissue concentrations of $270 \pm 73 \mu \mathrm{mol} / \mathrm{kg}$ at reperfusion. Baseline characteristics were comparable between the propofol and control group ( $\mathrm{N}=6$ per group, Table 12.1). No adverse events were observed after transplantation of propofol-treated kidneys and serum propofol concentrations were less than $1 \mu \mathrm{M}$ at 30 minutes after reperfusion.

Propofol was hypothesized to attenuate ischemic acute kidney injury in renal transplantation by preventing oxidative stress at reperfusion. Plasma concentrations of MDA, a product of lipid peroxidation and a marker of oxidative stress, increased after reperfusion in the control group (Figure 12.2). Addition of propofol to the organ preservation solution significantly reduced the increase in MDA concentration $(\mathrm{P}=0.02, \mathrm{P}=0.24$ and $\mathrm{P}=0.01$ at 2,10 and 30 minutes after reperfusion, respectively) and therefore prevented lipid peroxidation at reperfusion. Since oxidative stress may induce local vasoconstriction, we measured renovascular resistance with invasive blood pressure monitoring and perivascular flow probes. Renovascular resistance increased during the first minutes of reperfusion, which was attenuated by addition of propofol to the organ preservation solution ( $\mathrm{P}=0.04$ at 5 minutes after reperfusion, Figure 12.3).

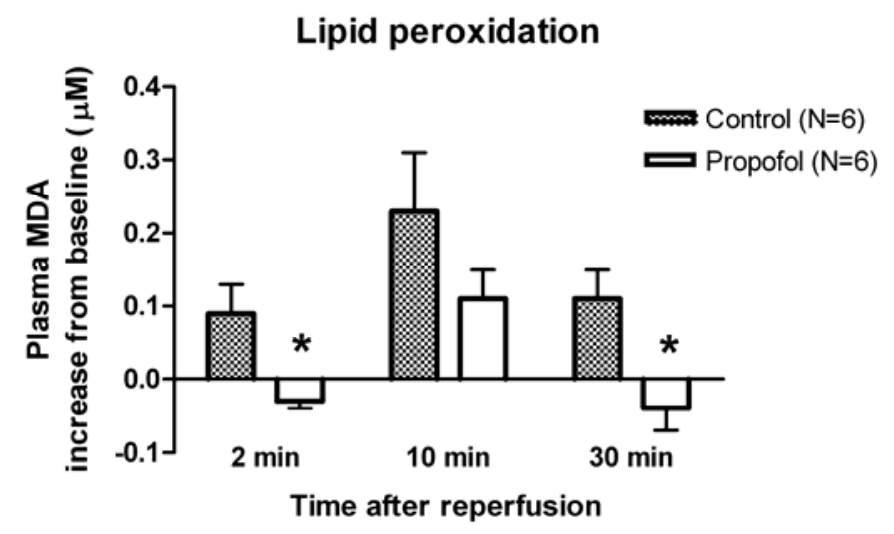

Figure 12.2 Addition of propofol to the organ preservation solution prevents lipid peroxidation at reperfusion of grafts subjected to 45 minutes of warm ischemia and 22 hours of hypothermic organ preservation. Lipid peroxidation was assessed by measuring malondialdehyde (MDA) concentrations in plasma just before and at 2, 10 and 30 minutes after reperfusion. Data are presented as means and standard errors. The asterisk denotes statistically significant differences between the propofol and control group ( $\mathrm{P}=0.02$ at 2 minutes and $\mathrm{P}=0.01$ at 30 minutes after reperfusion). 


\section{Renal perfusion}

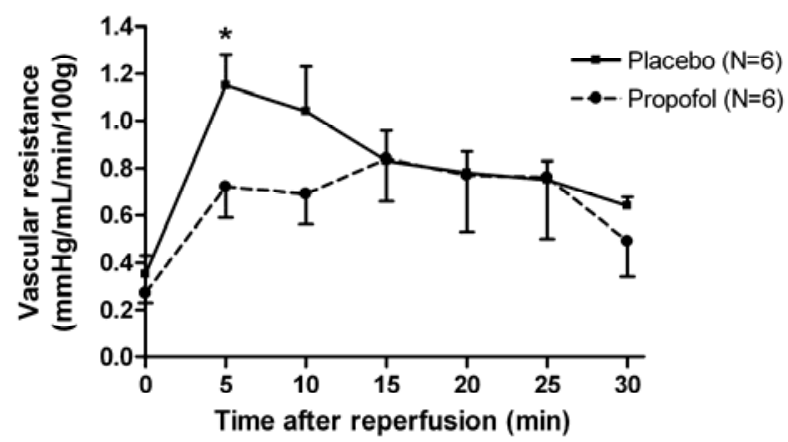

Figure 12.3 Addition of propofol to the organ preservation solution decreases renal vascular resistance in the first minutes after reperfusion in grafts subjected to 45 minutes of warm ischemia and 22 hours of hypothermic organ preservation. Renal blood flow was measured using a perivascular flow probe and corrected for perfusion pressure and kidney weight during the first 30 minutes after reperfusion of the kidney. Data are presented as means and standard errors. The asterisk denotes statistically significant differences between the propofol and control group $(\mathrm{P}=0.04)$.

\section{Effect of propofol on renal function in experimental kidney transplantation}

Transplantation of ischemically injured kidneys was followed by severe but recoverable renal dysfunction as indicated by a temporary rise in serum creatinine concentrations that returned to normal before the end of the observation time at 10 days after transplantation. The addition of propofol to the organ preservation solution reduced serum creatinine concentrations with a trend towards statistical significance $(\mathrm{P}=0.10$, Figure 12.4$)$. Our study was powered to detect a $50 \%$ difference in serum creatinine between treatment groups, which we consider to be required for initiation of clinical trials. Smaller effect sizes may still be relevant in the context of combination therapies, but require larger sample sizes to reach statistical significance. When two pigs from pilot experiments were added to the control group in a post hoc analysis, a significant reduction in serum creatinine concentration was observed when propofol was administered during organ preservation $(\mathrm{P}=0.03)$.

Histological assessment of renal biopsies showed that preservation and transplantation of kidneys after 45 minutes of warm ischemia induced tubular dilation and brush border loss but did not cause tubular casts or necrosis (Figure 12.5). The addition of propofol to the organ preservation solution had no effect 


\section{Kidney function after transplantation}

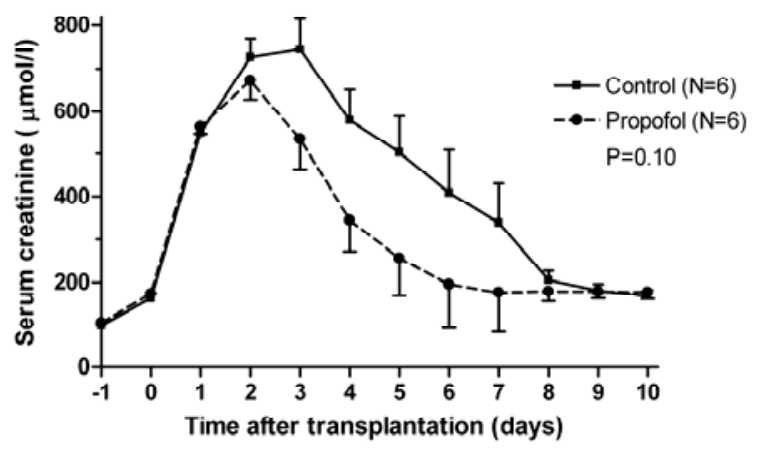

Figure 12.4 Addition of propofol to the organ preservation solution improves kidney function after transplantation of grafts subjected to 45 minutes of warm ischemia and 22 hours of hypothermic organ preservation. Serum creatinine over time corrected for animal weight for propofol and control groups. Data are presented as means and standard errors.

on the extent of tubular dilation and brush border loss $(\mathrm{P}=0.27$ and $\mathrm{P}=0.88$ after reperfusion, respectively). To assess the local inflammatory response to tissue injury, neutrophils were counted in tissue sections. Infiltration of neutrophils into the transplanted kidney was evident at 30 minutes after reperfusion (Figure 12.6). Addition of propofol to the preservation solution had no effect on the extent of neutrophil infiltration ( $\mathrm{P}=0.79)$.

\section{Discussion}

Interventions that protect kidneys from ischemia and reperfusion injury may improve early graft function in kidneys from donors after cardiac death that suffer prolonged ischemia before transplantation. In the current study, we showed that several synthetic monophenolic anti-oxidants were highly effective in protecting proximal tubular epithelial cells from hypothermic injury in vitro. Among these compounds, propofol could be dissolved in water at high concentrations by inclusion in cyclodextrin complexes, which allowed us to add propofol to organ preservation solutions. Loading of ischemically injured porcine kidneys with propofol during hypothermic machine perfusion improved renal function after autologous transplantation. We investigated several mechanisms 
by which propofol could exert this renoprotective effect and found that both lipid peroxidation and renal vasoconstriction were prevented by propofol, which is in line with its anti-oxidant effects. Therefore, it is highly likely that the beneficial effects of propofol are at least partly derived from these anti-oxidant properties. Propofol did not reduce the modest infiltration of neutrophils at 30 minutes after reperfusion, suggesting that its protection is not mediated by rapid

\section{HISTOLOGICAL ASSESSMENT OF RENAL INJURY}
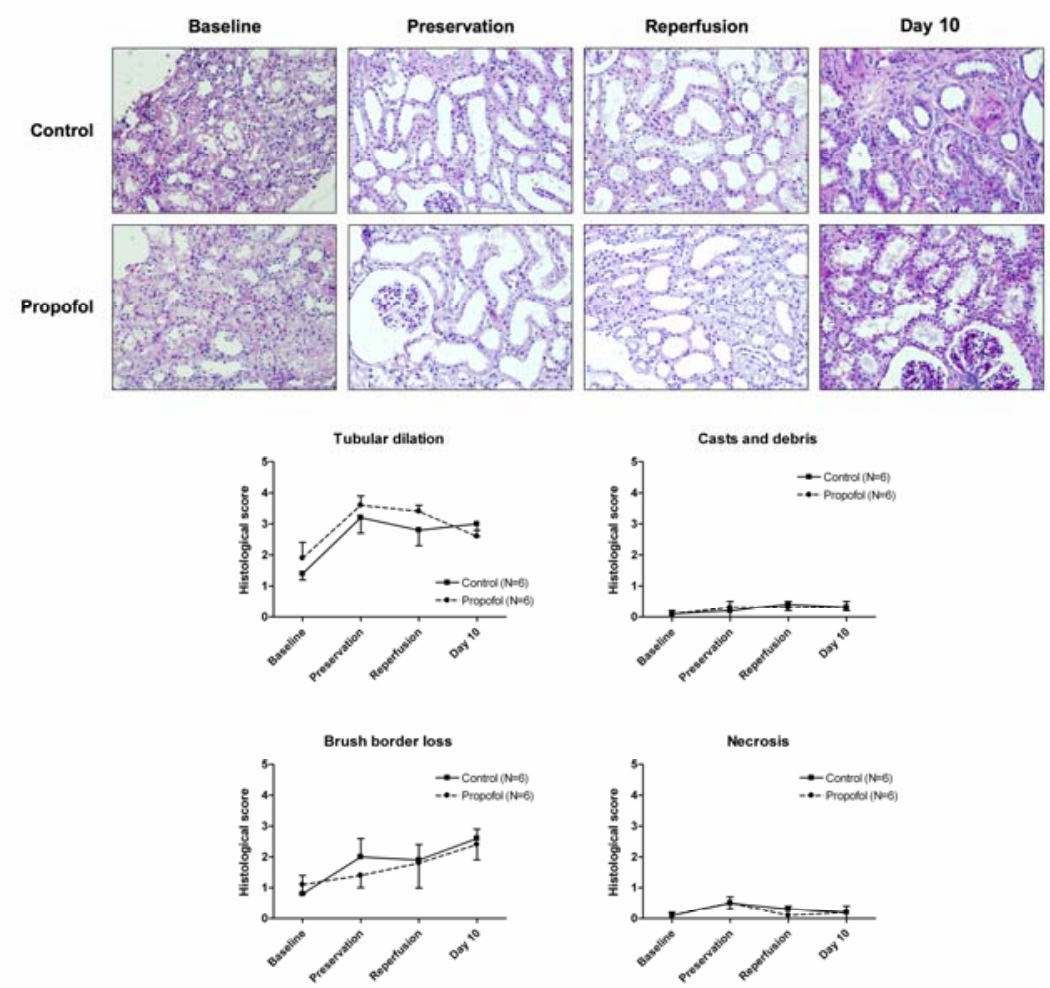

Figure 12.5 Addition of propofol to the organ preservation solution has no effect on renal injury after transplantation of grafts subjected to 45 minutes of warm ischemia and 22 hours of hypothermic organ preservation. Representative pictures of periodic acid-Schiff stained tissue sections at 400x magnification are shown. Tubular dilation, casts and debris, brush border loss and necrosis were blindly scored by an experienced nephropathologist on a scale of 0 to 5 . Data are presented as means and standard errors. 
and direct effects on inflammation. In contrast, propofol has direct cytoprotective effects on proximal tubular epithelial cells as shown in our in vitro studies. Treatment with propofol did not reduce tissue injury in renal biopsies taken at 30 minutes after reperfusion. However, this time point may be relatively early for assessment of renal injury.

Propofol is a hypnotic agent for intravenous use that is widely used for the induction and maintenance of anesthesia. ${ }^{13}$ Additionally, propofol has similar anti-oxidant properties as other monophenolic compounds such as alphatocopherol (vitamin E). ${ }^{14-16}$ In isolated perfused rat hearts, propofol dosedependently attenuates lipid peroxidation, mitochondrial permeability transition and cardiac dysfunction after ischemia and reperfusion. ${ }^{17}$ In vivo, administration of propofol improves outcomes in rodent models of hemorrhagic and septic shock, ischemia and reperfusion of many organs including the kidney, heart, gut, testis and skin and in acute lung injury. ${ }^{18-26}$ The renoprotective effect of propofol has recently been confirmed in a porcine model of aortic cross-clamping. ${ }^{27}$

Oxidative stress has been implicated in the pathogenesis of ischemic acute kidney injury. Paller and co-workers reported that administration of various anti-oxidants (superoxide dismutase, dimethylthiourea, allopurinol and deferoxamine) attenuate renal dysfunction and histological injury after renal ischemia and reperfusion in rats. ${ }^{28,29}$ These findings have subsequently been extended to large animal models of kidney transplantation after hypothermic organ preservation. ${ }^{30,31}$ However, the beneficial effects of anti-oxidants in experimental models of ischemic acute kidney injury and in randomized clinical trials in kidney transplantation are inconsistent. ${ }^{32-34}$ Monophenolic anti-oxidants have not been studied in clinical kidney transplantation neither are they included in commercially available preservation solutions, even though the monophenolic compounds alpha-tocopherol and trolox attenuated ischemic acute kidney injury in rodent models. ${ }^{35,36}$

In the current study, we have used a novel technique to deliver the water-insoluble monophenolic anti-oxidant propofol - a highly effective cytoprotective agent in vitro - by including this compound into a cyclodextrin complex which stabilizes hydrophobic drugs in aqueous solutions. ${ }^{8}$ Addition of these complexes to the preservation solution for hypothermic machine perfusion allowed ex vivo accumulation of propofol in the kidney at greater tissue concentrations than would have been possible with systemic administration of the drug, because side effects of hypotension and negative inotropy limit dosing of propofol in vivo. Therefore, ex vivo administration of high doses of propofol was expected to more fully exploit its anti-oxidant properties. Loading the kidney 


\section{NEUTROPHIL INFILTRATION IN KIDNEY}

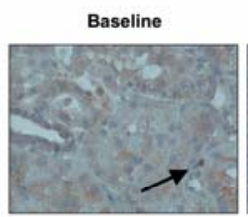

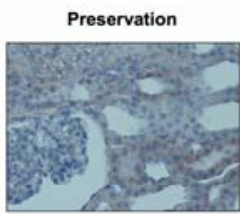

Reperfusion
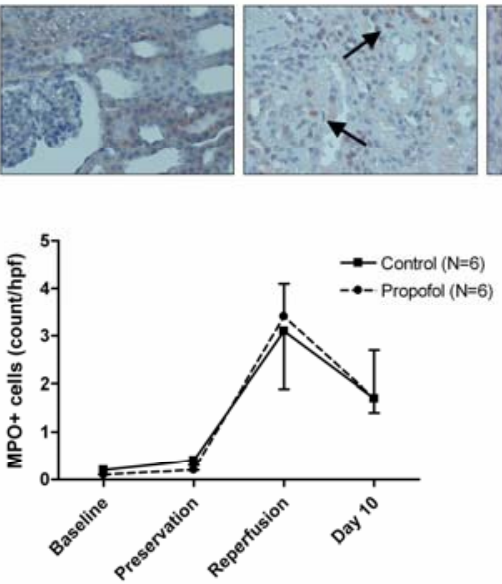

Day 10

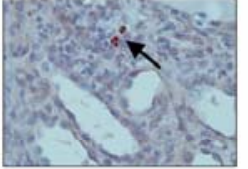

Figure 12.6 Addition of propofol to the organ preservation solution has no effect on neutrophil infiltration after transplantation of grafts subjected to 45 minutes of warm ischemia and 22 hours of hypothermic organ preservation. Representative pictures of myeloperoxidase (MPO) stained tissue sections at 400x magnification are shown. Data are presented as means and standard errors.

with anti-oxidants during hypothermic organ preservation may be of additional benefit since oxidative stress not only occurs at reperfusion but has also been reported to take place during cold ischemia. ${ }^{37}$ Propofol treatment was free from adverse events, while systemic plasma concentrations of propofol were undetectable $(<1 \mu \mathrm{M})$ in the early reperfusion period. This indicates that our protocol can safely be applied in human kidney transplantation, where propofol administered for anesthesia reaches systemic concentrations of up to $15 \mu \mathrm{M}$.

The efficacy of this novel anti-oxidant therapy was evaluated in a pig model of autologous kidney transplantation. Pigs are particularly useful for preclinical assessment of interventions targeted to attenuate ischemic acute kidney injury because their renal anatomy and physiology are highly comparable to humans. ${ }^{38}$ Furthermore, pigs have relatively little genetic variation and have a similar response to oxidative stress as humans. ${ }^{39}$ Autologous transplantation was used to prevent acute rejection and to allow specific analysis of ischemic acute kidney injury. Kidneys were subjected to 45 minutes of warm ischemia and 22 hours of cold ischemia before transplantation which resulted in extensive but 
recoverable renal injury comparable to clinical kidney transplantation from donors after cardiac death. To further improve clinical translation, interventions known to improve early graft function were included in the animal model (hypothermic machine perfusion, administration of mannitol at reperfusion and hemodynamic optimization during transplant surgery). A limitation of the current study is that all in vivo experiments were done in young and healthy animals that may not be entirely representative of wait-listed dialysis patients.

The current study shows that loading of donor kidneys with the phenolic anti-oxidant propofol during hypothermic organ preservation attenuates ischemic renal injury after kidney transplantation by preventing lipid peroxidation and renal vasoconstriction. Therefore, propofol is a valuable additive to organ preservation solutions for reduction of ischemic injury due to lipid peroxidation. The pathophysiology of ischemic acute kidney injury is highly complex and effective treatment of this condition is likely to require a combination of interventions targeting multiple pathways that may act independently from each other (e.g. oxidative stress, inflammation, apoptosis, regeneration). Given its excellent clinical safety record, we consider propofol to be a promising candidate for inclusion in such a combination of renoprotective agents. 


\section{References}

1. Wolfe RA, Ashby VB, Milford EL, et al. Comparison of mortality in all patients on dialysis, patients on dialysis awaiting transplantation, and recipients of a first cadaveric transplant. $\mathrm{N}$ Engl J Med 1999; 341:1725-1730.

2. Daemen JW, Oomen AP, Kelders WP, Kootstra G. The potential pool of non-heart-beating kidney donors. Clin Transplant 1997; 11:149-154.

3. Snoeijs MG, Dekkers AJ, Buurman WA, et al. In Situ Preservation of Kidneys From Donors After Cardiac Death: Results and Complications. Ann Surg 2007; 246:844-852.

4. Perico N, Cattaneo D, Sayegh MH, Remuzzi G. Delayed graft function in kidney transplantation. Lancet 2004; 364:1814-1827.

5. Halliwell B. Free radicals, antioxidants, and human disease: curiosity, cause, or consequence? Lancet 1994; 344:721-724.

6. Niki E. Lipid peroxidation: physiological levels and dual biological effects. Free Radic Biol Med 2009; 47:469-484.

7. Atkinson J, Epand RF, Epand RM. Tocopherols and tocotrienols in membranes: a critical review. Free Radic Biol Med 2008; 44:739-764.

8. Challa R, Ahuja A, Ali J, Khar RK. Cyclodextrins in drug delivery: an updated review. AAPS PharmSciTech 2005; 6:E329-357.

9. Weaver BM, Staddon GE, Mapleson WW. Tissue/blood and tissue/water partition coefficients for propofol in sheep. Br J Anaesth 2001; 86:693-703.

10. Pilz J, Meineke I, Gleiter CH. Measurement of free and bound malondialdehyde in plasma by high-performance liquid chromatography as the 2,4-dinitrophenylhydrazine derivative. J Chromatogr B Biomed Sci Appl 2000; 742:315-325.

11. Leemans JC, Stokman G, Claessen N, et al. Renal-associated TLR2 mediates ischemia/reperfusion injury in the kidney. J Clin Invest 2005; 115:2894-2903.

12. Trapani A, Laquintana V, Lopedota A, et al. Evaluation of new propofol aqueous solutions for intravenous anesthesia. Int J Pharm 2004; 278:91-98.

13. Marik PE. Propofol: therapeutic indications and side-effects. Curr Pharm Des 2004; 10:36393649 .

14. Murphy PG, Myers DS, Davies MJ, Webster NR, Jones JG. The antioxidant potential of propofol (2,6-diisopropylphenol). Br J Anaesth 1992; 68:613-618.

15. Aarts L, van der Hee R, Dekker I, de Jong J, Langemeijer H, Bast A. The widely used anesthetic agent propofol can replace alpha-tocopherol as an antioxidant. FEBS Lett 1995; 357:83-85.

16. Tsuchiya M, Asada A, Kasahara E, Sato EF, Shindo M, Inoue M. Antioxidant protection of propofol and its recycling in erythrocyte membranes. Am J Respir Crit Care Med 2002; 165:5460.

17. Javadov SA, Lim KH, Kerr PM, Suleiman MS, Angelini GD, Halestrap AP. Protection of hearts from reperfusion injury by propofol is associated with inhibition of the mitochondrial permeability transition. Cardiovasc Res 2000; 45:360-369.

18. Lee CJ, Subeq YM, Lee RP, Wu WT, Hsu BG. Low-dose propofol ameliorates haemorrhagic shock-induced organ damage in conscious rats. Clin Exp Pharmacol Physiol 2008; 35:766-774. 
19. Votta-Velis EG, Minshall RD, Visintine DJ, Castellon M, Balyasnikova IV. Propofol attenuates endotoxin-induced endothelial cell injury, angiotensin-converting enzyme shedding, and lung edema. Anesth Analg 2007; 105:1363-1370.

20. Wang HH, Zhou HY, Chen CC, Zhang XL, Cheng G. Propofol attenuation of renal ische$\mathrm{mia} /$ reperfusion injury involves heme oxygenase-1. Acta Pharmacol Sin 2007; 28:1175-1180.

21. Yuzer H, Yuzbasioglu MF, Ciralik H, et al. Effects of intravenous anesthetics on renal ischemia/reperfusion injury. Ren Fail 2009; 31:290-296.

22. Kobayashi I, Kokita N, Namiki A. Propofol attenuates ischaemia-reperfusion injury in the rat heart in vivo. Eur J Anaesthesiol 2008; 25:144-151.

23. Kaplan N, Yagmurdur H, Kilinc K, Baltaci B, Tezel S. The protective effects of intravenous anesthetics and verapamil in gut ischemia/reperfusion-induced liver injury. Anesth Analg 2007; 105:1371-1378.

24. Yagmurdur H, Ayyildiz A, Karaguzel E, et al. The preventive effects of thiopental and propofol on testicular ischemia-reperfusion injury. Acta Anaesthesiol Scand 2006; 50:1238-1243.

25. Tyner TR, Shahbazian R, Nakashima J, Kane S, Sian K, Yamaguchi KT. Propofol improves skin flap survival in a rat model: correlating reduction in flap-induced neutrophil activity. Ann Plast Surg 2004; 53:273-277.

26. Chen HI, Hsieh NK, Kao SJ, Su CF. Protective effects of propofol on acute lung injury induced by oleic acid in conscious rats. Crit Care Med 2008; 36:1214-1221.

27. Sanchez-Conde P, Rodriguez-Lopez JM, Nicolas JL, et al. The comparative abilities of propofol and sevoflurane to modulate inflammation and oxidative stress in the kidney after aortic crossclamping. Anesth Analg 2008; 106:371-378.

28. Paller MS, Hoidal JR, Ferris TF. Oxygen free radicals in ischemic acute renal failure in the rat. J Clin Invest 1984; 74:1156-1164.

29. Paller MS, Hedlund BE. Role of iron in postischemic renal injury in the rat. Kidney Int 1988; 34:474-480.

30. Koyama I, Bulkley GB, Williams GM, Im MJ. The role of oxygen free radicals in mediating the reperfusion injury of cold-preserved ischemic kidneys. Transplantation 1985; 40:590-595.

31. Baron P, Gomez-Marin O, Casas C, et al. Renal preservation after warm ischemia using oxygen free radical scavengers to prevent reperfusion injury. J Surg Res 1991; 51:60-65.

32. Gamelin LM, Zager RA. Evidence against oxidant injury as a critical mediator of postischemic acute renal failure. Am J Physiol 1988; 255:F450-460.

33. Pollak R, Andrisevic JH, Maddux MS, Gruber SA, Paller MS. A randomized double-blind trial of the use of human recombinant superoxide dismutase in renal transplantation. Transplantation 1993; 55:57-60.

34. Land W, Schneeberger H, Schleibner S, et al. The beneficial effect of human recombinant superoxide dismutase on acute and chronic rejection events in recipients of cadaveric renal transplants. Transplantation 1994; 57:211-217.

35. Takenaka M, Tatsukawa Y, Dohi K, Ezaki H, Matsukawa K, Kawasaki T. Protective effects of alpha-tocopherol and coenzyme Q10 on warm ischemic damages of the rat kidney. Transplantation 1981; 32:137-141.

36. Wongmekiat $\mathrm{O}$, Thamprasert $\mathrm{K}$, Lumlertgul D. Renoprotective effect of trolox against ischaemia-reperfusion injury in rats. Clin Exp Pharmacol Physiol 2007; 34:753-759.

37. Salahudeen AK. Cold ischemic injury of transplanted kidneys: new insights from experimental studies. Am J Physiol Renal Physiol 2004; 287:F181-187.

38. Sachs DH. The pig as a potential xenograft donor. Vet Immunol Immunopathol 1994; 43:185191. 
$\begin{array}{lllllll}\text { THERA P E U T C EFFE T OF P R O P O F O L } & 255\end{array}$

39. Godin DV, Garnett ME. Species-related variations in tissue antioxidant status--II. Differences in susceptibility to oxidative challenge. Comp Biochem Physiol B 1992; 103:743-748. 
256 


\section{Chapter 13}

Biological effects of $\mathrm{F}_{2}$-isoprostanes in experimental acute kidney injury 


\begin{abstract}
Background: $\mathrm{F}_{2}$-isoprostanes are formed by oxidative modification of arachidonic acid and are the gold standard for detection of oxidative stress in vivo. $\mathrm{F}_{2}-$ isoprostanes are biologically active compounds that signal through the thromboxane $\mathrm{A}_{2}(\mathrm{TP})$ receptor; infusion of $\mathrm{F}_{2}$-isoprostanes reduces glomerular filtration in the kidney by constricting afferent arterioles. We investigated whether endogenous $\mathrm{F}_{2}$-isoprostanes contribute to the pathogenesis of ischemic acute kidney injury, which is associated with oxidative stress and reduced glomerular filtration.

Methods: TP receptor knockout mice - that lack $\mathrm{F}_{2}$-isoprostanes and thromboxane $\mathrm{A}_{2}$ signaling - and wild-type control mice underwent 30 minutes of renal ischemia and 24 hours of reperfusion.

Findings: Kidney dysfunction, histological injury and the number of infiltrated neutrophils were similar between the two mouse strains, whereas TP receptor knockout mice had significantly more apoptotic cells than their wild-type counterparts. $\mathrm{F}_{2}$-isoprostanes and thromboxane $\mathrm{B}_{2}$ were readily detectable in urine collections after surgery.

Interpretation: Our findings indicate that $\mathrm{F}_{2}$-isoprostanes and thromboxane $\mathrm{A}_{2}$ signaling do not contribute critically to the pathogenesis of ischemic acute kidney injury, and more generally provide evidence against a prominent role for $\mathrm{F}_{2}$-isoprostanes signaling in exacerbating acute disease states associated with oxidative stress.
\end{abstract}

\title{
Published as
}

Snoeijs MG, Boonen B, Coffman TM, Peutz-Kootstra CJ, Buurman WA, van Heurn LW. Biological effects of $\mathrm{F}_{2}$-isoprostanes in experimental acute kidney injury. Free Rad Biol Med, in revision. 


\section{Introduction}

Acute kidney injury is a frequent complication after ischemia and reperfusion due to cardiovascular surgery and hemorrhagic shock and is independently associated with increased in-hospital mortality. ${ }^{1}$ In renal transplantation, acute kidney injury results in delayed graft function which is associated with an increased incidence of acute rejection and graft loss. ${ }^{2}$ At reperfusion, reintroduction of oxygen to the ischemic kidney rapidly leads to the formation of reactive oxygen species that may damage cellular lipids, proteins and DNA when antioxidant defences have been exhausted. The resulting oxidative stress is an important cause of acute kidney injury, since administration of various anti-oxidants has been shown to attenuate renal dysfunction and histological injury in animal models of renal ischemia and reperfusion..$^{3-5}$

$\mathrm{F}_{2}$-isoprostanes are formed by oxidative modification of arachidonic acid in cell membranes. They are cleaved and released into the plasma by plateletactivating factor acetylhydrolase. ${ }^{6,7}$ Measurement of plasma and urinary $F_{2}-$ isoprostanes has become accepted as the gold standard for detection of oxidative stress in vivo, ${ }^{8}$ and their production has been demonstrated in a rat model of renal ischemia and reperfusion. ${ }^{9}$ Interestingly, next to being accurate biomarkers of oxidative stress, $\mathrm{F}_{2}$-isoprostanes are biologically active compounds that signal through the thromboxane $\mathrm{A}_{2}(\mathrm{TP})$ receptor. ${ }^{10}$ Intra-arterial administration of $\mathrm{F}_{2}$ isoprostanes to rats and pigs results in dose-dependent reductions in renal blood flow and glomerular filtration rate due to vasoconstriction of afferent glomerular arterioles. ${ }^{911}$ This renal vasoconstriction has also been observed in human acute kidney injury. ${ }^{12}$

Taken together, the vasoconstrictive properties of locally produced $\mathrm{F}_{2}-$ isoprostanes may contribute to the reduction of glomerular filtration rate in ischemic acute kidney injury and may explain the protective effects of antioxidants in animal models of renal ischemia and reperfusion. To address this hypothesis, we studied the effects of genetic disruption of the TP receptor which eliminates $\mathrm{F}_{2}$-isoprostanes signaling ${ }^{13}$ - in a mouse model of renal ischemia and reperfusion. 


\section{Materials and methods}

\section{Renal ischemia and reperfusion in mice}

Homozygous TP receptor knockout breeding pairs (backcrossed on C57BL/6J mice for 13 generations) were provided by dr. T.M. Coffman. ${ }^{14}$ Wild-type C57BL/6J mice were obtained from Charles River (L'arbresle Cedex, France). Animals were housed in standard laboratory cages with free access to food and water. In random order, male wild-type and TP receptor knockout mice aged 911 weeks were anesthetized with ketamine and xylazine $(100$ and $10 \mathrm{mg} / \mathrm{kg}$ s.c., respectively). Body temperature was maintained at $37^{\circ} \mathrm{C}$ by a heating lamp until the animals had recovered from anesthesia. Ischemia was induced by clamping the left renal pedicle for 30 minutes using a nontraumatic vascular clamp through a midline abdominal incision. The surgeon was blinded for mouse genotype. Upon clamp removal, the kidney was inspected for restoration of blood flow and the contralateral kidney was excised. The abdomen was closed in 2 layers, $0.25 \%$ bupivacaine was applied topically for postoperative pain management and $1 \mathrm{~mL}$ prewarmed PBS was given subcutaneously to prevent dehydration. Animals were euthanized at 24 hours after reperfusion, when blood was collected by puncture of the vena cava. The left kidney was recovered for further analysis. Blood was stored on ice in heparanized tubes until centrifugation at 900 $\mathrm{g}$ at $4^{\circ} \mathrm{C}$ for $10 \mathrm{~min}$. Plasma creatinine and blood urea nitrogen (BUN) concentrations were measured. In a separate set of experiments, the contralateral kidney was left in situ and the animals were housed in metabolic cages to collect urine for 24 hours before and after surgery.

\section{Histological assessment of renal tissue}

Renal tissue was formalin-fixed and stained with periodic acid-Schiff for blinded assessment of renal injury by an experienced nephropathologist. Tubular dilation, casts and debris, brush border loss and necrosis at the corticomedullary junction were scored in 10 fields at $400 \mathrm{x}$ magnification on a scale of 0 to 5 ( 0 is normal; 1 involves $<10 \%$ of cortex; 2 involves $10-25 \%$ of cortex; 3 involves 25 $50 \%$ of cortex; 4 involves $50-75 \%$ of cortex; and 5 involves $>75 \%$ of cortex). ${ }^{15}$

For detection of neutrophils, tissue sections were incubated with polyclonal rabbit anti-human myeloperoxidase (MPO) antibodies (1:50 dilution; Hycult Biotech, Uden, The Netherlands) for 2 hours and with biotinylated polyclonal swine anti-rabbit IgG antibodies (1:500 dilution; Dako, Glostrup, Denmark) for 30 minutes. Endogenous peroxidase activity and non-specific 
binding were blocked with $0.6 \% \mathrm{H}_{2} \mathrm{O}_{2}$ and $10 \%$ normal pig serum. After incubation with streptavidin and horseradish peroxidase conjugated biotin (Dako), slides were developed with $\mathrm{H}_{2} \mathrm{O}_{2}$ and $\mathrm{AEC}$ and were counterstained with hematoxylin. The number of positive cells at the corticomedullary junction were counted in 10 fields at 400x magnification by a blinded investigator.

Apoptotic cells were detected by terminal deoxynucleotidyl transferase (TdT)-mediated dUTP nick-end labeling (TUNEL; In situ cell death detection kit; Roche Diagnostics, Indianapolis, IN) according to the manufacturer's instructions. ${ }^{16}$ Before labelling, nuclei were permeabilized by incubating the tissue sections with $300 \mu \mathrm{g} / \mathrm{mL}$ proteinase K (Sigma-Aldrich, St. Louis, MO) for 15 minutes. Endogenous peroxidase activity and non-specific binding were blocked with $0.6 \% \mathrm{H}_{2} \mathrm{O}_{2}$ and $3 \%$ bovine serum albumin. The slides were developed with $\mathrm{H}_{2} \mathrm{O}_{2}$ and AEC and the number of positive nuclei at the corticomedullary junction were counted in 10 fields at $400 \mathrm{x}$ magnification by a blinded investigator.

\section{TP receptor genotyping}

Genomic DNA was isolated from renal tissue according to the manufacturer's instructions (Wizard genomic DNA purification kit; Promega, Madison, WI). DNA was amplified using the primers 5'-GGGGGTAGCTATGGTGTTC-3' (for the wild-type allele), 5'-CTTCCTCGTGCTTTACGGTA-3' (for the mutant allele with PGK-neomycin insert) and 5'-GTGAGAAGGGCCGTGTGAT-3' (for both alleles) in 30 cycles at $94^{\circ} \mathrm{C}, 60^{\circ} \mathrm{C}$ and $72^{\circ} \mathrm{C}$ (60 seconds each). The PCR product was run on a $1.2 \%$ agarose gel with a DNA basepair ladder. The predicted amplicon sizes from the wild-type and mutant alleles were 150 and 700 basepairs, respectively.

\section{Measurement of urine thromboxane $B_{2}$ and $F_{2}$-isoprostanes}

Urine was collected on ice for 24 hours before and after surgery, centrifuged at $900 \mathrm{~g}$ at $4^{\circ} \mathrm{C}$ for 10 minutes and stored at $-80^{\circ} \mathrm{C}$. Urinary thromboxane $\mathrm{B}_{2}$ and $\mathrm{F}_{2}-$ isoprostanes concentrations were measured using commercially available enzyme immunoassays (Cayman Chemical, Ann Arbor, MI) according to the manufacturer's instructions.

\section{Laboratory animal use and ethical considerations}

Assuming a standard deviation of plasma creatinine of $15 \%$ of the mean, 10 mice per experimental group are necessary to detect a $20 \%$ difference between groups with statistical significance; we consider this difference to be biologically rele- 


\section{KIDNEY FUNCTION}
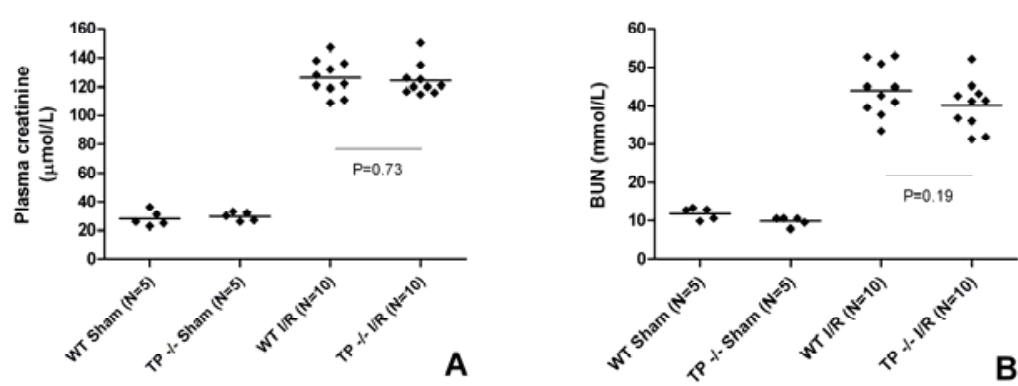

Figure 13.1 Kidney function is impaired to a similar extent in TP receptor knockout (TP -/-) and wild-type control mice (WT) after 30 minutes of renal ischemia and 24 hours of reperfusion (I/R). (A) Plasma creatinine concentration. (B) Blood urea nitrogen (BUN) concentration. Diamonds and lines represent individual mice and group means, respectively.

vant. In vivo experiments were approved by local laboratory animal and national genetically modified organism review boards (DEC 2007-139 and GGO IG 07110).

\section{Statistical methods}

Continuous variables are presented as means and standard deviations. Independent samples t-tests were used to compare continuous variables between experimental groups. For comparisons of continuous variables within experimental groups, paired samples t-test were used. $\mathrm{P}<0.05$ was considered statistically significant.

\section{Results}

\section{Effect of TP receptor genotype on renal ischemia and reperfusion injury}

Homozygous TP receptor knockout mice and wild-type controls were randomly subjected to 30 minutes of renal ischemia ( $\mathrm{N}=10$ per group) or sham surgery ( $\mathrm{N}=5$ per group). No complications occurred during surgery and all animals survived until euthanasia at 24 hours after reperfusion. Mean body weight of TP receptor knockout and wild-type mice was $24 \pm 0.8$ and $24 \pm 1.2 \mathrm{~g}$, respectively, before 
surgery and $22 \pm 1.5$ and $23 \pm 1.0 \mathrm{~g}$ at euthanasia. TP receptor genotype of each animal was confirmed by PCR of genomic DNA (data not shown).

Temporary renal ischemia induced severe kidney dysfunction as indicated by increased plasma concentrations of creatinine and BUN at 24 hours after reperfusion (Figure 13.1). TP receptor knockout and wild-type control mice experienced a similar extent of renal dysfunction after ischemia and reperfusion $(\mathrm{P}=0.73$ for creatinine and $\mathrm{P}=0.19$ for $\mathrm{BUN})$. Furthermore, substantial renal injury was observed on histological assessment of tissue sections after ischemia and reperfusion, indicated by tubular dilation, cast deposition, brush border loss and necrosis at the corticomedullary junction (Figure 13.3). In line with its effect on renal function, disruption of the TP receptor gene did not significantly reduce the extent of tissue injury after ischemia and reperfusion $(\mathrm{P}=0.58$ for tubular dilation, $\mathrm{P}=0.06$ for cast deposition, $\mathrm{P}=0.32$ for brush border loss and $\mathrm{P}=0.06$ for necrosis).

\section{HISTOLOGICAL ASSESSMENT OF RENAL INJURY}
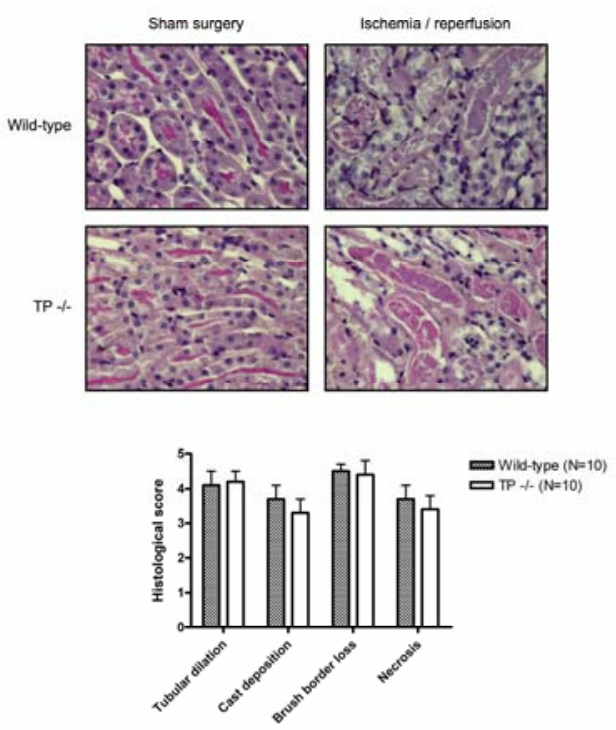

Figure 13.2 TP receptor knockout (TP -/-) and wild-type control mice experience a similar extent of renal injury after 30 minutes of renal ischemia and 24 hours of reperfusion. Representative pictures of periodic acid-Schiff stained tissue sections at 400x magnification are shown. Tubular dilation, casts deposition, brush border loss and necrosis were blindly scored by an experienced nephropathologist on a scale of 0 to $5 .^{15}$ 


\section{Effect of TP receptor genotype on neutrophil infiltration and apoptosis}

Tissue injury activates innate immunity and leads to infiltration of inflammatory cells into the damaged tissue. ${ }^{17}$ Influx of neutrophils into the kidney occurs relatively early after reperfusion and has been shown to exacerbate ischemic acute renal injury. ${ }^{18}$ In our experiment, renal ischemia and reperfusion resulted in massive accumulation of neutrophils around the injured tubules at the corticomedullary junction (Figure 13.3A). The extent of neutrophil infiltration was similar for TP receptor knockout and wild-type control mice $(\mathrm{P}=0.96)$. Furthermore, after renal ischemia and reperfusion, tubular epithelial cells undergo apoptotic cell death which may aggravate acute kidney injury. ${ }^{19}$ In line with our other findings, disruption of the TP receptor gene did not attenuate the induction of apoptosis in tubular epithelial cells at the corticomedullary junction after renal ischemia and reperfusion. On the contrary, TP receptor knockout mice had

NEUTROPHIL INFILTRATION

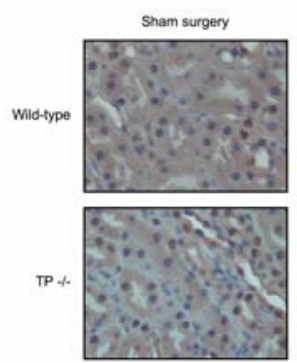

A

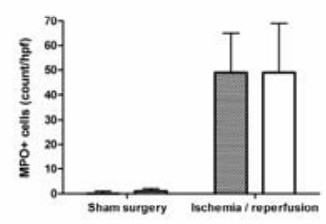

Ischemia / repertusion
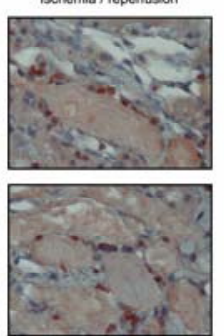

APOPTOSIS

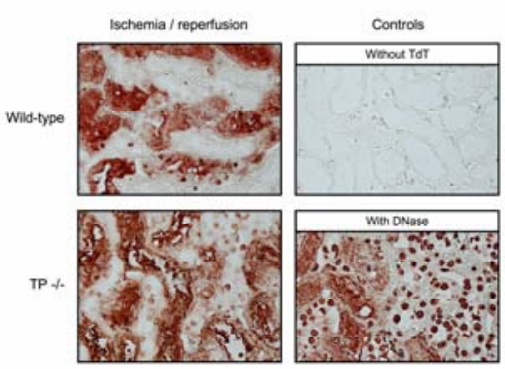

B

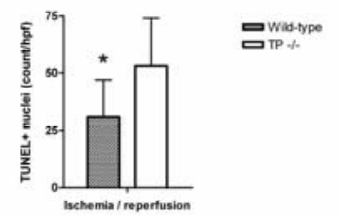

Figure 13.3 TP receptor knockout (TP -/-) have a similar extent of (A) neutrophil infiltration into the kidney and (B) significantly more tubular epithelial cell apoptosis after 30 minutes of renal ischemia and 24 hours of reperfusion as compared to wild-type control mice. Representative pictures of myeloperoxidase (MPO) and terminal deoxynucleotidyl transferase (TdT)-mediated dUTP nickend labeling (TUNEL) stained tissue sections at 400x magnification are shown. Tubular debris was diffusely positive for TUNEL staining and was not taken into account when quantifying apoptotic nuclei. Data are presented as means and standard deviations; the asterisk indicates statistical significance $(\mathrm{P}=0.01)$. 
Table 13.1 $\mathrm{F}_{2}$-isoprostanes and thromboxane $\mathrm{B}_{2}$ concentrations ( $\mathrm{ng} / \mathrm{mg}$ creatinine) in 24-hour urine collections before and after renal ischemia and reperfusion ${ }^{\mathrm{a}}$

\begin{tabular}{lccc}
\hline & $\begin{array}{c}\text { Before ischemia } \\
\text { and reperfusion }\end{array}$ & $\begin{array}{c}\text { After ischemia } \\
\text { and reperfusion }\end{array}$ & P \\
\hline F2-ISOPROSTANES & & & \\
Wild-type controls & $4.1 \pm 2.1$ & $3.3 \pm 0.8$ & 0.27 \\
TP receptor knockouts & $4.2 \pm 1.3$ & $3.4 \pm 1.1$ & \\
THROMBOXANE B2 & & & 0.01 \\
Wild-type controls & $8.8 \pm 2.3$ & $12.2 \pm 3.1$ & \\
TP receptor knockouts & $8.8 \pm 2.3$ & $11.5 \pm 1.7$ & \\
\hline
\end{tabular}

a Data are presented as mean (standard deviation). P values represent comparisons of urine concentrations before and after renal ischemia and reperfusion after pooling of both mouse strains.

significantly more apoptotic cells than their wild-type counterparts $(\mathrm{P}=0.01$, Figure 13.3B).

\section{Production of $F_{2}$-isoprostanes and thromboxane $A_{2}$}

Production of the TP receptor ligands $\mathrm{F}_{2}$-isoprostanes and thromboxane $\mathrm{A}_{2}$ increases after renal ischemia and reperfusion in rats. ${ }^{9,20}$ Since genetic disruption of the TP receptor did not alter the susceptibility to ischemic acute kidney injury in mice, we investigated whether TP receptor ligands were present in our experimental model. In urine collections before and after temporary renal ischemia, $F_{2}$-isoprostanes and thromboxane $\mathrm{B}_{2}$ (the stable metabolite of thromboxane $\mathrm{A}_{2}$ ) concentrations from TP receptor knockout and wild-type control mice were similar (Table 13.1). Urine thromboxane $\mathrm{B}_{2}$ concentrations increased by $44 \pm 35 \%$ following renal ischemia and reperfusion $(\mathrm{P}=0.01)$, whereas urine $\mathrm{F}_{2}$-isoprostanes concentrations were constant $(\mathrm{P}=0.27)$. These findings confirm the presence of the two major TP receptor ligands after renal ischemia and reperfusion.

\section{Discussion}

The current study was designed to establish the biological effects of locally produced $\mathrm{F}_{2}$-isoprostanes in a mouse model of renal ischemia and reperfusion. We found that mice with genetic deletion of the TP receptor - which eliminates $\mathrm{F}_{2}$-isoprostanes and thromboxane $\mathrm{A}_{2}$ signaling ${ }^{13}$ - suffered renal dysfunction of similar severity as wild-type mice with the same genetic background at 24 hours 
after reperfusion. Furthermore, the degree of histological injury and the number of neutrophils in the outer renal medulla were comparable between the two groups of mice. TP receptor knockout mice had significantly more apoptosis and a trend towards less necrosis than their wild-type counterparts, suggesting a change in the mode of cell death after renal ischemia and reperfusion when TP signaling is lost. Taken together, however, $\mathrm{F}_{2}$-isoprostanes and thromboxane $\mathrm{A}_{2}$ signaling do not seem to contribute critically to the development of ischemic acute kidney injury.

The biological effects of $\mathrm{F}_{2}$-isoprostanes have been studied in various experimental models. Administration of synthetic $\mathrm{F}_{2}$-isoprostanes increases systemic blood pressure in rodents and causes vasoconstriction of human arteries and veins in vitro. ${ }^{13,21,22}$ The vasoconstrictive actions of $\mathrm{F}_{2}$-isoprostanes are particularly evident in the renal microcirculation: intrarenal arterial administration of $1 \mu \mathrm{g} / \mathrm{kg} / \mathrm{min} 15-\mathrm{F}_{2}$-isoprostane acutely reduces glomerular filtration rate by $35 \%$ in pigs and $49 \%$ in rats, whereas systemic hemodynamic effects are not observed until administration of $10 \mu \mathrm{g} / \mathrm{kg} / \mathrm{min}$ 15- $\mathrm{F}_{2}$-isoprostane. ${ }^{9,11,13}$ Other biological effects of $\mathrm{F}_{2}$-isoprostanes include stimulation of leukocyte adhesion to endothelium and proliferation of endothelial and vascular smooth muscle cells, promoting angiogenesis and atherosclerosis in vivo. ${ }^{23,24}$ Conflicting reports have been published on the effects of $\mathrm{F}_{2}$-isoprostanes on platelets, some groups finding increased activation of platelets whereas others report that $\mathrm{F}_{2}$-isoprostanes prevent aggregation of platelets in vitro. ${ }^{13,25}$ These paradoxical effects may be explained by partial agonistic activity of $\mathrm{F}_{2}$-isoprostanes on TP receptors or by the presence of a second, inhibitory $\mathrm{F}_{2}$-isoprostanes receptor on platelets. ${ }^{10}$

It has been established that administration of synthetic $\mathrm{F}_{2}$-isoprostanes causes a variety of biological effects that are highly comparable to the actions of other TP receptor agonists. It has repeatedly been proposed that endogenous formation of $\mathrm{F}_{2}$-isoprostanes as a result of oxidative stress may elicit similar effects, thereby contributing to the pathogenesis of conditions as diverse as ischemia-reperfusion injury, atherosclerosis, tumor angiogenesis and asthmatic bronchoconstriction. However, biological actions of synthetic $\mathrm{F}_{2}$-isoprostanes have typically been observed after adding these compounds at concentrations two to three orders of magnitude greater than the physiological plasma concentrations of $\mathrm{F}_{2}$-isoprostanes in healthy volunteers. At sites of oxidative stress, $\mathrm{F}_{2}-$ isoprostanes may nevertheless reach concentrations at which adverse biological effects have been observed. ${ }^{26}$

The current study is the first to investigate the pathogenic actions of locally produced $\mathrm{F}_{2}$-isoprostanes in renal ischemia-reperfusion injury. This ex- 
perimental model is well suited for assessment of the biological effects of $F_{2}-$ isoprostanes, since oxidative stress plays an important role in the pathophysiology of ischemic acute kidney injury and because the actions of $F_{2}$-isoprostanes are particularly evident in the renal microcirculation. ${ }^{9,11}$ The hemodynamic effects of $\mathrm{F}_{2}$-isoprostanes are entirely mediated by $\mathrm{TP}$ receptors that are expressed in the glomeruli and intrarenal arteries of human and rodent kidneys. ${ }^{27-29}$ Mice with genetic deletion of the TP receptor are viable and are characterized by normal renal hemodynamics with attenuated renal vasoconstriction after administration of endotoxin or angiotensin-II..$^{14,30,31}$ In the current study, we found that ischemia and reperfusion induces acute kidney injury in TP receptor knockout mice to a similar extent as in wild-type mice, indicating that neither $\mathrm{F}_{2}$ isoprostanes nor thromboxane $\mathrm{A}_{2}$ signaling is critically involved in the pathophysiology of ischemic acute kidney injury. Our study does not account for potential TP receptor-independent actions of $\mathrm{F}_{2}$-isoprostanes. It has been proposed that esterified $\mathrm{F}_{2}$-isoprostanes may cause cellular injury in the absence of TP receptors by disruption of the fluidity and integrity of cell membranes, similar to other products of lipid peroxidation. ${ }^{32}$

Our findings seem to contradict previous experiments that have suggested thromboxane $A_{2}$ signaling to contribute to the pathogenesis of ischemic acute kidney injury. ${ }^{33}$ Specific inhibitors of thromboxane $A_{2}$ synthase have been shown to attenuate acute kidney injury in rodent models of renal ischemia and reperfusion. ${ }^{33}$ However, inhibition of thromboxane $A_{2}$ synthesis increases the production of the vasodilator prostacyclin as a result of the increased availability of their common precursor prostaglandin $\mathrm{H}_{2}$ - a phenomenon termed endoperoxide shunting. ${ }^{34}$ Since the beneficial effects of thromboxane A2 synthase inhibitors on ischemic acute kidney injury were eliminated when prostacyclin synthesis was blocked, ${ }^{35}$ these effects may have been caused by an increase in prostacyclin signaling as a result of endoperoxide shunting rather than by a decrease in thromboxane $\mathrm{A}_{2}$ signaling. A separate study found that pharmacological inhibition of TP receptor signaling attenuated renal dysfunction in a rat model of 60 minutes of renal ischemia followed by 6 hours of reperfusion. ${ }^{20}$ In contrast, we observed no effect of genetic deletion of TP receptors on acute kidney injury after 30 minutes of renal ischemia and 24 hours of reperfusion in mice. These conflicting findings may be caused by differences in the applied experimental models or by cross-reactivity of the drug used to inhibit TP receptor signaling. ${ }^{36}$

Taken together, we conclude that $\mathrm{F}_{2}$-isoprostanes and thromboxane $\mathrm{A}_{2}$ signaling do not contribute critically to the pathogenesis of ischemic acute kidney injury. Tissue injury due to ischemia and reperfusion is characterized by 
extensive oxidative stress and the biological actions of $\mathrm{F}_{2}$-isoprostanes are particularly evident in the renal microcirculation. Therefore, our findings more generally argue against a prominent role for $\mathrm{F}_{2}$-isoprostanes signaling in exacerbating acute disease states associated with oxidative stress. 


\section{References}

1. Chertow GM, Burdick E, Honour M, Bonventre JV, Bates DW. Acute kidney injury, mortality, length of stay, and costs in hospitalized patients. J Am Soc Nephrol 2005; 16:3365-3370.

2. Yarlagadda SG, Coca SG, Formica RN, Jr., Poggio ED, Parikh CR. Association between delayed graft function and allograft and patient survival: a systematic review and meta-analysis. Nephrol Dial Transplant 2009; 24:1039-1047.

3. Paller MS, Hoidal JR, Ferris TF. Oxygen free radicals in ischemic acute renal failure in the rat. J Clin Invest 1984; 74:1156-1164.

4. Koyama I, Bulkley GB, Williams GM, Im MJ. The role of oxygen free radicals in mediating the reperfusion injury of cold-preserved ischemic kidneys. Transplantation 1985; 40:590-595.

5. Baker GL, Corry RJ, Autor AP. Oxygen free radical induced damage in kidneys subjected to warm ischemia and reperfusion. Protective effect of superoxide dismutase. Ann Surg 1985; 202:628-641.

6. Stafforini DM, Sheller JR, Blackwell TS, et al. Release of free F2-isoprostanes from esterified phospholipids is catalyzed by intracellular and plasma platelet-activating factor acetylhydrolases. J Biol Chem 2006; 281:4616-4623.

7. Morrow JD, Hill KE, Burk RF, Nammour TM, Badr KF, Roberts LJ, 2nd. A series of prostaglandin F2-like compounds are produced in vivo in humans by a non-cyclooxygenase, free radical-catalyzed mechanism. Proc Natl Acad Sci U S A 1990; 87:9383-9387.

8. Kadiiska MB, Gladen BC, Baird DD, et al. Biomarkers of oxidative stress study II: are oxidation products of lipids, proteins, and DNA markers of CCl4 poisoning? Free Radic Biol Med 2005; 38:698-710.

9. Takahashi K, Nammour TM, Fukunaga M, et al. Glomerular actions of a free radical-generated novel prostaglandin, 8-epi-prostaglandin F2 alpha, in the rat. Evidence for interaction with thromboxane A2 receptors. J Clin Invest 1992; 90:136-141.

10. Khasawneh FT, Huang JS, Mir F, Srinivasan S, Tiruppathi C, Le Breton GC. Characterization of isoprostane signaling: evidence for a unique coordination profile of 8-iso-PGF(2alpha) with the thromboxane $\mathrm{A}(2)$ receptor, and activation of a separate cAMP-dependent inhibitory pathway in human platelets. Biochem Pharmacol 2008; 75:2301-2315.

11. Krier JD, Rodriguez-Porcel M, Best PJ, Romero JC, Lerman A, Lerman LO. Vascular responses in vivo to 8-epi PGF(2alpha) in normal and hypercholesterolemic pigs. Am J Physiol Regul Integr Comp Physiol 2002; 283:R303-308.

12. Alejandro V, Scandling JD, Jr., Sibley RK, et al. Mechanisms of filtration failure during postischemic injury of the human kidney. A study of the reperfused renal allograft. J Clin Invest 1995; 95:820-831.

13. Audoly LP, Rocca B, Fabre JE, et al. Cardiovascular responses to the isoprostanes iPF(2alpha)III and $\mathrm{PPE}(2)-\mathrm{III}$ are mediated via the thromboxane $\mathrm{A}(2)$ receptor in vivo. Circulation 2000; 101:2833-2840.

14. Thomas DW, Mannon RB, Mannon PJ, et al. Coagulation defects and altered hemodynamic responses in mice lacking receptors for thromboxane A2. J Clin Invest 1998; 102:1994-2001.

15. Leemans JC, Stokman G, Claessen N, et al. Renal-associated TLR2 mediates ischemia/reperfusion injury in the kidney. J Clin Invest 2005; 115:2894-2903. 
16. Kelly KJ, Sandoval RM, Dunn KW, Molitoris BA, Dagher PC. A novel method to determine specificity and sensitivity of the TUNEL reaction in the quantitation of apoptosis. Am J Physiol Cell Physiol 2003; 284:C1309-1318.

17. Thurman JM. Triggers of inflammation after renal ischemia/reperfusion. Clin Immunol 2007; 123:7-13.

18. Kelly KJ, Williams WW, Jr., Colvin RB, et al. Intercellular adhesion molecule-1-deficient mice are protected against ischemic renal injury. J Clin Invest 1996; 97:1056-1063.

19. Daemen MA, van 't Veer C, Denecker G, et al. Inhibition of apoptosis induced by ischemiareperfusion prevents inflammation. J Clin Invest 1999; 104:541-549.

20. Kramer HJ, Mohaupt MG, Pinoli F, Backer A, Meyer-Lehnert H, Schlebusch H. Effects of thromboxane A2 receptor blockade on oliguric ischemic acute renal failure in conscious rats. J Am Soc Nephrol 1993; 4:50-57.

21. Cracowski JL, Stanke-Labesque F, Devillier P, et al. Human internal mammary artery contraction by isoprostaglandin $\mathrm{f}$ (2alpha) type-III [8-iso-prostaglandin F(2alpha)]. Eur J Pharmacol 2000; 397:161-168.

22. Gardan B, Cracowski JL, Sessa C, et al. Vasoconstrictor effects of iso-prostaglandin F2alpha type-III (8-iso-prostaglandin F2alpha) on human saphenous veins. J Cardiovasc Pharmacol 2000; 35:729-734.

23. Benndorf RA, Schwedhelm E, Gnann A, et al. Isoprostanes inhibit vascular endothelial growth factor-induced endothelial cell migration, tube formation, and cardiac vessel sprouting in vitro, as well as angiogenesis in vivo via activation of the thromboxane $\mathrm{A}(2)$ receptor: a potential link between oxidative stress and impaired angiogenesis. Circ Res 2008; 103:1037-1046.

24. Tang M, Cyrus T, Yao Y, Vocun L, Pratico D. Involvement of thromboxane receptor in the proatherogenic effect of isoprostane F2alpha-III: evidence from apolipoprotein E- and LDL receptor-deficient mice. Circulation 2005; 112:2867-2874.

25. Minuz P, Andrioli G, Degan M, et al. The F2-isoprostane 8-epiprostaglandin F2alpha increases platelet adhesion and reduces the antiadhesive and antiaggregatory effects of NO. Arterioscler Thromb Vasc Biol 1998; 18:1248-1256.

26. Iuliano L, Pratico D, Greco C, et al. Angioplasty increases coronary sinus F2-isoprostane formation: evidence for in vivo oxidative stress during PTCA. J Am Coll Cardiol 2001; 37:7680.

27. Abe T, Takeuchi K, Takahashi N, Tsutsumi E, Taniyama Y, Abe K. Rat kidney thromboxane receptor: molecular cloning, signal transduction, and intrarenal expression localization. J Clin Invest 1995; 96:657-664.

28. Mannon RB, Coffman TM, Mannon PJ. Distribution of binding sites for thromboxane A2 in the mouse kidney. Am J Physiol 1996; 271:F1131-1138.

29. Brown GP, Venuto RC. Thromboxane receptors in human kidney tissues. Prostaglandins Other Lipid Mediat 1999; 57:179-188.

30. Boffa JJ, Just A, Coffman TM, Arendshorst WJ. Thromboxane receptor mediates renal vasoconstriction and contributes to acute renal failure in endotoxemic mice. J Am Soc Nephrol 2004; 15:2358-2365.

31. Kawada N, Dennehy K, Solis G, et al. TP receptors regulate renal hemodynamics during angiotensin II slow pressor response. Am J Physiol Renal Physiol 2004; 287:F753-759.

32. Niki E. Lipid peroxidation: physiological levels and dual biological effects. Free Radic Biol Med 2009; 47:469-484.

33. Lelcuk S, Alexander F, Kobzik L, Valeri CR, Shepro D, Hechtman HB. Prostacyclin and thromboxane A2 moderate postischemic renal failure. Surgery 1985; 98:207-212. 
34. Nowak J, FitzGerald GA. Redirection of prostaglandin endoperoxide metabolism at the platelet-vascular interface in man. J Clin Invest 1989; 83:380-385.

35. Klausner JM, Paterson IS, Kobzik L, et al. Vasodilating prostaglandins attenuate ischemic renal injury only if thromboxane is inhibited. Ann Surg 1989; 209:219-224.

36. Narumiya S, FitzGerald GA. Genetic and pharmacological analysis of prostanoid receptor function. J Clin Invest 2001; 108:25-30. 
272 


\section{Chapter 14}

Kidney transplantation from donors after cardiac death - a general discussion and summary of the thesis 


\begin{abstract}
Kidney transplantation is the optimal therapy for patients with end-stage renal disease but its use is limited by the shortage of organ donors. Kidney donation after cardiac death (DCD) increases the number of kidney transplantations but remains underutilized due to concerns about warm ischemic injury and the resulting early graft dysfunction. Therefore, the current thesis intends to describe the long-term outcome and survival benefit of DCD kidney transplantation, to define clinically applicable methods to reduce the incidence of primary non-function of DCD kidneys, and to shed new light on the pathophysiology and treatment of ischemic acute renal injury after DCD kidney transplantation. Here, we summarize and interpret the main findings of the thesis and provide an outlook on opportunities for further expansion of the pool of organ donors and for translation of our basic understanding of ischemic acute kidney injury into clinically effective therapies. Major efforts should continue to be made to improve the quality of DCD kidneys and thereby expand the utilization of this large pool of donor kidneys to its full potential.
\end{abstract}

\title{
Published as
}

Hoogland PE, Snoeijs MG, van Heurn LW. DCD kidney transplantation: results and measures to improve outcome. Curr Opin Organ Transplant 2010; 15:177-182. 


\section{Introduction}

Kidney transplantation is the optimal therapy for patients with end-stage renal disease but its use is limited by the shortage of organ donors. ${ }^{1}$ Liberal use of kidneys from donors after cardiac death holds the potential to increase the number of organ donors by 2.5-4 times, which is sufficient to reduce or even eliminate the waiting lists for kidney transplantation..$^{2,3}$ In contrast to donation after brain death (DBD), however, organs from donors after cardiac death (DCD) inevitably sustain a period of warm ischemia from circulatory arrest until initiation of organ preservation. This causes ischemic acute kidney injury which results in an increased incidence of delayed graft function and primary nonfunction as compared to kidney transplantation from conventional brain-dead donors. ${ }^{4}$ These early complications associated with DCD kidney transplantation have led to a reluctance to use these kidneys for transplantation and have restricted the expansion of DCD kidney donation to its full potential.

Therefore, the current thesis intends firstly to describe the long-term outcome and survival benefit of DCD kidney transplantation, secondly to define clinically applicable methods to reduce the incidence of primary non-function of DCD kidneys, and thirdly to shed new light on the pathophysiology and treatment of ischemic acute renal injury after DCD kidney transplantation. Here, we summarize and interpret the main findings of the thesis and provide an outlook on opportunities for further expansion of the pool of organ donors and for translation of our basic understanding of ischemic acute kidney injury towards clinically effective therapies.

\section{Results of kidney transplantations from donors after cardiac death}

Previous comparisons of the results of DCD and DBD kidney transplantations have shown a higher incidence of delayed graft function and primary nonfunction in DCD kidneys, which has been attributed to the ischemic injury suffered before organ recovery. Interestingly, graft survival of DCD kidneys that overcome the early postoperative period seems to be similar to that of DBD kidneys up to 5 to 10 years after transplantation. ${ }^{4-10}$ However, the long-term results of DCD kidney transplantation and its effect on the life expectancy of wait-listed dialysis patients remained to be established. 
To address this issue, we studied the long-term outcome of kidneys that were transplanted within the Eurotransplant region after being recovered from DCD donors in our organ procurement area from 1981 until 2006 (Chapter 2). Throughout this 25-year period, organ recovery from donors after cardiac death expanded the supply of donor kidneys from our organ procurement area by $44 \%$. The clinical outcome of the resulting DCD kidney transplantations ( $\mathrm{N}=297)$ were compared to a control group of DBD kidney transplantations (N=594) that were matched for potential confounders. As expected, we observed an increased incidence of delayed graft function (72\% vs. $18 \%$ ) and primary non-function ( $23 \%$ vs. $4 \%$ ) in DCD as compared to DBD kidneys. The high incidence of primary non-function resulted in an increased rate of graft loss of DCD kidneys in the first year after transplantation. However, DCD kidneys that did not experience primary non-function functioned as long as DBD kidneys with a hazard ratio for death-censored graft loss of 1.05 (95\% CI: 0.73-1.51, $\mathrm{P}=0.79$ ). Moreover, despite the increased rate of early graft loss, recipients of DCD kidneys survived as long as patients who received kidneys from conventional DBD donors with a mortality hazard ratio of 1.16 (95\% CI: 0.87-1.54, $\mathrm{P}=0.32$ ). These findings indicate that the long-term outcome of viable DCD kidneys is equivalent to grafts recovered from brain-dead donors.

Kidney transplantation from donors after brain death has repeatedly been shown to confer a survival advantage to wait-listed dialysis patients. ${ }^{1,11-13}$ Since recipients of DBD and DCD kidneys have similar survival rates after transplantation, it seems reasonable to assume a survival benefit for DCD kidney transplantation. This assumption was tested in a cohort of patients with endstage renal disease who were listed for their first kidney transplantation on the Dutch waiting list between 1999 and 2004 ( N=2575, Chapter 3). Survival after kidney transplantation from various donor types was compared to conventional therapy using sequential stratification, an extension of Cox regression adapted for intention-to-treat analysis of time-dependent treatments. As expected, the mortality rate after standard criteria DBD kidney transplantation was substantially lower than with dialysis treatment (HR 0.51, 95\% CI: 0.32-0.81, $\mathrm{P}=0.004$ ). Subsequently, survival after DCD kidney transplantation was compared to dialysis treatment with the option of later receiving a standard criteria DBD kidney. We found that the mortality rate of patients who received a standard criteria DCD kidney transplantation was 56\% (95\% CI: 20-76\%, $\mathrm{P}=0.007$ ) lower than in patients who received conventional therapy. Kidney transplantation from extended criteria donors (DBD and DCD donors over 60 years or between 
Table 14.1 Survival benefit of DCD kidney transplantation and of selected medical therapies for cardiovascular disease and cancer at 4 years after start of treatment

\begin{tabular}{|c|c|c|}
\hline Patients & Treatment & $\begin{array}{l}\text { Survival } \\
\text { benefit }^{\mathrm{a}}\end{array}$ \\
\hline $\begin{array}{l}\text { Patients with end-stage renal disease } \\
\text { on the waiting list for kidney transplantation }\end{array}$ & $\begin{array}{l}\text { DCD kidney transplantation } v s . \\
\text { dialysis treatment with the option } \\
\text { of later receiving DBD kidney } \\
\text { transplantation }\end{array}$ & + 2.4 months \\
\hline $\begin{array}{l}\text { Patients who had curative-intent resections of } \\
\text { stage III colon cancer in the previous 1-5 weeks }{ }^{15}\end{array}$ & $\begin{array}{l}\text { Adjuvant chemotherapy with } \\
\text { fluorouracil and levamisole for } 1 \\
\text { year vs. observation only }\end{array}$ & +2.3 months \\
\hline $\begin{array}{l}\text { Patients with diabetes, aged } 55 \text { years or older, } \\
\text { who had a previous cardiovascular event or at } \\
\text { least one other cardiovascular risk factor and } \\
\text { who had no clinical proteinurea, heart failure } \\
\text { or low ejection fraction }{ }^{16}\end{array}$ & Ramipril $10 \mathrm{mg} /$ day vs. placebo & +0.8 months \\
\hline $\begin{array}{l}\text { Women with node-positive early breast cancer } \\
\text { with oestrogen receptor-positive tumours }{ }^{17}\end{array}$ & $\begin{array}{l}\text { Adjuvant tamoxifen for } 5 \text { years } \\
v s . \text { no tamoxifen until recurrence }\end{array}$ & + 0.5 months \\
\hline $\begin{array}{l}\text { Patients with angina pectoris or previous } \\
\text { myocardial infarction and serum cholesterol } \\
5.5-8.0 \mathrm{mmol} / \mathrm{L}^{18}\end{array}$ & $\begin{array}{l}\text { Simvastatin } 10-40 \mathrm{mg} / \text { day to reduce } \\
\text { serum cholesterol to } 3.0-5.2 \\
\mathrm{mmol} / \mathrm{L} \text { vs. placebo }\end{array}$ & +0.3 months \\
\hline
\end{tabular}

a Survival benefit was calculated as the difference between the areas under the Kaplan-Meier curves until 4 years after start of treatment in publications of randomized clinical trials or meta-analyses of randomized clinical trials using individual patient data. ${ }^{19}$

50 and 60 years with cardiovascular risk factors $)^{14}$ was not associated with a statistically significant survival benefit.

The reduced mortality rate after DCD kidney transplantation translated into an increased life expectancy of 2.4 months in the first four years after transplantation. To put the magnitude of this increase in life expectancy into perspective, we calculated the absolute survival benefit of various medical interventions using published reports of randomized clinical trials (Table 14.1). ${ }^{19}$ The size of the survival benefit associated with DCD kidney transplantation compares favorably with the number of life-years gained from 4 years of treatment with statins or ACE inhibitors in patients at high risk of cardiovascular events or with tamoxifen in women with node-positive early breast cancer.

Taken together, these findings show that standard criteria DCD kidney transplantation is associated with increased survival of wait-listed dialysis patients. Our studies did not take into account the quality of life after kidney 
transplantation, which is generally considered to be greater than during dialysis treatment. ${ }^{20-22}$ It remains to be established how the quality of life after kidney transplantation from various donor types with different risks of early and late graft loss compare and this should be addressed in future studies.

\section{Prevention of primary non-function in kidney transplantation from donors after cardiac death}

Even though DCD kidney transplantation confers a survival advantage to waitlisted dialysis patients, the relatively high percentage of never functioning grafts provides a strong incentive to improve the current practice of DCD kidney transplantation. The clinical presentation of primary non-function is heterogeneous and may be classified into graft loss due to absence of renal perfusion in the first days after transplantation, graft loss due to complications such as acute rejection that occur before recovery from delayed graft function, and graft loss due to chronic allograft nephropathy in kidneys with extensive pre-existing degenerative changes (Table 14.2). Primary non-function is a serious complication after transplantation and exposes the recipient to the risks of surgery and immunosuppression without delivering the benefits of dialysis independence. Moreover, although recipients of never functioning kidneys retain their waiting times according to Eurotransplant allocation policies, their opportunities for

Table 14.2 Classification of primary non-function after DCD kidney transplantation

\begin{tabular}{cccc}
\hline Classification & Timing & Potential cause & $\begin{array}{c}\text { Suggested } \\
\text { preventive strategies }\end{array}$ \\
\hline $\begin{array}{c}\text { Absence of renal } \\
\text { perfusion }\end{array}$ & $\begin{array}{c}\text { First days after } \\
\text { transplant }\end{array}$ & $\begin{array}{c}\text { Severe acute ischemic } \\
\text { injury to the renal } \\
\text { vasculature }\end{array}$ & $\begin{array}{c}\text { Assessment of acute ischemic injury } \\
\text { before transplantation and } \\
\text { optimization of organ preservation } \\
\text { and recipient hemodynamics }\end{array}$ \\
$\begin{array}{c}\text { Complications during } \\
\text { delayed graft function }\end{array}$ & $\begin{array}{c}\text { First weeks after } \\
\text { transplant }\end{array}$ & $\begin{array}{c}\text { Regular complications } \\
\text { such as acute rejection }\end{array}$ & $\begin{array}{c}\text { Careful monitoring of recipients } \\
\text { during delayed graft function, } \\
\text { including regular protocol biopsies }\end{array}$ \\
$\begin{array}{c}\text { Chronic allograft } \\
\text { nephropathy }\end{array}$ & $\begin{array}{c}\text { First months } \\
\text { after transplant }\end{array}$ & $\begin{array}{c}\text { Exacerbation of pre- } \\
\text { existing degenerative } \\
\text { changes in the periopera- } \\
\text { tive period }\end{array}$ & $\begin{array}{c}\text { Histological assessment of } \\
\text { pre-transplant biopsies in } \\
\text { kidneys from old donors }\end{array}$ \\
\hline
\end{tabular}


retransplantation may be limited by immunological sensitization to donor antigens. ${ }^{23}$ Strategies to reduce the incidence of primary non-function are therefore essential to achieve more widespread acceptance of DCD kidney transplantation. In the current thesis, we examined the transplantation process from donor management to recipient surgery in order to identify clinically applicable methods to prevent primary non-function. With the gradual implementation of our findings into clinical practice, the incidence of primary non-function of DCD kidneys transplanted in our unit decreased from 21\% in the period 1981-2005 (47 out of 229 transplants) to 5\% in the period 2006-2008 (4 out of 74 transplants).

\section{Donor management}

In our organ procurement area, in situ perfusion has been used to rapidly initiate organ preservation in donors after cardiac death. ${ }^{24}$ This minimally invasive surgical technique consists of the insertion of a double-balloon triple-lumen catheter through the femoral artery into the aorta. After inflation of both balloons, the abdominal aorta can be selectively perfused with hypothermic organ preservation solution, flushing and cooling the kidneys in situ until organ recovery. In a study of 133 consecutive in situ perfusions in our organ procurement area, we observed that the majority of potential DCD organ donors (58\%) did not result in kidney transplantation; complicated in situ perfusion was the most frequent cause for the failure to proceed to organ recovery (Chapter 4). For uncontrolled donation after unsuccessful cardiopulmonary resuscitation, in situ perfusion is an indispensable technique that provides the opportunity to meet legal and logistical requirements for organ recovery without excessive warm ischemia times. For controlled donation after cardiac death, however, these requirements can be met before scheduled withdrawal of supportive treatment. In this context, it is feasible to transport the donor to the operating room after circulatory arrest, where a surgical team is present to initiate organ preservation by rapid laparotomy and direct aortic cannulation. ${ }^{25}$ In our organ procurement area, this technique was used in a small number of controlled DCD donors to recover the liver as well as the kidneys. These donors had shorter warm ischemia times and lower rates of discard and primary non-function compared to controlled donors managed by in situ perfusion. These findings have recently been confirmed in an extension of our study that included controlled DCD donors from a neighbouring organ procurement area that routinely applied direct aortic cannulation. Taken together, we consider rapid laparotomy and direct aortic cannulation rather than in situ perfusion using double-balloon triple-lumen 
catheters to be the preferred method for initiation of organ preservation in controlled DCD donors.

\section{Assessment of chronic degenerative changes in kidneys from old donors}

After successful organ recovery from donors after cardiac death, assessment of pre-existent degenerative changes and acute ischemic injury in DCD kidneys at high risk of early graft loss may allow selection of grafts with satisfactory outcome. When accurate selection criteria are defined, DCD kidney transplantation can be safely expanded to include old donors or uncontrolled donors with prolonged warm ischemia. Without such selection, however, we found that the results of kidney transplantations from DCD donors older than 60 years $(\mathrm{N}=52)$ were inferior to those from younger DCD donors $(\mathrm{N}=147)$ transplanted at our unit between 1994 and 2006 (Chapter 5). In fact, with a median death-censored graft survival of approximately 5 years, we felt that the outcome of old DCD kidneys was unacceptable without refinements in graft selection. Among several published selection criteria for kidneys from old donors, we found that only histological assessment of degenerative changes in pre-transplant kidney biopsies was predictive of graft function and survival. In contrast, donor age, kidney function, kidney weight and perfusion parameters were not associated with early graft loss. In a subsequent study, we demonstrated that histological assessment of pre-transplant kidney biopsies was reproducible among pathologists and that evaluation of small needle biopsies gave a reasonably precise estimate of degenerative changes in the entire kidney (Chapter 6). These findings indicate that histological assessment of renal biopsies is a clinically useful tool to select kidneys from old donors with satisfactory outcome and suggest that this approach may be more appropriate than setting arbitrary age limits for kidney donation.

\section{Assessment of ischemic acute kidney injury}

Organ preservation by hypothermic machine perfusion results in superior transplant outcomes compared to static cold storage. ${ }^{26}$ In addition, machine perfusion may provide a useful platform to assess ischemic acute kidney injury. Perfusate flow rates and vascular resistance are indicative of perfusion quality and may reflect ischemic injury suffered before organ procurement. ${ }^{27,28}$ Moreover, cytoplasmic proteins that leak from damaged tubular epithelial cells such as lactate dehydrogenase, glutathione-S-transferase or fatty-acid binding protein can be measured in the perfusion solution as biomarkers of cellular injury. ${ }^{29-31}$ Unfortunately, these 'viability tests' have insufficient diagnostic accuracy to be clinically useful in deciding whether to transplant or discard DCD kidneys that have 
suffered prolonged warm ischemia. ${ }^{32-34}$ We have recently found that the concentration of redox-active iron in the preservation solution increased during machine perfusion. ${ }^{35}$ Redox-active iron seems to reflect warm ischemic injury since its concentrations were greater in DCD compared to DBD grafts and in primarily non-functioning compared to viable kidneys. However, the bleomycin detectable iron assay that we used to measure redox-active iron can not be applied within a clinically relevant time frame. Therefore, we explored the proteome of the perfusion solution in an unbiased fashion using difference gel electrophoresis in order to identify novel biomarkers of ischemic acute kidney injury (Chapter 7). We found two proteins with significantly different concentrations in the perfusate of ischemically injured kidneys from uncontrolled DCD donors compared to samples from DBD kidneys without warm ischemic injury. Future studies should determine the identity of these biomarkers and their diagnostic value for the selection of DCD kidneys with prolonged ischemia times that have a low risk of early graft failure are therefore suitable for transplantation.

\section{Recipient management}

When recovered DCD kidneys are considered to be of sufficient quality for transplantation, recipient surgery should follow as soon as possible to minimize cold ischemia time and thereby prolong graft survival. ${ }^{36}$ During transplant surgery, optimization of recipient hemodynamics and establishment of adequate renal blood flow after reperfusion contribute importantly to early graft function of DBD kidneys. ${ }^{37-40}$ In a cohort of DCD kidney transplantations at our unit from 1994 to 2006, we found that low systolic arterial and central venous pressure during surgery were associated with increased risk of primary non-function (odds ratios of 2.6, $\mathrm{P}=0.03$ and $3.1, \mathrm{P}=0.007$, respectively; Chapter 8 ). This increased risk was independent of donor factors and was also observed in a paired comparison of patients receiving kidneys from the same organ donors. These findings indicate that careful optimization of the hemodynamic status of transplant recipients by intravascular volume expansion and judicious use of vasoactive drugs may provide the opportunity to prevent primary non-function of DCD kidneys. The effects of volume expansion on cardiac output can be accurately predicted by analysis of pulse pressure variation during mechanical ventilation. ${ }^{41}$ It would therefore be of interest to study whether this technique may improve hemodynamic management and early graft function in kidney transplant recipients. Furthermore, the study shows that primary non-function of DCD kidneys is not exclusively determined by donor factors but that recipient factors also contribute to this complication. We therefore suggest that DCD kidneys with exten- 
sive ischemic injury should not be transplanted into marginal recipients with severely reduced cardiac output. Finally, the importance of recipient factors indicates that it is unrealistic to expect viability testing before transplantation to entirely eliminate primary non-function.

\section{Pathophysiology and treatment of ischemic acute kidney injury after renal transplantation}

Kidney transplantation from donors after cardiac death is currently limited to grafts that have suffered relatively short periods of warm ischemia. Modulation of ischemic acute kidney injury holds the potential to reduce the incidence of early graft dysfunction and to allow expansion of the donor pool with kidneys that have suffered prolonged ischemic injury. In the current thesis, we studied the pathophysiological mechanisms underlying ischemic acute kidney injury in human kidney transplantation and we evaluated novel therapies for ischemic acute kidney injury in a clinically relevant large animal model with the eventual goal to improve early graft function in DCD kidney transplantation.

\section{Ischemic acute renal injury after human kidney transplantation}

To study the effects of renal ischemia and reperfusion on kidney transplantation, we compared two groups of donor kidneys with a different extent of ischemic injury but with similar baseline characteristics: (1) DCD kidneys that suffered extensive ischemic injury from circulatory arrest until organ preservation $(\mathrm{N}=8)$, and (2) living donor kidneys that suffered minimal warm and cold ischemic injury $(\mathrm{N}=8)$. Although all grafts eventually provided life-sustaining renal function, creatinine clearance and sodium reabsorption of DCD kidneys was greatly reduced as compared to living donor kidneys in the early postoperative period. To study the pathophysiology of ischemia and reperfusion injury after human kidney transplantation, we compared the function of the renal microvasculature as well as the extent of tubular injury and inflammation between these two groups of donor kidneys.

Adequate reperfusion is essential for functional recovery of donor kidneys by preventing ongoing tissue injury after revascularization. ${ }^{42}$ By direct visualization of the cortical peritubular capillary network during transplant surgery, we found that renal microvascular perfusion was $42 \%$ lower in DCD kidneys compared to living donor kidneys in the early reperfusion period, which 
was accounted for by smaller capillary diameters in DCD kidneys (Chapter 9). The vascular endothelium is covered by a dynamic network of proteoglycans and glycoproteins referred to as the glycocalyx. ${ }^{43}$ We found that the endothelial glycocalyx was rapidly degraded after transplantation of ischemically injured kidneys, as evidenced by smaller red blood cell exclusion zones in images of the peritubular capillary network and by greater renal wash-out of glycocalyx constituents in DCD compared to living donor kidneys. Since the glycocalyx determines vascular permeability and transduces shear stress to the endothelium, ${ }^{44-47}$ loss of glycocalyx integrity in DCD kidneys may cause capillary compression by interstitial edema and impaired flow-induced vasodilation. This may explain the smaller capillary diameters observed in DCD compared to living donor kidneys. Our findings suggest that microvascular dysfunction in ischemically injured kidneys may exacerbate renal damage as a result of inadequate reperfusion, thereby contributing to early graft dysfunction of DCD kidneys.

In rodent models, renal ischemia and reperfusion results in tubular epithelial injury, activating innate immunity to mount an excessive inflammatory response that intensifies ischemic acute kidney injury. ${ }^{48}$ In human kidney transplantation, we found that DCD kidneys were characterized by a 12 to 18 fold increase in necrotic, but not apoptotic, tubular epithelial cell death in comparison to living donor kidneys (Chapter 10). Cell death was not associated with oxidative damage at reperfusion of the donor kidney, since renal $\mathrm{F}_{2}$-isoprostanes production - the gold standard biomarker for oxidative stress ${ }^{49}$ - was not observed. Nevertheless, DCD kidneys consumed more vitamin E at reperfusion. This suggests that more reactive oxygen species were being generated after prolonged renal ischemia but that natural anti-oxidant defences were sufficient to prevent oxidative damage in DCD kidney transplantation. Spillage of intracellular contents of necrotic cells and breakdown of extracellular matrices such as the endothelial glycocalyx cause the release of damage-associated molecular patterns (DAMPs) that activate pattern-recognition receptors to induce inflammation. In line with this concept, systemic inflammation in the postoperative period was significantly increased in recipients of DCD kidneys as compared to patients who received kidneys from living donors.

Taken together, ischemically injured DCD kidneys with profoundly reduced early graft function were characterized by microvascular dysfunction, tubular epithelial cell death and systemic inflammation in the early postoperative period. We propose that these phenomena propagate one another, culminating in a vicious circle of ever more severe acute kidney injury until inflammation resolves and renal repair starts to restore homeostasis, or until the kidney fails 


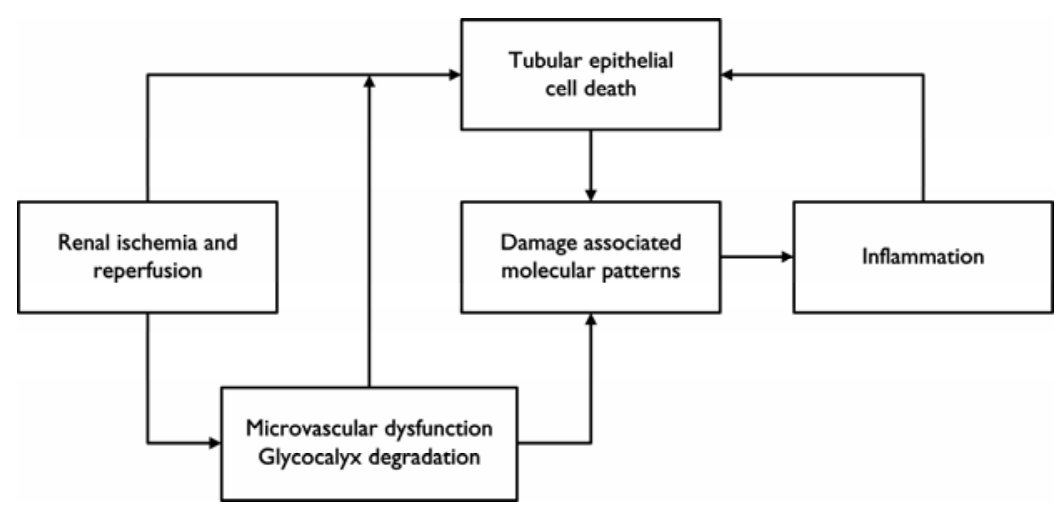

Figure 14.1 Generalized model of the pathophysiology of ischemic acute renal injury in human kidney transplantation.

permanently (Figure 14.1). Since dysfunction of the peritubular capillary network is a proximal factor in this process, interventions aimed at improving microvascular integrity and perfusion may hold particular promise for the treatment of ischemic acute renal injury after kidney transplantation. These findings may apply more generally to other conditions associated with ischemic acute kidney injury such as cardiovascular surgery and hypovolemic shock.

\section{Novel therapies for ischemic acute kidney injury in animal models}

Increased understanding of the pathophysiology of ischemic acute kidney injury in human kidney transplantation may lead to the identification of novel therapeutic targets and interventions. These interventions should be evaluated in representative animal models of kidney transplantation before clinical trials are to be initiated. In this regard, pigs are particularly suitable since their renal anatomy and physiology are highly comparable to those of men..$^{50}$ Autologous kidney transplantation avoids graft rejection and therefore allows the isolated study of ischemic acute kidney injury. In the current thesis, we performed autologous transplantations of ischemically injured kidneys in pigs to evaluate new interventions for acute ischemic injury in kidney transplantation. In this animal model, transplantation of kidneys that had been exposed to different periods of warm ischemia followed by 22 hours of hypothermic machine perfusion resulted in renal dysfunction that was proportional to the duration of warm ischemia (Chapter 11). Exposure to 45 minutes of warm ischemia caused severe but recoverable renal dysfunction similar to that typically observed in human DCD kidney transplantation. 
Generation of reactive oxygen species at reperfusion and during cold ischemia is generally considered to be an important contributor to ischemic acute kidney injury and causes renal vasoconstriction and tubular epithelial cell death. ${ }^{51-53}$ Therefore, we tested whether simple monophenolic anti-oxidants protect porcine tubular epithelial cells from hypothermic injury and we found that several compounds were highly effective (Chapter 12). The monophenolic anti-oxidant propofol could be dissolved in water at high concentrations by inclusion into cyclodextrins. This allowed us to add propofol to organ preservation solutions and to load ischemically injured porcine kidneys with this anti-oxidant during hypothermic machine perfusion. This prevented lipid peroxidation and attenuated the increase in renovascular resistance in the early reperfusion period. The effective protection against reactive oxygen species resulted in a modest improvement of early graft function with a trend towards statistical significance when compared to control pigs ( $\mathrm{N}=6$ per group, $\mathrm{P}=0.10$ ). Since the pathophysiology of ischemic acute kidney injury is highly complex, effective treatment of this condition is likely to require a combination of interventions targeting multiple pathways (e.g. oxidative stress, tissue perfusion, cell death, inflammation, repair). Our results indicate that propofol is a promising candidate for inclusion in such a combination of renoprotective agents.

In the porcine autotransplantation experiments, prevention of lipid peroxidation by propofol was associated with an attenuated increase of renovascular resistance in the early reperfusion period. Since we had previously found that ischemically injured human DCD kidneys were characterized by a similar impairment of microvascular perfusion, we performed additional studies to elucidate the molecular mechanism by which oxidative stress may induce renal vasoconstriction. Oxidative modification of arachidonic acid in cell membranes leads to formation of stable $\mathrm{F}_{2}$-isoprostanes that are cleaved and released into the plasma and then possess biological activity by signaling through the thromboxane $\mathrm{A}_{2}$ receptor. ${ }^{54,55}$ Indeed, administration of $\mathrm{F}_{2}$-isoprostanes to rats and pigs causes dose-dependent reductions in renal blood flow and glomerular filtration rate due to vasoconstriction of afferent glomerular arterioles. ${ }^{56,57}$ The effects of locally produced $\mathrm{F}_{2}$-isoprostanes may therefore contribute to the reduction of glomerular filtration rate observed in ischemic acute kidney injury. However, although $\mathrm{F}_{2}$-isoprostanes were readily dectected in urine collections after surgery, we found that mice with genetic disruption of the thromboxane $\mathrm{A}_{2}$ receptor - which eliminates $\mathrm{F}_{2}$-isoprostanes signaling - were not protected from ischemic acute kidney injury when compared to wild-type mice with the same genetic background (Chapter 13). This finding indicates that $\mathrm{F}_{2}$-isoprostanes 
signaling does not contribute critically to the pathogenesis of ischemic acute kidney injury and that the protective effects of anti-oxidants therefore can not be attributed to reduced $\mathrm{F}_{2}$-isoprostanes signalling. The association between oxidative stress and renal vasoconstriction may alternatively be explained by scavenging of the vasodilator nitric oxide by locally produced reactive oxygen species. ${ }^{53}$

\section{Potential for further expansion of the organ donor pool}

Despite the progress in kidney transplantation from donors after cardiac death and the expanded use of kidneys from old donors after brain death and living donors, the waiting time for transplant candidates of approximately 4 years in The Netherlands has not decreased over the past decade. Therefore, continuing efforts to further expand the donor pool are necessary to improve the treatment of patients with end-stage renal disease.

\section{Expansion of the pool of deceased organ donors}

Considering the decline of kidney function with advancing age, kidney donation in The Netherlands is currently restricted to donors under 75 years for donation after brain death and donors under 65 years for controlled donation after cardiac death. Considerable variation exists between old individuals with regards to the decline in creatinine clearance and the extent of glomerulosclerosis in renal biopsies. ${ }^{58,59}$ Therefore, the pool of deceased organ donors may be expanded by elimination of arbitrary age limits and by instead focusing on careful assessment of renal function and structure in old donors. Kidneys from old donors with moderate degenerative changes that are not considered suitable for conventional transplantation may still be used as dual transplants in order to provide recipients with sufficient nephron mass (Figure 14.2). ${ }^{60}$

In uncontrolled donation after cardiac death, kidneys suffer extensive ischemic injury from cardiopulmonary resuscitation until organ preservation by in situ perfusion. The impact of ischemic acute kidney injury may be exacerbated by pre-existing degenerative changes, similar to the increased sensitivity of kidneys from old donors to delayed graft function and acute rejection. ${ }^{61}$ Therefore, we do not advocate recovery of kidneys from uncontrolled DCD donors over 65 years. The pool of uncontrolled DCD donors can be expanded, however, by the inclusion of patients in whom attempts at cardiopulmonary resuscitation have been abandoned outside the hospital. ${ }^{6}$ In a review of 735 ambulance rides for cardiopulmonary resuscitation in our organ procurement area in 2006, we 


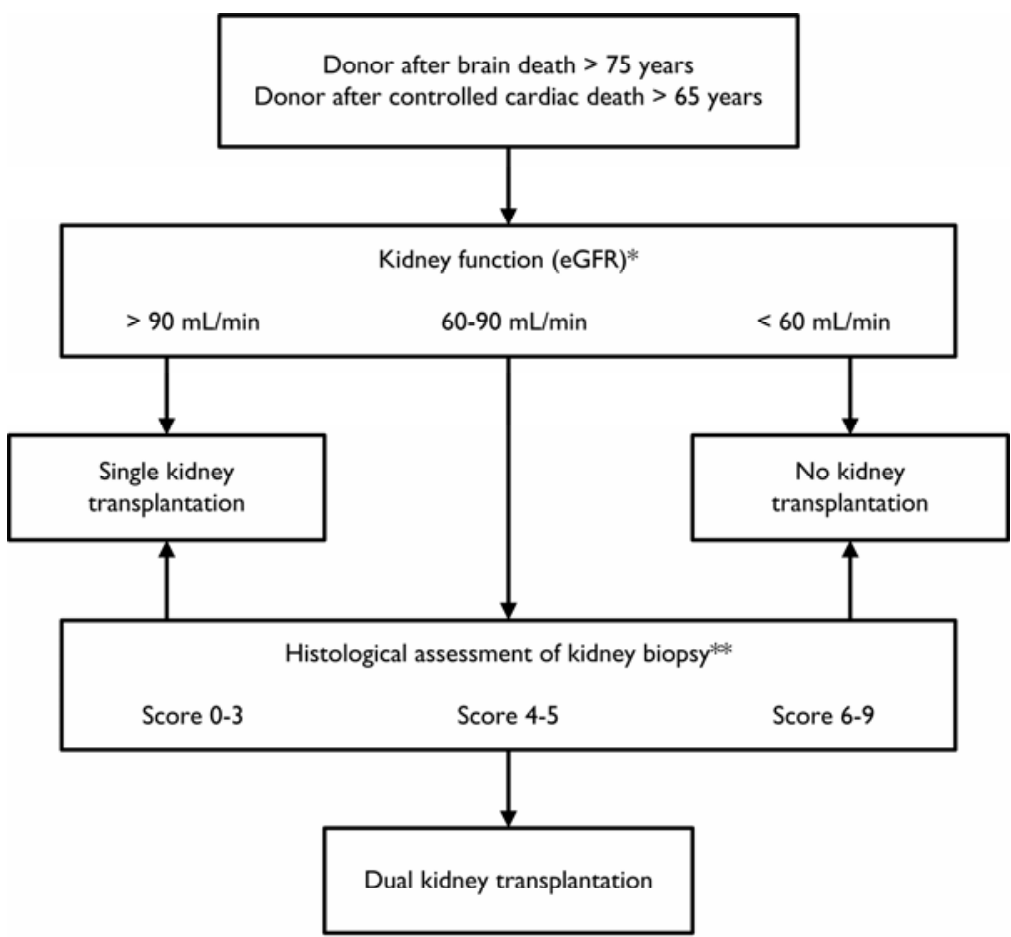

* Glomerular filtration rate is estimated by the Cockgroft-Gault formula. Kidney biopsies are always assessed in patients with proteinurea $(>0.3 \mathrm{~g} / \mathrm{L}$ or dipstick $\geq 1+)$.

(glomerulosclerosis $0-3$, vascular narrowing $0-3$, and interstitial fibrosis / tubular atrophy 0-3).

Figure 14.2 Flow chart for the selection of kidneys from old DBD and controlled DCD donors based on renal function and structure.

identified 34 potential organ donors (age under 55 years, resuscitation time under 45 minutes) who had not been transported to the emergency department. Transfer of these patients to the hospital using an automated chest compression device could have a substantial impact on the number of kidneys available for transplantation. These proposals are currently being implemented in our organ procurement area.

Expansion of the number of deceased organ donors is of paramount importance to improve the treatment of wait-listed dialysis patients. However, other factors such as the number of patients progressing to end-stage renal disease, the availability of living kidney donors, the consent rate for deceased 
organ donation and the way deceased donor kidneys are allocated also hold opportunities to reduce the waiting times for kidney transplantation.

\section{Pushing the limits of ischemic acute kidney injury}

Expansion of uncontrolled donation after cardiac death is restricted by the limited capacity of the kidney to recover from extensive ischemia-reperfusion injury. Given the complexity of the pathophysiology of ischemic acute kidney injury, it is unlikely that any single intervention will entirely prevent early graft dysfunction after kidney transplantation. Nevertheless, laboratories around the world have identified hundreds of therapeutic targets that attenuate acute kidney injury in rodent models and only a handful of these targets have been evaluated in clinical kidney transplantation using adequately powered randomized trials. Comprehensive efforts should therefore be initiated to translate the promising findings obtained in small animal models into a combination of clinical interventions that attenuate ischemic acute renal injury in kidney transplant recipients, with the ultimate aim to expand the pool of donor kidneys for patients with endstage renal disease.

The current paradigm in kidney transplantation is to rapidly transfer organs from donors to recipients while minimizing metabolic activity by hypothermic storage. For deceased donor kidneys with extensive ischemic injury, reperfusion with blood containing leukocytes and complement components in patients with end-stage renal disease may exacerbate reperfusion injury and limit renal regeneration. Furthermore, recognition of donor antigens in the context of tissue injury may direct the recipient's immune system towards allograft rejection. ${ }^{62}$ A different perspective on kidney transplantation is to reperfuse donor kidneys ex vivo using normothermic machine perfusion. This may create an optimal environment for repair of damaged tissue and in addition allows for accurate assessment of renal function before transplantation. In a canine model of autologous renal transplantation, kidneys with 2 hours of warm ischemia functioned immediately after 18 hours of $e x$ vivo recovery with a highly enriched cell culture medium, whereas control kidneys that were transplanted immediately or after hypothermic machine preservation did not provide lifesustaining function. ${ }^{63}$ More recently, we have demonstrated in a porcine model of autologous kidney transplantation that normothermic perfusion with donor blood using clinically approved cardiopulmonary bypass equipment is safe and may be used for local delivery of therapeutics before transplantation. Ultimately, donor kidneys recovered several hours after cardiac arrest may be repaired using tissue engineering techniques. The feasibility of this approach has been demon- 
strated in deceased rat hearts that had been reseeded with neonatal cardiac cells and could generate pump function under physiological load and electrical stimulation. ${ }^{64}$ Recent findings suggest that this technique may also apply to the more complex architecture of the kidney ${ }^{65}$ Clinical application of these recent advances in tissue engineering would revolutionize renal replacement therapy.

\section{Conclusion}

In the current thesis, we show that the liberal use of organs from donors after cardiac death greatly increases the number of available donor kidneys. The resulting kidney transplantations are characterized by an increased incidence of primary non-function and delayed graft function. Nevertheless, viable grafts that do not experience primary non-function survive as long as conventional kidneys from donors after brain death and wait-listed dialysis patients experience a survival benefit from DCD kidney transplantation. The risk of primary nonfunction with DCD kidneys can be reduced by organ preservation using rapid laparotomy and direct aortic cannulation for controlled DCD donors, by selection of old DCD kidneys using histological assessment of pre-implantation biopsies and by careful optimization of the hemodynamic status of recipients during transplant surgery. With regards to the pathophysiological mechanisms of delayed graft function, ischemically injured DCD kidneys are characterized by microvascular dysfunction, tubular epithelial cell death and systemic inflammation in the early postoperative period. Treatment of ischemic acute kidney injury is likely to require a combination of interventions targeting these pathophysiological pathways. In a clinically relevant large animal model, the anti-oxidant propofol improves outcomes after kidney transplantation and therefore is a promising candidate for inclusion in such a cocktail of renoprotective agents. Major efforts should continue to be made to improve the quality of DCD kidneys and thereby expand the utilization of this large pool of donor kidneys to its full potential. 


\section{References}

1. Wolfe RA, Ashby VB, Milford EL, et al. Comparison of mortality in all patients on dialysis, patients on dialysis awaiting transplantation, and recipients of a first cadaveric transplant. $\mathrm{N}$ Engl J Med 1999; 341:1725-1730.

2. Terasaki PI, Cho YW, Cecka JM. Strategy for eliminating the kidney shortage. Clin Transpl 1997:265-267.

3. Daemen JW, Oomen AP, Kelders WP, Kootstra G. The potential pool of non-heart-beating kidney donors. Clin Transplant 1997; 11:149-154.

4. Wijnen RM, Booster MH, Stubenitsky BM, de Boer J, Heineman E, Kootstra G. Outcome of transplantation of non-heart-beating donor kidneys. Lancet 1995; 345:1067-1070.

5. Nicholson ML, Metcalfe MS, White SA, et al. A comparison of the results of renal transplantation from non-heart-beating, conventional cadaveric, and living donors. Kidney Int 2000; 58:2585-2591.

6. Sanchez-Fructuoso AI, Marques M, Prats D, et al. Victims of cardiac arrest occurring outside the hospital: a source of transplantable kidneys. Ann Intern Med 2006; 145:157-164.

7. Weber M, Dindo D, Demartines N, Ambuhl PM, Clavien PA. Kidney transplantation from donors without a heartbeat. N Engl J Med 2002; 347:248-255.

8. Cho YW, Terasaki PI, Cecka JM, Gjertson DW. Transplantation of kidneys from donors whose hearts have stopped beating. N Engl J Med 1998; 338:221-225.

9. Cooper JT, Chin LT, Krieger NR, et al. Donation after cardiac death: the university of wisconsin experience with renal transplantation. Am J Transplant 2004; 4:1490-1494.

10. Gok MA, Buckley PE, Shenton BK, et al. Long-term renal function in kidneys from non-heartbeating donors: A single-center experience. Transplantation 2002; 74:664-669.

11. McDonald SP, Russ GR. Survival of recipients of cadaveric kidney transplants compared with those receiving dialysis treatment in Australia and New Zealand, 1991-2001. Nephrol Dial Transplant 2002; 17:2212-2219.

12. Rabbat CG, Thorpe KE, Russell JD, Churchill DN. Comparison of mortality risk for dialysis patients and cadaveric first renal transplant recipients in Ontario, Canada. J Am Soc Nephrol 2000; 11:917-922.

13. Oniscu GC, Brown H, Forsythe JL. Impact of cadaveric renal transplantation on survival in patients listed for transplantation. J Am Soc Nephrol 2005; 16:1859-1865.

14. Port FK, Bragg-Gresham JL, Metzger RA, et al. Donor characteristics associated with reduced graft survival: an approach to expanding the pool of kidney donors. Transplantation 2002; 74:1281-1286.

15. Moertel CG, Fleming TR, Macdonald JS, et al. Fluorouracil plus levamisole as effective adjuvant therapy after resection of stage III colon carcinoma: a final report. Ann Intern Med 1995; 122:321-326.

16. Effects of ramipril on cardiovascular and microvascular outcomes in people with diabetes mellitus: results of the HOPE study and MICRO-HOPE substudy. Heart Outcomes Prevention Evaluation Study Investigators. Lancet 2000; 355:253-259.

17. Tamoxifen for early breast cancer: an overview of the randomised trials. Early Breast Cancer Trialists' Collaborative Group. Lancet 1998; 351:1451-1467. 
18. Randomised trial of cholesterol lowering in 4444 patients with coronary heart disease: the Scandinavian Simvastatin Survival Study (4S). Lancet 1994; 344:1383-1389.

19. Salukhe TV, Dimopoulos K, Sutton R, Coats AJ, Piepoli M, Francis DP. Life-years gained from defibrillator implantation: markedly nonlinear increase during 3 years of follow-up and its implications. Circulation 2004; 109:1848-1853.

20. Evans RW, Manninen DL, Garrison LP, Jr., et al. The quality of life of patients with end-stage renal disease. N Engl J Med 1985; 312:553-559.

21. Laupacis A, Keown P, Pus N, et al. A study of the quality of life and cost-utility of renal transplantation. Kidney Int 1996; 50:235-242.

22. Liem YS, Bosch JL, Arends LR, Heijenbrok-Kal MH, Hunink MG. Quality of life assessed with the Medical Outcomes Study Short Form 36-Item Health Survey of patients on renal replacement therapy: a systematic review and meta-analysis. Value Health 2007; 10:390-397.

23. Billen EV, Christiaans MH, Lee J, van den Berg-Loonen EM. Donor-directed HLA antibodies before and after transplantectomy detected by the luminex single antigen assay. Transplantation 2009; 87:563-569.

24. Booster MH, Wijnen RM, Vroemen JP, van Hooff JP, Kootstra G. In situ preservation of kidneys from non-heart-beating donors--a proposal for a standardized protocol. Transplantation 1993; 56:613-617.

25. Casavilla A, Ramirez C, Shapiro R, et al. Experience with liver and kidney allografts from nonheart-beating donors. Transplantation 1995; 59:197-203.

26. Moers C, Smits JM, Maathuis MH, et al. Machine perfusion or cold storage in deceased-donor kidney transplantation. N Engl J Med 2009; 360:7-19.

27. Tesi RJ, Elkhammas EA, Davies EA, Henry ML, Ferguson RM. Pulsatile kidney perfusion for evaluation of high-risk kidney donors safely expands the donor pool. Clin Transplant 1994; 8:134-138.

28. Matsuno N, Konno O, Mejit A, et al. Application of machine perfusion preservation as a viability test for marginal kidney graft. Transplantation 2006; 82:1425-1428.

29. Baxby K, Taylor RM, Anderson M, Johnson RW, Swinney J. Assessment of cadaveric kidneys for transplantation. Lancet 1974; 2:977-979.

30. Daemen JW, Oomen AP, Janssen MA, et al. Glutathione S-transferase as predictor of functional outcome in transplantation of machine-preserved non-heart-beating donor kidneys. Transplantation 1997; 63:89-93.

31. Gok MA, Pelsers M, Glatz JF, et al. Comparison of perfusate activities of glutathione Stransferase, alanine aminopeptidase and fatty acid binding protein in the assessment of nonheart-beating donor kidneys. Ann Clin Biochem 2003; 40:252-258.

32. Sonnenday CJ, Cooper M, Kraus E, Gage F, Handley C, Montgomery RA. The hazards of basing acceptance of cadaveric renal allografts on pulsatile perfusion parameters alone. Transplantation 2003; 75:2029-2033.

33. Moers C, Varnav OC, Treckmann J, et al. GST and HFABP during machine perfusion of deceased donor kidneys are independent predictors of delayed graft function but not of primary non-function and graft survival. Transpl Int 2009; 22:42.

34. Pirenne J, Smits J, Monbaliu D, et al. Renal resistance during machine perfusion is a risk factor for delayed graft function and poorer graft survival. Transpl Int 2009; 22:56.

35. de Vries B, Snoeijs MG, von Bonsdorff L, Ernest van Heurn LW, Parkkinen J, Buurman WA. Redox-active iron released during machine perfusion predicts viability of ischemically injured deceased donor kidneys. Am J Transplant 2006; 6:2686-2693. 
36. Opelz G, Dohler B. Multicenter analysis of kidney preservation. Transplantation 2007; 83:247253.

37. Luciani J, Frantz $\mathrm{P}$, Thibault $\mathrm{P}$, et al. Early anuria prevention in human kidney transplantation. Advantage of fluid load under pulmonary arterial pressure monitoring during surgical period. Transplantation 1979; 28:308-312.

38. Carlier M, Squifflet JP, Pirson Y, Decocq L, Gribomont B, Alexandre GP. Confirmation of the crucial role of the recipient's maximal hydration on early diuresis of the human cadaver renal allograft. Transplantation 1983; 36:455-456.

39. Dawidson IJ, Sandor ZF, Coorpender L, et al. Intraoperative albumin administration affects the outcome of cadaver renal transplantation. Transplantation 1992; 53:774-782.

40. Lundell A, Persson NH, Kallen R, Ekberg H. Impaired renal artery blood flow at transplantation is correlated to delayed onset of graft function. Transpl Int 1996; 9:57-61.

41. Marik PE, Cavallazzi R, Vasu T, Hirani A. Dynamic changes in arterial waveform derived variables and fluid responsiveness in mechanically ventilated patients: a systematic review of the literature. Crit Care Med 2009; 37:2642-2647.

42. Brodsky SV, Yamamoto T, Tada T, et al. Endothelial dysfunction in ischemic acute renal failure: rescue by transplanted endothelial cells. Am J Physiol Renal Physiol 2002; 282:F11401149.

43. Reitsma S, Slaaf DW, Vink H, van Zandvoort MA, oude Egbrink MG. The endothelial glycocalyx: composition, functions, and visualization. Pflugers Arch 2007; 454:345-359.

44. Vink H, Duling BR. Capillary endothelial surface layer selectively reduces plasma solute distribution volume. Am J Physiol Heart Circ Physiol 2000; 278:H285-289.

45. van den Berg BM, Vink H, Spaan JA. The endothelial glycocalyx protects against myocardial edema. Circ Res 2003; 92:592-594.

46. VanTeeffelen JW, Brands J, Jansen C, Spaan JA, Vink H. Heparin impairs glycocalyx barrier properties and attenuates shear dependent vasodilation in mice. Hypertension 2007; 50:261267.

47. Kumagai R, Lu X, Kassab GS. Role of glycocalyx in flow-induced production of nitric oxide and reactive oxygen species. Free Radic Biol Med 2009; 47:600-607.

48. Bonventre JV, Zuk A. Ischemic acute renal failure: an inflammatory disease? Kidney Int 2004; 66:480-485.

49. Kadiiska MB, Gladen BC, Baird DD, et al. Biomarkers of oxidative stress study II: are oxidation products of lipids, proteins, and DNA markers of CCl4 poisoning? Free Radic Biol Med 2005; 38:698-710.

50. Sachs DH. The pig as a potential xenograft donor. Vet Immunol Immunopathol 1994; 43:185191.

51. Salahudeen AK. Cold ischemic injury of transplanted kidneys: new insights from experimental studies. Am J Physiol Renal Physiol 2004; 287:F181-187.

52. Paller MS, Hoidal JR, Ferris TF. Oxygen free radicals in ischemic acute renal failure in the rat. J Clin Invest 1984; 74:1156-1164.

53. Schnackenberg CG. Physiological and pathophysiological roles of oxygen radicals in the renal microvasculature. Am J Physiol Regul Integr Comp Physiol 2002; 282:R335-342.

54. Morrow JD, Hill KE, Burk RF, Nammour TM, Badr KF, Roberts LJ, 2nd. A series of prostaglandin F2-like compounds are produced in vivo in humans by a non-cyclooxygenase, free radical-catalyzed mechanism. Proc Natl Acad Sci U S A 1990; 87:9383-9387. 
55. Audoly LP, Rocca B, Fabre JE, et al. Cardiovascular responses to the isoprostanes iPF(2alpha)III and $\mathrm{PPE}(2)-\mathrm{III}$ are mediated via the thromboxane $\mathrm{A}(2)$ receptor in vivo. Circulation 2000; 101:2833-2840.

56. Takahashi K, Nammour TM, Fukunaga M, et al. Glomerular actions of a free radical-generated novel prostaglandin, 8-epi-prostaglandin F2 alpha, in the rat. Evidence for interaction with thromboxane A2 receptors. J Clin Invest 1992; 90:136-141.

57. Krier JD, Rodriguez-Porcel M, Best PJ, Romero JC, Lerman A, Lerman LO. Vascular responses in vivo to 8-epi PGF(2alpha) in normal and hypercholesterolemic pigs. Am J Physiol Regul Integr Comp Physiol 2002; 283:R303-308.

58. Lindeman RD, Tobin J, Shock NW. Longitudinal studies on the rate of decline in renal function with age. J Am Geriatr Soc 1985; 33:278-285.

59. Kaplan C, Pasternack B, Shah H, Gallo G. Age-related incidence of sclerotic glomeruli in human kidneys. Am J Pathol 1975; 80:227-234.

60. Remuzzi G, Cravedi P, Perna A, et al. Long-term outcome of renal transplantation from older donors. N Engl J Med 2006; 354:343-352.

61. de Fijter JW, Mallat MJ, Doxiadis, II, et al. Increased immunogenicity and cause of graft loss of old donor kidneys. J Am Soc Nephrol 2001; 12:1538-1546.

62. Matzinger P. The danger model: a renewed sense of self. Science 2002; 296:301-305.

63. Brasile L, Stubenitsky BM, Booster MH, et al. Overcoming severe renal ischemia: the role of ex vivo warm perfusion. Transplantation 2002; 73:897-901.

64. Ott HC, Matthiesen TS, Goh SK, et al. Perfusion-decellularized matrix: using nature's platform to engineer a bioartificial heart. Nat Med 2008; 14:213-221.

65. Ross EA, Williams MJ, Hamazaki T, et al. Embryonic stem cells proliferate and differentiate when seeded into kidney scaffolds. J Am Soc Nephrol 2009; 20:2338-2347. 
294 


\section{Samenvatting}

Niertransplantatie van donoren na

hartstilstand - een samenvatting van het proefschrift 


\section{Samenvatting}

Niertransplantatie is de beste behandeling voor patiënten met terminale nierinsufficiëntie maar door het tekort aan donornieren blijven veel mensen verstoken van optimale zorg. Orgaandonatie na hartstilstand kan het aantal beschikbare donornieren sterk uitbreiden en hierdoor zorgen voor een toename van het aantal niertransplantaties. Deze bron van donornieren wordt echter niet ten volle benut uit vrees voor ischemische orgaanschade en de daarmee gepaard gaande functiestoornissen van de transplantaatnier. Om deze reden worden in dit proefschrift de lange termijn resultaten en het overlevingsvoordeel van niertransplantaties van donoren na hartstilstand bestudeerd, worden klinisch toepasbare methoden beschreven om het optreden van primaire non-functie bij deze donornieren te verminderen en wordt nieuw inzicht verkregen in de pathofysiologie en behandeling van acute ischemische nierschade bij niertransplantatie van donoren na hartstilstand. Men zal zich moeten blijven inspannen om de kwaliteit van nieren van donoren na hartstilstand te verbeteren en daarmee het potentiële aanbod van deze donornieren optimaal te benutten.

\section{Gepubliceerd als}

Hoogland PE, Snoeijs MG, van Heurn LW. DCD kidney transplantation: results and measures to improve outcome. Curr Opin Organ Transplant 2010; 15:177-182. 


\section{Inleiding}

Niertransplantatie is de beste behandeling voor patiënten met terminale nierinsufficiëntie maar door het tekort aan donornieren blijven veel mensen verstoken van deze optimale zorg. ${ }^{1}$ Orgaandonatie na hartstilstand kan het aantal niertransplantaties 2,5 tot 4 maal doen stijgen, hetgeen voldoende is om de wachtlijst voor niertransplantatie te verkorten of zelfs te elimineren. ${ }^{2}$ In tegenstelling tot orgaandonatie na hersendood worden de organen van donoren na hartstilstand echter blootgesteld aan een periode van warme ischemie (afwezigheid van doorbloeding) tussen hartstilstand en orgaanpreservatie. Deze ischemie veroorzaakt acute nierschade, waardoor het risico op vertraagde transplantaatfunctie en primaire non-functie hoger is dan bij niertransplantaties van hersendode orgaandonoren. ${ }^{3}$ Deze complicaties hebben geleid tot terughoudendheid bij de acceptatie van deze nieren voor transplantatie, waardoor het grote potentieel aan orgaandonoren na hartstilstand niet ten volle wordt benut.

Om deze reden werden in dit proefschrift de lange termijn resultaten en het overlevingsvoordeel van niertransplantaties van donoren na hartstilstand bestudeerd, werden klinisch toepasbare methoden gezocht om het optreden van primaire non-functie bij deze donornieren te verminderen en werd nieuw inzicht verkregen in de pathofysiologie en de behandeling van acute ischemische nierschade bij niertransplantatie van donoren na hartstilstand. In dit hoofdstuk worden de resultaten van het onderzoek samengevat.

\section{Resultaten van niertransplantaties van donoren na hartstilstand}

Eerder onderzoek naar de resultaten van niertransplantaties van donoren na hartstilstand laat zien dat deze nieren een verhoog risico hebben op vertraagde transplantaatfunctie en primaire non-functie dan nieren van hersendode donoren, hetgeen wordt toegeschreven aan warm ischemische schade. Opmerkelijk is dat de prognose van functionele nieren van donoren na hartstilstand vergelijkbaar is met die van hersendode donornieren, in ieder geval tot 5 à 10 jaar na transplantatie..$^{3-9} \mathrm{Er}$ is echter geen informatie over de resultaten van niertransplantaties van donoren na hartstilstand op langere termijn en ook het effect van deze transplantaties op de levensverwachting van dialysepatiënten is onbekend. 
Om deze vragen op te helderen bestudeerden wij de lange termijn resultaten van alle nieren van donoren na hartstilstand die vanuit onze donorregio tussen 1981 en 2006 binnen het Eurotransplant gebied werden getransplanteerd (Hoofdstuk 2). In deze periode van 25 jaar leidde ons programma voor nierdonatie na hartstilstand tot een toename van $44 \%$ in het aanbod aan donornieren vanuit onze regio. De niertransplantaties die door dit programma mogelijk waren gemaakt $(\mathrm{N}=297)$ werden vergeleken met niertransplantaties van conventionele hersendode donoren met een overeenkomstig risicoprofiel ( $\mathrm{N}=594)$. Zoals eerder beschreven hadden nieren van donoren na hartstilstand een hogere incidentie van vertraagde transplantaatfunctie ( $72 \%$ vs. $18 \%$ ) en primaire non-functie ( $23 \%$ vs. $4 \%)$ dan nieren van hersendode donoren. De hogere incidentie van primaire non-functie bij nieren van donoren na hartstilstand leidde tot een toegenomen risico op transplantaatverlies. Nieren zonder primaire non-functie functioneerden echter even lang als nieren van hersendode donoren met een relatief risico op transplantaatverlies van 1,05 (95\% CI: 0,73-1,51; $\mathrm{P}=0,79)$. Bovendien was de overleving van ontvangers van beide groepen nieren vergelijkbaar met een relatief risico op sterfte van 1,16 (95\% CI: 0,87-1,54; $\mathrm{P}=0,32)$. Dit onderzoek laat zien dat de resultaten van functionele nieren van donoren na hartstilstand op lange termijn vergelijkbaar zijn met die van hersendode donornieren.

In verschillende analyses blijkt niertransplantatie van hersendode donoren te leiden tot een langere levensverwachting voor dialysepatiënten die zijn toegelaten tot de wachtlijst voor transplantatie. ${ }^{1,10-12}$ Aangezien de overleving van ontvangers van nieren van orgaandonoren na hartstilstand vergelijkbaar is met die van donoren na hersendood, lijkt het plausibel dat niertransplantatie van donoren na hartstilstand ook gepaard gaat met een overlevingsvoordeel. Deze veronderstelling werd door ons getoetst in een cohort patiënten dat tussen 1999 en 2004 op de Nederlandse wachtlijst voor een eerste niertransplantatie werd geplaatst ( $\mathrm{N}=2575$, Hoofdstuk 3$)$. De overleving na niertransplantatie van verschillende groepen postmortale donoren werd vergeleken met conventionele behandeling door sequentiële stratificatie, een statistische methode die het mogelijk maakt om tijdsafhankelijke behandelingen te analyseren volgens het intention-to-treat principe. Zoals verwacht was het risico op overlijden na niertransplantatie van standaard hersendode donoren aanzienlijk lager dan bij dialysebehandeling (HR 0,51; 95\% CI: 0,32-0,81; P=0,004). Vervolgens werd de overleving na niertransplantatie van donoren na hartstilstand vergeleken met voortzetting van dialysebehandeling met de mogelijkheid om later een nier van een standaard hersendode donor te ontvangen. We vonden dat het risico op overlijden na niertransplantatie van standaard donoren na hartstilstand $56 \%$ 
lager was dan bij deze conventionele behandeling (HR 0,44; 95\% CI: 0,24-0,80; $\mathrm{P}=0,007$ ). Dit lagere risico op overlijden vertaalde zich in een 2,4 maanden langere levensverwachting na niertransplantatie van donoren na hartstilstand. Niertransplantatie van zogenaamde 'extended criteria' donoren (orgaandonoren ouder dan 60 jaar of tussen 50 en 60 jaar met cardiovasculaire risicofactoren $)^{13}$ gaf daarentegen geen overlevingsvoordeel. Dit onderzoek toont aan dat niertransplantatie van donoren na hartstilstand leidt tot een langere levensverwachting voor dialysepatiënten op de wachtlijst, ook al hebben deze nieren een hoger risico op vroeg transplantaatverlies.

\section{Preventie van primaire non-functie bij niertransplantaties van donoren na hartstilstand}

Ondanks het overlevingsvoordeel bij niertransplantatie van donoren na hartstilstand geeft het hoge percentage niet-functionele nieren een sterke impuls tot verbetering van de resultaten van deze niertransplantaties. De klinische presentatie van primaire non-functie is heterogeen en de oorzaak van het transplantaatverlies kan worden onderverdeeld in afwezige renale doorbloeding in de eerste dagen na transplantatie, complicaties zoals acute afstoting voordat herstel van nierfunctie is opgetreden bij vertraagde transplantaatfunctie of chronische

Tabel 15.1 Classificatie van primaire non-functie na niertransplantatie van donoren na hartstilstand

\begin{tabular}{|c|c|c|c|}
\hline Classificatie & Tijdstip & Mogelijke oorzaak & Voorstel tot preventie \\
\hline $\begin{array}{l}\text { Afwezige renale } \\
\text { doorbloeding }\end{array}$ & $\begin{array}{l}\text { Eerste dagen } \\
\text { na transplanta- } \\
\text { tie }\end{array}$ & $\begin{array}{l}\text { Ernstige acute ischemi- } \\
\text { sche schade aan de } \\
\text { renale bloedvaten }\end{array}$ & $\begin{array}{l}\text { Beoordeling van acute ischemische } \\
\text { schade voor transplantatie en } \\
\text { optimalisatie van orgaanpreservatie } \\
\text { en hemodynamische toestand } \\
\text { ontvanger }\end{array}$ \\
\hline $\begin{array}{l}\text { Complicaties tijdens } \\
\text { vertraagde transplan- } \\
\text { taatfunctie }\end{array}$ & $\begin{array}{l}\text { Eerste weken } \\
\text { na transplanta- } \\
\text { tie }\end{array}$ & $\begin{array}{l}\text { 'Normale' complicaties } \\
\text { zoals acute afstoting }\end{array}$ & $\begin{array}{l}\text { Zorgvuldig onderzoek van ontvan- } \\
\text { gers tijdens vertraagde transplantaat- } \\
\text { functie met onder meer protocollaire } \\
\text { biopten }\end{array}$ \\
\hline $\begin{array}{c}\text { Chronische allograft } \\
\text { nephropathie }\end{array}$ & $\begin{array}{c}\text { Eerste } \\
\text { maanden na } \\
\text { transplantatie }\end{array}$ & $\begin{array}{l}\text { Verergering van pre- } \\
\text { existente degeneratieve } \\
\text { veranderingen in de } \\
\text { postoperatieve periode }\end{array}$ & $\begin{array}{l}\text { Histologische beoordeling van pre- } \\
\text { implantatie biopten bij nieren van } \\
\text { oude orgaandonoren }\end{array}$ \\
\hline
\end{tabular}


allograft nefropathie bij nieren met ernstige pre-existente degeneratieve afwijkingen (Tabel 15.1). Primaire non-functie is een ernstige complicatie na niertransplantatie en leidt tot onnodige blootstelling aan het risico van de chirurgische ingreep en de immunosuppressieve behandeling. Hoewel patiënten na primaire non-functie hun wachttijd bij Eurotransplant behouden, wordt de mogelijkheid tot retransplantatie beperkt door immunologische sensibilisatie tegen antigenen van de donor. ${ }^{14}$ Strategieën om het risico op primaire nonfunctie te beperken zijn daarom van groot belang om uitgebreidere acceptatie van nieren van donoren na hartstilstand te bewerkstelligen. Om deze reden werd in dit proefschrift het gehele transplantatieproces van donor tot ontvanger onder de loep genomen om klinisch toepasbare methoden te vinden die primaire nonfunctie kunnen voorkomen. Geleidelijke implementatie van de bevindingen van dit onderzoek ging gepaard met een daling van de incidentie van primaire nonfunctie bij niertransplantaties van donoren na hartstilstand in ons ziekenhuis van $21 \%$ in de periode $1981-2005$ naar $5 \%$ in de periode 2006-2008.

\section{Behandeling van de donor}

In onze donorregio wordt bij donatie na hartstilstand orgaanpreservatie gestart door in situ perfusie. ${ }^{15}$ Deze minimaal invasieve techniek bestaat uit het inbrengen van een catheter via de arteria femoralis in de aorta. Na het opblazen van twee ballonnen in deze catheter kan de abdominale aorta selectief worden geperfundeerd met een hypotherme preservatievloeistof, waardoor de nieren in situ worden gespoeld en gekoeld. In een cohort van 133 opeenvolgende in situ perfusies in onze donorregio vonden wij dat de meerderheid van de potentiële orgaandonaties na hartstilstand (58\%) niet resulteerde in niertransplantatie; complicaties bij in situ perfusie waren de meest frequente oorzaak voor het beëindigen van de donatieprocedure (Hoofdstuk 4). Bij onaangekondigde donatie na niet-succesvolle reanimatie is in situ perfusie een onmisbare techniek die het mogelijk maakt te voldoen aan de juridische en logistieke vereisten voor orgaandonatie zonder de toelaatbare periode van warme ischemie te overschrijden. Bij aangekondigde orgaandonatie na het staken van medisch zinloze behandeling in de intensive care kan aan deze vereisten worden voldaan voordat de behandeling wordt stopgezet. In deze situatie is het mogelijk om de orgaandonor na overlijden te transporteren naar een operatiekamer waar het chirurgisch team gereed is om orgaanpreservatie te starten door een spoedlaparotomie en directe cannulatie van de aorta. ${ }^{16}$ In onze regio werd deze techniek toegepast bij een beperkt aantal donaties na hartstilstand waarbij naast de nieren ook de lever werd uitgenomen voor transplantatie. Deze donoren hadden een kortere warme ischemietijd en 
een lager percentage afgekeurde en niet-functionele nieren in vergelijking met aangekondigde donoren na hartstilstand bij wie in situ perfusie werd gebruikt voor orgaanpreservatie. Deze bevindingen werden recent bevestigd door uitbreiding van het onderzoek met orgaandonaties uit een naburige regio waar standaard gebruik werd gemaakt van directe aortacannulatie. Om deze reden geven wij voor orgaanpreservatie bij donoren na aangekondigde hartstilstand de voorkeur aan spoedlaparotomie met directe aortacannulatie boven in situ perfusie.

\section{Beoordeling van chronisch degeneratieve afwijkingen in nieren van oude donoren}

Na succesvolle uitname van nieren bij donoren na hartstilstand kan beoordeling van pre-existente degeneratieve veranderingen en acute ischemische schade leiden tot selectie van nieren die succesvol kunnen worden getransplanteerd. $\mathrm{Bij}$ zorgvuldige selectie zou nierdonatie na hartstilstand kunnen worden uitgebreid met oude donoren of met donoren met langdurige warme ischemie. Daarentegen waren de resultaten van niertransplantaties van donoren na hartstilstand ouder dan 60 jaar in ons ziekenhuis $(\mathrm{N}=52)$ zonder een dergelijke selectie beduidend slechter dan die van jongere donoren ( $\mathrm{N}=147$, Hoofdstuk 5). Met een mediane transplantaatoverleving van ongeveer 5 jaar vonden wij de resultaten van deze oude donornieren niet acceptabel zonder verdere orgaanselectie. Tussen de verschillende gepubliceerde selectiecriteria voor nieren van oude donoren bleek alleen histologische beoordeling van nierbiopten de transplantaatfunctie en -overleving te voorspellen, in tegenstelling tot de leeftijd en nierfunctie van de orgaandonor, het niergewicht en de kenmerken tijdens orgaanpreservatie. In een vervolgonderzoek vonden we bovendien dat de histologische beoordeling van pre-implantatie nierbiopten reproduceerbaar was en een aanvaardbare schatting gaf van de degeneratieve veranderingen in de gehele nier (Hoofdstuk 6). Deze bevindingen geven aan dat histologische beoordeling van nierbiopten een bruikbaar middel is om nieren van oude donoren te selecteren voor transplantatie en suggereren verder dat deze aanpak te verkiezen is boven het stellen van arbitraire leeftijdsgrenzen voor nierdonatie.

\section{Beoordeling van acute ischemische nierschade}

Orgaanpreservatie met behulp van hypotherme machinale perfusie verbetert de resultaten na niertransplantatie ten opzichte van statische preservatie met ijs. ${ }^{17}$ Machinale perfusie biedt bovendien mogelijkheden voor de beoordeling van acute nierschade door ischemie. De perfusiesnelheid en de vaatweerstand schetsen de toestand van het renale vaatbed en vormen zo een weerslag van de ische- 
mische schade die voor orgaanuitname is geleden. ${ }^{18,19}$ Verder kunnen in de perfusievloeistof eiwitten worden gemeten die uit beschadigde tubulaire epitheelcellen lekken zoals lactaat dehydrogenase, glutathion-S-transferase en fatty-acid binding protein. ${ }^{20-22}$ De zogenaamde 'viabiliteitstests' hebben echter onvoldoende voorspellende waarde om van klinisch nut te zijn bij het accepteren of afkeuren van nieren van donoren na hartstilstand. ${ }^{23-25}$ Recent vonden wij dat de concentratie redox-actief ijzer in de preservatievloeistof toenam tijdens machinale perfusie. ${ }^{26}$ Het gehalte redox-actief ijzer lijkt samen te hangen met de mate van ischemische schade, aangezien hogere ijzerconcentraties worden gevonden bij nieren van donoren na hartstilstand dan bij nieren van hersendode orgaandonoren en bij nieren met primaire non-functie dan bij functionele nieren. De bepaling die gebruikt werd om redox-actief ijzer te meten kan echter niet binnen een klinisch relevant tijdsbestek worden uitgevoerd. Als alternatief hebben wij daarom het proteoom van de preservatievloeistof met differentiële gel elektroforese onderzocht om op onbevooroordeelde wijze nieuwe biomarkers voor acute ischemische nierschade te ontdekken (Hoofdstuk 7). In het perfusaat van ischemisch beschadigde nieren van donoren na onaangekondigde hartstilstand werden twee eiwitten gevonden die significant afweken van hersendode donornieren zonder warm ischemische schade. De identiteit van deze nieuwe biomarkers en hun voorspellende waarde voor de selectie van nieren van donoren na hartstilstand, met een laag risico op vroeg transplantaatverlies ondanks langdurige ischemie, zal in vervolgonderzoek moeten worden bepaald.

\section{Behandeling van de ontvanger}

Wanneer de uitgenomen nieren van donoren na hartstilstand van voldoende kwaliteit worden geacht voor transplantatie dienen deze nieren zo spoedig mogelijk te worden geïmplanteerd om de koude ischemietijd te beperken en de transplantaatoverleving te verbeteren. ${ }^{27}$ Optimalisatie van de hemodynamische toestand van de ontvanger en een adequate renale doorbloeding na reperfusie bepalen in belangrijke mate de vroege transplantaatfunctie van hersendode donornieren. ${ }^{28-31}$ In een cohort van niertransplantaties van donoren na hartstilstand in ons ziekenhuis van 1994 tot 2006 vonden wij dat een lage systolische arteriële en centraal veneuze bloeddruk tijdens implantatie was geassocieerd met een verhoogd risico op primaire non-functie ( $O R$ 2,6; $P=0,03$ en $O R$ 3, $1 ; \mathrm{P}=0,007$; respectievelijk; Hoofdstuk 8). Dit verhoogde risico op primaire non-functie was onafhankelijk van de kenmerken van de orgaandonor en werd bevestigd in een gepaarde vergelijking van patiënten die nieren ontvingen van dezelfde donoren. Deze bevindingen laten zien dat zorgvuldige optimalisatie van de hemodynami- 
sche toestand van de ontvanger door expansie van het intravasculaire volume en oordeelkundig gebruik van vasoactieve medicatie de mogelijkheid biedt om primaire non-functie van nieren van donoren na hartstilstand te voorkomen. Bovendien toont dit onderzoek aan dat primaire non-functie niet alleen afhankelijk is van kenmerken van de donornier, maar dat de ontvanger eveneens een belangrijke rol speelt bij het ontstaan van deze ernstige complicatie. We stellen dan ook voor om nieren met uitgebreide ischemische schade niet te transplanteren bij ontvangers met ernstig beperkte hartfunctie. Tenslotte impliceert het belang van de ontvanger bij het ontstaan van primaire non-functie dat het onrealistisch is om te verwachten dat de beoordeling van orgaanschade voor implantatie zal leiden tot het volledig voorkomen van deze complicatie.

\section{Pathofysiologie en behandeling van acute ischemische nierschade na niertransplantatie}

Op dit moment blijft niertransplantatie van donoren na hartstilstand beperkt tot nieren met een relatief korte periode van warme ischemie. Preventie van acute ischemische nierschade kan het optreden van vroege functiestoornissen in de transplantaatnier voorkomen en biedt hierdoor de mogelijkheid om niertransplantaties van donoren na hartstilstand uit te breiden met organen die ernstiger ischemische schade hebben geleden. Om deze reden bestudeerden we in dit proefschrift de pathofysiologische mechanismen die leiden tot acute ischemische nierschade bij niertransplantaties en evalueerden we een nieuwe behandeling voor deze nierschade in een klinisch relevant proefdiermodel met de uiteindelijke doelstelling om de vroege functie van nieren van donoren na hartstilstand te verbeteren.

Pathofysiologie van acute ischemische nierschade bij humane niertransplantaties Om de effecten van renale ischemie en reperfusie bij humane niertransplantaties te bestuderen hebben we twee groepen donornieren met een verschillende mate van ischemische schade met elkaar vergeleken: (1) nieren van donoren na hartstilstand die ernstige ischemische schade ondervonden tussen circulatiestilstand en orgaanpreservatie ( $\mathrm{N}=8)$, en (2) nieren van levende donoren die een minimale periode van warme en koude ischemie ondergingen $(\mathrm{N}=8)$. Hoewel alle donornieren uiteindelijk functioneerden, was de kreatinineklaring van de nieren van donoren na hartstilstand sterk verminderd ten opzichte van levende donornieren 
in de eerste 10 dagen na transplantatie. Om de pathofysiologie van acute ischemische nierschade na transplantatie te onderzoeken werd bij deze twee groepen nieren zowel de functie van de renale microcirculatie als de mate van tubulaire schade en ontsteking gemeten.

Adequate doorbloeding van getransplanteerde nieren is van groot belang om voortdurende weefselschade na reperfusie te voorkomen en functioneel herstel te bevorderen. ${ }^{32}$ Door directe beeldvorming van corticale peritubulaire capillairen tijdens niertransplantaties vonden wij dat vroeg na reperfusie de microvasculaire perfusie in nieren van donoren na hartstilstand $42 \%$ lager was dan in levende donornieren, hetgeen verklaard werd door een significant kleinere capillaire diameter in nieren van donoren na hartstilstand (Hoofdstuk 9). Het endotheel van de bloedvaten wordt bedekt met de glycocalyx, een dynamisch netwerk van proteoglycanen en glycoproteïnen. ${ }^{33} \mathrm{Wij}$ zagen dat de glycocalyx van ischemisch beschadigde nieren was afgebroken, aangezien de afstand tussen rode bloedcellen en de vaatwand kleiner was in nieren van donoren na hartstilstand en bovendien meer bestanddelen van de glycocalyx uit deze nieren werden gewassen dan bij levende donornieren. Aangezien de glycocalyx bepalend is voor de vasculaire permeabiliteit en voor de overdracht van oppervlaktespanning op het endotheel, ${ }^{34-37}$ kan het verlies van de glycocalyx in nieren van donoren na hartstilstand leiden tot capillaire compressie door interstitieel oedeem en vaatvernauwing. Dit zou kunnen verklaren waarom de diameter van de bloedvaten in deze nieren kleiner was. De microvasculaire dysfunctie in ischemisch beschadigde nieren kan leiden tot exacerbatie van acute nierschade als gevolg van onvoldoende weefseldoorbloeding en kan op deze wijze bijdragen aan de vroege nierfunctiestoornissen bij nieren van donoren na hartstilstand.

In proefdiermodellen leidt ischemie en reperfusie van de nier tot schade aan het tubulusepitheel, waardoor het aangeboren immuunsysteem wordt geactiveerd en een felle ontsteking veroorzaakt die de acute ischemische nierschade verergert..$^{38} \mathrm{Bij}$ humane niertransplantaties vonden wij dat nieren van donoren na hartstilstand 12 tot 18 maal meer necrotische, maar niet apoptotische, celdood ondergingen dan levende donornieren (Hoofdstuk 10). Deze toegenomen celdood was niet gerelateerd aan oxidatieve schade bij reperfusie van de donornier, aangezien geen renale productie van $\mathrm{F}_{2}$-isoprostanes - de gouden standaard voor het meten van oxidatieve stress ${ }^{39}$ - werd waargenomen. Toch verbruikten de nieren van donoren na hartstilstand meer vitamine $\mathrm{E}$ bij reperfusie dan levende donornieren. Dit suggereert dat er meer vrije zuurstof radicalen werden gevormd na langdurige renale ischemie, maar dat de natuurlijke verdedigingsmechanismen tegen oxidatieve stress voldoende waren om schade aan de getransplanteer- 
de nier te voorkomen. Bij necrotische celdood en bij schade aan de extracellulaire matrix (bijv. glycoxalyx) komen schade-gerelateerde moleculaire patronen (DAMP's) vrij die via toll-like receptor signalering kunnen leiden tot activatie van het immuunsysteem. In overeenstemming met dit concept vonden wij in de vroeg post-operatieve fase een significant toegenomen systemische ontstekingsreactie bij ontvangers van nieren van donoren na hartstilstand in vergelijking met patiënten die een levende donor niertransplantatie hadden ondergaan.

Ischemisch beschadigde nieren van donoren na hartstilstand worden derhalve in de vroeg postoperatieve periode gekenmerkt door ernstige nierfunctiestoornissen die gepaard gaan met microvasculaire dysfunctie, tubulaire celdood en systemische ontsteking. Wij stellen dat deze fenomenen elkaar versterken waardoor een vicieuze cirkel ontstaat van steeds ernstiger acute nierschade totdat de excessieve ontsteking verdwijnt en homeostase wordt hersteld door regeneratie van het nierweefsel (Figuur 15.1). Aangezien stoornissen van de peritubulaire microcirculatie vroeg optreden binnen dit proces, lijken interventies gericht op de verbetering van de microvasculaire integriteit en doorbloeding bijzonder interessant voor de preventie van acute ischemische nierschade na transplantatie. Deze bevindingen kunnen ook van belang zijn voor andere situaties die gepaard gaan met acute ischemische nierschade, zoals cardiovasculaire chirurgie en hypovolemische shock.

\section{Nieuwe behandelingen voor acute ischemische nierschade in diermodellen}

Toegenomen inzicht in de pathofysiologie van acute ischemische nierschade leidt tot nieuwe therapeutische doelen en interventies. Deze interventies moeten

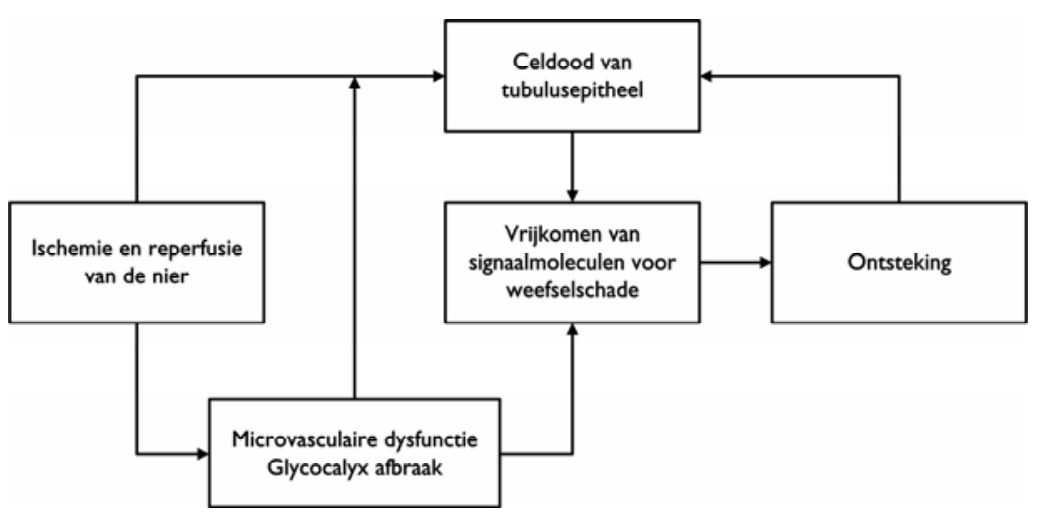

Figuur 15.1 Samenvattend model van de pathofysiologie van acute ischemische nierschade bij humane niertransplantatie. 
worden geëvalueerd in een representatief diermodel voordat onderzoek bij patiënten kan plaatsvinden. Het varken is hiervoor een bijzonder geschikt proefdier, aangezien de anatomie en fysiologie van de varkensnier grote overeenkomsten vertonen met die van de mens. ${ }^{40} \mathrm{Om}$ acute afstoting te voorkomen kan gebruik worden gemaakt van autologe transplantaties; hiermee is het mogelijk acute ischemische nierschade geïsoleerd te bestuderen. In dit proefschrift werden daarom autologe transplantaties van ischemisch beschadigde nieren in het varken uitgevoerd om nieuwe interventies voor acute nierschade te evalueren. Transplantatie van nieren die waren blootgesteld aan verschillende periodes van warme ischemie gevolgd door hypotherme machinale perfusie resulteerde in nierfunctiestoornissen die proportioneel waren aan de duur van warme ischemie (Hoofdstuk 11). Blootstelling aan 45 minuten warme ischemie veroorzaakte ernstige maar herstelbare nierschade die goed vergelijkbaar was met humane niertransplantaties van donoren na hartstilstand.

Het ontstaan van vrije zuurstof radicalen bij reperfusie en tijdens hypotherme orgaanpreservatie wordt gezien als een belangrijke oorzaak van acute ischemische nierschade en leidt tot vaatvernauwing in de nier en celdood van het tubulusepitheel. ${ }^{41-43} \mathrm{Om}$ deze reden onderzochten wij of tubulaire epitheelcellen van het varken door eenvoudige monophenolische anti-oxidanten worden beschermd tegen koude preservatieschade; we vonden dat verschillende van deze stoffen effectief waren (Hoofdstuk 12). De monophenolische anti-oxidant propofol kon in hoge concentraties worden opgelost in water door gebruik te maken van cyclodextrine. Hierdoor konden wij propofol toevoegen aan de preservatievloeistof teneinde ischemisch beschadigde varkensnieren op te laden met deze anti-oxidant tijdens machinale perfusie. Dit voorkwam de peroxidatie van vetzuren en de toename in vaatweerstand tijdens de vroege reperfusiefase. Deze effectieve bescherming tegen oxidatieve stress leidde tot een bescheiden verbetering van nierfunctie in de eerste week na transplantatie vergeleken met een controlegroep zonder propofol met een trend naar statistische significantie $(\mathrm{N}=6$ per groep, $\mathrm{P}=0.10)$. Gezien de complexiteit van de pathofysiologie van acute ischemische nierschade is voor behandeling van deze aandoening hoogstwaarschijnlijk een combinatie van interventies nodig die zich richt op verschillende mechanismen van acute nierschade (bijv. oxidatieve stress, renale doorbloeding, celdood, ontstekingsreactie, regeneratie). Ons onderzoek laat zien dat propofol een geschikt medicijn is om op te nemen in een dergelijke combinatie van beschermende stoffen.

In de autotransplantatie experimenten met varkens ging preventie van vetzuur peroxidatie gepaard met een verminderde toename in vaatweerstand in 
de vroege reperfusiefase. Aangezien we eerder in ischemisch beschadigde nieren van donoren na hartstilstand een vergelijkbare reductie in microvasculaire doorbloeding hadden geobserveerd, werd verder onderzoek verricht naar het moleculaire mechanisme waarlangs oxidatieve stress vaatvernauwing veroorzaakt. Oxidatieve modificatie van arachidonzuur leidt tot vorming van stabiele $\mathrm{F}_{2}$-isoprostanes die van de celmembraan vrijkomen in het plasma en daar biologisch actief zijn door signalering via thromboxaan $\mathrm{A}_{2}$ receptoren. ${ }^{44,45}$ Toediening van $\mathrm{F}_{2}$-isoprostanes aan ratten en varkens veroorzaakt een dosisafhankelijke afname in de renale doorbloeding en glomerulaire filtratiesnelheid door vaatvernauwing in de afferente glomerulaire arteriolen. ${ }^{46,47}$ Lokaal geproduceerde $\mathrm{F}_{2}$ isoprostanes kunnen daarom bijdragen aan de afname van glomerulaire filtratiesnelheid bij acute ischemische nierschade. Hoewel $\mathrm{F}_{2}$-isoprostanes aanwezig waren in de urine na renale ischemie en reperfusie, vonden wij echter dat muizen zonder thromboxaan $\mathrm{A}_{2}$ receptor - waardoor signalering van $\mathrm{F}_{2}$-isoprostanes niet mogelijk is - niet beschermd waren tegen acute ischemische nierschade (Hoofdstuk 13). Dit impliceert dat signalering van $\mathrm{F}_{2}$-isoprostanes geen essentiële bijdrage levert aan het ontstaan van acute ischemische nierschade. Het beschermende effect van anti-oxidanten kan daarom niet worden toegeschreven aan de verminderde signalering van $\mathrm{F}_{2}$-isoprostanes. Het verband tussen oxidatieve stress en renale vaatvernauwing kan alternatief worden verklaard door het wegvangen van de vaatverwijder stikstofoxide door lokaal gevormde vrije zuurstof radicalen. ${ }^{43}$

\section{Conclusie}

In dit proefschrift wordt beschreven dat liberaal gebruik van orgaandonatie na hartstilstand leidt tot een substantiële toename van het aanbod aan donornieren. De hieruit voortvloeiende niertransplantaties worden gekenmerkt door een toegenomen risico op primaire non-functie en vertraagde transplantaatfunctie. Desalniettemin functioneren nieren van donoren na hartstilstand die de vroeg postoperatieve fase hebben doorstaan even lang als nieren van hersendode donoren en hebben dialysepatiënten een langere levensverwachting na niertransplantatie van donoren na hartstilstand. Het risico op primaire non-functie van deze nieren kan worden beperkt door gebruik te maken van orgaanpreservatie door spoedlaparotomie en directe aortacannulatie bij aangekondigde donaties na hartstilstand, door selectie van oude donornieren op basis van histologische beoordeling van pre-implantatie biopten en door optimalisatie van de hemody- 
namische toestand van de ontvanger tijdens niertransplantatie. Ischemisch beschadigde nieren van donoren na hartstilstand met vertraagde transplantaatfunctie worden gekenmerkt door microvasculaire dysfunctie, tubulaire celdood en systemische ontsteking in de vroeg postoperatieve periode. Effectieve behandeling van acute ischemische nierschade vereist waarschijnlijk een combinatie van interventies die zich richten op deze verschillende pathofysiologische mechanismen. In een klinisch relevant diermodel resulteerde toediening van de anti-oxidant propofol in verbetering van de nierfunctie na transplantatie. Deze stof lijkt dan ook een geschikte kandidaat voor opname in een combinatie van interventies om de donornier te beschermen tegen ischemische schade. Men zal zich moeten blijven inspannen om de kwaliteit van nieren van donoren na hartstilstand te verbeteren en daarmee het potentiële aanbod van deze donornieren optimaal te benutten. 


\section{Referenties}

1. Wolfe RA, Ashby VB, Milford EL, et al. Comparison of mortality in all patients on dialysis, patients on dialysis awaiting transplantation, and recipients of a first cadaveric transplant. $\mathrm{N}$ Engl J Med 1999; 341:1725-1730.

2. Terasaki PI, Cho YW, Cecka JM. Strategy for eliminating the kidney shortage. Clin Transpl 1997:265-267.

3. Wijnen RM, Booster MH, Stubenitsky BM, de Boer J, Heineman E, Kootstra G. Outcome of transplantation of non-heart-beating donor kidneys. Lancet 1995; 345:1067-1070.

4. Barlow AD, Metcalfe MS, Johari Y, Elwell R, Veitch PS, Nicholson ML. Case-matched comparison of long-term results of non-heart beating and heart-beating donor renal transplants. $\mathrm{Br}$ J Surg 2009; 96:685-691.

5. Sanchez-Fructuoso AI, Marques M, Prats D, et al. Victims of cardiac arrest occurring outside the hospital: a source of transplantable kidneys. Ann Intern Med 2006; 145:157-164.

6. Weber M, Dindo D, Demartines N, Ambuhl PM, Clavien PA. Kidney transplantation from donors without a heartbeat. N Engl J Med 2002; 347:248-255.

7. Cho YW, Terasaki PI, Cecka JM, Gjertson DW. Transplantation of kidneys from donors whose hearts have stopped beating. N Engl J Med 1998; 338:221-225.

8. Cooper JT, Chin LT, Krieger NR, et al. Donation after cardiac death: the university of wisconsin experience with renal transplantation. Am J Transplant 2004; 4:1490-1494.

9. Gok MA, Buckley PE, Shenton BK, et al. Long-term renal function in kidneys from non-heartbeating donors: A single-center experience. Transplantation 2002; 74:664-669.

10. McDonald SP, Russ GR. Survival of recipients of cadaveric kidney transplants compared with those receiving dialysis treatment in Australia and New Zealand, 1991-2001. Nephrol Dial Transplant 2002; 17:2212-2219.

11. Rabbat CG, Thorpe KE, Russell JD, Churchill DN. Comparison of mortality risk for dialysis patients and cadaveric first renal transplant recipients in Ontario, Canada. J Am Soc Nephrol 2000; 11:917-922.

12. Oniscu GC, Brown H, Forsythe JL. Impact of cadaveric renal transplantation on survival in patients listed for transplantation. J Am Soc Nephrol 2005; 16:1859-1865.

13. Port FK, Bragg-Gresham JL, Metzger RA, et al. Donor characteristics associated with reduced graft survival: an approach to expanding the pool of kidney donors. Transplantation 2002; 74:1281-1286.

14. Billen EV, Christiaans MH, Lee J, van den Berg-Loonen EM. Donor-directed HLA antibodies before and after transplantectomy detected by the luminex single antigen assay. Transplantation 2009; 87:563-569.

15. Booster MH, Wijnen RM, Vroemen JP, van Hooff JP, Kootstra G. In situ preservation of kidneys from non-heart-beating donors--a proposal for a standardized protocol. Transplantation 1993; 56:613-617.

16. Casavilla A, Ramirez C, Shapiro R, et al. Experience with liver and kidney allografts from nonheart-beating donors. Transplantation 1995; 59:197-203.

17. Moers C, Smits JM, Maathuis MH, et al. Machine perfusion or cold storage in deceased-donor kidney transplantation. N Engl J Med 2009; 360:7-19. 
18. Tesi RJ, Elkhammas EA, Davies EA, Henry ML, Ferguson RM. Pulsatile kidney perfusion for evaluation of high-risk kidney donors safely expands the donor pool. Clin Transplant 1994; 8:134-138.

19. Matsuno N, Konno O, Mejit A, et al. Application of machine perfusion preservation as a viability test for marginal kidney graft. Transplantation 2006; 82:1425-1428.

20. Baxby K, Taylor RM, Anderson M, Johnson RW, Swinney J. Assessment of cadaveric kidneys for transplantation. Lancet 1974; 2:977-979.

21. Daemen JW, Oomen AP, Janssen MA, et al. Glutathione S-transferase as predictor of functional outcome in transplantation of machine-preserved non-heart-beating donor kidneys. Transplantation 1997; 63:89-93.

22. Gok MA, Pelsers M, Glatz JF, et al. Comparison of perfusate activities of glutathione Stransferase, alanine aminopeptidase and fatty acid binding protein in the assessment of nonheart-beating donor kidneys. Ann Clin Biochem 2003; 40:252-258.

23. Sonnenday CJ, Cooper M, Kraus E, Gage F, Handley C, Montgomery RA. The hazards of basing acceptance of cadaveric renal allografts on pulsatile perfusion parameters alone. Transplantation 2003; 75:2029-2033.

24. Moers C, Varnav OC, Treckmann J, et al. GST and HFABP during machine perfusion of deceased donor kidneys are independent predictors of delayed graft function but not of primary non-function and graft survival. Transpl Int 2009; 22:42.

25. Pirenne J, Smits J, Monbaliu D, et al. Renal resistance during machine perfusion is a risk factor for delayed graft function and poorer graft survival. Transpl Int 2009; 22:56.

26. de Vries B, Snoeijs MG, von Bonsdorff L, Ernest van Heurn LW, Parkkinen J, Buurman WA. Redox-active iron released during machine perfusion predicts viability of ischemically injured deceased donor kidneys. Am J Transplant 2006; 6:2686-2693.

27. Opelz G, Dohler B. Multicenter analysis of kidney preservation. Transplantation 2007; 83:247253.

28. Luciani J, Frantz $P$, Thibault $P$, et al. Early anuria prevention in human kidney transplantation. Advantage of fluid load under pulmonary arterial pressure monitoring during surgical period. Transplantation 1979; 28:308-312.

29. Carlier M, Squifflet JP, Pirson Y, Decocq L, Gribomont B, Alexandre GP. Confirmation of the crucial role of the recipient's maximal hydration on early diuresis of the human cadaver renal allograft. Transplantation 1983; 36:455-456.

30. Dawidson IJ, Sandor ZF, Coorpender L, et al. Intraoperative albumin administration affects the outcome of cadaver renal transplantation. Transplantation 1992; 53:774-782.

31. Lundell A, Persson NH, Kallen R, Ekberg H. Impaired renal artery blood flow at transplantation is correlated to delayed onset of graft function. Transpl Int 1996; 9:57-61.

32. Brodsky SV, Yamamoto T, Tada T, et al. Endothelial dysfunction in ischemic acute renal failure: rescue by transplanted endothelial cells. Am J Physiol Renal Physiol 2002; 282:F11401149.

33. Reitsma S, Slaaf DW, Vink H, van Zandvoort MA, oude Egbrink MG. The endothelial glycocalyx: composition, functions, and visualization. Pflugers Arch 2007; 454:345-359.

34. Vink H, Duling BR. Capillary endothelial surface layer selectively reduces plasma solute distribution volume. Am J Physiol Heart Circ Physiol 2000; 278:H285-289.

35. van den Berg BM, Vink H, Spaan JA. The endothelial glycocalyx protects against myocardial edema. Circ Res 2003; 92:592-594. 
36. VanTeeffelen JW, Brands J, Jansen C, Spaan JA, Vink H. Heparin impairs glycocalyx barrier properties and attenuates shear dependent vasodilation in mice. Hypertension 2007; 50:261267.

37. Kumagai R, Lu X, Kassab GS. Role of glycocalyx in flow-induced production of nitric oxide and reactive oxygen species. Free Radic Biol Med 2009; 47:600-607.

38. Bonventre JV, Zuk A. Ischemic acute renal failure: an inflammatory disease? Kidney Int 2004; 66:480-485.

39. Kadiiska MB, Gladen BC, Baird DD, et al. Biomarkers of oxidative stress study II: are oxidation products of lipids, proteins, and DNA markers of CCl4 poisoning? Free Radic Biol Med 2005; 38:698-710.

40. Sachs DH. The pig as a potential xenograft donor. Vet Immunol Immunopathol 1994; 43:185191.

41. Salahudeen AK. Cold ischemic injury of transplanted kidneys: new insights from experimental studies. Am J Physiol Renal Physiol 2004; 287:F181-187.

42. Paller MS, Hoidal JR, Ferris TF. Oxygen free radicals in ischemic acute renal failure in the rat. J Clin Invest 1984; 74:1156-1164.

43. Schnackenberg CG. Physiological and pathophysiological roles of oxygen radicals in the renal microvasculature. Am J Physiol Regul Integr Comp Physiol 2002; 282:R335-342.

44. Morrow JD, Hill KE, Burk RF, Nammour TM, Badr KF, Roberts LJ, 2nd. A series of prostaglandin F2-like compounds are produced in vivo in humans by a non-cyclooxygenase, free radical-catalyzed mechanism. Proc Natl Acad Sci U S A 1990; 87:9383-9387.

45. Audoly LP, Rocca B, Fabre JE, et al. Cardiovascular responses to the isoprostanes iPF(2alpha)III and iPE(2)-III are mediated via the thromboxane A(2) receptor in vivo. Circulation 2000; 101:2833-2840.

46. Takahashi K, Nammour TM, Fukunaga M, et al. Glomerular actions of a free radical-generated novel prostaglandin, 8-epi-prostaglandin F2 alpha, in the rat. Evidence for interaction with thromboxane A2 receptors. J Clin Invest 1992; 90:136-141.

47. Krier JD, Rodriguez-Porcel M, Best PJ, Romero JC, Lerman A, Lerman LO. Vascular responses in vivo to 8-epi PGF(2alpha) in normal and hypercholesterolemic pigs. Am J Physiol Regul Integr Comp Physiol 2002; 283:R303-308. 
\begin{tabular}{ll|l|l}
3 & 12 & HOOF D T U K 15
\end{tabular} 


\section{Curriculum vitae}

Name:

Home address:

Date and place of birth:

E-mail:
Maarten Gerardus Jan Snoeijs

(male)

Wilhelminastraat 71, Epen, The Netherlands 20-01-1981; Breda, The Netherlands

m.snoeijs@mumc.com

\section{Education and professional appointments}

\begin{tabular}{|c|c|c|}
\hline $1992-1998$ & Grammar School & $\begin{array}{l}\text { Scholengemeenschap Helinium } \\
\text { Hellevoetsluis, The Netherlands }\end{array}$ \\
\hline $1998-2005$ & Medicine & $\begin{array}{l}\text { M.D. cum laude } \\
\text { Maastricht University Medical Center } \\
\text { Maastricht, The Netherlands }\end{array}$ \\
\hline $2000-2002$ & $\begin{array}{l}\text { Student assistant } \\
\text { (perfusionist) }\end{array}$ & $\begin{array}{l}\text { Department of Surgery } \\
\text { Maastricht University Medical Center } \\
\text { Maastricht, The Netherlands } \\
\text { (prof. G. Kootstra) }\end{array}$ \\
\hline $2004-2005$ & Research trainee & $\begin{array}{l}\text { National Heart Lung and Blood Institute } \\
\text { National Institutes of Health } \\
\text { Bethesda, MD, United States } \\
\text { (dr. R.W. Childs) }\end{array}$ \\
\hline $2005-2009$ & Clinical research fellow & $\begin{array}{l}\text { Department of Surgery } \\
\text { Maastricht University Medical Center } \\
\text { Maastricht, The Netherlands } \\
\text { (prof. L.W.E. van Heurn / W.A. Buurman) }\end{array}$ \\
\hline $2005-2009$ & Transplant coordinator & $\begin{array}{l}\text { Department of Surgery } \\
\text { Maastricht University Medical Center } \\
\text { Maastricht, The Netherlands }\end{array}$ \\
\hline 2010 - present & General surgical training & $\begin{array}{l}\text { Department of Surgery } \\
\text { Maastricht University Medical Center } \\
\text { Maastricht, The Netherlands } \\
\text { (dr. L.P.S. Stassen) }\end{array}$ \\
\hline
\end{tabular}




\section{Scientific output}

1. Snoeijs MG, Schaefer S, Christiaans MH, van Hooff JP, van den Berg-Loonen PM, Peutz-Kootstra CJ, Buurman WA, van Heurn LW. Kidney transplantation using elderly non-heart-beating donors: a single-center experience. Am J Transplant 2006; 6:1066-1071. [IF: 6.6].

2. de Vries B, Snoeijs MG, von Bonsdorff L, van Heurn LW, Parkkinen J, Buurman WA. Redox-active iron released during machine perfusion predicts viability of ischemically injured deceased donor kidneys. Am J Transplant 2006; 6:2686-2693. [IF: 6.6].

3. Snoeijs MG, Dekkers AJ, Buurman WA, van den Akker L, Welten RJ, Schurink GW, van Heurn LW. In Situ Preservation of Kidneys From Donors After Cardiac Death: Results and Complications. Ann Surg 2007; 246:844-852. [IF 8.5].

4. Snoeijs MG, van Heurn LW, van Mook WN, Christiaans M, van Hooff H. Controlled donation after cardiac death: a European experience. Transplant Rev 2007; 21:219229.

5. Snoeijs MG, Wiermans B, Christiaans MH, van Hooff JP, Timmerman BE, Schurink GW, Buurman WA, van Heurn LW. Recipient hemodynamics during non-heartbeating donor kidney transplantation are major predictors of primary nonfunction. Am J Transplant 2007; 7:1158-1166. [IF: 6.6].

6. Snoeijs MG, Buurman WA, Christiaans MH, van Hooff JP, Goldschmeding R, van Suylen RJ, Peutz-Kootstra CJ, van Heurn LW. Histological assessment of preimplantation biopsies may improve selection of kidneys from old donors after cardiac death. Am J Transplant 2008; 8:1844-1851. [IF 6.6].

7. Snoeijs MG, Mathijssen RA, Christiaans MH, van Hooff JP, van Heurn LW, Buurman WA, van Suylen RJ, Peutz-Kootstra CJ. The renal biopsy in non-heart-beating organ transplantation. Book chapter in 'Organ donation and transplantation after cardiac death', D. Talbot and A.M. D'Alessandro, editors. New York: Oxford University Press; 2009, p. 173-202.

8. de Vries EE, Snoeijs MG, van Heurn E. Kidney donation from children after cardiac death. Crit Care Med 2010; 38:249-253. [IF: 6.6].

9. Snoeijs MG, Boonstra LA, Buurman WA, Goldschmeding R, van Suylen RJ, van Heurn LW, Peutz-Kootstra CJ. Histological assessment of pre-transplant kidney biopsies is reproducible and representative. Histopathology 2010; 56:198-202. [IF: 4.1].

10. Snoeijs MG, van Heurn LW, Buurman WA. Biological modulation of renal ischemiareperfusion injury. Curr Opin Organ Transplant 2010; 15:190-199. [IF: 0.4].

11. Hoogland ER, Snoeijs MG, van Heurn LW. DCD kidney transplantation: results and measures to improve outcome. Curr Opin Organ Transplant 2010; 15:177-182. [IF: $0.4]$. 
12. Vermeulen Windsant IC, Snoeijs MG, Hanssen SJ, Altintas S, Heijmans JH, Koeppel TA, Schurink GW, Buurman WA, Jacobs MJ. Hemolysis is associated with acute kidney injury during major aortic surgery. Kidney Int, in press. [IF: 6.4].

13. Snoeijs MG, Schaubel DE, Hené R, Hoitsma AJ, Idu MM, Ijzermans JN, Ploeg RJ, Ringers J, Christiaans MHL, Buurman WA, van Heurn LWE. Kidneys from donors after cardiac death provide survival benefit. J Am Soc Nephrol, in press. [IF 7.5].

\section{Grants and awards}

\begin{tabular}{lll}
\hline 2004 & $\begin{array}{l}\text { KWF Cancer Foundation } \\
\text { Dutch Kidney Foundation }\end{array}$ & Student travel grant $(€ 5.000)$ \\
2006 & $\begin{array}{l}\text { Jules Coenegracht sr. } \\
\text { Foundation }\end{array}$ & Research grant $(€ 23.000)$ \\
2007 & $\begin{array}{l}\text { European Society for } \\
\text { Organ Transplantation }\end{array}$ & $\begin{array}{l}\text { Preservation grant }(€ 10.000) \text { in coopera- } \\
\text { tion with Leicester General Hospital }\end{array}$ \\
2007 & $\begin{array}{l}\text { Netherlands Organisation for } \\
\text { Health Research and Development }\end{array}$ & Clinical research trainee grant $(€ 63.350)$ \\
2007 & $\begin{array}{l}\text { Dutch Kidney Foundation } \\
2008\end{array}$ & Kolff grant for student-assistant $(€ 5.000)$ \\
2009 & Dutch Transplantation Society & Genzyme speakers award \\
& & \\
2009 & $\begin{array}{l}\text { Maastricht University Medical } \\
\text { Center }\end{array}$ & Pelerin Science award \\
\hline
\end{tabular}

\section{Professional memberships}

College of Surgeons of the Netherlands

Dutch Transplantation Society

European Society for Organ Transplantation

The Transplantation Society 
\begin{tabular}{ll|l|l|l}
316 & HOOF D T U K 15
\end{tabular} 


\section{Dankwoord}

Mijn promotores Ernst van Heurn en Wim Buurman wil ik van harte danken voor de kans die ze me hebben gegeven binnen het chirurgisch transplantatie onderzoek in Maastricht. Er was alle vrijheid om eigen initiatieven te ontplooien en hierdoor omvat dit proefschrift een breed spectrum aan onderzoeksmethoden. De kritische blik van Wim en de enthousiaste steun van Ernst waren bijzonder stimulerend. Daarnaast bedank ik professor Daemen, Leunissen, Nicholson, Pirenne en Stehouwer hartelijk voor het beoordelen van mijn proefschrift. De paranimfen Wim de Jongh en Roeland Rohof dank ik voor hun bereidwilligheid om als steun en toeverlaat te dienen tijdens de verdediging van mijn proefschrift.

Wetenschappelijk onderzoek wordt in teamverband verricht en vereist input van een verscheidenheid aan disciplines. Ik wil daarom alle ziekenhuizen die onze donornieren hebben getransplanteerd enorm bedanken voor hun bijdrage aan de vrijwel complete database met resultaten van deze niertransplantaties. Ook de Nederlandse Transplantatie Stichting en dan in het bijzonder Martin Heemskerk, Aline Hemke en Cynthia Konijn wil ik bedanken voor hun steun bij het aanleveren van informatie over de resultaten en kenmerken van Nederlandse niertransplantaties. Voor advies en hulp bij het analyseren van deze gegevens ben ik Ton Ambergen, Douglas Schaubel en Bjorn Winkens zeer erkentelijk. Voor het histologisch onderzoek van biopten van donornieren dank ik Roel Goldschmeding, Carine Peutz en Robert Jan van Suylen voor hun medewerking. Ook het secretariaat van de afdeling pathologie dank ik voor hun ondersteuning van mijn zoektocht naar verloren gewaande niercoupes. Mia Meers, Bianca Pulinx en Wil Wodzig dank ik voor onze interessante samenwerking bij het ontdekken van nieuwe biomarkers in de preservatievloeistof van donornieren.

Voor het wetenschappelijk onderzoek met proefpersonen wil ik in de eerste plaats alle patiënten bedanken die belangeloos hebben ingestemd om deel te nemen aan dit onderzoek. Verder wil ik Jan-Willem Daemen, Noud Peppelenbosch, Geert Willem Schurink, Jan Tordoir en de andere leden van het operatieteam enorm bedanken voor hun bereidwilligheid om bij het implanteren van donornieren de operatie kortdurend stil te leggen om metingen te verrichten en bloedmonsters af te nemen. Maarten Christiaans, Elly van Duijnhoven, Marielle Gelens, professor van Hooff en de transplantatie verpleegkundigen dank ik voor hun gastvrijheid en behulpzaamheid op de niertransplantatie afdeling. Voor de 
technische expertise en de enthousiaste discussies omtrent de endotheliale glycocalyx en de doorbloeding van de renale microcirculatie bedank ik Hans Vink en zijn team hartelijk.

Voor het wetenschappelijk onderzoek met proefdieren wil ik allereerst mijn complimenten uitspreken over de uitstekende zorg van Petra Dijkstra, Noortje Peters, Frans Slangen en Joyce Suyk voor de varkens die binnen het onderzoek werden gebruikt. Ook bedank ik Jan-Willem Daemen en Geert Willem Schurink bijzonder voor het vrijmaken van tijd om mee te werken aan deze dierproeven en voor hun betrokkenheid bij het onderzoek. Jaakko Parkkinen dank ik voor het inbrengen van zijn biochemische expertise en voor het kritisch evalueren van de resultaten van het onderzoek. Het 'Academisch' Slachthuis Kerkrade en in het bijzonder Marc Simons bedank ik voor de mogelijkheid om kosteloos nieren te verkrijgen en te preserveren in zijn kantoor. Tenslotte wil ik Pauline Wouters bedanken voor het zorgvuldig coördineren van de fok van de genetisch gemodificeerde muizen.

Dit proefschrift zou niet tot stand gekomen zijn zonder de jarenlange inspanningen van de niertransplantatie groep van het Maastricht Universitair Medisch Centrum en ik wil dan ook de betrokken chirurgen, nefrologen, anesthesisten, urologen, weefseltypeerders en pathologen bedanken voor hun fantastische klinische werk. In het bijzonder wil ik de transplantatiecoördinatoren en donatiefunctionarissen enorm bedanken voor hun collegialiteit en toewijding. Ik heb met heel veel plezier samengewerkt met Juliette Hermens, Marloes Homberg, Pieter Hoogland, Wim de Jongh, Patrick Mertens, Margriet Rouflart, Angelica Smeets, Guido Starberg, Monique Willems en Tineke Wind. Ook alle kidneyracers bedank ik voor hun inzet en voor de vele hand- en spandiensten die eenieder heeft verricht ten behoeve van dit onderzoek. De transplantatiechirurgie in Maastricht is begin jaren tachtig geïnitieerd door professor Kootstra en ik was dan ook zeer vereerd toen ik door hem werd uitgenodigd voor een bijzonder inspirerend diner. Transplantatiegeneeskunde bestaat niet zonder orgaandonoren. Ik heb groot respect voor alle overledenen en hun nabestaanden die belangeloos organen beschikbaar stelden voor patiënten die wachtten op een langer en beter leven door transplantatie. Ik moedig iedereen aan zich in te schrijven in het nationale donorregister!

Naast mijn participatie in de klinische transplantatiezorg maakte ik deel uit van het onderzoekslaboratorium van de algemene heelkunde. Ik wil mijn collega's Kim Augustin, Annemarie van Bijnen, Johanne Bloemen, Bas Boonen, Maartje van den Broek, Stephanie Bukkems, Simon Dello, Joep Derikx, Hans van Eijk, Irma Geenen, Joep Grootjans, Jacco de Haan, Mohammed Hadfoune, Bas 
Hanssen, Femke Hellenthal, Sandra Hex, Caroline Hodin, Kirsten Huntjens, Dennis Japink, Trudy Jeunhomme, Charlotte de Jonge, Xavier Keuter, Kaatje Lenaerts, Tim Lubbers, Robert Matthijsen, Robbert Nijenhuis, Jeroen Nijhuis, Marcel van de Poll, Sander Rensen, Sedi Roosta, Lai Nguyen, Martien Schellart, Marc Schreinemacher, Yanti Slaats, Geertje Thuijls, Froukje Verdam, Iris Vermeulen Windsant, Guy Vijgen, Ruben Visschers, Eva de Vries, Kim van Wijck, Nina Wijnands en Tim Wolfs van harte danken voor de leuke en leerzame tijd op het laboratorium. Ook wil ik de studenten Rianne Beckers, Jorine Boer, Bas Boonen, Liesbeth Boonstra, Angela Dekkers, Bas Pieters, Bianca Wiermans en Isabelle Zwart, die tijdens hun stage hebben bijgedragen aan het onderzoek, hartelijk bedanken voor hun inzet.

De afgelopen jaren heb ik veel tijd aan het wetenschappelijk onderzoek besteed. Gelukkig was er ook voldoende gelegenheid voor ontspanning en ik wil mijn vrienden van het Onafhankelijk Maastrichts Studenten Genootschap Plutarchus dan ook enorm bedanken voor de geweldige momenten die gelukkig ook na de studententijd blijven voortduren. Ook Wout bedank ik voor onze voortdurende vriendschap.

In de periode waarbinnen dit proefschrift werd geschreven viel er helaas ook tegenslag te verwerken: mijn moeder overleed aan een hersentumor. Zij verzamelde trouw alle artikelen, presentaties en posters van mijn onderzoek en ik ben er zeker van dat zij vol trots naar de verdediging had geluisterd. Omdat dit niet langer mogelijk is draag ik dit proefschrift op aan mijn moeder. Mijn vader, Mieneke, Barbara, Koen, Amber, Harmen, Ninke, Hans, Mirjam, Hellen, Marcel, Robbert en Chris bedank ik voor hun steun, liefde en betrokkenheid.

Tenslotte wil ik Sophie bedanken voor alle liefde die ze mij gegeven heeft. De afgelopen tijd hebben we ons huis gekocht en verbouwd, ben ik gestart met de opleiding chirurgie terwijl dit proefschrift nog moest worden afgerond en was er ook nog onze bruiloft te regelen! Ik realiseer me dat je daardoor niet altijd op de eerste plaats stond en ik ben daarom heel gelukkig met het geduld dat je voor me hebt gehad. Ik houd van je. 
$320 \mid$ H O O F D S T U K 15

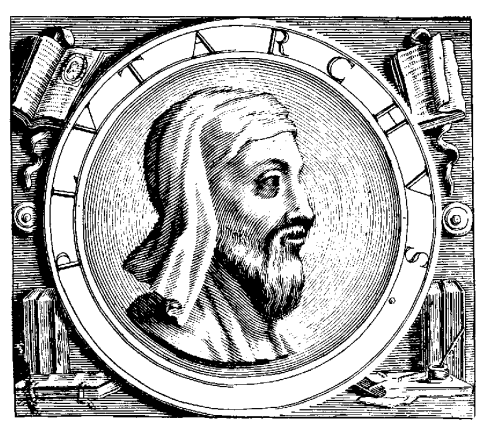


Table 1.2 Studies comparing the outcome of DCD and DBD kidney transplantations

\begin{tabular}{|c|c|c|c|c|c|c|c|c|c|c|c|}
\hline \multirow{2}{*}{ Transplant center } & \multirow{2}{*}{ Study period } & \multirow{2}{*}{ Donor type } & \multirow{2}{*}{$\begin{array}{l}\text { Sample } \\
\text { size }\end{array}$} & \multirow{2}{*}{$\begin{array}{l}\text { Donor age } \\
(\mathrm{yrs})^{1}\end{array}$} & \multirow{2}{*}{$\begin{array}{l}\text { Warm } \\
\text { ischemia } \\
(\min )^{1}\end{array}$} & \multirow{2}{*}{$\begin{array}{l}\text { Delayed } \\
\text { graft } \\
\text { function }\end{array}$} & \multirow{2}{*}{$\begin{array}{l}\text { Primary } \\
\text { non- } \\
\text { function }\end{array}$} & \multirow{2}{*}{$\begin{array}{l}\text { Acute } \\
\text { rejection }\end{array}$} & \multirow{2}{*}{$\begin{array}{l}\text { Creatinine } \\
\text { at } 1 \text { year } \\
(\mu \mathrm{mol} / \mathrm{L})^{1}\end{array}$} & \multicolumn{2}{|c|}{ Graft survival } \\
\hline & & & & & & & & & & 1 year & 5 years \\
\hline \multirow{2}{*}{ Maastricht ${ }^{13}$} & \multirow{2}{*}{ 1980-1992 } & DCD 2/3/4 & 57 & 49 (7-61) & $30(8-88)$ & $60 \%$ & $14 \%$ & $53 \%$ & $174 \pm 59$ & $73 \%$ & $54 \%$ \\
\hline & & $\mathrm{DBD}^{2}$ & 114 & $43(7-60)$ & $0(0-8)$ & $35 \%$ & $8 \%$ & $50 \%$ & $174 \pm 100$ & $73 \%$ & $55 \%$ \\
\hline \multirow{2}{*}{ Maastricht $^{302}$} & \multirow{2}{*}{ 1993-1995 } & DCD 2/3/4 & 37 & $45 \pm 16$ & $49 \pm 34$ & $49 \%$ & $19 \%$ & - & - & - & - \\
\hline & & $\mathrm{DBD}^{2}$ & 74 & $41 \pm 15$ & $0 \pm 0$ & $34 \%$ & $7 \%$ & - & - & - & - \\
\hline \multirow{2}{*}{ Nijmegen ${ }^{15}$} & \multirow{2}{*}{ 1989-1999 } & DCD $1 / 2 / 3 / 4$ & 47 & - & $32(11-55)$ & $64 \%$ & $4 \%$ & $40 \%$ & - & $84 \%$ & - \\
\hline & & $\mathrm{DBD}^{2}$ & 94 & - & $0 \pm 0$ & $18 \%$ & $2 \%$ & $33 \%$ & - & $88 \%$ & - \\
\hline \multirow{2}{*}{ The Netherlands ${ }^{16}$} & \multirow{2}{*}{ 2001-2002 } & DCD 3 & 100 & $46(14-74)$ & $20(5-42)$ & $47 \%$ & $11 \%$ & - & $147 \pm 56$ & $83 \%$ & - \\
\hline & & DBD & 176 & $49(10-75)$ & $0(0-5)$ & $23 \%$ & $5 \%$ & - & $146 \pm 59$ & $92 \%$ & - \\
\hline \multirow{2}{*}{ Leicester ${ }^{17}$} & \multirow{2}{*}{ 1992-2002 } & DCD $2 / 3$ & 112 & $46 \pm 11$ & $25 \pm 14$ & $84 \%$ & $5 \%$ & $30 \%$ & $190 \pm 85$ & $92 \%$ & $78 \%$ \\
\hline & & $\mathrm{DBD}^{2}$ & 164 & $45 \pm 13$ & $0 \pm 1$ & $22 \%$ & $2 \%$ & $38 \%$ & $155 \pm 64$ & $91 \%$ & $86 \%$ \\
\hline \multirow{2}{*}{ South Thames ${ }^{303}$} & \multirow{2}{*}{ 1988-1991 } & DCD & 81 & - & - & - & $26 \%$ & - & - & $55 \%$ & $49 \%$ \\
\hline & & DBD & 111 & - & - & - & - & - & - & $81 \%$ & $68 \%$ \\
\hline \multirow{2}{*}{ Newcastle $^{304}$} & \multirow{2}{*}{ 1998-2004 } & DCD $2 / 3$ & 100 & $43 \pm 20$ & $21 \pm 8$ & $62 \%$ & - & $27 \%$ & $42 \pm 20^{3}$ & - & $80 \%$ \\
\hline & & DBD & 100 & $44 \pm 20$ & $0 \pm 0$ & $40 \%$ & - & $25 \%$ & $46 \pm 20^{3}$ & - & $87 \%$ \\
\hline \multirow{2}{*}{ Cambridge $^{19}$} & \multirow{2}{*}{ 1996-2006 } & DCD 3 & 104 & $41 \pm 16$ & $15(13-21)$ & $64 \%$ & $6 \%$ & $24 \%$ & $46 \pm 16^{3}$ & $90 \%$ & $78 \%$ \\
\hline & & DBD & 104 & $46 \pm 15$ & $0(0-0)$ & $29 \%$ & $2 \%$ & $15 \%$ & $46 \pm 18^{3}$ & $95 \%$ & $81 \%$ \\
\hline \multirow{2}{*}{ Plymouth $^{21}$} & \multirow{2}{*}{ 2005-2008 } & DCD 3 & 57 & $54(11-71)$ & $14(13-16)$ & $44 \%$ & $0 \%$ & $16 \%$ & $141 \pm 52$ & $88 \%$ & - \\
\hline & & DBD & 58 & - & - & $14 \%$ & $2 \%$ & $28 \%$ & $132 \pm 36$ & $93 \%$ & - \\
\hline \multirow{2}{*}{ Madrid²6 } & 1989-2004 & DCD $1 / 2$ & 320 & $36 \pm 12$ & - & $61 \%$ & $4 \%$ & - & $64 \pm 21^{3}$ & $87 \% \%^{4}$ & $82 \%^{4}$ \\
\hline & $1989-2004$ & $\mathrm{DBD}^{2}$ & 458 & $35 \pm 14$ & - & $20 \%$ & $1 \%$ & - & $59 \pm 22^{3}$ & $91 \%^{4}$ & $86 \%{ }^{4}$ \\
\hline & & DCD $2 / 4$ & 66 & $30 \pm 15$ & $29 \pm 23$ & $62 \%$ & $5 \%$ & $35 \%$ & $203 \pm 135$ & $78 \%$ & $67 \%$ \\
\hline Barcelona $^{27}$ & 1985-1996 & DBD & 122 & $32+15$ & $0 \pm 0$ & $32 \%$ & $0 \%$ & $33 \%$ & $148 \pm 49$ & $88 \%$ & $78 \%$ \\
\hline A Corñ 29 & $1000-2004$ & DCD 1/2/3/4 & 100 & $37 \pm 14$ & $64 \pm 52$ & $84 \%$ & $16 \%$ & $24 \%$ & $168 \pm 62$ & $79 \%$ & $70 \%$ \\
\hline A Corvind & $1990-2004$ & DBD & 1025 & $41 \pm 18$ & - & $26 \%$ & $10 \%$ & $21 \%$ & $168 \pm 133$ & $83 \%$ & $72 \%$ \\
\hline
\end{tabular}




\begin{tabular}{|c|c|c|c|c|c|c|c|c|c|c|c|}
\hline Zürich ${ }^{30}$ & $1985-2000$ & $\begin{array}{l}\mathrm{DCD} \\
\mathrm{DBD}^{2}\end{array}$ & $\begin{array}{l}122 \\
122\end{array}$ & $\begin{array}{l}37 \pm 13 \\
38 \pm 18\end{array}$ & $\begin{array}{l}29 \pm 9 \\
1 \pm 2\end{array}$ & $\begin{array}{l}48 \% \\
24 \%\end{array}$ & $\begin{array}{l}6 \% \\
5 \%\end{array}$ & $\begin{array}{l}43 \% \\
55 \%\end{array}$ & $\begin{array}{l}133 \pm 53 \\
141 \pm 62\end{array}$ & $\begin{array}{l}92 \%^{4} \\
90 \%^{4}\end{array}$ & $\begin{array}{l}84 \%^{4} \\
82 \% \%^{4}\end{array}$ \\
\hline Warsaw ${ }^{31}$ & 1986-1994 & $\begin{array}{l}\text { DCD } 4 \\
\text { DBD }^{2}\end{array}$ & $\begin{array}{l}76 \\
100\end{array}$ & $\begin{array}{l}40 \pm 11 \\
39 \pm 11\end{array}$ & $\begin{array}{l}31 \pm 24 \\
0 \pm 0\end{array}$ & $\begin{array}{l}66 \% \\
33 \%\end{array}$ & $\begin{array}{l}4 \% \\
3 \%\end{array}$ & $\begin{array}{l}66 \% \\
46 \%\end{array}$ & $\begin{array}{l}155 \\
141\end{array}$ & $\begin{array}{l}82 \% \\
90 \%\end{array}$ & $\begin{array}{l}67 \% \\
73 \%\end{array}$ \\
\hline Dijon $^{34}$ & 1985-1991 & $\begin{array}{l}\text { DCD } 4 \\
\text { DBD }\end{array}$ & $\begin{array}{l}14 \\
143\end{array}$ & $\begin{array}{l}- \\
-\end{array}$ & - & - & - & - & $\begin{array}{l}127 \pm 52 \\
153 \pm 94\end{array}$ & $\begin{array}{l}86 \%^{4} \\
90 \%^{4}\end{array}$ & - \\
\hline Vienna $^{37}$ & 1984-1996 & $\begin{array}{l}\text { DCD 2/4 } \\
\text { DBD }^{2}\end{array}$ & $\begin{array}{l}28 \\
87\end{array}$ & $\begin{array}{l}36 \pm 16 \\
38 \pm 15\end{array}$ & - & $\begin{array}{l}68 \% \\
36 \%\end{array}$ & $\begin{array}{l}15 \% \\
6 \%\end{array}$ & $\begin{array}{l}37 \% \\
39 \%\end{array}$ & - & $\begin{array}{l}86 \% \\
87 \%\end{array}$ & - \\
\hline United States ${ }^{49}$ & 1994-1996 & $\begin{array}{l}\text { DCD } 3 \\
\text { DBD }^{2}\end{array}$ & $\begin{array}{l}229 \\
8718\end{array}$ & $\begin{array}{l}46 \pm 13 \\
44 \pm 13\end{array}$ & $\begin{array}{l}14 \pm 14 \\
0 \pm 0\end{array}$ & $\begin{array}{l}48 \% \\
22 \%\end{array}$ & $\begin{array}{l}4 \% \\
1 \%\end{array}$ & $\begin{array}{l}19 \% \\
14 \%\end{array}$ & $\begin{array}{l}170 \pm 80 \\
160 \pm 70\end{array}$ & $\begin{array}{l}83 \% \\
86 \%\end{array}$ & - \\
\hline United States $^{301}$ & 1998-2004 & $\begin{array}{l}\text { DCD } 3 \\
\text { DBD }^{2}\end{array}$ & $\begin{array}{l}1177 \\
42858\end{array}$ & $\begin{array}{l}37 \pm 16 \\
37 \pm 17\end{array}$ & $\begin{array}{l}- \\
-\end{array}$ & $\begin{array}{l}41 \% \\
24 \%\end{array}$ & $\begin{array}{l}- \\
-\end{array}$ & $\begin{array}{l}9 \% \\
10 \%\end{array}$ & $\begin{array}{l}- \\
-\end{array}$ & $\begin{array}{l}90 \% \\
89 \%\end{array}$ & $\begin{array}{l}67 \% \\
67 \%\end{array}$ \\
\hline Rochester ${ }^{53}$ & 1991-1993 & $\begin{array}{l}\text { DCD } 3 \\
\text { DBD }\end{array}$ & $\begin{array}{l}19 \\
76\end{array}$ & $\begin{array}{l}- \\
-\end{array}$ & $\begin{array}{l}26(20-35) \\
0(0-0)\end{array}$ & $\begin{array}{l}22 \% \\
7 \%\end{array}$ & $0 \%$ & $\begin{array}{l}- \\
-\end{array}$ & $\begin{array}{l}177 \\
150\end{array}$ & $\begin{array}{l}76 \% \\
84 \%\end{array}$ & $\begin{array}{l}- \\
-\end{array}$ \\
\hline Washington ${ }^{305}$ & 1994-1997 & $\begin{array}{l}\text { DCD } 2 \\
\text { DBD }^{2}\end{array}$ & $\begin{array}{l}23 \\
17\end{array}$ & $\begin{array}{l}- \\
-\end{array}$ & $\begin{array}{l}27 \pm 14 \\
0 \pm 0\end{array}$ & $\begin{array}{l}76 \% \\
6 \%\end{array}$ & $\begin{array}{l}9 \% \\
0 \%\end{array}$ & $\begin{array}{l}- \\
-\end{array}$ & $\begin{array}{l}128 \\
174\end{array}$ & $\begin{array}{l}- \\
-\end{array}$ & $\begin{array}{l}- \\
-\end{array}$ \\
\hline Wisconsin ${ }^{58}$ & $1984-2000$ & $\begin{array}{l}\mathrm{DCD} 3 \\
\mathrm{DBD}^{2}\end{array}$ & $\begin{array}{l}382 \\
1089\end{array}$ & $\begin{array}{l}34 \pm 16 \\
33 \pm 17\end{array}$ & $\begin{array}{l}17 \pm 8 \\
0 \pm 0\end{array}$ & $\begin{array}{l}28 \% \\
21 \%\end{array}$ & $\begin{array}{l}1 \% \\
1 \%\end{array}$ & $\begin{array}{l}44 \% \\
45 \%\end{array}$ & $\begin{array}{l}- \\
-\end{array}$ & $\begin{array}{l}82 \% \\
89 \%\end{array}$ & $\begin{array}{l}65 \% \\
73 \%\end{array}$ \\
\hline Michigan $^{55}$ & $2000-2004$ & $\begin{array}{l}\text { DCD } 3 \\
\text { DBD }\end{array}$ & $\begin{array}{l}24 \\
100\end{array}$ & $\begin{array}{l}28 \pm 14 \\
34 \pm 18\end{array}$ & $\begin{array}{l}5 \\
0\end{array}$ & $\begin{array}{l}8 \% \\
24 \%\end{array}$ & $\begin{array}{l}0 \% \\
1 \%\end{array}$ & $\begin{array}{l}- \\
-\end{array}$ & - & $\begin{array}{l}- \\
-\end{array}$ & $\begin{array}{l}- \\
-\end{array}$ \\
\hline Taiwan ${ }^{45}$ & 1998-2003 & $\begin{array}{l}\text { DCD } 2 / 3 / 4 \\
\text { DBD }\end{array}$ & $\begin{array}{l}31 \\
120\end{array}$ & $\begin{array}{l}42 \pm 10 \\
41 \pm 10\end{array}$ & - & $\begin{array}{l}42 \% \\
27 \%\end{array}$ & $\begin{array}{l}- \\
-\end{array}$ & $\begin{array}{l}36 \% \\
40 \%\end{array}$ & $\begin{array}{l}136 \pm 72 \\
133 \pm 96\end{array}$ & $\begin{array}{l}97 \% \\
90 \%\end{array}$ & $\begin{array}{l}88 \% \\
83 \%\end{array}$ \\
\hline Singapore ${ }^{46}$ & 1994 & $\begin{array}{l}\text { DCD } \\
\text { DBD }\end{array}$ & $\begin{array}{l}28 \\
25\end{array}$ & $\begin{array}{l}34 \pm 8 \\
24 \pm 11\end{array}$ & $\begin{array}{l}22 \pm 9 \\
0 \pm 0\end{array}$ & $\begin{array}{l}50 \% \\
40 \%\end{array}$ & $\begin{array}{l}4 \% \\
4 \%\end{array}$ & $\begin{array}{l}- \\
-\end{array}$ & $\begin{array}{l}133 \pm 40 \\
131 \pm 93\end{array}$ & $\begin{array}{l}98 \% \\
96 \%\end{array}$ & $\begin{array}{l}- \\
-\end{array}$ \\
\hline
\end{tabular}

1 Data are reported as median (range) or as mean \pm standard deviation.

2 Statistical analysis accounts for potential selection bias, using either multivariable regression analyses or matched control groups.

3 Kidney function is reported as estimated glomerular filtration rate $(\mathrm{mL} / \mathrm{min})$.

4 Graft survival is censored for recipient death with functioning graft. 


\section{Risk factors for primary non-function}

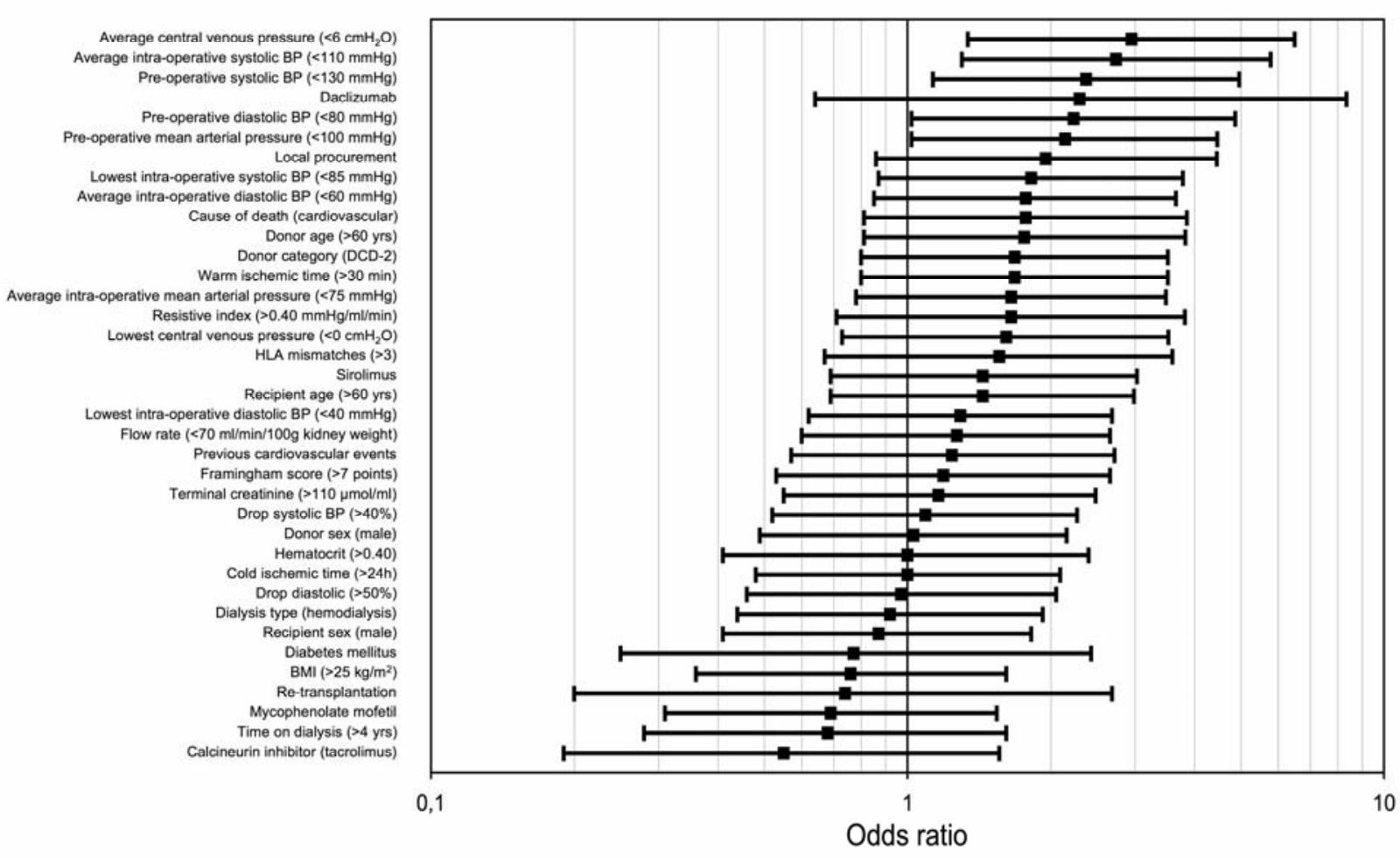

Figure 8.1 Univariable risk analysis for primary non-function of DCD kidney transplants 
